\title{
Erosion Potential from Missoula Floods in the Pasco Basin, Washington
}

\author{
R. G. Craig
}

J. P. Hanson

Kent State University

Kent, Ohio

December 1985

Prepared by Kent State University for Pacific Northwest Laboratory under Contract DE-AC06-76RLO 1830

with the U.S. Department of Energy

Pacific Northwest Laboratory Operated for the U.S. Department of Energy by Battelle Memorial Institute 


\title{
DISCLAIMER
}

This report was prepared as an account of work sponsored by an agency of the United States Government. Neither the United States Government nor any agency thereof, nor any of their employees, makes any warranty, express or implied, or assumes any legal liability or responsibility for the accuracy, completeness, or usefulness of any information, apparatus, product, or process disclosed, or represents that its use would not infringe privately owned rights. Reference herein to any specific commercial product, process, or service by trade name, trademark, manufacturer, or otherwise, does not necessarily constitute or imply its endorsement, recommendation, or favoring by the United States Government or any agency thereof. The views and opinions of authors expressed herein do not necessarily state or reflect those of the United States Government or any agency thereof.

\author{
PACIFIC NORTHWEST LABORATORY \\ operated by \\ BATTELLE \\ for the \\ UNITED STATES DEPARTMENT OF ENERGY \\ under Contract DE-AC06-76RLO 1830
}

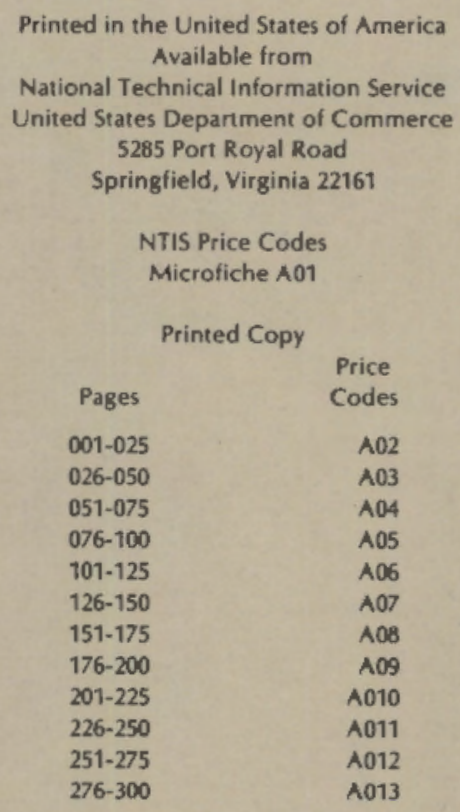


EROSION POTENTIAL FROM MISSOULA FLOODS IN THE PASCO BASIN, WASHINGTON

R. G. Craig

J. P. Hanson

Kent State University

Kent, Ohio

December 1985

Prepared by Kent State University for Pacific Northwest Laboratory under Contract DF-AC06-76RLO 1830 with the U.S. Department of Energy

Pacific Northwest Laboratory Richland, Washington 99352 


\section{EXECUTIVE SUMMARY}

Localities within the Pasco Basin preserve evidence of Missoula floods. Deposits are 468 sand-sized, 368 gravel-sized, and $18 \%$ finer than sand-sized. Mean thickness is 39 meters.

High water marks at wallula Gap require a discharge or approximately 12.5 Mcms. At Sentinel Gap, the slope-area method shows that the high water marks require a discharge of 34.6 Mcms. Since this discharge greatly exceeds any estimated For Missoula Eloods, there must have been backwater ponding from Wallula Gap. Projecting the slope of the water surface at the upper end oi Wallula Gap to the downstream cross section at Gable Mountain leads to a discharge of 9.5 Mcms at Sentinel Gap.

The HEC-6 steady state code and Eour sediment transport equations were applied. Assuming sand-sized particles, DuBoys function estimated 4 to 9 meters of scour. Yang's equation estimated 3 to 4 meters of scour. These are a minimum.

A hydrograph synthesized for the boundaries of the Pasco Basin shows the maxina of the flood would occur atter 90 nours at Sentinel Gap, and at 114 hours at Wallula Gap. The 200 areas will remain inundated for four days and six hours. With a quasi-dynamic sediment transport computation, HEC-6 scour estimates range from 0.61 meters to 0.915 meters. This is a minimum amount and erosion is highly variable suggesting reworking of sediment.

The Meyer-peter Meuller equations show less than 1 meter ol net scour in the 200 areas. More extensive erosion was achieved during particular time steps of this analysis suggesting that sediment re-working would occur. 
ACKNOWLEDGEMENTS

We wish to thank Dr. Michael Foley of PNL for initiating this contract and for discussions concerning the Missoula floods. We thank Richard waitt of the U.S. Geological Survey for acting as reviewer of early work on this project and its predecessor and for the time in the field describing evidence of the floods in general and multiple floods in particular. Personnel at the Battelie, PNL and Rockwell Hanford operations, including especially Bruce Bjornstad and wally walters provided useful and interesting discussions of the flood phenomena.

Many graduate students in the geological simulations group at KSU were instrumental in the work. Mr. David Hose helped with the computer work and with word-processing and drafting figures. Mr. Samuel Figuli converted the ADI code to HP BASIC and produced some of the computer graphics. Mr. John Stamm converted for use a second ADI code algorithm for benchmarking of our code. $\mathrm{Mr}$. Barry Roberts helped in modelling ice sheet dynamics and understanding the history of the cordilieran ice sheet. Mr. Thomas Dwyer, now with the state of South Carolina, wrote the first version of the ADI solution procedure and much of the chapter describing its derivation.

A portion of this project formed the masters thesis of $\mathrm{Mr}$. Hanson. Jim was primarily responsibie for the HEC-2 and HEC-6 analyses and the Meyer-Peter and Meuller equation.

Two student research assistants, Ms. Melissa Guster and Mr. Wayne Bevan were of great help in data acquigition and analysis. Mrs. Dorothy Craig acted as program assistant and kept the project records organized. 


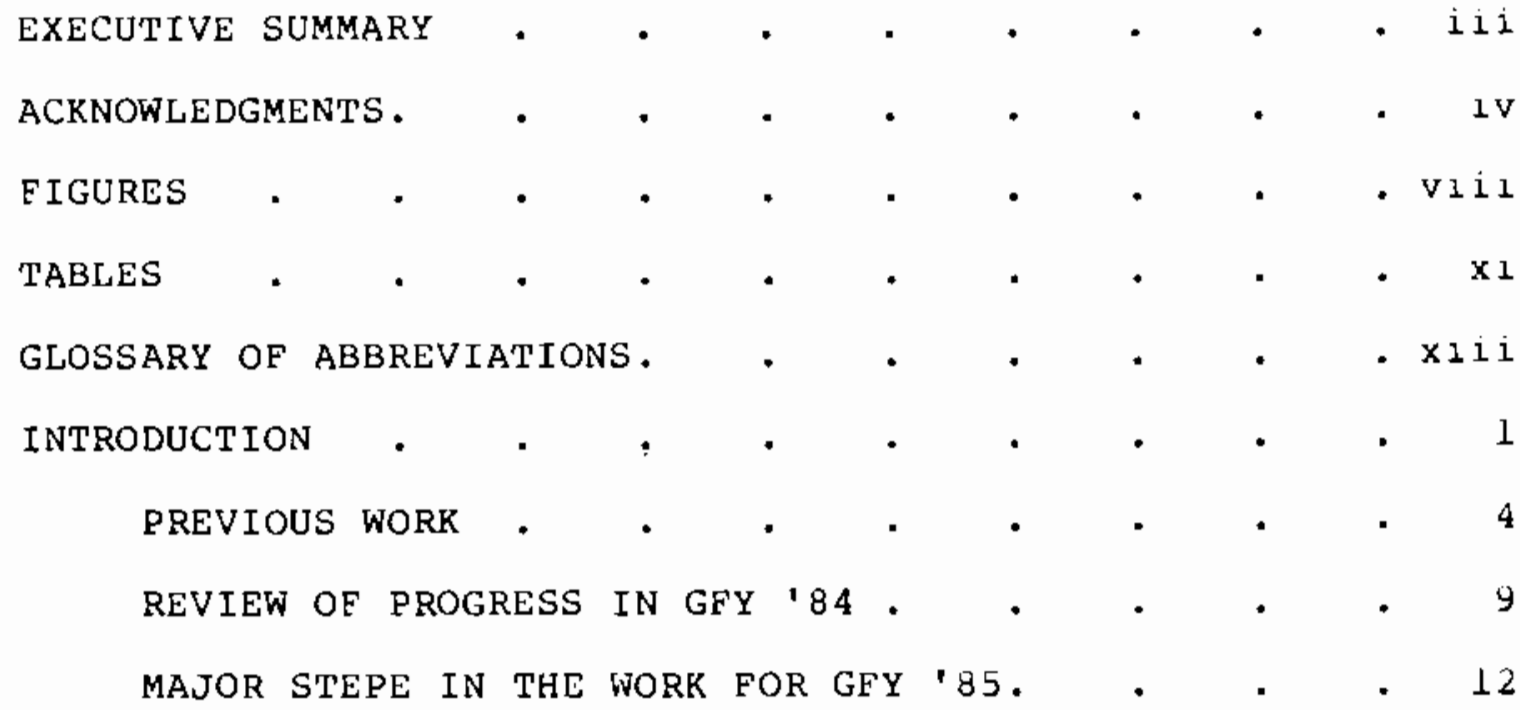

EVIDENCE OF THE MISSOULA ELOODS IN THE PASCO BASIN. $\quad . \quad 14$

FLOOD PATHS TO AND EROM THE PASCO BASIN • • $\quad 14$

EEATURES IN THE PASCO BASIN . . • • . . I8

SEDIMENT DISTRIBUTION $\quad . \quad$ - $\quad . \quad$ • $\quad . \quad 20$

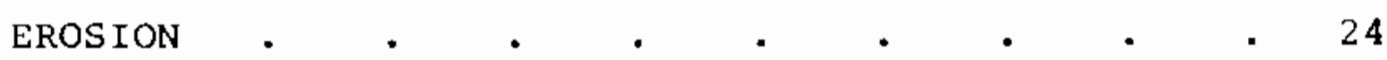

LIMITATIONS AND UNCERTAINTIES • • • • . . 27

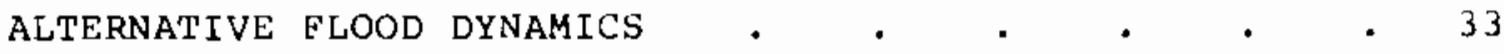

SCABLANDS TRACTS AND THE OKANOGAN LOGE • . . 33

ELOODS CONEINED TO THE COLUMBIA RIVER • • • • 36

SELECTION OE A BOUNDING SCENARIO • $\quad$ • • $\quad$ • 40

LIMITATIONS AND UNCERTAINTIES • . • . . 45

STEADY STATE HYDRAULICS OF 'THE BOUNDING SCENARIO • $\quad 50$

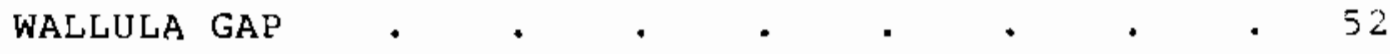

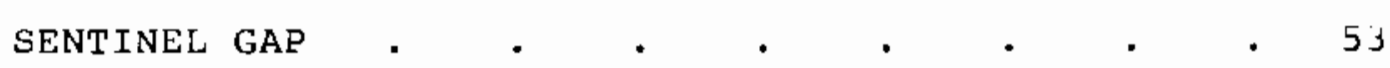

LIMI'PATIONS AND UNCERTAINTIES • . . . . . 60

EROSION POTENTIAL UNDER STEADY STATE CONDITIONS $\quad \cdot \quad \cdot \quad 72$

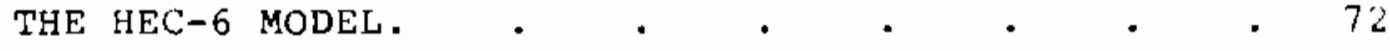

ALTERNATIVE TRANSPORT EQUATIONS $\quad$ • • . $\quad$ • 72 
Totélateti's Method . . . . . . 73

Laursen's Formula . . . . . . . 75

Yang's Regression Curve . . . . . 75

Du Boy's Method. . . . . . . . 76

EROSION AT THE 200 AREAS (STEADY STATE). . . 78

THE STEAdY-STATE Methodology . . . . . . 81

Gravel Size Particles . . . . . . 81

Du Boy's Method . . . . . . 82

Toffaleti's Method . . . . . . . 83

Yang's Relationship . . . . . . 83

Madden's Modification of Laursen's Relationship.

Sand Size Particles..$\quad$. $\quad . \quad$. 83

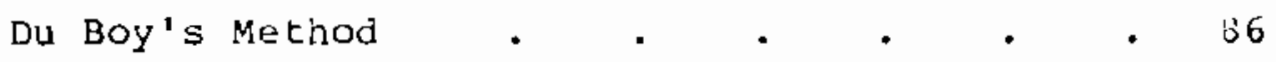

Toffaleti's Method . . . . . . 86

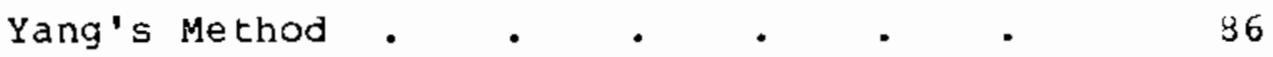

Madden's Modification of Laursen's

LIMITATIONS AND UNCERTAINTIES • . . . . . 88

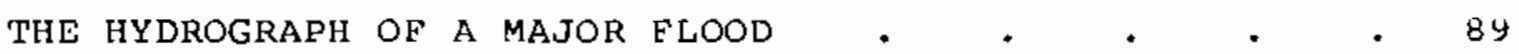

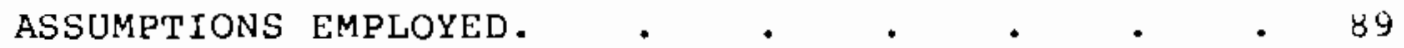

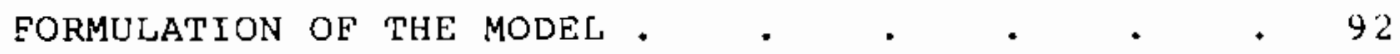

ITERATIVE SOLUTION OF THE HYDROGRAPH . . . . 96

DYNAMICS AT THE INLET AND OUTLE'T . . . . . LUS

LIMITATIONS AND UNCERTAINTIES . . . . . IU5

EROSION PO'TEN'TIAL FOR THE MAJOR FLOOD . . . . . L LU

EQUILIBRLUM SEDIMENT TRANSPORT. . . . . . 108

SELECTION OF THE TRANSPORT EQUATION. . . . . LU8

REPRESENTING THE DYNAMICS OF A MAJOR FLOOD • • • • 115 
THE GOVERNING EQUATIONS • • • • • • • • $\quad$ • 15

VERTICAL INTEGRATION OF THE CONTINUITY EQUATION • 116

VERTICAL INTEGRATION OF THE THREE-DIMENSIONAL MOMENTUM EQUATION WITH ERICTION • • • • • 119

THE DEPTH-AVERAGED EQUATIONS . • . . . 123

Effective Shear Stresses. . . . . 124

Bottom Shear Stresses . . . . . . 126

Grid System . . . . . . . . . 127

Finite Difference Approximations . • . 127

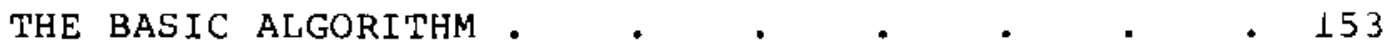

ESTIMATING THE EROSION DYNAMICS $\quad \cdot \quad \cdot \quad \cdot \quad \cdot \quad \cdot \quad \cdot \quad 161$

MEYER-PETER AND MEULLLRS EQUATION . . . . 161

FORMULATION AS A COMPUTER ALGORITHM. • . . $\quad 162$

QUASI-DYNAMIC APPLICATION $\quad$ • $\quad . \quad$. $\quad$ • 164

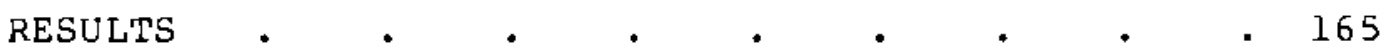

LIMITATIONS AND UNCERTAINTIES . . . . . 167

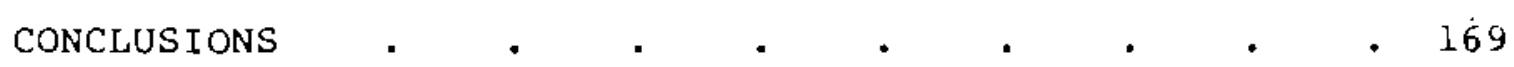

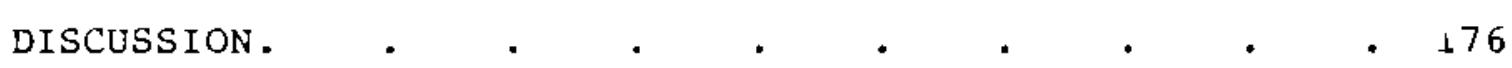

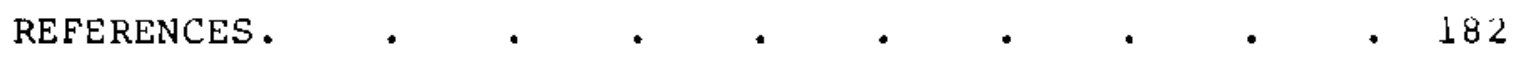

$\begin{aligned} & \text { APPENDIX A - SEDIMENT SIZE DISTRIBUTION FOR THE } \\ & \text { HANFORD RESERVATION } \cdot\end{aligned}$

APPENDIX B - COMPUTER CODE FOR FLOOD HYDROGRAPH • • Bl

APPENDIX C - COMPUTER CODE FOR ADI METHOD • • • . CL

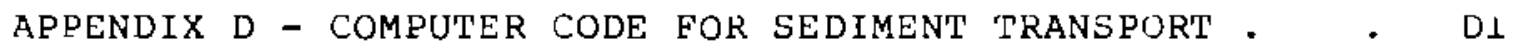

$\begin{aligned} \text { APPENDIX E - RESULTS USING MEYER-PETER AND MEULLER'S } & \text { EQUATION FOR SEDIMENT TRANSPORT . . E . E }\end{aligned}$ 


\section{FIGURES}

1.1 Physiography of the Pasco Basin and routes occupied by Missoula Elood waters. Flow directions adopted from Tallman and Fecht, 1978

1.2 Generalized drainage of the Scablands o:

Washington showing locations where velocities at maximum discharges have been estimated from field data. From: Baker (1978, Figure 4.6, p. 64).

1.3 Configuration of Lake Columbia during the time of flooding from Lake Missoula. Locations of sections preserving evidence of multiple floods are shown. Originally published by GSA, in Geology, v.12, p.465, Figure 1 by B.F. Atwater . 8

2.1 Landsat photo mosaic of the Channeled Scablands of eastern Washington. North is to the top. Photograph produced by Harlan Foote, PNL . . 15

2. 2 Channelways and Elow directions of Missoula floods high-lighting paths into the Quincy and Pasco Basins. Modified Erom: Baker (1978, Figure 5.2, p.83)

2.3 Digital elevation data for the region of the Pasco Basin at 30-second spacing. Locations of 807 wells used to characterize the sediment distribution within the Pasco Basin are shown

2.4 Typical grain-sizes deposited by Missoula flood-flows in the Pasco Basin. Hammer is $32 \mathrm{~cm}$ long. Photograph by J.R. Hanson . 25

2.5 Boulders deposited by Missoula flood waters $14.5 \mathrm{~km}$ downstream of Sentinel Gap. The largest boulder in the scene is about $2.4 \mathrm{~m}$ in median diameter. Photograph by R.G. Craig . . . 26

3.1 Reconstructed pathways of Llood waters across the Scablands of Washington. Modified trom: Bretz (1969, p.506) . . . . . . 34

3.2 Estimated storage and discharges of Elood waters in various channels of the scablands of washington. Originally published by GSA, in Special Paper 144, p.21, Figure 12, by V.R. Baker 
3.3 Backwater curve developed in the Pasco Basin downstream of sentinel Gap due to the entry oi flood waters from the Snake River and Esquatzel Coulee..$\quad$..$\quad$. . . .

3.4 Flood scenario Eor a Missoula Elood in which nearly all flow was coneined to the valley ot:

3.5 Oblique aerial view of Lower Crab Creek. View to the west..$\quad \cdot \quad \cdot \quad \cdot$.

4.1 Plan view of cross-sections (11) used in HEC-2 analyses for the Wallula Gap constriction. From: Underberg (1983a, p. 75). . .

4.2 Profiles of the cross-sections for the analysis of discharge at Wallula Gap. Reter to Eigure 4.1. From: Underberg $(1983 \mathrm{a}, \mathrm{p} .76\rangle$. .

4.3 Clark's plot of his Eour models Eor dam laibure at the Rathdrum prairie region. Maximum discharge is 13.7 million cms. Dashed lines represent discharge estimates of Missoula Eloods at various locations in the Scablands. From: Clarke, Mathews and Pack (1984, p.294)

4.4 Wallula Gap rating curve. Peak discharge equal to $12.5 \mathrm{million}$ cms (inundation to $350 \mathrm{~m}$ or $1150 \mathrm{ft})$; inundation of the 200 areas occurs at $2.8 \mathrm{mili}$ ion cms.

4.5 Positions of the Pasco Basin cross-sections displayed on digital elevation data at 30-second spacing.

4.6 Profiles of the cross-sections for the Sentinel Gap analyses. Refer to Figure 4.5 . . .

4.7 Sentinel Gap rating curve (at cross-section 34 ). Peak discharge through Sentinel Gap, $9.5 \mathrm{million}$ cms. corresponding to an elevation oi $366 \mathrm{~m}$ (1200 Et)

4.8 Locations of cross-sections used cor flood analyses in the upper Pasco Basin. Region of expanding $\vec{E}$ low indicated. Location of the 200 areas are indicated (dots) . . . .

4.9 Sentine1 Gap rating curve at the narrowest section of the constriction, cross-section 31 . 71

6.1 A typical hydrograph for a jokulhlaup. The flood observed in Iceland at Vatnajokul in 1954. From: Nye (1976, p.194) 
6.2 Relation between water suriace elevation or Lake Lewis and the volume of water that would be held in that lake (from: Craig, Singer and Underberg, 1983, Table 8

6.3 Iterative solutions of the Poisson Eunction provide aifferent estimates of the Elood hydrograph at Sentinel Gap. The tinal hydrograph chosen $(m=15)$ is given by the solid lin

6.4 Illustration of the method of iteration used to select the appropriate hydrograph for Wallula Gap. Each value of $m$ produces a different estimate of the volume of water that would be ponded in the Pasco Basin. . 100

6.5 Final hydrograph pair chosen to represent worst case flood scenario considered. The shaded area represents the volume of water that would be ponded in the Pasco Basin . . 104

8.1. The staggered grid representation of variables used in the alternating direction implicit method of solution of the Navier-stokes equations 


\section{TABLES}

2.1 Summary of Elood evidence in the Pasco Basin . 19

2.2 Example computation of grain-size distribution

from well-log data . . . . .

2.3 Statistics of sediment thickness in the Hanford Reservation based on well-log information. . 31

4.1 Wallula Gap rating curve based upon HEC-2 runs invoking critical depth as starting

conditions for backwater computations.

4.2 Projection of water surface elevation from

Wallula Gap to obtain starting water surbace elevations For HEC-2 runs at Sentinel Gap •

4.3 Sentinel Gap rating curve based upon HEC-2 runs using the projected water surtace elevation from Wallula Gap . $\quad . \quad$. $\quad . \quad$. $\quad . \quad$. 64

4.4 Sentinel Gap rating curve based upon HEC-2 runs using the projected water surface elevation from Wallula Gap. Includes water surface elevation to cross-section 31 (narrowest section in the constriction) . . . . .

5.1 Estimate of sediment load for a Missoula Elood based on volume of sediment in the Pasco Basin. 80

5.2 Modern sediment loads Erom two rivers. . . 80

5.3 Aggradation ( + ) and degradation (-) values For each cross-section in the Sentinel Gap analyses at a water discharge of 7.5 million cms using gravel-size (64 mm) particles . . .

5.4 Aggradation (+) and degradation (-) values for each cross-section in the Sentinel Gap analyses at a water discharge of $2.2 \mathrm{million}$ cms using gravel-size $(64 \mathrm{~mm})$ particles . . .

5.5 Aggradation (+) and degradation (-) values ror each cross-section in the Sentinel Gap analyses at a water discharge of $2.5 \mathrm{mill}$ ion cms using gravel-size (2 mm) particles . . .

6.1. Results of iterative solution of the flood hydrograph for sentinel Gap during a Scabland Elood 
6.2 Results of iterative solution oi the tlood

hydrograph for Wallula Gap during a Scabland flood. Solution is made using the final hydrograph for sentinel Gap as illustrated in Figure 6.3 . $. \quad . \quad . \quad . \quad . \quad .101$

6.3 Velocity and depth at sentinel and Wallula Gays

for each (six hour) time step of a Scabland flood in which tlood waters are confined to the Columbia River valley . . . . . 106

7.1 Convergence procedure used to obtain inflowing sediment load for each transport function in the HEC-6 analyses

7.2 Estimated sediment transport rates Eor various assumed sediment volumes for a Eixed discharge in the Pasco Basin (a) and equilibrium sediment transport rates (b) computed with four sediment transport functions (Table 7.1) and the hydrograph ô chapter 6 . $6 . \quad$. $\quad$. 113

7.3 Maximum erosion at each cross-section for the Sentinel Gap data set using the computed Wallula Gap hydrograph Erom Table 6 .

9.1 Summation of aggradation (+) or degradation ( - ) for the region of the 200 areas using the Meyerpeter and Meuller equation. . . . . 166 


\section{Units of Measurement}

Abbreviation

$\mathrm{cm}$

ft

$\mathrm{ft} / \mathrm{sec}$

$\mathrm{km} 2$

$\mathrm{xm}^{3}$

m

mm

Mefs

Mcms

$\operatorname{mi} 2$

$\mathrm{mi} 3$

$\mathrm{m} / \mathrm{sec}$

Locations

Abbreviation

Coid Cr. Erenchman $\mathrm{H}$. Gable Mtn. Johnson $\mathrm{Cr}$. Middle Can. Priest $R$. Saddle Mtns. Umtanum $R$.

Other Terminology

Abbreviation

$B$

Elev

$\overrightarrow{E m}$

$\mathrm{G}$

$M$

$\operatorname{Max}$

Min

R

$S$

Sec

$\mathrm{T}$

St. Dev.

St. Error

St. Kurtosis

St. Skewness
Unit

centimeter

feet

feet per second

square kilometer

cubic kilometer

meter

millimeter

million cubic feet per second

million cubic meters per second square mile

cubic mile

meter per second

Location

Cold Creek

Frenchman Hills

Gable Mountain

Johnson Creek

Middle Canyon

Priest River

Saddle Mountain

Umtanum Ridge

Term

Basalt

Elevation

Formation

Gravel

Mud

Maximum

Minimum

Range

Sand

Sec

Township

Standard Deviation

Standard Error

Standardized Kurtosis

Standardized Skewness 


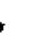




\section{INTRODUCTION}

Nuclear wastes stored at the Hanford Nuclear Reservation near Richland, washington are in surficial materials of relatively young age. Most of the sediments containing these wastes were deposited by major flood events during the last glaciation. At that time an enormous proglacial lake, Lake Missoula, drained rapidly, releasing over 500 cubic miles of water. These floodwaters entered the Pasco Basin through several inlet points and finally drained through wallula Gap (Baker, 1973; see also: Figure 1.1). During the waning stages of such floods most of the sedimentary materials now in the Pasco Basin were deposited. These materials now act as 'host' for the nuclear wastes stored in various forms.

In place stabilization and disposal is one method under consideration for the disposal of Hanford defense wastes. Before such a method can be accepted, its long-term implications must be assessed. One component of that assessment is the evaluation of possible floods in the future that could disrupt the site. Floods of the 'Missoula' type are included in that concern. This report addresses some aspects of such floods to determine the erosion and transportation of sediment likely, should such floods recur. Conclusions about sediment stability during such floods will form one component of the decision-making process about handling the wastes.

Missoula floods were enormous events but were very shortlived. Field evidence and theoretical arguments clearly show that many such floods occurred. The most recent episode of flooding came during tne last glaciation, about 15,000 years ago. 


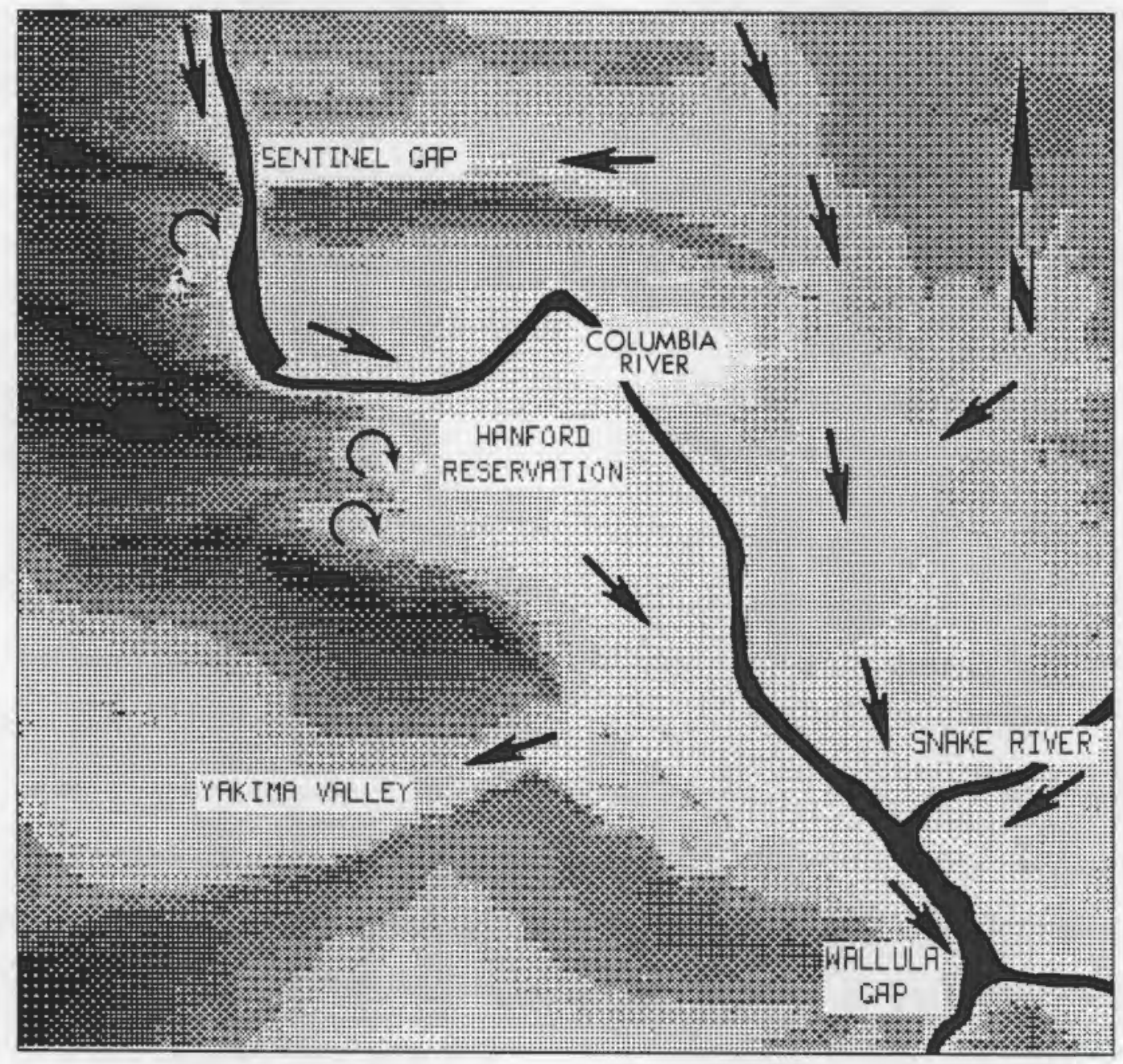

FIGURE 1.1. Physiography of the Pasco Basin and the routes occupied by Missoula Elood waters. Flow directions adopted trom Tallman and Fecht, $197 b$. 
During that glaciation, anywhere from 2 (Bjornstad, 1980) to 80 (Waitt, 1985) floods occurred. Such floods only occur during glaciations because the glaciers themselves set the requisite 'boundary conditions' (Clarke, Mathews, and Pack, 1985). During the maximum of glaciation, lobes of ice from the Canadian Cordillera -- the cordilleran ice sheet -- advance into northern Washington, Idaho and Montana. At Lake Pend Orielle, the ice blocks the Clark Fork River. A lake builds up, backing into Montana as far as the city of Missoula. Water rises until it is deep enough to float the ice lobe and the ice-dam breaks. Water released from the lake, surges across the Columbia Plateau and converges upon the Pasco Basin on its way to the Pacific Ocean. Evidence for these floods is found within the basin of Lake Missoula. There, sediments deposited in the lake record a sequence of fillings and emptyings (Chambers, 1971). In the vicinity of the Pasco Basin, multiple sedimentary layers record several flood events (Bretz, 1969). Areas between the two locations, such as the San Poil Valley in the okanogan Highlands of Washington, record most of the temporal sequence, times of floods and times between floods (Atwater, 1984).

Theoretical arguments also suggest that many floods would occur during any glaciation as extreme as the last. Projections of change in global ice volume linked to estimates of average rate of advance of the Cordilleran ice sheet show that the ice would advance sufficiently far into Idaho to create an ice-dam during almost every glacial period (past or future). The lake fills sufficiently fast to produce multiple floods. The theoretically estimated number of such floods during the last 
glaciation matches closely the reconstructed field record (Craig, Singer, and Underberg, 1983). Using the same model, Craig (1983; Craig and Singer, 1984) estimate flooding will occur again by 50,000 years in the future. Given the uncertainty in such forecasts, it is conceivable that the floods could come even sooner. PREVIOUS WORK

The enormity of such floods dwarfs any in the historical record (Baker, 1978). Volumes of water released are more than 75 times that of typical major floods of the Amazon River. Velocities exceed that of any known or postulated storm-produced floods. Sediment transport during such periods of high discharge and high velocities is greater in volume and size than any other flood event known. Given the magnitude of the events involved, a modicum of field work has been done to establish the characteristics of these floods.

The most extensive and exhaustive examination of the flood evidence was by Bretz $(1923,1924,1925,1927,1928,1930,1932$, 1959, 1969). In this work, Bretz documented the course followed by the floods, the velocities and discharges at many locations, the depths of flow involved, the fact that at least severai floods were responsible for the evidence preserved, the extreme erosion in the 'Scablands' and the enormous depositional features created during the waning stages of the flood.

Pardee (1942) presents evidence of a recurring glacial lake (Lake Missoula) east of the Bitter Root Mountains dammed by the Purcell Trench lobe of the Cordilleran ice sheet. Pardee (1942, p.176) recorded evidence of a lake that obtained a maximum depth 
of nearly $610 \mathrm{~m}(2000 \mathrm{ft})$, an areal extent of $7513 \mathrm{~km}^{2}$ (2900 $\mathrm{mi}^{2}$ ) and a volume of $2084 \mathrm{~km}^{3}\left(500 \mathrm{mi}^{3}\right)$. After this discovery, Lake Missoula was considered the source for the floods proposed by Bretz.

Chambers (1971) studied the deposits formed in Lake Missoula during the many fillings of that lake. He recognized the variations in depositional character during infilling as the lake became deeper at a given spot. By this means, he was able to show that many individual fillings of the lake were represented at certain locations, such as Ninemile Creek. Chambers counted varves in the deposits of a single lake-filling event and thus estimated that it took at least 30 to 60 years to fill the lake. By counting the number of separate rhythmically-bedded layers, Chambers was able to show that at least $37 \mathrm{filling-and-emptying}$ events occurred.

Baker (1973) documented both erosional and depositional features left by the floods which allowed a reconstruction of their fluvial hydraulics. Evidence Baker considered included the nigh-water marks from scouring of loess hills at places where the flood waters crossed drainage divides. Using these divide crossings, Baker was able to estimate the gradient of the water surface at the flood maximum. From this, a computation of the water velocity and discharge at numerous localities was produced. other features Baker considered included the maximum size of boulders transported by the flood and the amplitude and wavelength of ripples in sediments deposited by the flood. Each of these was used to reconstruct aspects of flood water dynamics. Baker's primary results are summarized in Figure 1.2. Additional 


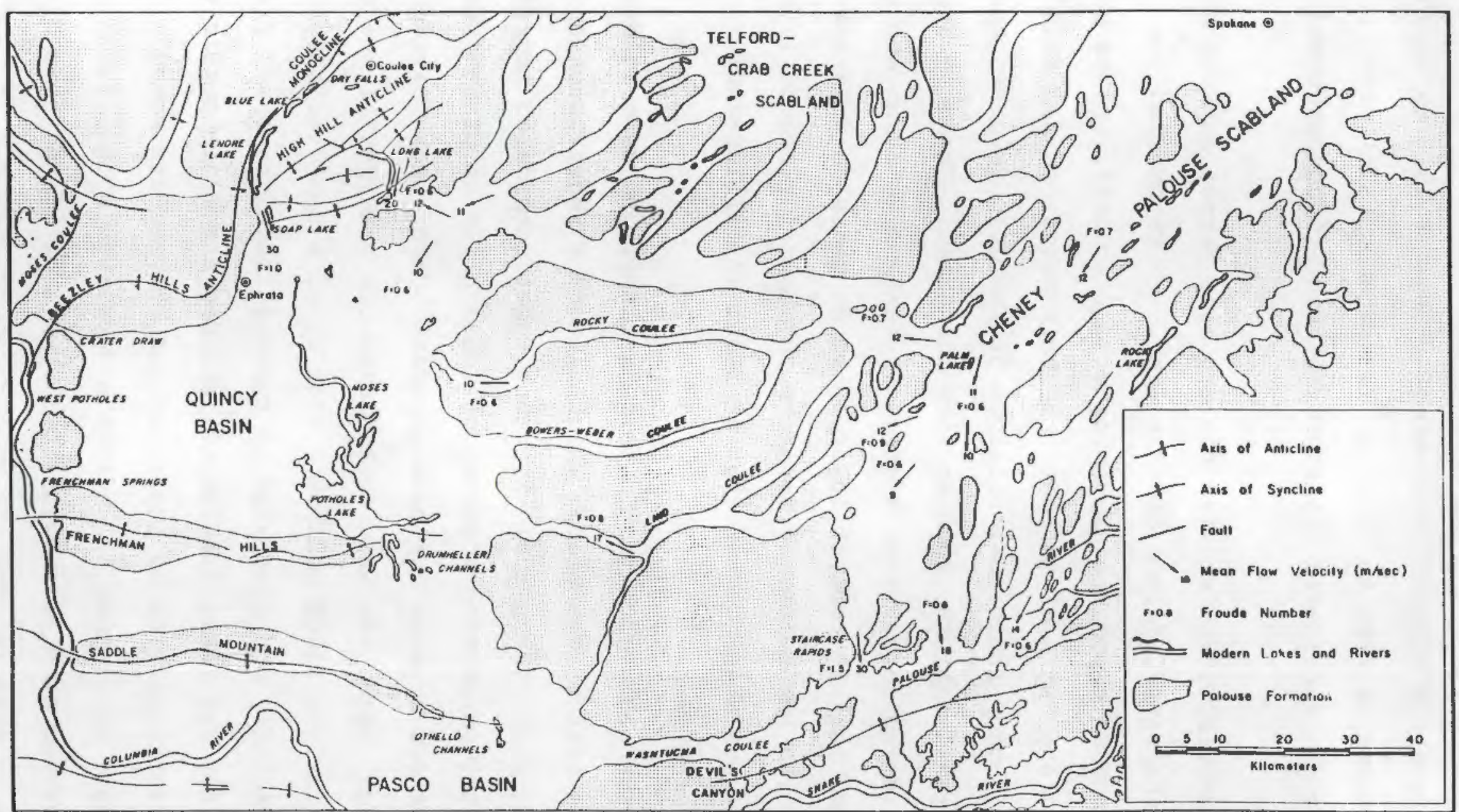

FIGURE 1.2. Generalized Drainage of the Scablands ot Washington showing Locatıons Where Velocities at Maximum Discharges Have Been Estimated From Field Data. From: Baker (1978, Figure 4.6, p.64). 
data were added by Baker and by Patton during later investigations (Baker, 1978; Patton and Baker, 1978).

waitt has studied the sediments left by these floods in the backwater areas near the Pasco Basin (waitt, 1980). From a detailed analysis of the sediments and the interflood deposits, including several ash layers from volcanic eruptions in the Cascades, waitt concluded that many floods must have occurred during the latest glaciation (the Fraser Glaciation). Further studies by waitt have bracketed the age of these floods between 17,000 and 13,500 years ago (waitt, 1983). Waitt has shown that as many as 80 such floods may have occurred in that time span. The average time between floods was probably 40-60 years (Waitt, 1984).

Atwater (1984) has studied deposits formed in other proglacial lakes at the southern margin of the cordilleran ice sheet. Those lakes were in existence during at least part of the lifespan of Lake Missoula. A lake (Lake Columbia) created by the Okanogan lobe of the Cordilleran ice sheet occupied the region of present day Lake Roosevelt (Figure 1.3). Between Missoula floods, sedimentation in Lake columbia consisted primarily of varved deposits. These are assumed to represent annual layers. Counts of these varves show that 35 to 55 years passed between floods. The times of the floods can also be recognized in these deposits. Incursions of sediment-laden floodwaters disrupted the varve deposition and a chaotic mass of turbidite-like deposits formed. After stable conditions were re-established in the lake, varve deposition began again. Atwater shows that at least 70 floods may have affected glacial Lake columbia during the Fraser 


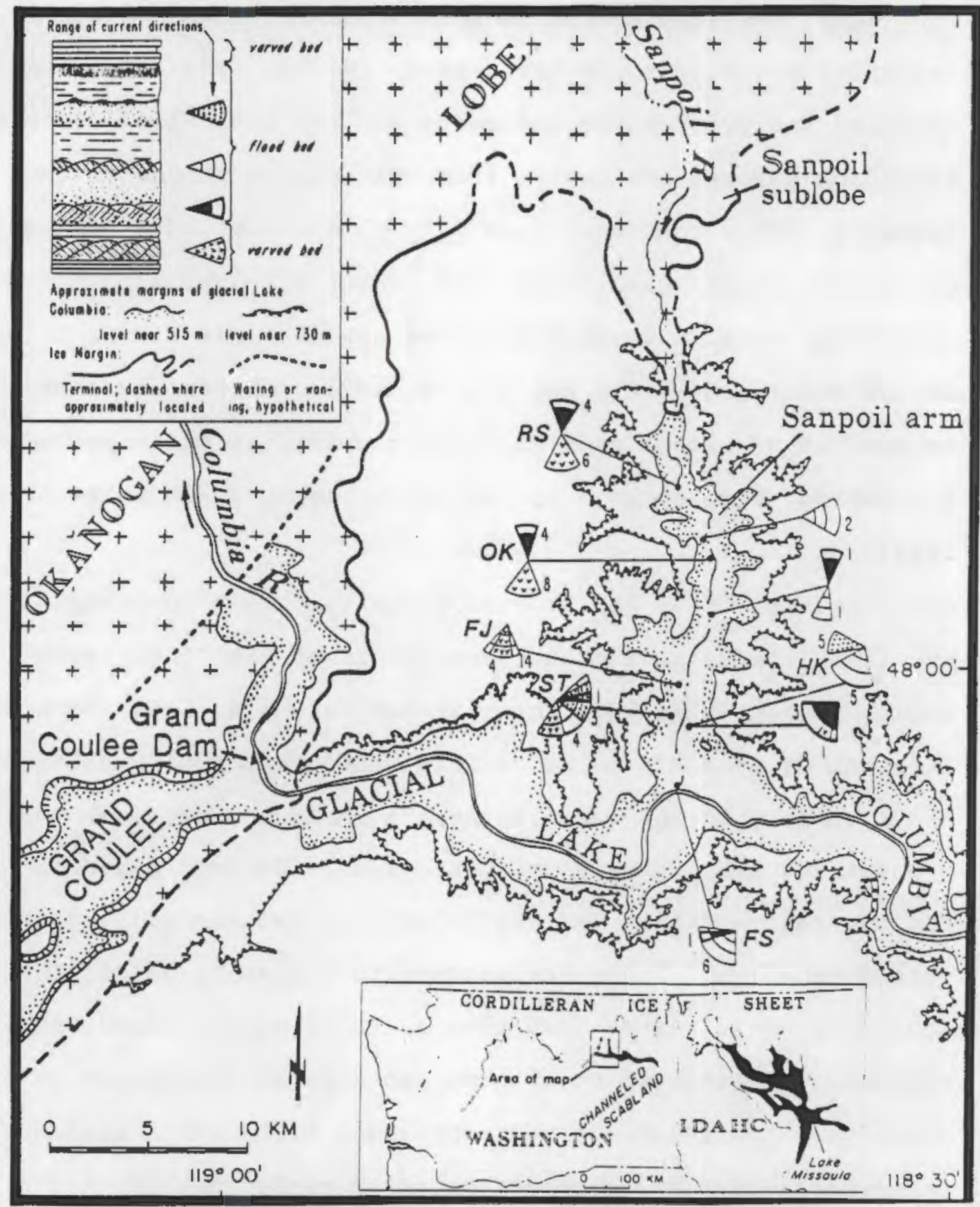

FIGURE 1.3. Configuration of Lake Columbia during the time oi flooding from Lake Missoula. Locations of sections preserving evidence of multiple rioods are shown. Originally published by GSA, in Geology, v.12, P.465, Figure l by B.F. Atwater. 
Glacial stage. He also suggests that the character of the floods varied in a systematic way during this period. The greatest floods occurred in the middle of the sequence. Earlier and later floods had lesser discharge. A fairly regular progression of discharges characterized the sequence. This agrees with the theoretical evaluation of Craig (Craig, Singer and Underberg, 1983; Craig and Singer, 1984).

REVIEW OF PROGRESS IN GFY 184

This report represents the summary of a two-year Investigation of the dynamics of floods from Lake Missoula. An Interim report was produced at the end of GFY '84. During that time, work focused upon: (1) collating evidence from published field studies that could shed light upon the problem, (2) establishing the conditions controlling the timing and nature of breakup of the ice dam, (3) representing the control upon flood behavior exerted by the configuration of the ice sheet margin and ice sheet dynamics and, (4) determining a method to represent the dynamics of the floods themselves.

Evidence concerning the nature of individual floods includes the discharge and velocity data of Baker (1973; 1978) and Patton and Baker (1978). High water marks were also reported by Brecz (1969). These data are sumarized in Table 2.1. Specific data relevant to the Pasco Basin are reported in section 2. Results of each of these inquiries are summarized below.

The floods occurred when waters of Lake Missoula, impounded behind the ice dam, reached sufficient levels to float or otherwise disrupt the dam. At that time, rapid failure of the dam occurred, probably enhanced by thermal erosion of the ice by 
the flood waters. Three mechanisms of ice dam failure are possible: floatation, overtopping and tunnelling. Controls on the operation of these mechanisms include the density of water, density of ice, brittleness and fracturing of the ice and the temperature of the water. Re-establishment of the ice dam depends upon the extent of the failure during the last flood and the rate of advance of the ice sheet. Timing of the failure depends upon the rate of infilling of the lake and the amount of water left in the lake after the last flood. Volume of wacer released in a flood depends upon the dam failure mechanism, the relative rates of advance of the ice and filling of the lake, amount of sedimentation in the lake and the configuration and chickness of the ice margin at the northern edges of the lake. The hydraulic behavior in an individual flood depends upon the configuration of the southern margin of the cordilleran ice sheet in Washington; the existence, extent and locations of proglacial lakes; the amount of water released during a flood; previous occurrence of floods of a similar nature; and the remperature of the floodwaters.

The dynamic behavior of a flood can only be represented through the use of a complex set of physically based equations. The equations required are a simplification of the threedimensional Reynold's equations. Because we are not especially interested in the vertical transport of water or of sediment, a full three-dimensional model is not required. A one-dimensional representation is not sufficient because the floodwaters bifurcate and rejoin at numerous locations. Even where flows do not anastomose, channel width variations and secondary currents 
are significant parts of the flows. Thus, at least a twodimensional representation is required. For the mathematical model, a vertically integrated, two-dimensional model was selected.

The terms representing turbulence in the Reynold's equations do not allow a closed-form solution. For the Missoula floods, turbulent behavior was an Important component of the flow (Baker, 1973). Representation of the turbulent forces is achieved by an approximation scheme based upon a weighted average of neighbor terms.

Solutions of the relevant equations in the interim report were based upon an explicit numerical finite-difference representation. Conditional stability was maintained through the use of a diffusing-difference approximation and a varying time step. The length of the time step depended upon the maximum velocity observed in the previous time step. Friction was represented through use of the Chezy-Manning formula. Solutions focused upon the behavior of the flood in the area of the Rathdrum Prairie, near the dam failure point. This was chosen to provide the most critical test of stability of the approximation procedure. By coupling the algorithm to a grid representing the configuration of the lake and of the ice margin, it was possible to follow the draining of the lake in the early stages of the flood.

Although the explicit diffusing-difference scheme used does provide a reasonable solution of the flood dynamics, even during these critical events, a more stable solution scheme was desired. The conditional stability of the explicit scheme required an 
extremely short time step (six seconds) for computational accuracy. This precluded the use of the model to study the entire sequence of a flood event, from the time of dam failure to the creation of hydraulic ponding at Wallula Gap. An improved solution scheme has been investigated during the GFY ' 85 work. MAJOR STEPS IN THE WORK FOR GEY 185

Work in GFY ' 85 considered four points. First, a new solution scheme was defined, implemented as code and tested. Second, an estimate of the time-varying boundary conditions of a flood in the Pasco Basin was made. Third, the HEC-2 code of the U.S. Army Corps of Engineers was used to estimate flow behavior during a flood in the Pasco Basin. Finally, the HEC-6 code of the Corp of Engineers was applied to estimate sediment transport near the 200 areas during such a flood. This forms a benchmark against which to compare future modelling efforts.

The characteristics of different floods that could affect wastes stored in the Pasco Basin are constrained by different types of field evidence in the neighborhood of the Pasco Basin. This evidence is reviewed in chapter 2. Representation of the flood required selection of a flood scenario which would represent a 'worst case' for disruption of the wastes. That scenario, and the rationale for its selection, are described in chapter 3. Characteristics of the hydraulics of that flood scenario can be obtained using the simplifying assumption of onedimensional steady state conditions. That description is provided in chapter 4. Those conditions are used to describe a one-dimensional steady-state scenario of erosion during a flood in chapter 5 . 
A more realistic assumption is to recognize the time-varying nature of the floods. In the absence of a solution of flood dynamics in the upstream areas, a hydrograph must be synthesized for the inflow areas. A procedure was developed that uses field evidence to constrain the character of that hydrograph. The method and its results are presented in chapter 6. That hydrograph is used to describe a one-dimensional time-varying sequence of erosional events using the HEC-6 code in chapter 7 .

Because the floods have a demonstrable two-dimensional aspect, and because knowledge of its nature is required to estimate the fate of wastes entrained from the tianford area during a flood, a two-dimensional model of the floods has been implemented. The model provides a representation of the timevarying nature of the floods. An implicit multi-operational solution procedure provides a stable solution over the time span of interest. Development of the code is described in chapter 8 . Results of the hydrograph analysis are applied in chapter 9 to the computation of the amount of erosion which would be expected during such a flood.

Results of the different approaches to the estimation of the erosion potential of a flood are summarized in chapter 10 . Those Lead to a set of recommendations concerning the stability of the site. Also given are recommendations on testing these conclusions and a summary of the limitations of the analysis. Limitations and uncertainties involved in each step of the analysis are presented at the end of each chapter. 
EVIDENCE OF THE MISSOULA FLOODS IN THE PASCO BASIN

FLOOD PATHS TO AND FROM THE PASCO BASIN

During a flood of the magnitude of the Missoula floods, erosion is great enough to scour existing surficial materials to great depth. Much of the Columbia Plateau is covered by $30 \mathrm{~m}$ or more of the Palouse loess (Bretz, 1956). Where the flood waters passed, much of that loess was eroded, exposing the basalts of the Columbia Group below (Bretz, 1956). The contrast between these two allows easy recognition of many of the flood paths. other portions of the floodways are recognized by the extreme plucking of basalts which occurred. In some places, channels deepened into coulees by this erosion (Bretz, 1956). Still other pathways are recognized by the sediment that was deposited in the waning stages of the floods. Combined, these different lines of evidence provide a clear indication of the channels occupied by the floods (Figure 2.1).

At the dam failure point and immediately downstream, flood waters surged through a deep narrow valley, which constrained the flow (Rathdrum Prairie). At the end of that valley, an expansion of the flooded area slowed flood velocities. The Spokane River valley provided a channel for much of the water. Water continued down that valley and joined the Columbia River. As long as the course of the Columbia River remained open, flood waters may have remained almost exclusively within its valley. Many side valleys would have been flooded but little serious diversion of the flood waters would have occurred. Both Bretz (1969) and Waitt (1979) discuss evidence that some of the floods have followed such a path. 


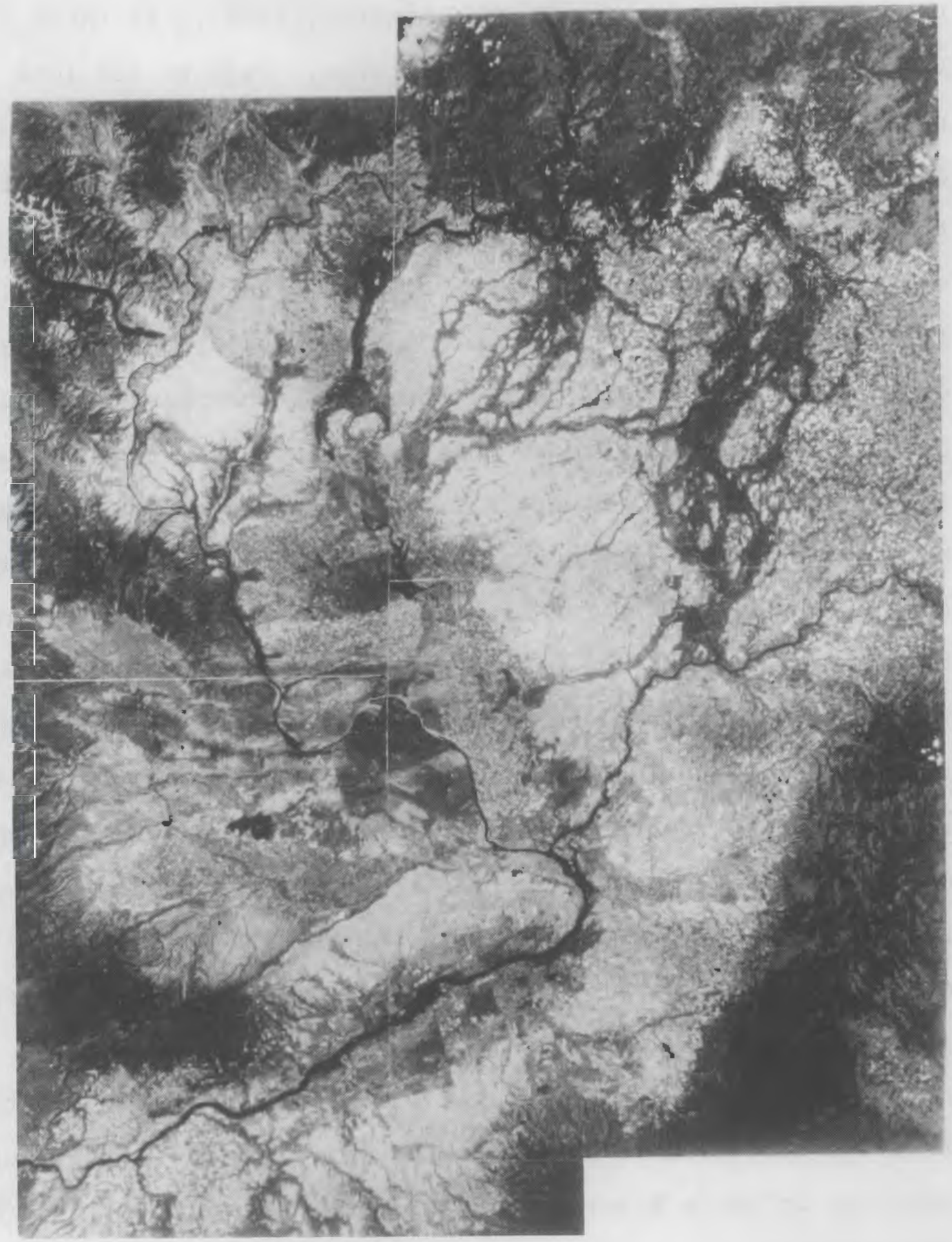

FIGURE 2.1. Landsat photo mosaic of the Channeled Scablands of eastern Washington. North is to the top. Photograph produced by Harlan Foote, PNL. 
During most of the floods, the Okanogan lobe of the Cordilleran ice sheet was probably sufficiently advanced to block the path of the Columbia River (Atwater, 1984). At these times, Lake Columbia was probably in existence. With an ice lobe blocking the path of the flood waters, alternative pathways were created. In these cases, the waters spilled out of the valley of the Spokane River and spread across the Columbia Plateau. Some of the water advanced down the Columbia River valley as far as the ice dam of the Okanogan lobe. There it surged down the Grand Coulee in the direction of the Drumheller channels. In the Quincy Basin, waters ponded until four outlets were occupied simultaneously. Other waters crossing the Scablands through numerous channels also converged upon the Quincy Basin. Major outflow occurred down the Drumheller Channels and spread around Frenchman Hills and the Saddle Mountains (refer to Figure 2.2). Other flows from the Spokane River valley spread south and copped the divide into the drainage of the Palouse River. There It took two courses. Some waters continued down the old course of the Palouse River and entered the Pasco Basin through Esquatzel Coulee. Other flows in the Palouse Basin topped the divide to the snake River and surged up and down that valley. These also finally converged on the Pasco Basin. Flows bifurcating around the Frenchman Hills and the Saddle Mountains from the direction of the Quincy Basin would have either surged into the Columbia River and passed into the Pasco Basin through Sentinel Gap, or would have flowed into Esquatzel coulee, joining flows down the old Palouse channel and passed into the Pasco Basin. 


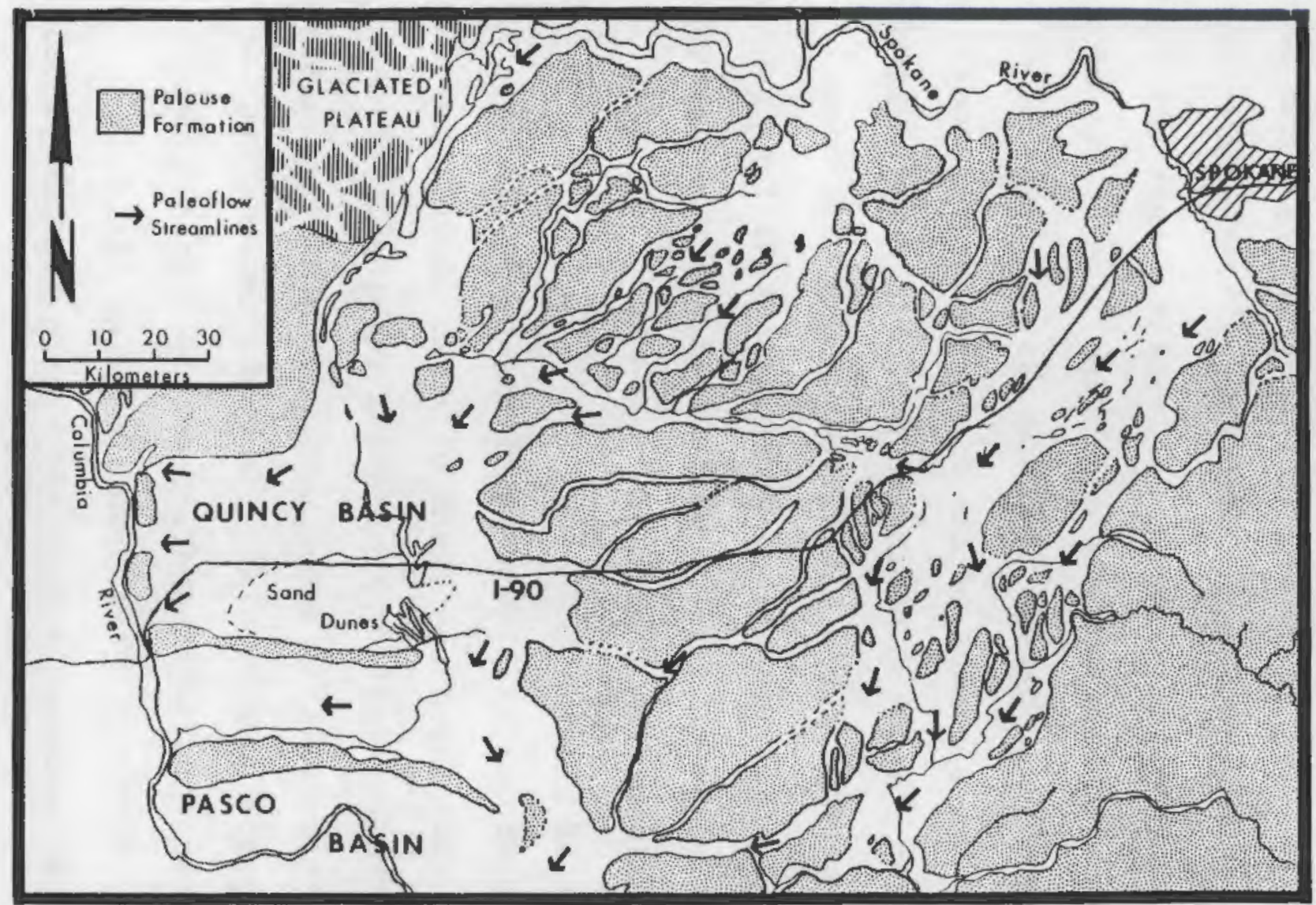

FIGURE 2.2 .

Channelways and Flow directions of a Missoula rlood high-lighting paths into the Quincy and Pasco Basins. Modified trom: Baker (1978, Figure 5.2, p.83). 
Thus, there are two major types of Missoula flood: (1)

floods confined to the valley of the columbia River and, (2)

floods dispersed across the scablands and converged on the Pasco Basin through at least three significant channels. The control on which type of flood occurred was exerted by the position of the margin of the Okanogan lobe. It is likely that the first type of flood was typical of the early and late stages of a flood sequence. The dispersed type of flood was more typical of the middle part of the sequence of floods, while the Okanogan lobe was advanced far enough to block the columbia River. It can be expected that each of these flood types would have been characterized by differing flood dynamics within the Pasco Basin. That possibility is explored in chapter 3 , and a bounding scenario is defined from that.

FLOOD FEATURES IN THE PASCO BASIN

J. Harlen Bretz (1923) was the first to investigate and propose a catastrophic flood event of a magnitude that could inundate the greater portion of eastern washington at one time. The reconstruction of that event was based entirely on field evidence; evidence such as giant bar deposits, coulees, and high water marks. In this investigation we are mainly interested in the high water marks that exist in the Pasco Basin.

Within the Pasco Basin high water mark evidence consists of divide crossings, glacial silt lines from flood waters, bergmounds (glacial material trapped in ice and stranded on mountain sides as lake levels dropped), and scouring and widening of Sentinel Gap, which served as a constriction for flows entering the Pasco Basin from the north. Table 2.1 summarizes 
TABLE 2.1. Summary of flood evidence in the Pasco Basin.

Location

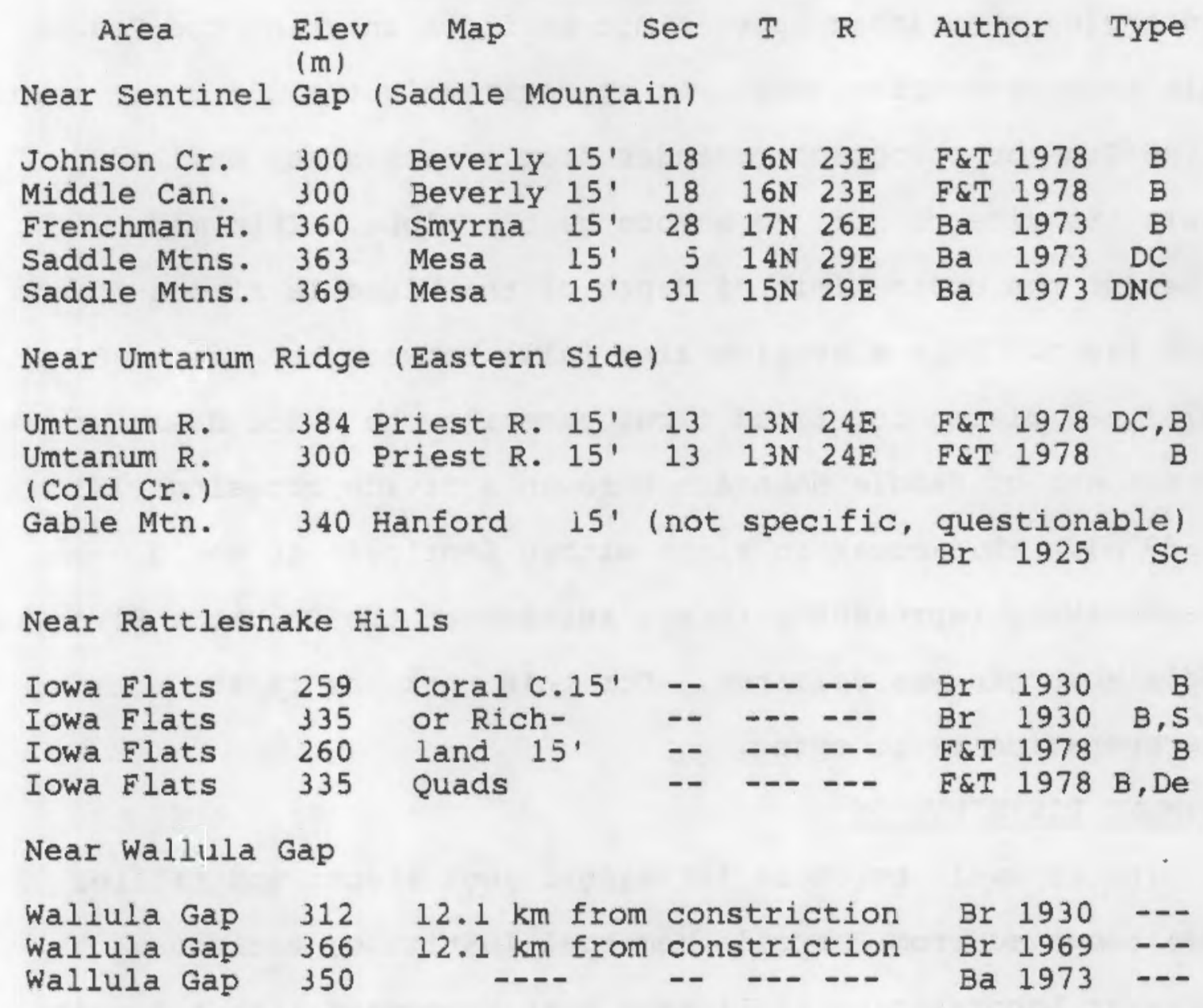

KEY TO TABLE 2.1.

AUTHOR

$\mathrm{Br}$ - J. Harlen Bretz

$\mathrm{Ba}$ - V. Baker

F - K. Fecht

$\mathrm{T}$ - A. Tallman
TYPE

$$
\begin{aligned}
\text { B - Bergmounds } \\
\text { DC - Divide Crossing } \\
\text { DNC - Divide Not Crossed } \\
\text { SC - Scour } \\
\text { S - Silt } \\
\text { De - Ice-rafted Debris }
\end{aligned}
$$


the field evidence within the Pasco Basin.

Aerial photographs and a topographic map of the Beverly 15, quadrangle, suggest an upper limit on flows entering the Pasco Basin through Sentinel Gap. At approximately the 366 m elevation in the Gap the topography changes from a very steep wall of basalt (Sentinel Bluff) to a more gentle slope. This may represent the upper limit of depth of the Missoula Floods in the Pasco Basin. This elevation also falls between the limits Baker (1973) has placed for flood flows entering the Pasco Basin at the eastern end of Saddle Mountain through a divide crossing $1363 \mathrm{~m}$ to $369 \mathrm{~m})$. This break in slope within sentinel Gap could alternatively represent a former terrace of the Columbia River as Saddle Mountain was uplifted. For this work the first interpretation is accepted.

SEDIMENT DISTRIBUTION

The Rockwell borehole lithologic logs (Fecht and Lillie, 1982) received from Battelle Memorial Institute, Pacific Northwest Laboratories (PNL) have been processed into a format usable for this project. The original format of the data is lllustrated in Table 2.2. Processing included synthesizing grain-size data from 1,850 wells located in the Pasco Basin; the majority of which were within the Hanford Reservation. Well-logs were matched with well locations (latitude and longitude coordinates) with a program supplied by PNL. Once this process was completed, wells that did not reach the top of the Ringold Fm. (boundary placed by PNL investigators) were stripped from the data set. A total of 807 wells were thus available to characterize the sediment distribution within the Pasco Basin 
(Figure 2.3). Since well locations were in the form of Hanford Plant Coordinates, locations were transformed into latitude and longitude coordinates. This was done to facilitate graphical representation of the location of these wells on a familiar coordinate system. A computer program "CONVRT", provided by Battelle PNL (Appendix A), was used in the transformation. The next step was to simplify the information recorded by each driller into meaningful information about the sediment distribution within the Pasco Basin. Since it is nearly Impossible to synthesize the actual driller's descriptions of the sediments (inconsistent terminology; lack of meaningful terminology) sediment type (constituent) was catagorized over each depth interval using Battelle's GSMB description: G for gravel, S for sand, $M$ for mud and $B$ for solid basalt. The depth for each interval of sediment was divided by the number of. constituents assigned by PNL to a particular interval. An example of this procedure is described below. In Table 2.2, A, the first 7 feet of the Glaciofluvial sediments (consisting of the Hanford Fm. or the Pasco Gravels) is comprised of three constituents, sand, mud, and gravel (SMG). This interval of sediments was divided into thirds and each constituent was given equal weight, 2.33 feet. The next interval consists entirely of gravel (G), 8 feet. Sand and gravel (SG) are assumed to be 2.5 feet thick because the next interval is 5 feet thick. In the next interval sand (S) is 5 feet and then at a depth of 38 feet the Glaciofluvial Sediments end and Ringold Formation begins so sand and gravel (SG) each are assigned 6.5 feet of the 13 feet of 
TABLE 2.2. Example computation of grain-size distribution from we1l-log data.

A. Input -- Data Obtained From Rockwell Lithologic Borehole

Data Base for the Hanford Reservation.

$$
\begin{gathered}
\text { Well \# } 11 \quad 33 \text { 13A } \\
\text { Latitude } \\
46 \text { Longitude } \\
18^{\prime} 24.75 "
\end{gathered}
$$

$11 \quad 3313 \mathrm{~A} \quad 030848380.00120 .00 \mathrm{RODDA}$

$113313 \mathrm{~A} \quad 0.0 \quad$ GLACIAL FLUVIAL SEDIMENTS

$113313 \mathrm{~A}$ SMG 7.0 SANDY LOAM; LARGE BOULDER AT $7{ }^{\prime}$

$113313 \mathrm{~A} \quad \mathrm{G} \quad 15.0$ BOULDERS

$113313 A$ SG 20.0 COARSE SAND AND GRAVEL

$113313 \mathrm{~A}$ S 25.0 COARSE SAND, GETTING FINER

$113313 \mathrm{~A}$ SG 38.0 COARSE SAND AND FINE GRAVEL

$113313 \mathrm{~A} \quad 38.0 \quad$ RINGOLD FORMATION

$113313 \mathrm{~A}$ SM 40.0 COARSE SAND AND YELLOW CLAY

$113313 \mathrm{~A}$ SGM $\quad 47.0$ SAND, GRAVEL AND CLAY

$113313 \mathrm{~A} \quad \mathrm{~S} \quad 58.0$ YELLOW SAND

$113313 \mathrm{~A}$ SG $\quad 58.0$ YELLOW SAND AND GRAVEL

$113313 \mathrm{~A}$ MSG 60.0 YELLOW CLAY, SAND AND GRAVEL

$113313 \mathrm{~A}$ MSG 80.0 YELLOW CLAY, CRS. SAND \& GRAVEL

$113313 \mathrm{~A}$ MSG 84.0 YELLOW CLAY, SAND \& GRAVEL

$113313 \mathrm{~A} \quad \mathrm{M} \quad 100.0$ YELLOW CLAY

113313 A MS 105.0 YELLOW CLAY W/COARSE GRAY SAND

$113313 \mathrm{~A}$ SGM 108.0 WHT.SAND, WATER GRAVEL W/BL CLAY

$11 \quad 3313 \mathrm{~A}$ MS 110.0 SLATE AND SAND

$113313 \mathrm{~A}$ MS 115.0 BLUE CLAY AND SAND

$113313 \mathrm{~A} M \quad 120.0$ BLUE CLAY AND SHALE

B. Results -- Sediment to top of Ringold Formation.

\begin{tabular}{l|ccc:c} 
& Gravel (G) Sand (S) Mud (M) & Total \\
\hline Thickness (ft) & 19.34 & 16.33 & 2.33 & 38.0 \\
Percent & 50.9 & 43.0 & 6.1 & 100.0
\end{tabular}




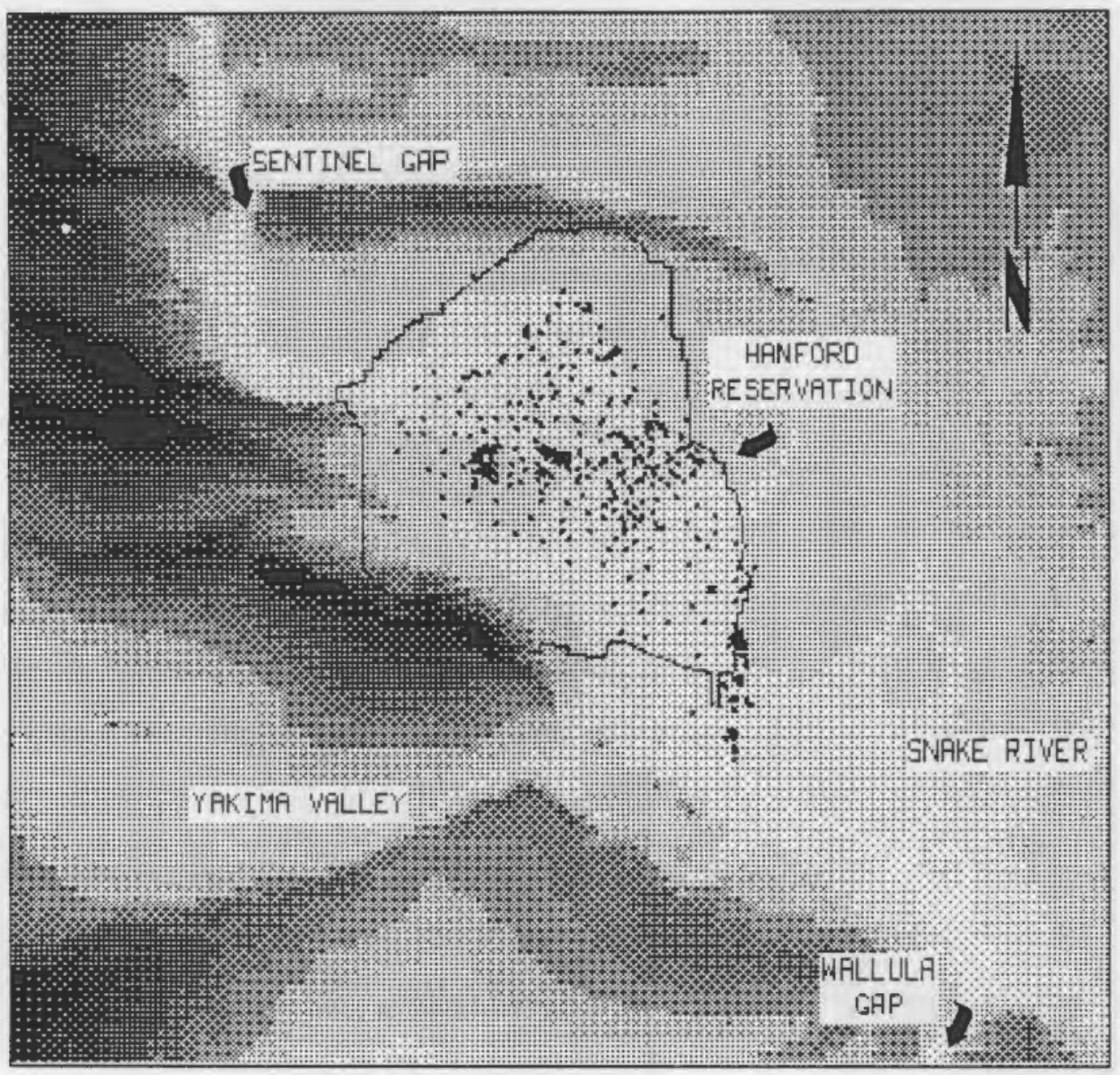

FIGURE 2.3. Digital elevation data For the region of the Pasco Basin at 30-second spacing. Locations of 807 weils used to characterize the sediment distibution within the Pasco Basin are shown (dots). 
sediment. For this analysis, sediments of the Ringold Formation are not of interest so computations stop once the top of the Ringold was encountered. In summary, there is 19.34 feet or $50.9 \%$ gravel, 16.33 feet or $43.0 \%$ sand, and 2.33 feet or $6.1 \%$ mud at this well location (Table $2.2, \mathrm{~B}$ ).

The well-log information includes two major geologic units; the Quaternary units consisting of alluvial fan material, colluvium, alluvium, and loess deposits; and the Hanford Formation (Pleistocene), consisting of the Pasco Gravels (deposited by Lake Missoula flood-flows, Figure 2.4). The information from each well-log has been summarized into total thicknesses of the gravel, sand, and mud components. These data were then converted into percentages of each sediment type (Appendix A). The mean thickness of the combined Hanford Formation and Pasco Gravels is approximately 39 meters containing on average of $36 \%$ gravel, $46 \%$ sand and $18 \%$ mud. More detail on grain size variation has not been included due to the complexities involved in extracting that information. EROSION

Bretz (1969,p.537) refers to Sentinel Gap as an area of kolk activity or pronounced scour. Evidence in support of his statement can be found downstream of Sentinel Gap (Figure 2.5); with boulders up to $2.4 \mathrm{~m}(8 \mathrm{ft})$ in diameter are deposited 14.5 $\mathrm{km}$ downstream of the gap. It is believed that the floods scoured these large boulders from Sentinel Gap and as the competency of the flows diminished, deposition occurred. Other evidence of scour in the Pasco Basin includes the channels cut into the basalts forming Ringold and Koontz Coulees at the eastern edge of 


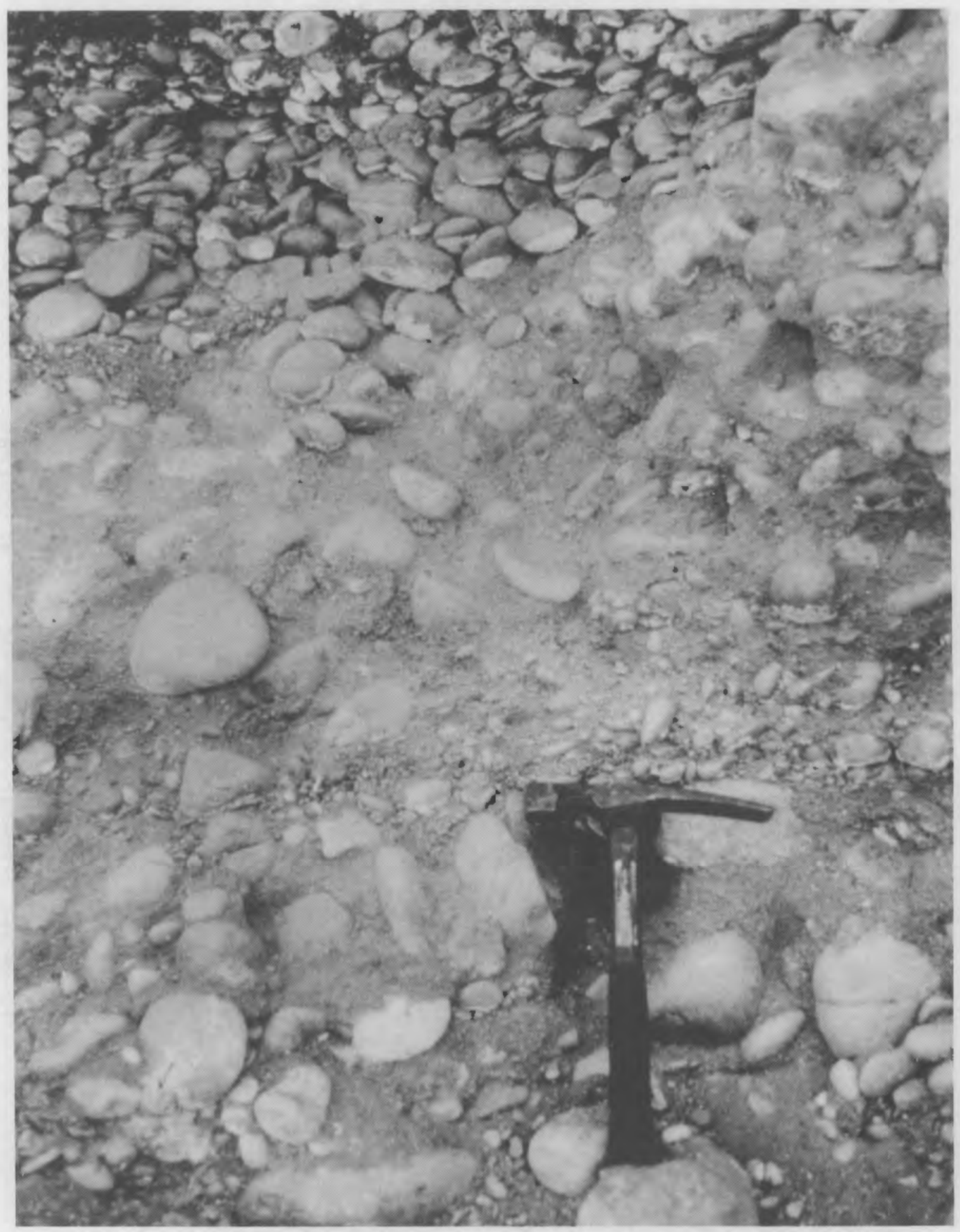

FIGURE 2.4. Typical grain sizes deposited by Missoula Iloodflows in the Pasco Basin. Hammer is $32 \mathrm{~cm}$ long. Photograph by J.P. Hanson. 


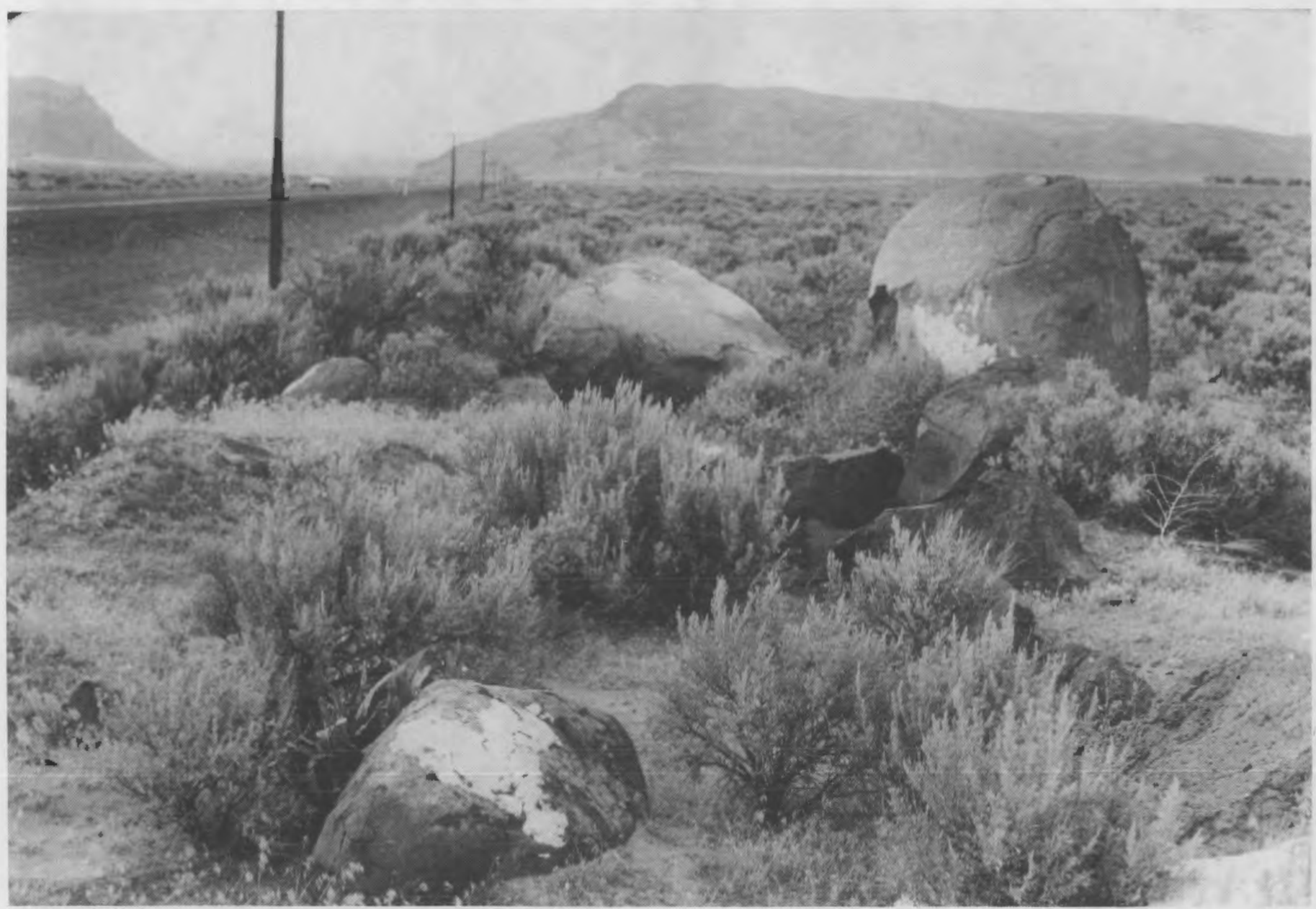

FIGURE 2.5. Boulders deposited by Missoula flood waters $14.5 \mathrm{~km}$ downstream of Sentinel Gap. The largest boulder in the scene is about $2.4 \mathrm{~m}$ im median diameter. Photograph by R. G. Craig. 
the Pasco Basin south of Saddle Mountains. Deep channels are also cut on both sides of Gable Mountain where the main channel from a Missoula-type flood would have flowed.

\section{LIMITATIONS AND UNCERTAINTIES}

Missoula floods were characterized by one of the most intensive releases of energy by a natural event on the surface of the earth. The event was both short and powerful. Its power led to preservation of a great deal of evidence. Its brevity results in a great deal of uncertainty about how to interpret that evidence. Within a confined area such as the Pasco Basin, only certain areas favor preservation of evidence. Thus, there is a reasonable supply of evidence at the margins of the basin which reflects the maximum level reached by the floodwaters. Within the basin, there are voluminous deposits of sediment, which probably represent sedimentation in the waning stages of a flood. At the water gaps and at some of the higher inundated sites such as Gable Mountain, there is evidence of the erosional power of the discharges at their height.

Each of these lines of evidence records one aspect of the flood behavior at one time in the flood. High water marks only tell us about the water profile at the point of maximum discharge from Wallula Gap. At all other times water profiles are little constrained or are completely unknown from field evidence. Sedimentation occurred in the Pasco Basin sometime during the waning stages of a flood. During the early stages of a flood, sediment was being eroded in at least some locations. The fact that very little sediment of earlier floods is recognized within the Pasco Basin is strong evidence that it has been reworked and 
possibly removed. That process may continue even beyond the time of maximum discharge in the flood. Transport capacity may be sufficient to carry all materials as suspended load or bedload until the very last stages of a flood. Thus, field evidence alone provides little constraint upon the erosive capacity of a flood.

At the inflow points, especially at sentinel Gap, there is abundant material of large size indicating the transport and erosive capacity of the flood waters. Unfortunately, it is not possible to establish when during the flood such deposits were formed. If it could be established that such features formed at the time of maximum discharge through Sentinel Gap, then the details of the velocity distribution could be worked out. At least a maximum erosive capacity could be provided. Since such deposits may have formed at some time after the maximum discharge through sentinel Gap, their characteristics only allow us to estimate the minimum erosive capacity through the Gap.

Within an individual flood, passage of the flood wave was a short-lived peak. It may have required several days to a week to pass from the failure point through wallula Gap. Maximum water stages occurred at different times at different points. Even within the Pasco Basin the high water at Wallula Gap may have occurred as much as one day after the maximum at Sentinel Gap. Because of this, the water surface profile at any one time would not correspond to that recorded by the high water marks around the Basin. High water marks in the southeast (near Wallula Gap) were created at a different time than the high water marks in the 
northwest (near Sentinel Gap). Thus, water surface profiles reconstructed from high water marks are of little value in estimating the actual water surfaces during times of peak flood. There is no information available to reconstruct water surface gradients at other times in the flood.

The highly unsteady nature of the flows also suggests that the times of maximum discharge through a given area would not necessarily correspond to the times of maximum velocity at the spot. This is due to variations in the cross sectional area and the geometry of the flows. It is further compounded by the existence of multiple inlets and outlets to the Pasco Basin. For a short while at maximum elevation, the waters may have been especially slow moving. Thus, maximum elevation may not correspond to either maximum discharge or to maximum velocity. Discharge and velocity are not even simply related to elevation at some locations such as the gaps. This is because hydraulic jumps between supercritical and subcritical flow must have occurred during the largest floods.

Further difficulties arise because of the fact that many floods have occurred. As if the time-transgressive nature of peak discharge during a single flood weren't enough, each of the problems discussed above is amplified by the fact that the evidence about a flood in one place may not represent the same flood as that recorded at another location. Thus, we might estimate the minimum erosive capacity of one flood from sediments downstream from Sentinel Gap. Estimates of the high water marks from the Gap itself may have been produced during a different flood. In most cases we cannot know which evidence to attribute 
to each flood. If we synthesize a picture of 'the flood' by combining evidence of extremes from many different floods, we may create a 'monster flood' which at no time did or will occur. It is because of this that the impression of Missoula floods gleaned from the field evidence may help us little in understanding the characteristics of a single flood.

More difficulties arise when we recognize that the Fraserage floods were not the only Missoula floods to occur (Tallman, Lillie and Fecht, 1981). Some deposits in the Pasco Basin remain from these earlier floods. There is no reason to suppose that all erosional and high water evidence in the Pasco Basin or elsewhere in the Scablands is of Fraser-age. Thus, a synthetic picture of a flood may include some components that reflect earlier floods when the hydrologic, topographic and structural controls were much different.

Our estimate of the thickness of the Pasco Gravels is subject to uncertainty. Within the Hanford Reservation sediment thickness ranges from a minimum of $.6 \mathrm{~m}(2 \mathrm{ft})$ to a maximum of $109.4 \mathrm{~m}$ (359 ft) (Table 2.3). The mean thickness of $39 \mathrm{~m}(121.5$ ft) was calculated for the Pasco Gravels combined with the other Quaternary units. This value does not include areas outside of the Hanford Reservation since no well logs were available. Excluding this area may introduce error because the northern portion of the Pasco Basin contains a bar deposit $30 \mathrm{~m}$ (100 ft)

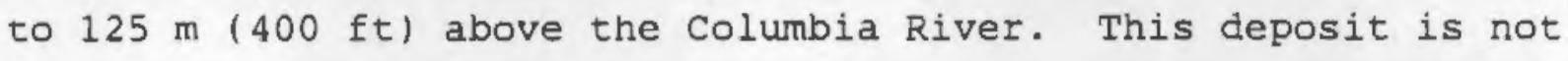
included in our estimate. The southern part of the Pasco Basin also contains great thicknesses ( $250 \mathrm{~m}$ or more) of flood gravels 
(a)

( personal communication from Randy Brown, 1984). We have not included these values in our estimate because the boundary between the Pasco Flood Gravels and the Ringold Formation has not been established.

TABLE 2.3. Statistics of the sediment thickness in the Hanford Reservation based on well-log information.

\begin{tabular}{|c|c|c|c|c|c|c|c|}
\hline Min & $\operatorname{Max}$ & $\begin{array}{l}\text { Mean } \\
\text { feet) }\end{array}$ & Variance & $\begin{array}{l}\text { St. } \\
\text { Dev. }\end{array}$ & $\begin{array}{l}\text { St. } \\
\text { Error }\end{array}$ & $\begin{array}{l}\text { St. } \\
\text { Skew- } \\
\text { ness }\end{array}$ & $\begin{array}{l}\text { St. } \\
\text { Kurt } \\
\text { osis }\end{array}$ \\
\hline 2 & 359 & 121 & 6926 & 83.22 & 2.93 & 1.18 & 0.65 \\
\hline
\end{tabular}

It is difficult enough to characterize floods of the past. Estimation of the behavior of future floods is fraught with additional difficulties. For example, since we do not know how much each flood modified its path by erosion and deposition, we cannot be sure that the configuration (such as geometry and roughness) of the channels to be occupied by the next flood will reflect recent modifications. If the changes have been great, the floods can be expected to have different character. It is not unreasonable to assume that each flood modifies its path and that these modifications tend to be cumulative. Thus, there will be some systematic variation in flood characteristics. It is difficult to extrapolate these trends from the available record since dating of individual features is not available.

It is difficult to estimate the magnitude of the uncertainty

(a) Personal communication from Randy Brown, Geological Consultant, Pasco, Washington, June, 1984, personal conversation, phone (509)547-2067. 
that results from each of these limitations in our knowledge. It is even more difficult to estimate the uncertainty that results from the combination of all of these problems (and the ones we have not thought of). We assume that there may be an order of magnitude error in our reconstructions of erosive and transport capacity from the field evidence. Our estimates of the water surface slope may be in error by a similar amount, even if only considered to represent the water surface slope at the maximum water depth, as opposed to the water surface slope at the maximum discharge or at the maximum velocity. We conclude that discrepancies between model results and field data of one order of magnitude would not be surprising. Errors exceeding two orders of magnitude would be cause for suspicion. In any case, the two procedures must be compared very carefully to avoid false conclusions about the correctness of one or the other. 


\section{ALTERNATIVE FLOOD DYNAMICS}

SCABLAND TRACTS AND THE OKANOGAN LOBE

It is now widely accepted that there were multiple Scablands floods during the latest (Fraser) glaciation (Baker and Bunker, 1985; Waitt, 1985). The flood sequence probably began about 17,500 years bp and lasted until about 13,500 years bp (waitt, 1984). Each flood was very short-lived, perhaps lasting less than one month. The number of floods which occurred during the Fraser is not clearly established. It is quite certain that at least ten floods did occur.

Each flood impacted the Scablands; creating or enlarging channelways by erosion and deflecting paths of future floods by deposition of major fluvial features such as point bars, eddy bars and pendant bars. It is unlikely that each flood followed precisely the same course. This is further implied by the difference in volumes of water involved in each flood (Atwater, 1984; Craig, Singer and Underberg, 1983). Bretz (1959, 1969) has identified each of these channelways and documented some of the evidence of floods in them (Figure 3.1). Baker (1973) used such evidence and basic equations of one-dimensional steady flow to estimate the maximum velocities and discharges of water that could be involved in the various channelways (Figure 3.2). of interest to the problem of flood dynamics at the 200 areas is the convergence of the various channelways on the Pasco Basin. That basin forms a natural concentration area for flood waters entering through the various paths (these pathways are lllustrated in Figure 3.1). All flood waters must converge on the Pasco Basin prior to passing through Wallula Gap. 


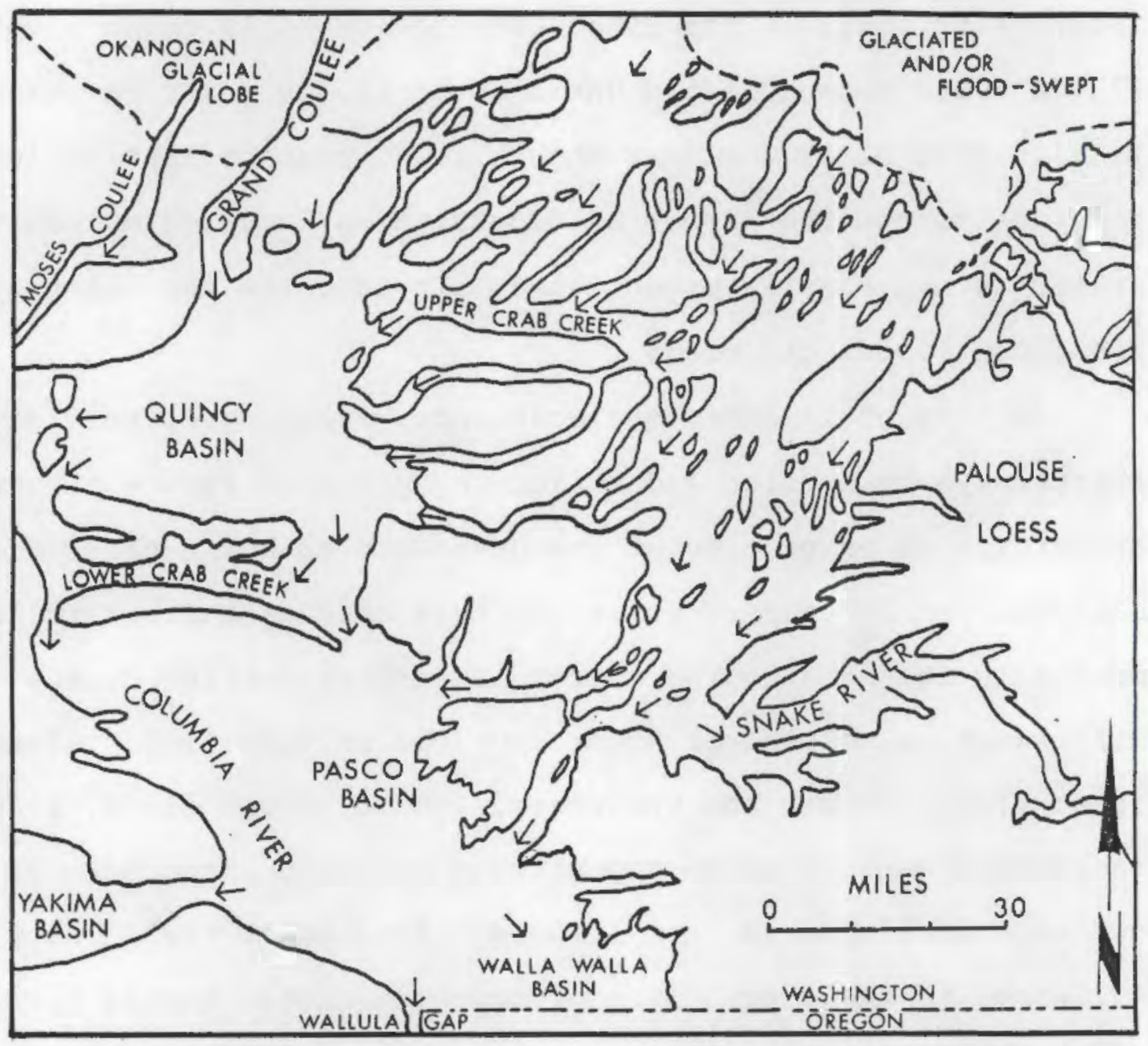

FIGURE 3.1. Reconstructed pathways of flood waters across the Scablands of Washington. Modified Erom: Bretz (1969, p.506). 


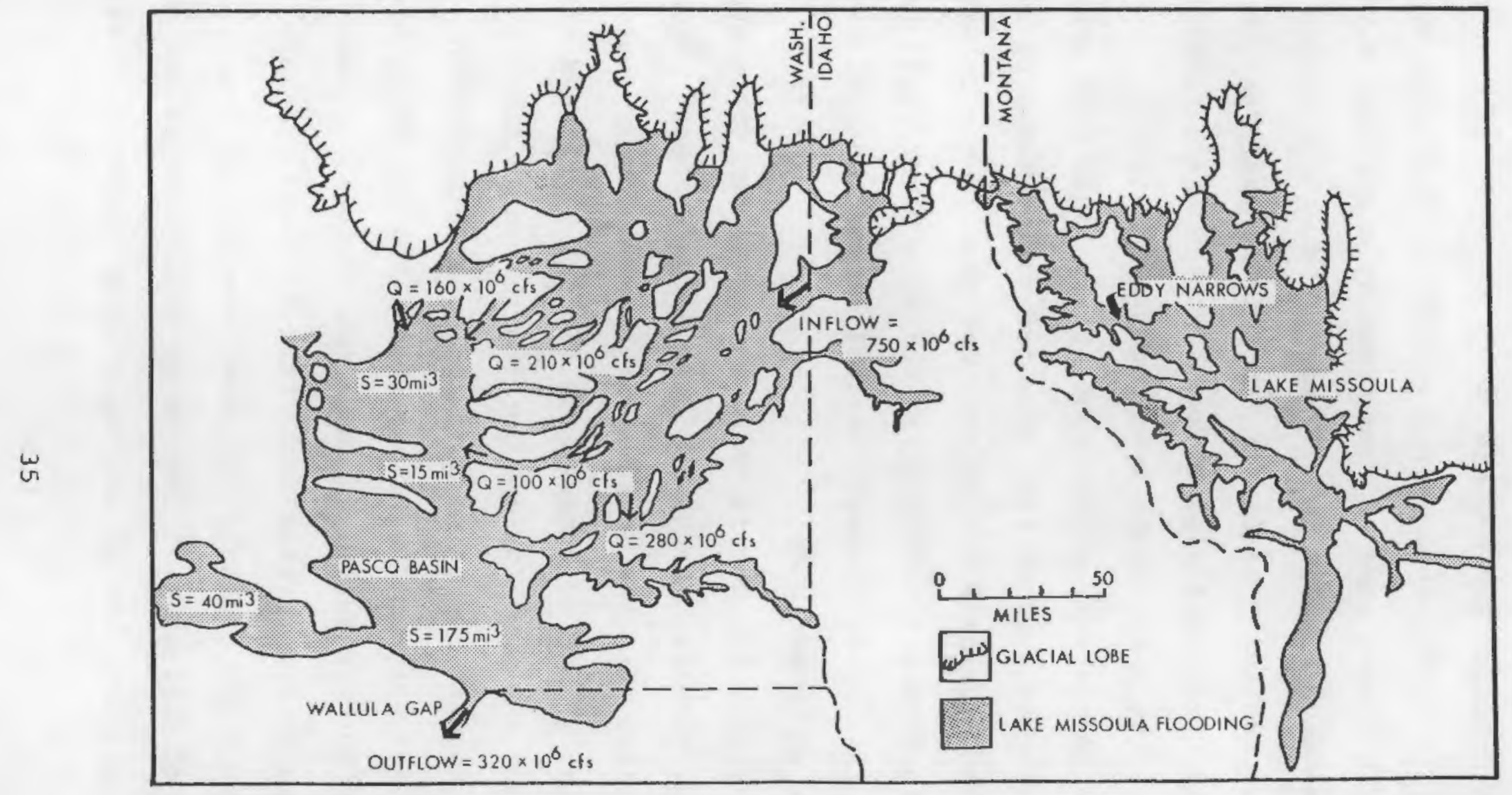

FIGURE 3.2. Estimated storage and discharges of flood waters in various channels of the Scablands of Washington. Originally published by GSA, in Special Paper 144, p.21,.Figure 12, by V.R. Baker. 
-- Major flood waters coursing across the Scablands

following several paths would have converged and passed down Esquatzel coulee crossing the region of the city of Pasco and entering the Columbia River there.

-- Certain flood waters going across the Scablands took a more southerly route, some of them crossing a drainage divide and entering the snake River Basin. These flood waters backed up the Snake River, creating a large bar deposit (Tammany Bar) in that region (Waitt, 1985 ) and also flowed down the snake River to converge upon the Pasco Basin downstream from Pasco.

-- A third route by which flood waters could have converged upon the Pasco Basin is by flow from the Quincy Basin by several routes to the Columbia River on the west side of the Columbia Plateau. Flood waters entering the Columbia River would have flowed down that river through Sentinel Gap and entered the Pasco Basin on the northwest side.

To illustrate how one flood would modify the topography of later floods, consider the case of the Palouse River. Presently that river flows into the snake River in a southerly route over Palouse Falls. Prior to some of the floods, it drained more westerly, down the Lind Coulee, joining the snake River much farther to the west. Erosion by flood waters topping the drainage divide between the Palouse River and the Snake River cut a new course for the snake, which it now follows. Floods subsequent to this diversion would have followed the more southerly route and probably continued the erosion and enlargement of that route. Less water would have passed down the Lind Coulee and the time of arrival of that surge -- relative to 
other surges -- would have been changed.

Flood scenarios which include the passage of water across the Scablands probably did not include flow down the Columbia River in its more northerly portions. The Okanogan lobe of the Cordilleran ice sheet would have blocked the Columbia River at its northwestern bend at that time. Flows would have been diverted down Grand Coulee, Moses Coulee and in other places across the Scablands themselves. Thus, with the Okanogan Lobe olocking the Columbia River, flood waters could not enter the Columbia River until they reached a more southerly portion of that river's path (refer to Figure 2.2 ). On the other hand, if the Okanogan lobe were not blocking the Columbia River, flood waters were probably confined almost exclusively to the river valley of the Columbia.

An important point to consider in this scenario is that a great amount of flood water would have entered the Pasco Basin southeast of the location of the 200 areas. During the same time flood waters probably entered the Pasco Basin through Sentinel Gap. Thus, it may be that the 200 areas and the surrounding region of the Pasco Basin would have been an area of convergence of flows. Some waters coming down the Columbia, some passing up the Columbia. This may have led to very complex flow relations in that area. The fact that waters entered the Pasco Basin south of their entry point in sentinel Gap would suggest that hydraulic ponding could have begun prior to entry of waters through Sentinel Gap. Thus, waters entering through Sentinel Gap may have had altered discharge characteristics because they would in 
effect be in a backwater situation (Figure 3.3).

Once the flood waters had entered the Pasco Basin there are a number of paths which those flood waters could take. There is clear evidence some flood water coursed up the Yakima River Valley creating-fine grained slackwater deposits at numerous localities in that valley (waitt, 1983). Other flood waters must have flowed up the valley of the Walla Walla River, again depositing fine-grained slackwater sediments in that locality (Baker, 1978). Both of these rivers drain into the Pasco Basin. Any waters which coursed up those river valleys must have eventually finally drained from them again. Up to the level the flood waters reached, the only exit from the Pasco Basin is through wallula Gap. It appears likely that flood waters would have converged from so many routes onto the Pasco Basin and/or converged at such a high discharge, that the wallula Gap would not be able to pass those flood waters without significant increase in water depths within the Pasco Basin. This phenomenon is called hydraulic ponding and the backwater curve that would result has been illustrated in Figure 3.3 . FLOODS CONFINED TO THE COLUMBIA RIVER

A second flood scenario occurred during the last glaciation (Bretz, 1969) and would probably occur in any sequence of floods during a glaciation. In this scenario, the Okanogan lobe has either not yet advanced to block the Columbia River or, it is beginning its retreat at the last stages of a glaciation. At this time, the Columbia River is open as a conduit for flood waters to pass through -- all the way from the spokane River to Wallula Gap. In that case, the Columbia River would form the 


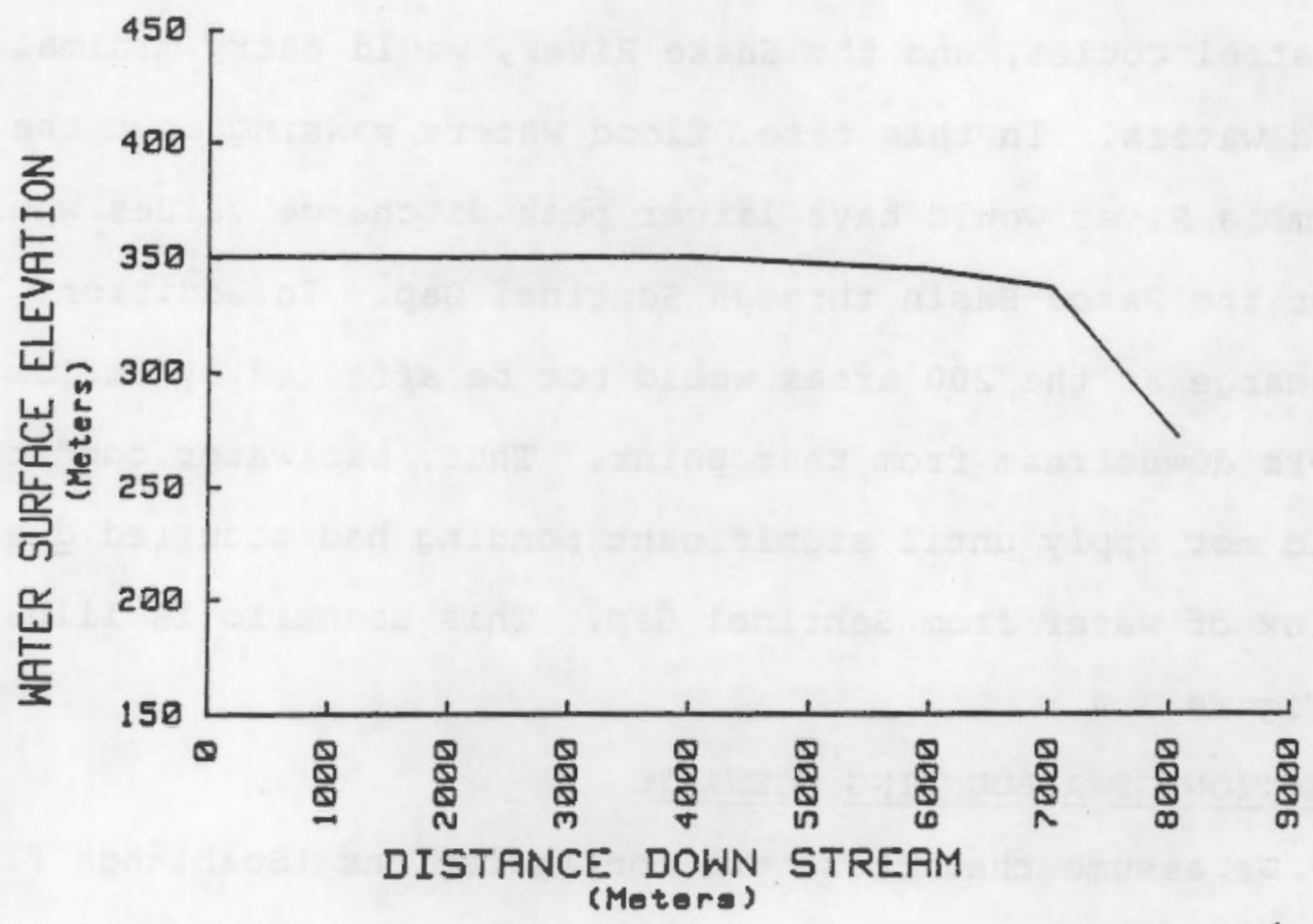

FIGURE 3.3. Backwater curve developed in the pasco Basin downstream of Sentinel Gap due to the entry of 1 lood waters from the Snake River and Esquatzel Coulee. 
principal or perhaps sole path of flood waters draining from Lake Missoula. During such a flood, all flood waters might pass through Sentinel Gap and enter the Pasco Basin by that inlet. The other conduits for flood waters across the Scablands, Esquatzel coulee, and the snake River, would carry minimal or no flood waters. In this case, flood waters passing down the Columbia River would have larger peak discharge values where they enter the Pasco Basin through Sentinel Gap. In addition, discharge at the 200 areas would not be affected by inflow of waters downstream from that point. Thus, backwater conditions would not apply until significant ponding had occurred due to the influx of water from sentinel Gap. This scenario is illustrated in Figure 3.4 .

SELECTION OF A BOUNDING SCENARIO

We assume that these two configurations (Scablands floods and Columbia River floods) represent the end members of a sequence of possible floods. A large number of floods of both types may have occurred. Each flood would have varied somewhat from the others. For example, an important control on flood characteristics would be the total volume of flood waters released from Lake Missoula (Craig, Singer and Underberg, 1983). other controls could include the existence of proglacial lakes in the path of the flood (Atwater, 1984), the exact configuration of the southern margin of the Cordilleran ice sheet (Waitt, 1983), and the occurrence of previous floods modifying the pathways. At present, it is not possible to define clearly the exact details of the worst case flood scenario for each of these two distinct configurations. Because of the possible time- 


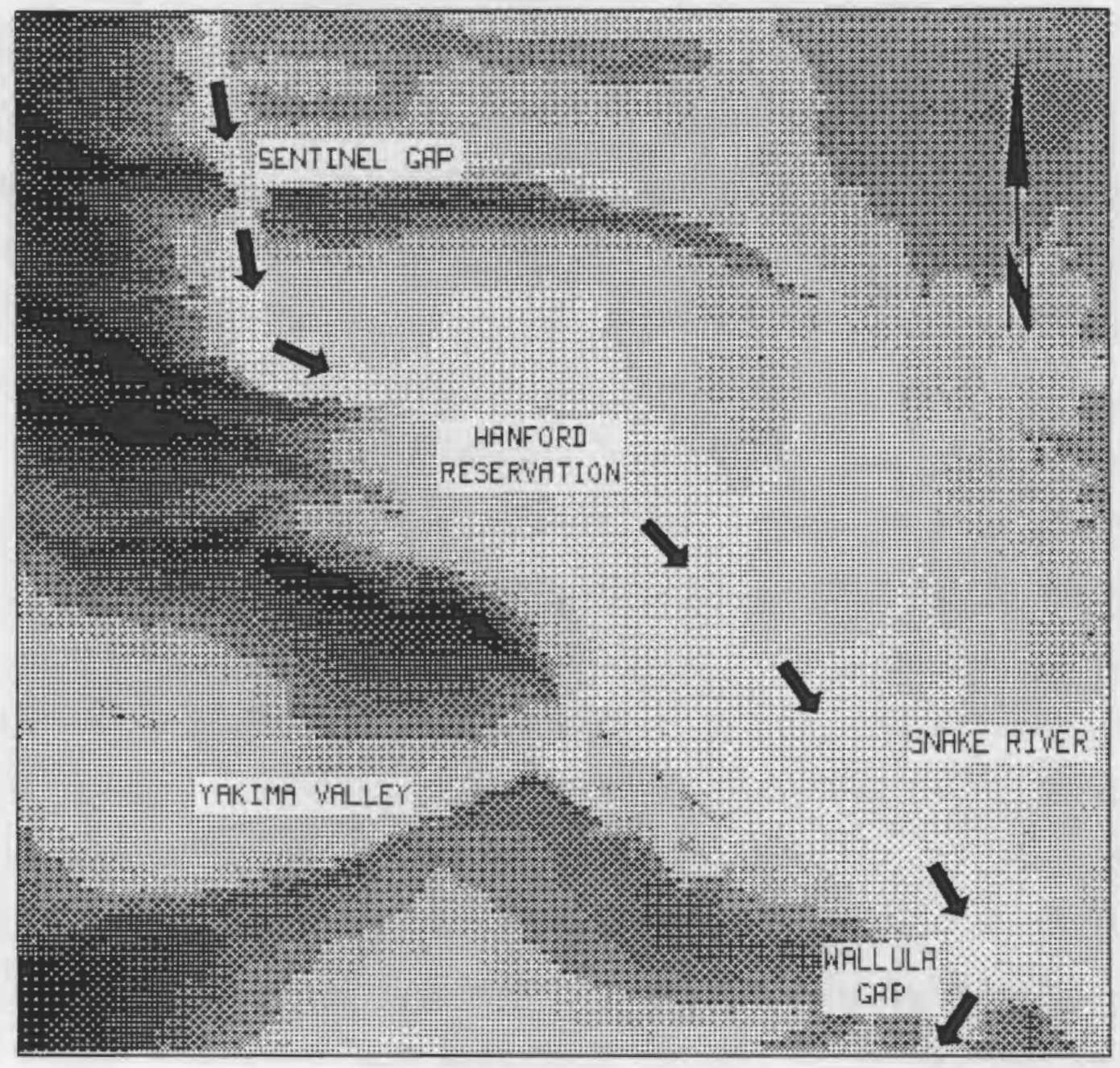

FIGURE 3.4. Flood scenario Eor a Missoula Elood ir wnich ntariy all Elow was confined to the valley oi che loluidia River. 
transgressive nature of the evidence of maximum flood levels and velocities at various points within the Scablands, we do not attempt to construct a worst case scenario by synthesis of the maximum discharges of the contributing pathways. Instead, we focus our attention upon the Pasco Basin itself and the evidence which exists there. This evidence has been reviewed in section two. The most critical piece of evidence is the reported high water mark at Wallula Gap.

To synthesize a worst case scenario for each of these two configurations, we assume for each that the maximum water levels at Wallula Gap were reached during that flood. Thus, on the one hand we consider the characteristics of the flood that would cross the Scablands and produce a $350 \mathrm{~m}$ (1150 ft) high water mark at Wallula Gap. On the other hand, we investigate the dynamics of a flood that would be required to produce that same high water mark at Wallula Gap if all of the waters came down the columbia River.

We have used the HEC-2 model to synthesize a rating curve at Wallula Gap which relates discharge and elevation at the Gap. This rating curve will be reported in the next section. For the case of the Scablands flood scenario, little else can be said but that it is possible to have the entire volume of waters from Lake Missoula pass through Wallula Gap and produce a hydrograph sufficient to explain the high water mark. This rating curve does not produce any evidence in conflict with the available field data. We are able to estimate the maximum amount of water that would pass through Sentinel Gap under that scenario. This also allows an estimate of the minimum amount of water that must 
be supplied by flows across the Scablands. These calculations are described in section four.

A more difficult situation arises for floods confined to the Columbia River. We have found that flows confined to the Columbia River (if not influenced by flow conditions downstream), upon passing through Sentinel Gap, would produce a high water mark there matching the field data only if discharges greatly exceed the greatest estimated discharge from Lake Missoula at the outlet point itself. This is an unlikely situation. In a fully dynamic wave, there is no reason to believe that the flood crest would become more concentrated as it passes down the system. Rather, it is almost certain that the flood wave would attenuate. Maximum discharge would be lower in magnitude and the discharge would take place over a longer time span.

We assume that the high water marks at Sentinel Gap do not correspond to maximum discharge down the columbia. Rather, they must have been created at a time when additional waters were contributed by flows across the scablands or after backwater conditions developed during flows down the columbia. In the first case, flows across the Scablands would have created ponding in the lower part of the Pasco Basin. Flows entering through Sentinel Gap would have been slowed as they entered the lower Pasco Basin. The result is to create a backwater curve to Sentinel Gap. In that case, higher water levels would be expected at Sentinel Gap (for a given discharge) since flows would have been slower.

In the second case, flows down the Columbia River would not 
encounter waters in the Pasco Basin until later in the flood. At any rate, it is probable that ponding would be delayed beyond the timing of the first scenario. Maximum discharges, and probably maximum velocities and transport capacities, would be greater in the second scenario.

This suggests that the most extreme flood events which involved the passage of water across the Scablands would not represent the most extreme flood potential at the 200 areas. Water entering Sentinel Gap at peak water levels (required to Inundate the 200 areas) would enter during a backwater situation, with lower flood velocities. Instead, we assume that the most erosion potential would arise when floodwaters came into sentinel Gap without a contribution of water across the Scablands. In that case, no backwater curve would be produced in the early stages of flooding. Flood waters would have entered at very high velocity, limited only by the maximum discharge possible through Sentinel Gap. Under these conditions high velocities would ensue within the 200 areas and the greatest erosion potential would occur. It is quite likely that in the later stages of even these floods a backwater curve of the M1 type would arise and discharges and flood velocities would decrease accordingly. We conclude from this analysis that the critical scenario to be investigated for understanding the stability of materials in the region of the 200 areas on the Hanford Reservation is one which involves floodwaters exclusively derived from the Columbia River pathway. This report focuses upon that second scenario and the resulting erosion potential. 


\section{LIMITATIONS AND UNCERTAINTIES}

There are a number of important limitations and uncertainties that arise in this analysis concerning the exact route of the Scablands Floods. An alternative that was not considered is a surge of flood waters across the Scablands eventually passing though the Drumheller channels area and westward down the Crab Creek drainageway (Figure 3.5, refer also to Figure 3.1 ) on the north side of Saddle Mountains. This surge would then enter the Columbia drainage system and flow down that system into the Pasco Basin through Sentinel Gap. If such a path were occupied it would produce floods down the Columbia River similar to those confined exclusively to the Columbia River.

Such floods would be of a smaller magnitude than those which are confined strictly to the Columbia River. Some of the flood flow that would cross the Scablands would still pass down the Columbia River and also flow over Pasco. The total volume would not pass through the crab creek drainageway. Thus, it is assumed that this is a less severe scenario to consider than flows entirely confined to the Columbia River drainage.

Another possibility that can be considered is that during a Scablands flood there may be surges up the Columbia River. This can occur in two ways. Floods crossing through the Crab creek drainageway surging into the Columbia River may surge both upstream and downstream. Surges upstream would eventually recede and lead to a secondary surge down the Columbia River. Another probable surge mechanism comes from flows coming into the Pasco Basin through Esquatzel Coulee. As these flows enter the Pasco Basin, surges would probably occur both up and down the Columbia 


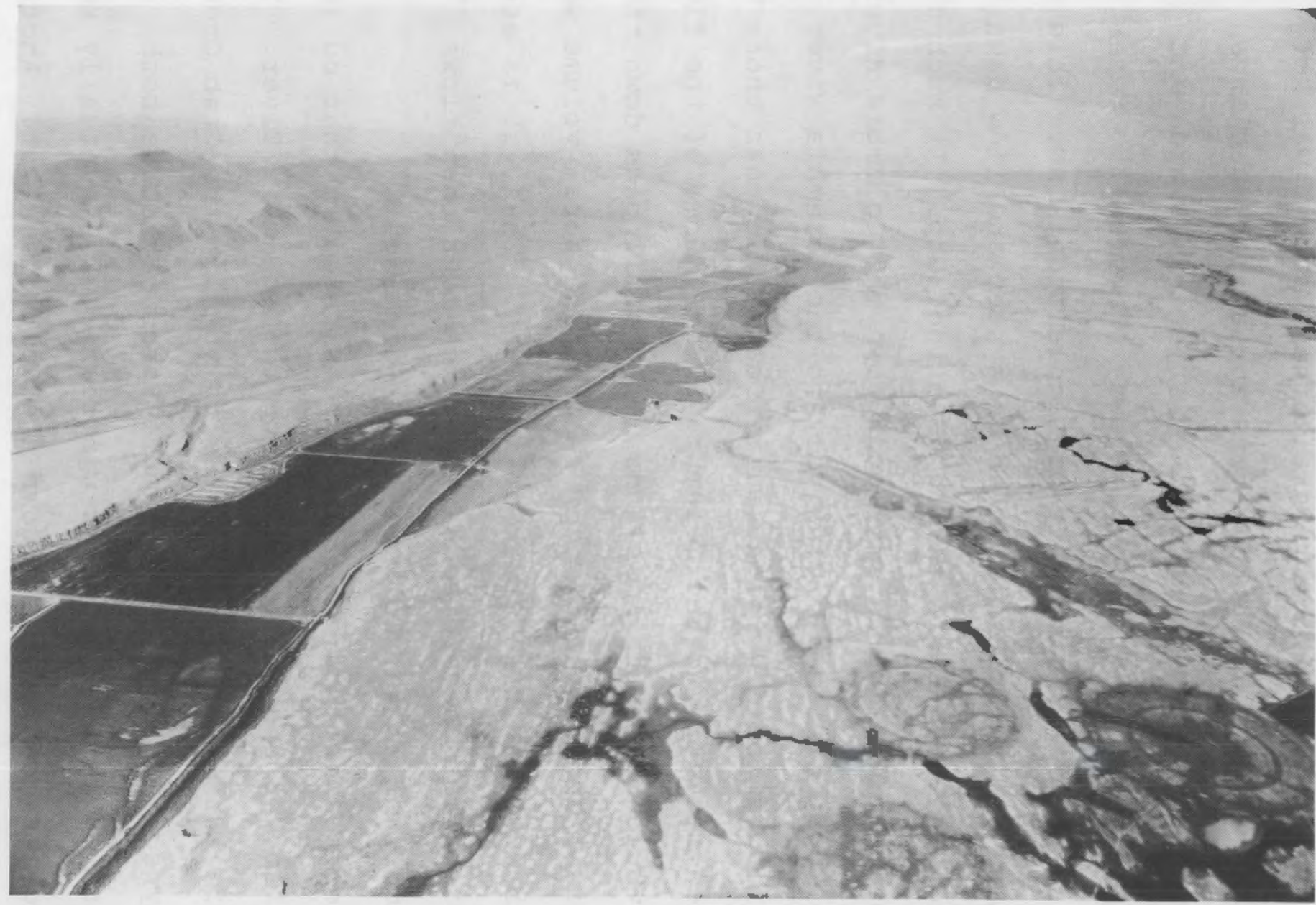

FIGURE 3.5. Oblique aerial view of Lower Crab Creek. view to the west. 
River again. In this case surges may or may not pass beyond the limits of the Pasco Basin through Sentinel Gap. This case is especially important because it could involve transport of sediment up the Columbia River prior to or intermingled with flows down the columbia River. A similar situation would occur with flows entering the Pasco Basin by way of the snake River. We have been assuming that the flows down the Columbia River can be described by the high water marks that are preserved within the Pasco Basin. This would imply that flows down the Columbia River would be of sufficient magnitude to lead to nydraulic ponding to approximately $366 \mathrm{~m}$ (1200 feet). It is entirely conceivable that the high water marks that are preserved within the Pasco Basin were not created by floods which passed strictly down the Columbia River. Instead, they may represent floods which crossed the Scablands. The floods which coursed down the Columbia River may have been considerably smaller in magnitude, insufficient to produce these high water marks. It is assumed, that if this is the case, the flood scenario that is actually being considered is more extreme than the correct worst case. Thus, in this sense the analysis is conservative. There is a similar difficulty with the interpretation of maximum velocities that are recorded by sedimentation and erosion evidence within the Pasco Basin. Again, this evidence may be a result of floods which were strictly across the Scablands. Just as in the case of high water marks, if the high velocity evidence was in fact derived from a flood which crossed the Scablands, it Is assumed that this would indicate a less serious flood for the stability of the 200 areas. This is because the water will be 
dispersed upon entering the Pasco Basin and some of it will actually flow up the Pasco Basin being further dispersed. Thus, it is assumed that the velocities and sediment transport would not be as great as floods confined entirely to the Columbia River.

Regardless of the source of the flood waters, there are multiple pathways that these waters could take once they had crossed the location of the 200 areas. As mentioned, flood waters may actually pass up the Pasco Basin at different times during a flood, depending upon the exact pathways followed by that flood in reaching the Pasco Basin.

Even flows down the Columbia River have multiple dispersive pathways. For example, flood waters undoubtedly have passed into the Yakima River Basin during different floods. There is considerable evidence that this has occurred in many, if not most, of the floods (waitt, 1985). Similar evidence exists which suggest that flood waters have passed into the Walla walla Basin (Baker, 1978) depositing significant amounts of sediment in that basin. of course, flood waters could flow strictly down the Columbia River through wallula Gap and beyond. In addition, there is a possibility that flood waters could actually pass up the Snake River during a flood, especially one which had passed down the Columbia River. In addition to these possible exits from the Pasco Basin, there is a great deal of dispersion of sediment that undoubtedly did occur within the Pasco Basin. Thus, the exact dispersion of the sediment that would be entrained during a flood is not at all certain. There are a 
number of possibilities and this introduces great uncertainty in the estimates that are made.

Another assumption which is fundamental to the solution of flood characteristics within the Basin is whether flows were subcritical or supercritical in nature. Since flows can exist in either mode for any given discharge, it is almost impossible from the field evidence to decipher the nature of a flow during one of these floods. It is quite likely that supercritical flow did occur in at least some areas at some times during each flood. At any of the areas where flows were supercritical at some times, they were undoubtedly also subcritical at other times during the same flood, both before and following the supercritical events. Thus the evidence of supercritical flow may be removed in many locations.

Whether the flow was subcritical or supercritical determines the water velocities and the transport capacity of the flood. The dependence of transport capacity upon the flow velocity (and therefore depth) is not well-established. The assumed relation varies from one theory of sediment transport to another. This again introduces great uncertainty in the solutions that have been obtained. Such uncertainty may be of an order of magnitude. Since full three-dimensional computation of flow velocities has not been obtained, we have not made exact computations of those velocities in the beginning. Even with three-dimensional computations available, uncertainties in factors such as the friction coefficient would mean that the values suffer great inexactness. 
STEADY STATE HYDRAULICS OF THE BOUNDING SCENARIO

The first method used in determining the flood characteristics of a Missoula flood event is a steady state computer model. The model, HEC-2, was developed by the United States Army Corps of Engineers (HEC-2 Hydrologic Engineering Center, 1982). The program calculates water surface profiles under the following assumptions: (1) Flow is steady, (2) Flow is gradually-varied, (3) Elow is one-dimensional, (4) the channel nas small slope $(<1 / 10)$.

Concerning the first two of these assumptions (steady and gradually-varied flow or no change in depth with time and very little or a gradual change in depth over the length of the channel), in present-day non-flood-stage rivers, stream discharge and depth of flow do not fluctuate greatly from day-to-day or point-to-point along a channel reach. Therefore, the assumption of steady, gradually-varied flow is useful in determining nydraulic characteristics of normal flow in a river system. With Missoula-type flows, the stage of the flow actually changes as a function of time as the flood wave passes a certain point within the Pasco Basin. Flow is actually "unsteady" and the true nature of the flow is best represented as a flood-wave or surge. Also, since breached anticlinal structures are present in this region, flow is constricted producing great increases in velocities. As flows enter and exit these constrictions, hydraulic "drops" and "jumps" may occur, which would indicate that the stage of the flow is changing "rapidly" over a relatively short distance, suggesting that flow is actually rapidly varied at certain points within the constrictions. 
Assumption three, flows are one-dimensional, implies that the velocity components in the downstream or upstream directions are the only components of significant magnitude to influence the flow characteristics of the channel. In a Missoula-type flood, or any flood, lateral and vertical velocity components will affect the overall flow characteristics of the river. Lateral and vertical velocity components will affect the characteristics of a normal river also. Assumption four, the channel has a small slope, is necessary so that corrections do not have to be made in the pressure head term. Slopes can be as great as 6 degrees for slope of 1 in 10 ) before the pressure head term would be affected Dy 1\% (Chow, 1959,p.33): the present day channel slope for the Pasco Basin is .02 degrees $(.0004 \mathrm{~m} / \mathrm{m})$.

Under normal flow conditions, the Corps of Engineers has expressed satisfaction in the results of HEC-2 analyses using steady, gradually-varied flow and the mean velocity in the downstream direction as an approximation of the velocity components of a river system (HEC Hydrologic Engineering Center, 1976). Even though Missoula flood-flows were unsteady, rapidly varied in some locations, and multi-dimensional, important characteristics of the hydraulics of these flood-flows can be estimated using these simplifying assumptions.

The methodology for implementation of the HEC- 2 code involves combining the code with topographic cross-sections, a constant discharge, and certain starting conditions which include starting computations with: known water surface elevation, estimated energy slope, or critical depth. Each of the above 
starting conditions were used at some point in this study. Other input parameters include a value of .040 as an estimate of Manning's "n" for the channel roughness and specification of subcritical or supercritical flow conditions.

The HEC-2 code was used to construct rating curves for both Wallula Gap and Sentinel Gap based upon field evidence of maximum discharges (high water marks) in the Pasco Basin. Determination of the flow characteristics at Wallula Gap is of interest because flows from all possible channelways converged at the Pasco Basin and exited through that constriction. Sentinel Gap is of interest because determination of the flow characteristics through this constriction [and through the Pasco Basin] will allow us to better describe the hydraulics of the Missoula flows at the 200 areas.

WALLULA GAP

Based upon Baker's (1973) estimate of the maximum water surface elevation at Wallula Gap, Underberg (1983a and b) laid the foundation for construction of a rating curve for discharges through wallula Gap. We have used his cross-section data in these analyses. Starting conditions for backwater computations at Wallula Gap were based on the assumption that flow was critical in the constriction. This is a reasonable assumption since flow transition occurs from a wide channel (lake) configuration to a narrow, constricted configuration with an (a) increased bed gradient ( personal communication from Barkau, (a) Personal communication from Bob Barkau, U.S Army Corps of Engineers, Hydrologic Engineering Center, Davis, California 95616, September, 1985, phone conversation (916)756-1104. 
1985). At these large discharge values, flows reached the transition from subcritical to critical flow between crosssections $G$ and $H$ (Figure 4.1 ), the narrowest section of the constriction; Underberg (1983a and b) obtained similar results. Figures 4.1 and 4.2 show the location and cross-section profiles used in the development of the Wallula Gap rating curve.

In this study a second iteration of Underberg's (1983a and b) methodology was completed with similar results for the channel nydraulics of the Wallula Gap constriction. Underberg (1983a and b) estimated a discharge between 12.5 and $13 \mathrm{million} \mathrm{cms}$ as the maximum flow produced by a Missoula flood at Wallula Gap. We have found that the discharge needed to obtain Baker's evidence of high water marks was 12.5 million cms. This is $37 \%$ greater than Baker's (1973) estimate of 9.1 million cms and more than 6 times the estimate of Bretz (1926, p.258, 38.9 cubic miles/day) of 1.9 million cms. Our estimate of 12.5 million cms closely agrees with Clarke's estimate (Clarke, Mathews and Pack, 1984) of the upper-limit released at dam failure at the Rathdrum Prairie. Clarke (Clarke, Mathews and Pack, 1984) computed a maximum discharge of 13.7 million cms (Figure 4.3 ). Table 4.1 and Figure 4.4 reports the Wallula Gap rating curve.

\section{SENTINEL GAP}

Three techniques were used for construction of a rating curve for flows entering the Pasco Basin through sentinel Gap, where flow was constricted before entering the basin. The first technique implemented the slope/area method (HEC-2, 1982) as starting conditions for calculating water surface profiles from downstream of Gable Mountain to the constriction at Sentinel Gap. 


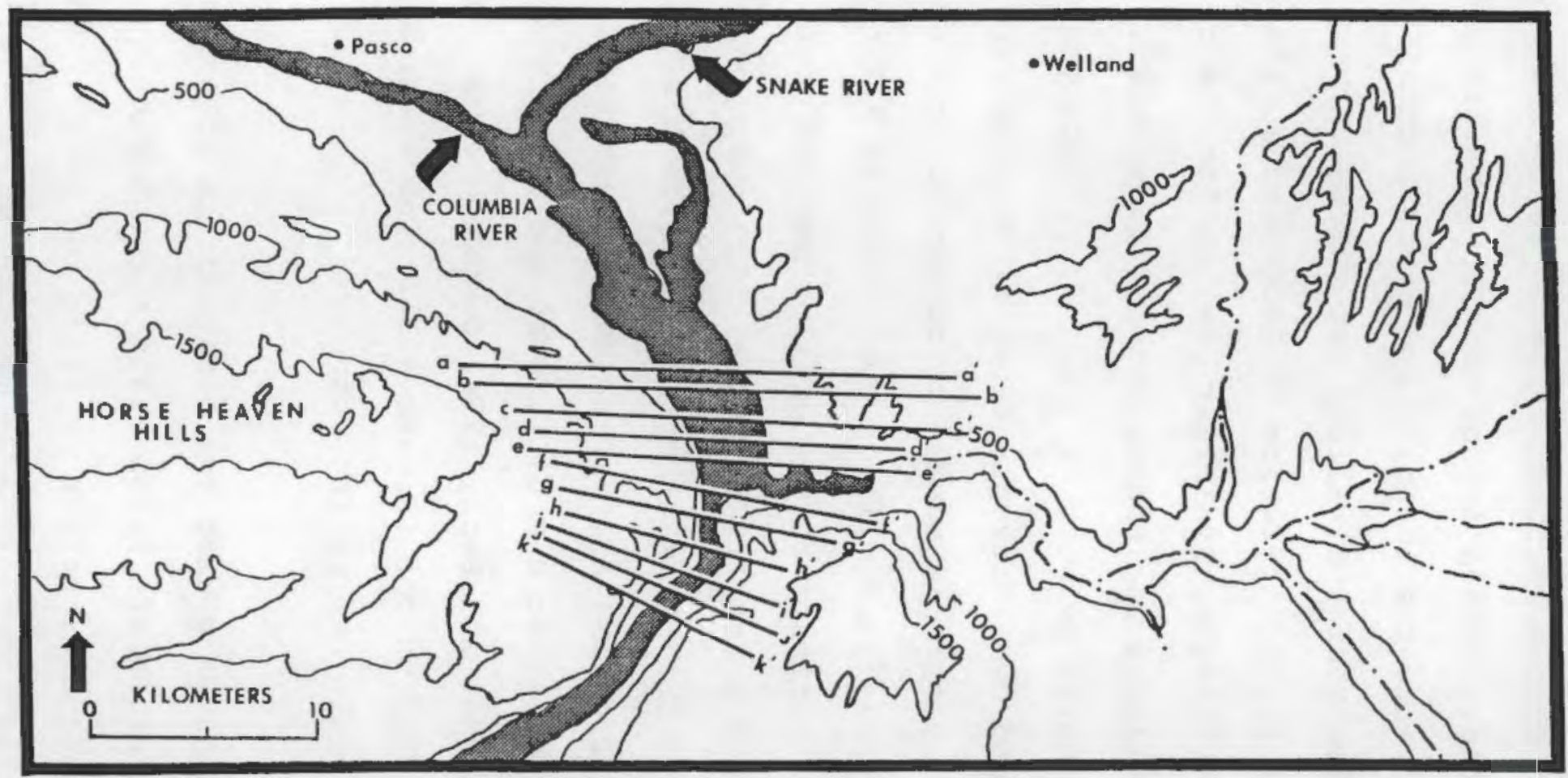

FIGURE 4.1. Plan view of cross-sections (11) used in HEC-2 analyses ror the Wallula Gap analyses. From. Underberg (1983a, p.75). 


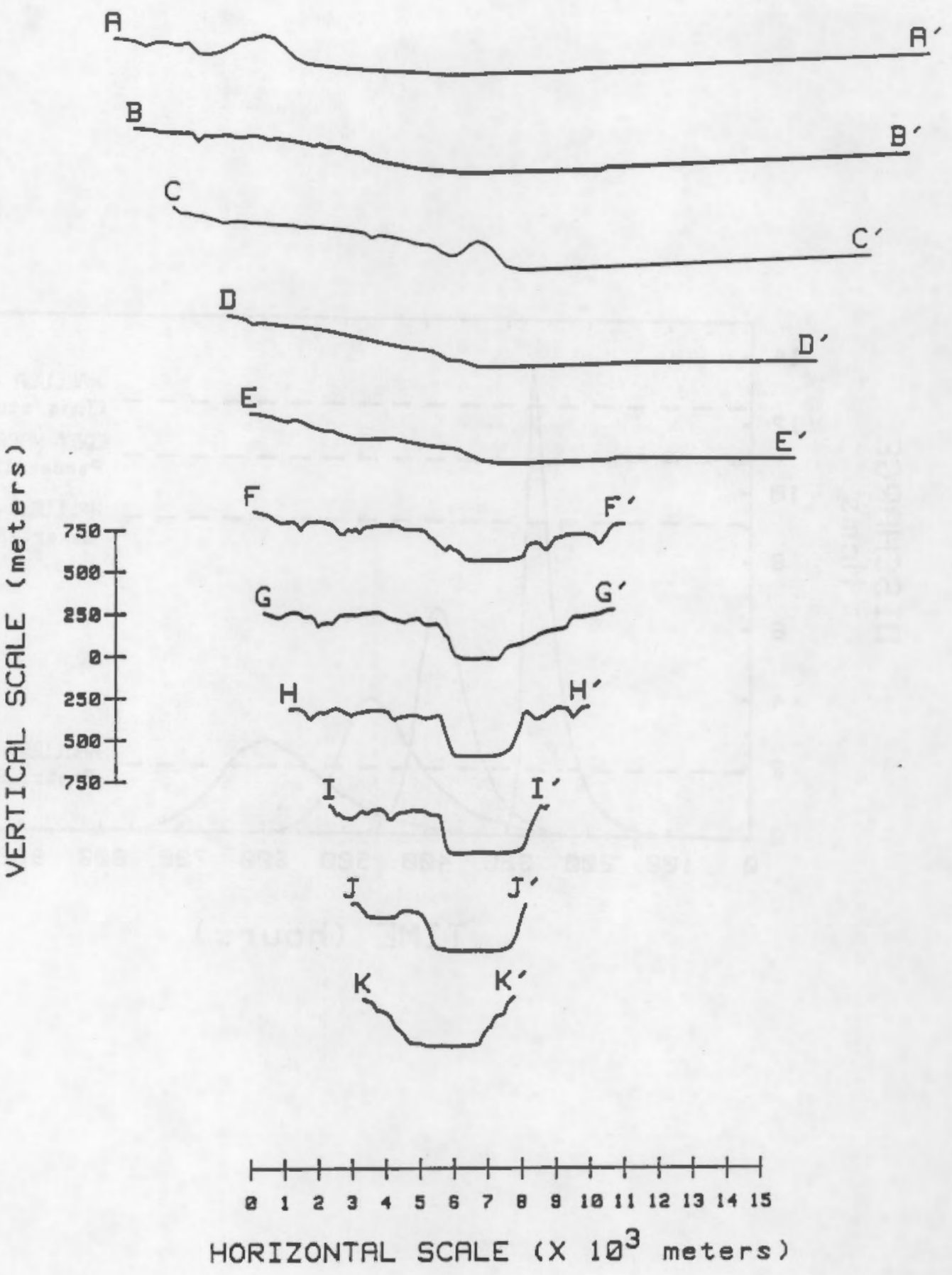

FIGURE 4.2. Profiles of the cross-sections for the analysis or: discharge at Wallula Gap. Refer to Figure 4.1. From: Underberg (1983a, p.76). 


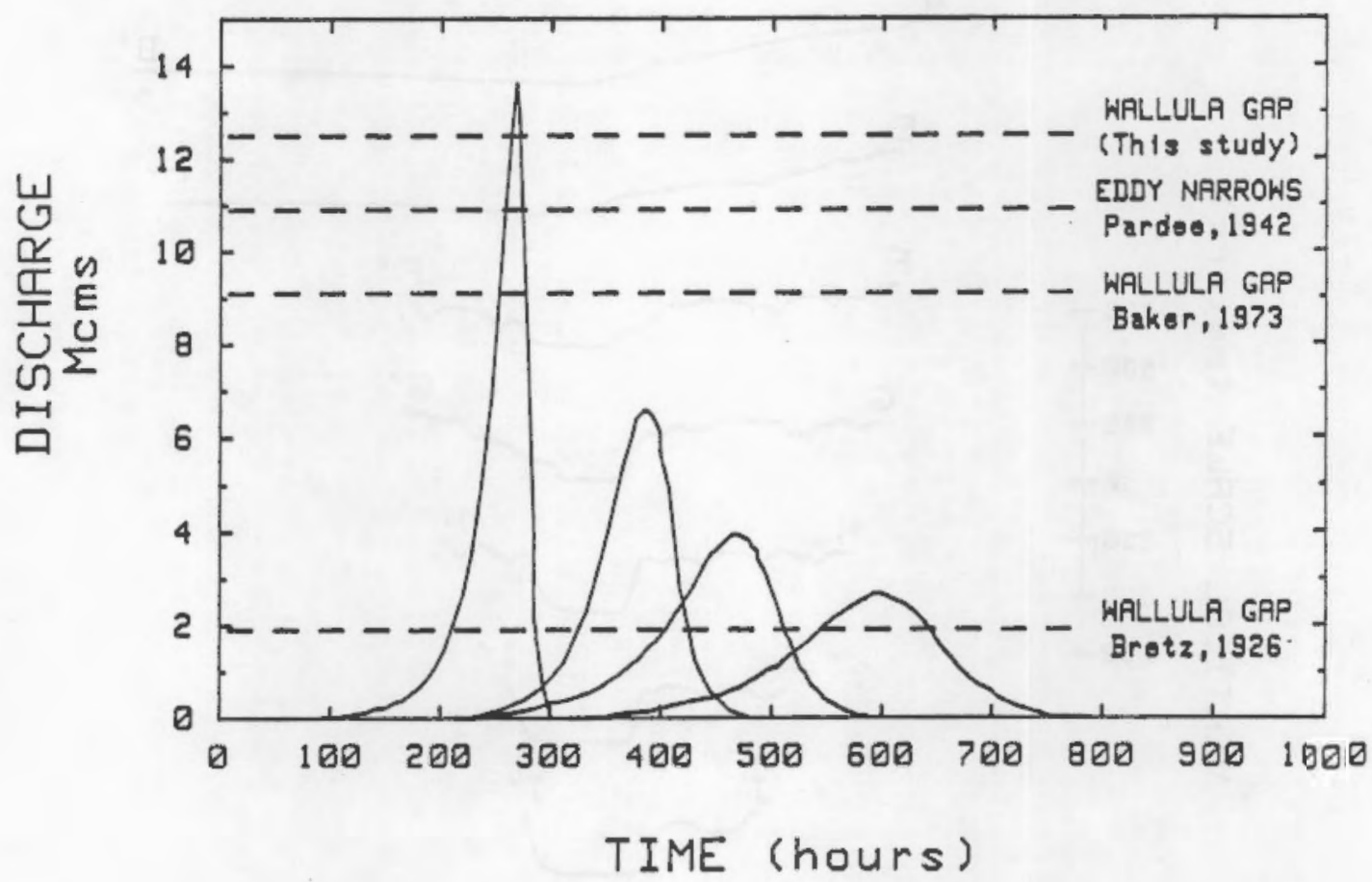

FIGURE 4.3. Clarke's plot of his four models for dam failure at the Rathdrum prairie region. Maximum discharge is 13.7 million cms. Dashed lines represent discharge estimates of Missoula floods at various locations in the Scablands. From: Clarke, Mathews and Pack (1984, p.294). 
TABLE 4.1. Wallula Gap rating curve based upon HEC-2 runs lnvoking critical depth as starting conditions for backwater computations.

WALLULA GAP

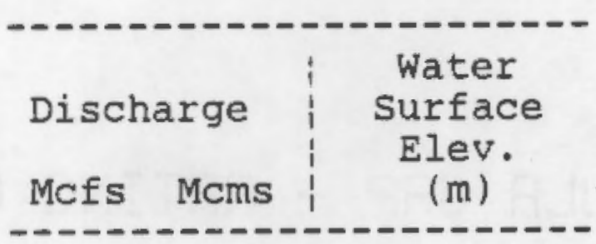

$$
35.31 \quad 1.0 \quad 154.9
$$

$\begin{array}{lll}70.62 & 2.0 & 186.9\end{array}$

$105.93 \quad 3.0 \quad 210.7$

$141.24 \quad 4.0 \quad 232.6$

$176.55 \quad 5.0 \quad 250.9$

$211.86 \quad 6.0 \quad 267.7$

$247.17 \quad 7.0 \quad 282.3$

$282.48 \quad 8.0 \quad 296.3$

$\begin{array}{lll}317.79 & 9.0 & 308.8\end{array}$

$\begin{array}{lll}321.32 & 9.1 & 310.1\end{array}$

$\begin{array}{lll}335.45 & 9.5 & 315.0\end{array}$

$353.1010 .0 \quad 321.0$

$388.41 \quad 11.0 \quad 332.9$

$427.72 \quad 12.0 \quad 344.5$

$441.38 \quad 12.5 \quad 350.3$

$459.03 \quad 13.0 \quad 356.4$

$500.0014 .2 \quad 369.5$ 


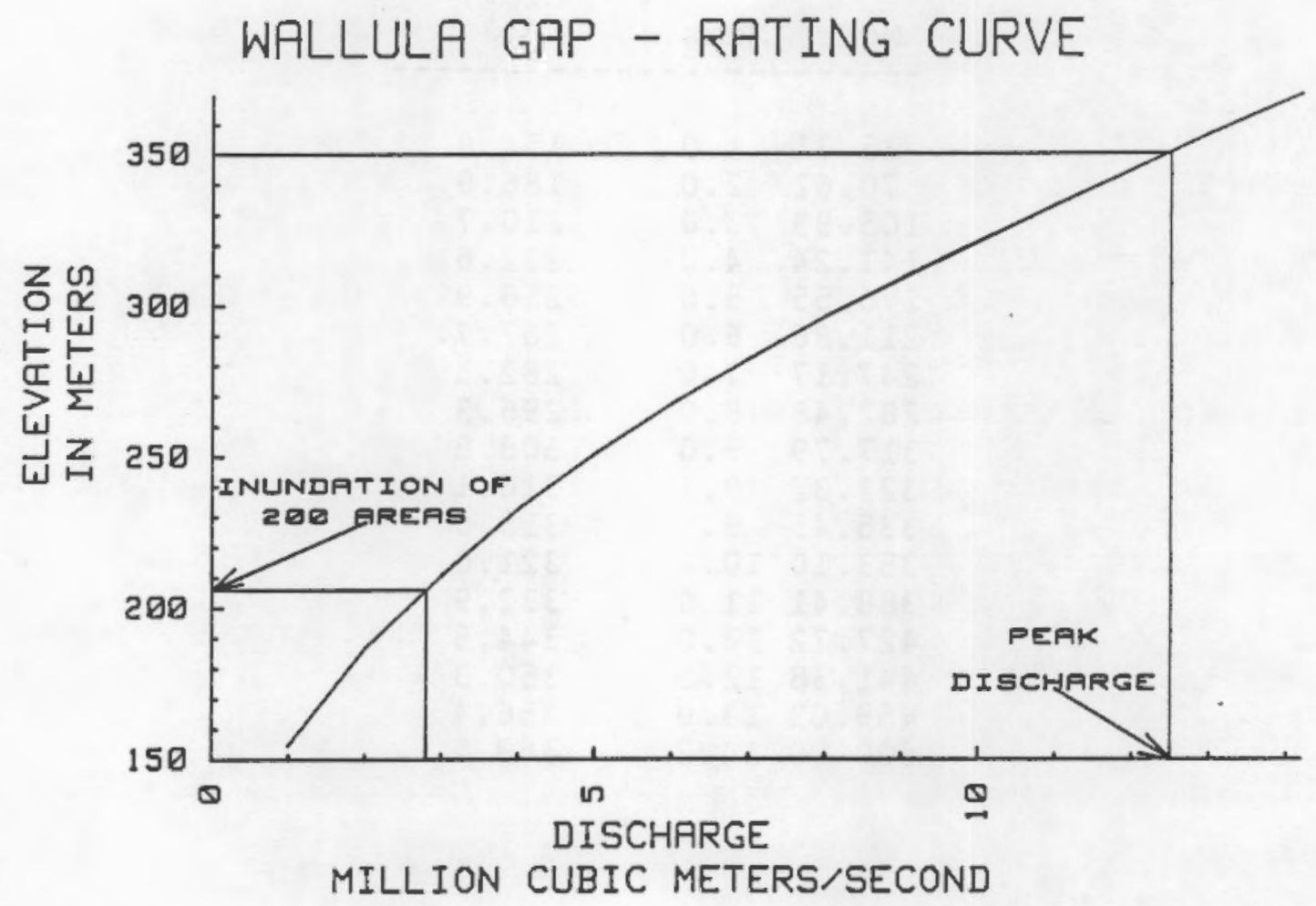

FIGURE 4.4. Wallula Gap rating curve. Peak discharge equal to $12.5 \mathrm{million} \mathrm{cms}$; (inundation to $350 \mathrm{~m}$ or $1150 \mathrm{tt}$ ) inundation of the 200 Areas, 2.8 million cms. 
The slope of the energy gradient was assumed to equal the bed surface slope. For the Pasco Basin, the bed slope is approximately $.0004 \mathrm{~m} / \mathrm{m}$. Using this method, a discharge of 34.6 million cms was not sufficient to yield the observed high water marks $(366 \mathrm{~m})$. This is greater than any estimate of Missoula Flood discharges. At the greatest discharges reasonable (Figure 4.3, 13.7 million cms; Clarke, Mathews and Pack, 1984), when flows are restricted to the present Columbia River channel, critical velocities occur in the gap producing a water surface of only $306 \mathrm{~m}$. Using this method, such extreme discharges fail to predict inundation of Gable Mountain and bergmounds or a divide crossing at the eastern end of Umtanum Ridge (Table 2.1).

The second method used to construct the Sentinel Gap rating curve utilizes a fixed elevation downstream from Gable Mountain of $350 \mathrm{~m}$, a level within the Pasco Basin at which Baker (1973, p.15, par. 1) believes water to have ponded behind Wallula Gap. This elevation was used to initiate backwater computations through the Pasco Basin and Sentinel Gap. For this run, an M1 profile exists and a discharge of 7.5 million cms yields, upstream of the gap, a water surface at $366 \mathrm{~m}$. This agrees with evidence of ponding around Frenchman Hills (Baker, 1973, p.15, diagram) and evidence of scour at Sentinel Bluff. Velocities at this discharge in Sentinel Gap reach $16 \mathrm{~m} / \mathrm{sec}$.

The third technique used to develop the Sentinel Gap rating curve, a method [probably a better estimate] producing a more accurate rating curve for Sentinel Gap, involves the projection of the water surface from the furthest upstream cross-section of the Wallula Gap data set (Figure 4.1) to the furthest downstream 
cross-section of the Sentinel Gap data set (Figure 4.5,4.6). The projection was over a distance of $64.4 \mathrm{~km}$ using water surface elevations and water surface gradients from the results of HEC- 2 runs for the Wallula Gap analyses.

Water surface gradients were obtained by calculating the change in water surface elevation from the two most upstream cross-sections (A and B, Figure 4.1) of the Wallula Gap data set and dividing by the distance between the cross-sections, $1402 \mathrm{~m}$ (Table 4.2). Cross-sections $A$ and $B$ were used because the gradient of the water surface decreases farther north in the Pasco Basin. The projection of the water surface from wallula Gap will give a better estimate of the water surface near Gable Mountain than will projecting a horizontal water surface from Wallula Gap to Gable Mountain.

This technique was necessary for the construction of a rating curve at sentinel Gap. Use of a water surface elevation at a specified discharge to start backwater computations seemed to be appropriate, more reliable, and more informative than the slope/area method used earlier because it allows development of a rating curve for the Sentinel Gap constriction. Table 4.2 contains the projected water surface elevation from wallula Gap for each discharge there.

At this time, a point of caution should be mentioned in using the projected water surface elevation method. HEC-2 iterates through water surface elevations and converges on an elevation for each cross-section based on a tolerance value of plus or minus $1.5 \mathrm{~m}(5 \mathrm{ft})$ for the velocity head term. From the 


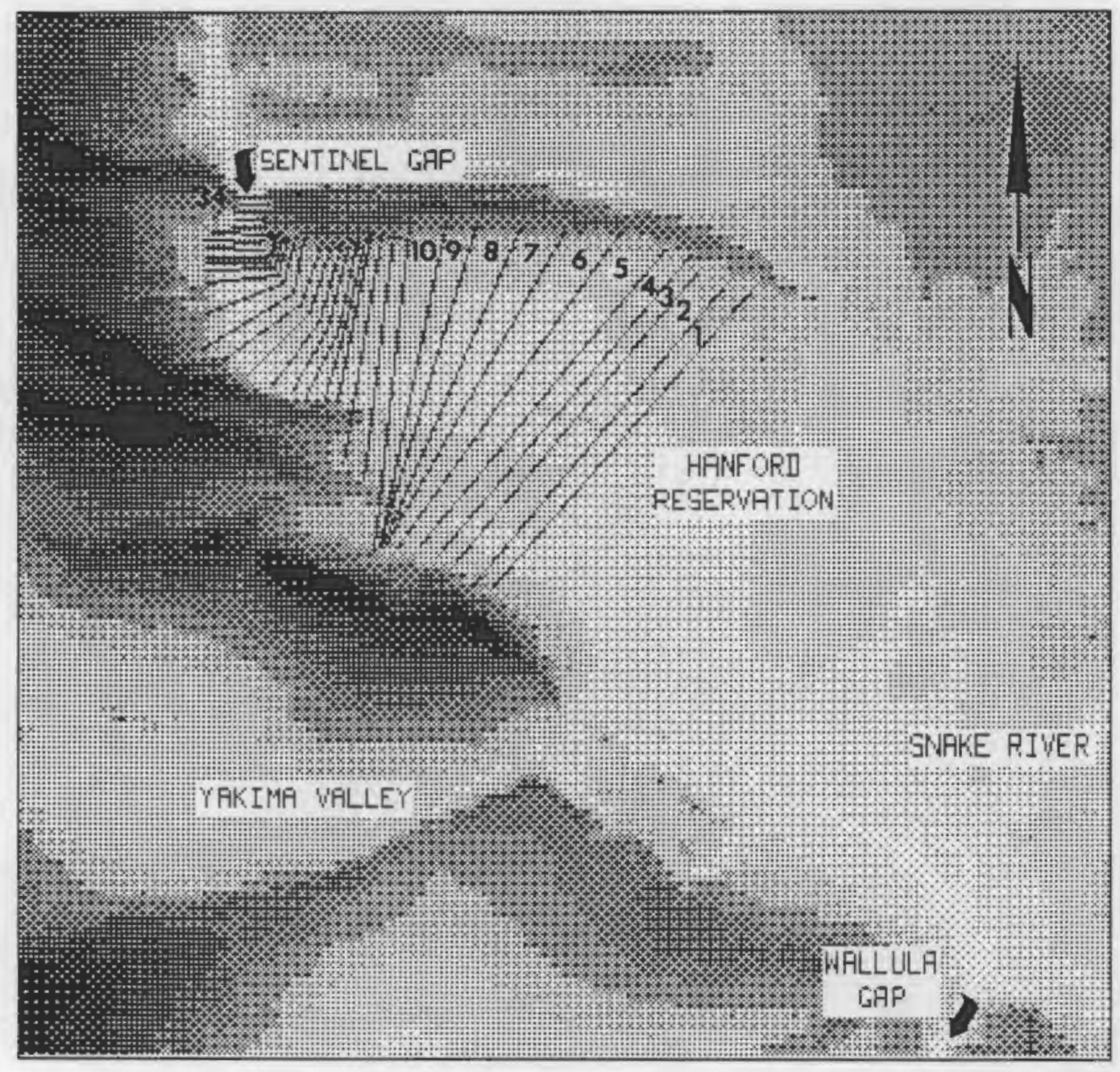

FIGURE 4.5. Positions of the Pasco Basin cross-sections displayed on digital elevation data at 30-secund spacing. 


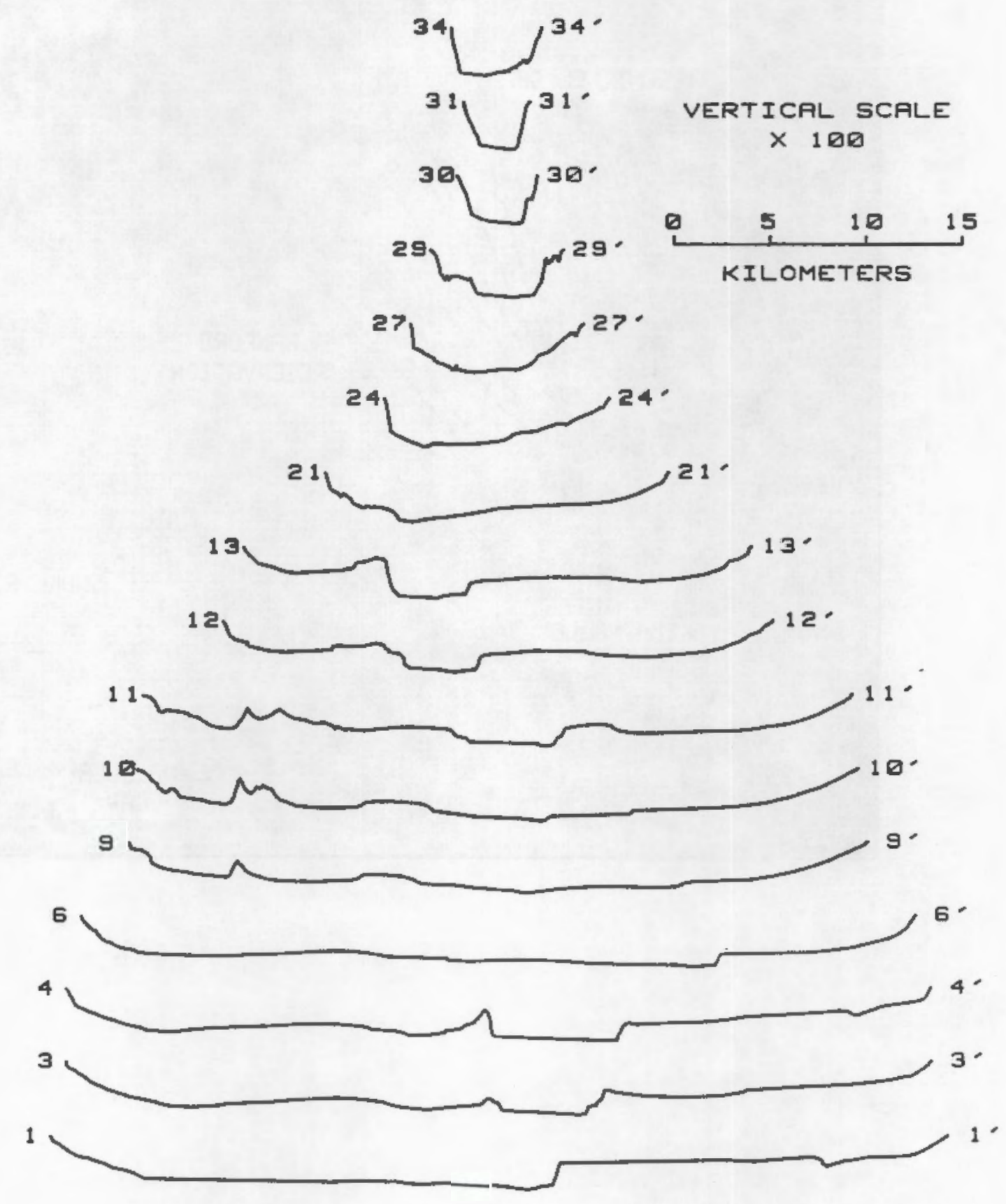

FIGURE 4.6 . Profiles of the cross-sections for the sentinel Gap analyses. Refer to Figure 4.5 . 
TABLE 4.2. Projection of the water surface elevation from Wallula Gap to obtain starting water surface elevations for HEC-2 runs at Sentinel Gap.

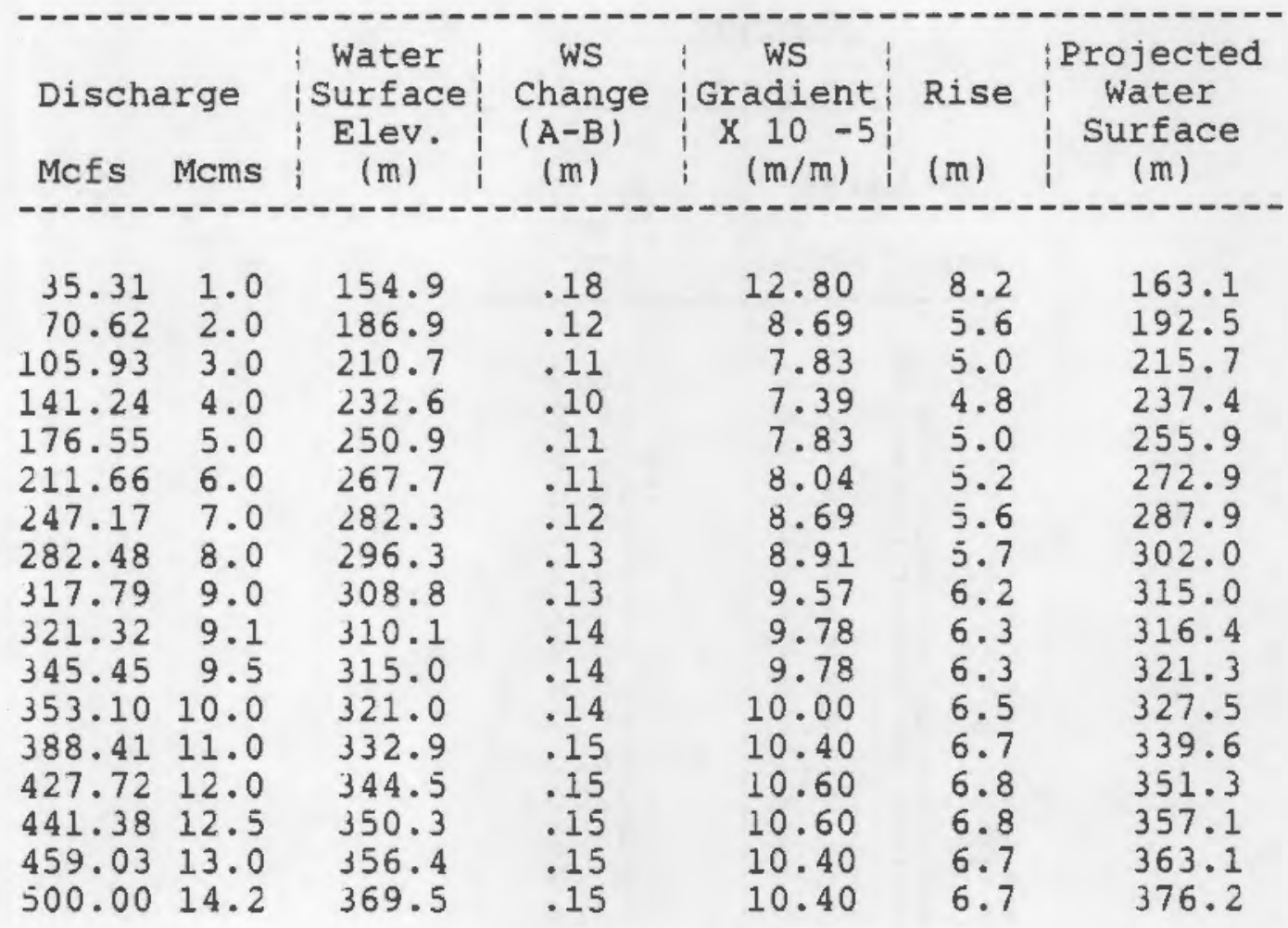

table presented above, it is evident that the change in elevation from cross-section $A$ to $B$ is a fraction of this tolerance value. Since our projection is based on the amount of change in elevation from these two cross-sections, it is conceivable that the gradient may be off by as much as $1.5 \mathrm{~m}$ ( $5 \mathrm{ft}$ ).

Using the projected water surface elevations as starting conditions for the HEC-2 model allows computation of water surface elevations at the upstream cross-section at Sentinel Gap, thus developing a rating curve of discharge versus elevation. Table 4.3 and Figure 4.7 present the rating curve for Sentinel Gap. 
TABLE 4.3. Sentine 1 Gap rating curve based upon HEC-2 runs using the projected water surface elevation from wallula Gap.

\section{SENTINEL GAP}

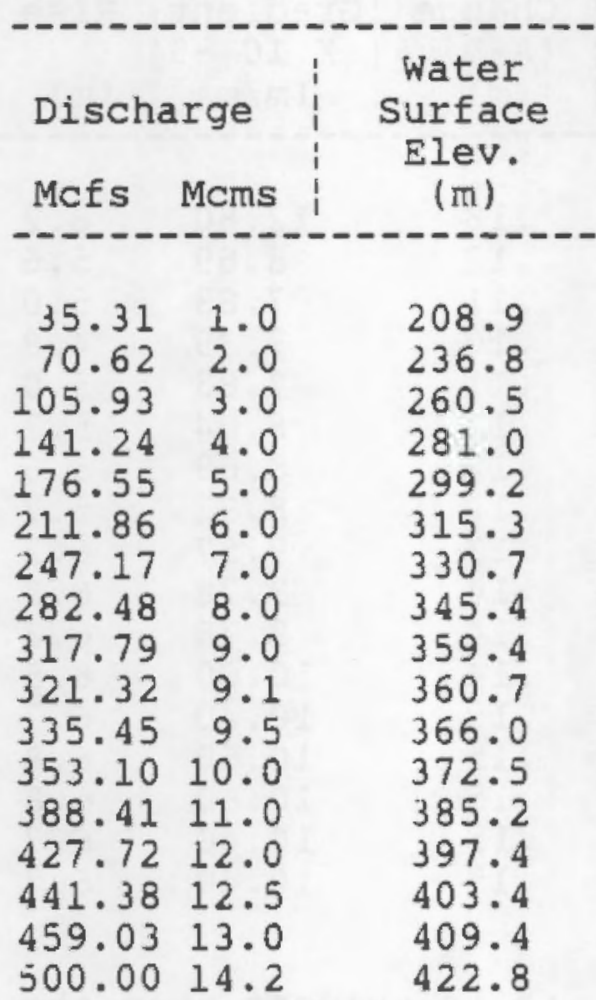




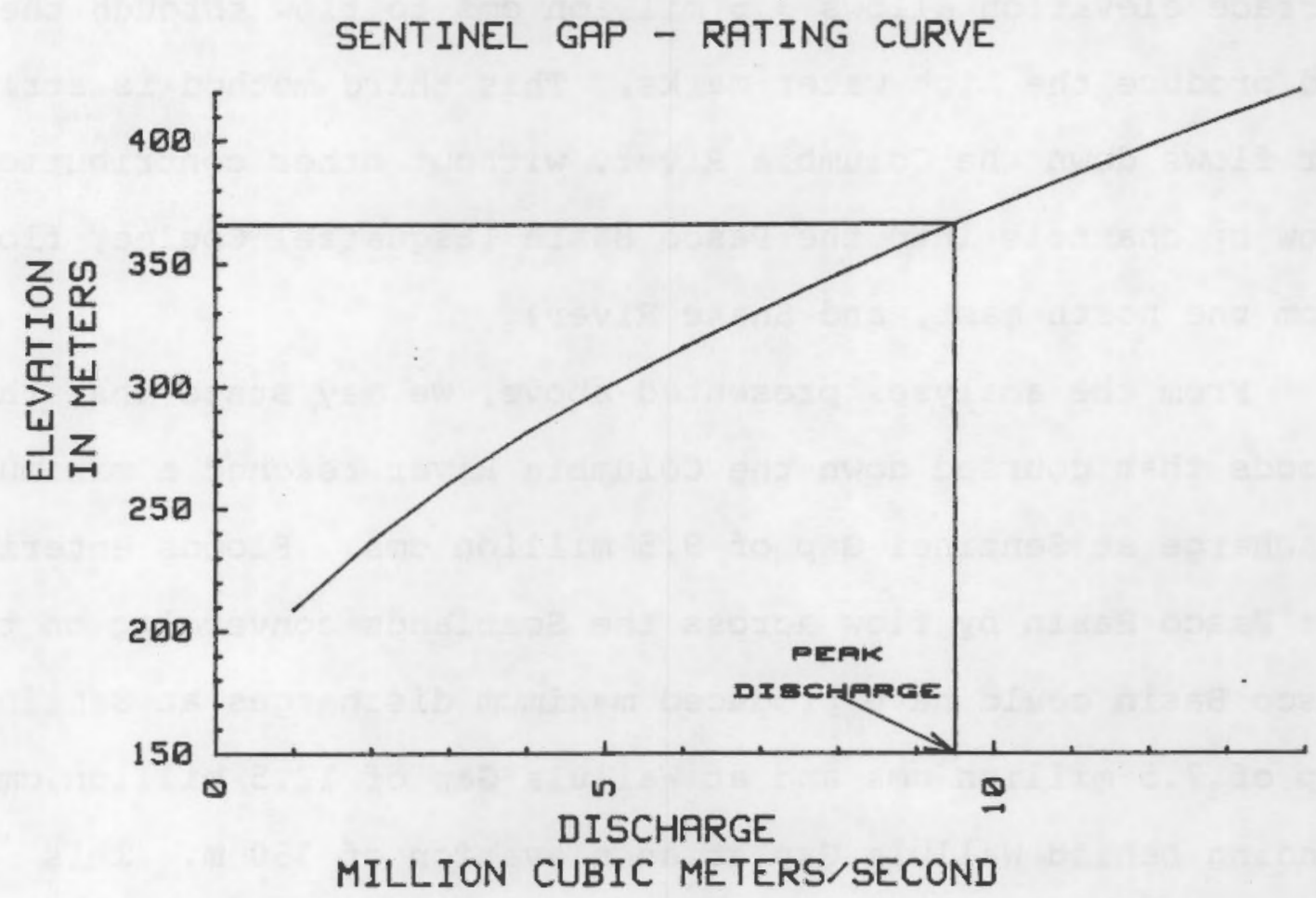

FIGURE 4.7. Sentinel Gap rating curve (at cross-section 34). Peak discharge through Sentinel Gap, $9.5 \mathrm{million}$ cms. corresponding to an elevation of $366 \mathrm{~m}$ (1200 it). 
Projection of the water surface elevation from wallula Gap suggests a larger discharge is needed to produce the high water marks at Sentinel Gap than was estimated from HEC-2 analyses considering convergent flow at the Pasco Basin. Use of Baker's (1973) water surface elevation allowed 7.5 million cms to flow through Sentinel Gap, whereas projection of the wallula Gap water surface elevation allows 9.5 million cms to flow through the gap and produce the high water marks. This third method is strictly for flows down the Columbia River, without other contributions to flow by channels into the Pasco Basin (Esquatzel Coulee, flows from the north east, and Snake River).

From the analyses presented above, we may state that the floods that coursed down the Columbia River reached a maximum discharge at Sentine 1 Gap of 9.5 million cms. Floods entering the Pasco Basin by flow across the Scablands converging on the Pasco Basin could have produced maximum discharges at Sentinel Gap of 7.5 million $\mathrm{cms}$ and at Wallula Gap of 12.5 million cms ponding behind wallula Gap at an elevation of $350 \mathrm{~m}$. This suggests that the high water marks around the Pasco Basin were not produced by discharges confined to the Columbia River but by convergent flow through multiple channels emptying into the Pasco Basin. This also allows us to postulate that at least 5 million cms converged on the Pasco Basin through channels other than Sentinel Gap when flood flows coursed over the Scablands. LIMITATIONS AND UNCERTAINTIES

The primary sources of uncertainty in these analyses are the assumptions of steady, gradually-varied, one-dimensional flow to be used in the analysis of an unsteady event. Even if unsteady 
techniques were utilized, a major question in the validity of this analysis would be whether the techniques and assumptions may be extrapolated to flood flows of this magnitude.

Based upon the methodology used in this study, other sources of uncertainty that may affect results of this analysis include:

1. Relative areas for main and overbank channels may be inaccurate.

2. Distances between cross-sections may be too large to allow the assumption of gradually varied flow.

3. Improper expansion and contraction coefficients may have been applied.

Concerning the last point, examination of Figure 4.8 , at cross-section 12 , shows that flow has expanded from the crosssection immediately upstream from it. For these analyses, the decrease in energy from the upstream cross-section (12) to crosssection 11 may be accounted for by simulating expansion of the channel by using a coefficient. Starting with a coefficient of 1.0 , we increment it to 1.1 at cross-section $1 ; 1.3$ at crosssection 3; and then to account for the abrupt change in channel geometry, a coefficient of 1.8 is used at cross-section 11 . To determine the appropriate coefficients, a trial and error procedure was used until transition to critical flow at these expansion points did not occur. Addition of the expansion/contraction coefficients represents energy dissipation by factors other than friction and provides more reasonable results than analyses using no expansion/contraction coefficient. The Army Corps of Engineers have devised a method to 


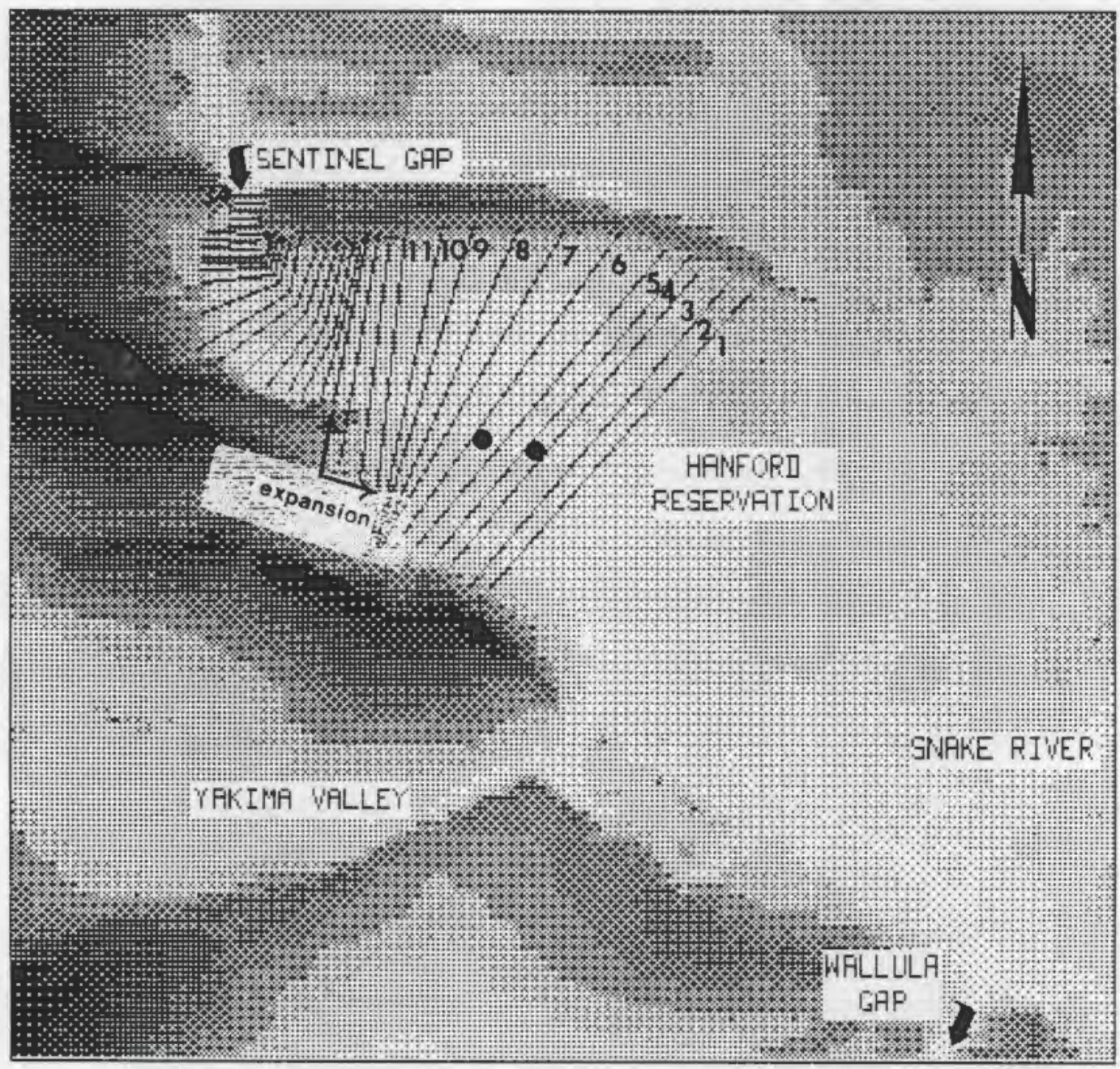

FIGURE 4.8. Location ol cross-sections used for Elood anaiyses in the upper Pasco Basin. Region of expanding rlow is indicated. Location of the 200 areas are indicated (dots). 
validate the results obtained from HEC-2 analyses. Members of the Corps believe that the equations used to describe the hydraulics of the flow (Bernoulli energy equation with Manning's equation to account for energy loss due to friction) are valid if the energy slope from cross-section to cross-section does not vary by more than 50\%. In this analysis, differences in energy slope between cross-sections greater than $50 \%$ occur where flow expands rapidly (the regions discussed above) and where flows are constricted (cross-sections 34 to 33 ) in Sentinel Gap. In either case, since a backwater procedure is used, the estimates determining the channel hydraulics for the region of the Hanford Reservation should not be affected. Since fluctuation in the energy slope does occur at the northernmost cross-section (entry to Sentinel Gap), the rating curve for the sentinel Gap region is also given for the tightest part of the constriction within the gap, cross-section 31 (Table 4.4 and Figure 4.9). This reduces the boundary effect error. 
TABLE 4.4. Sentinel Gap rating curve based upon HEC-2 runs using the projected water surface elevation from Wallula Gap. Includes water surface elevation to cross-section 31 (narrowest section in the constriction).

\section{SENTINEL GAP}

\begin{tabular}{|c|c|c|}
\hline \multicolumn{2}{|c|}{ Discharge } & $\begin{array}{c}\text { Water } \\
\text { Surface } \\
\text { Elev. }\end{array}$ \\
\hline Mcfs & Mcms & (m) \\
\hline $\begin{array}{r}35.31 \\
70.62 \\
105.93 \\
141.24 \\
176.55 \\
211.86 \\
247.17 \\
282.48 \\
317.79 \\
321.32 \\
353.10 \\
388.41 \\
427.72 \\
441.38 \\
459.03\end{array}$ & $\begin{array}{r}1.0 \\
2.0 \\
3.0 \\
4.0 \\
5.0 \\
6.0 \\
7.0 \\
8.0 \\
9.0 \\
9.1 \\
10.0 \\
11.0 \\
12.0 \\
12.5 \\
13.0\end{array}$ & $\begin{array}{l}198.6 \\
219.7 \\
238.6 \\
255.0 \\
269.4 \\
280.4 \\
292.0 \\
304.2 \\
315.6 \\
317.0 \\
327.0 \\
338.3 \\
349.2 \\
354.6 \\
361.9\end{array}$ \\
\hline
\end{tabular}




\section{SENTINEL GRP - RATING CURVE}

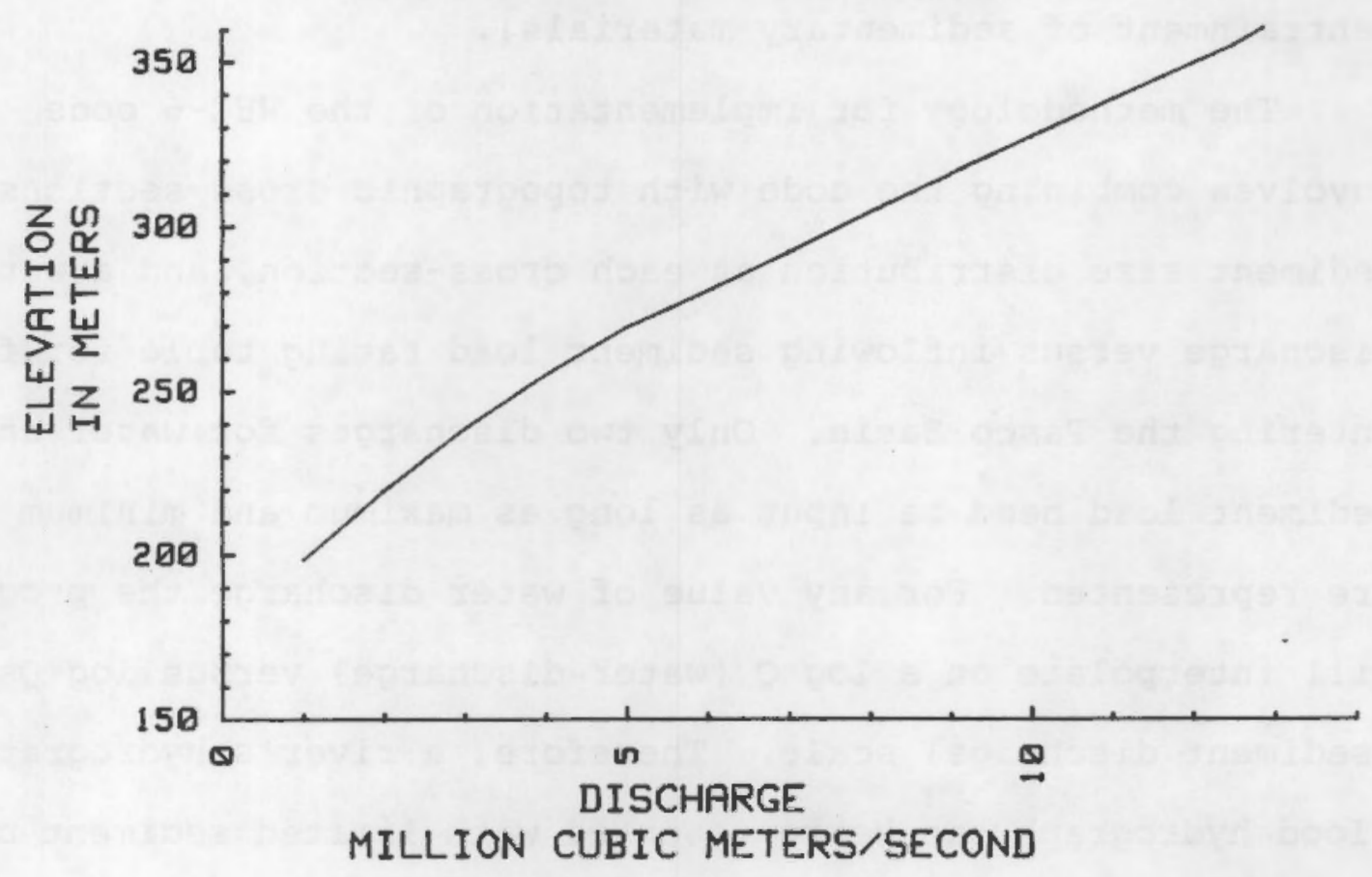

FIGURE 4.9 . Sentinel Gap Rating Curve at the narrowest section of the constriction, cross-section 31 . 
EROSION POTENTIAL UNDER STEADY STATE CONDITIONS

\section{THE HEC-6 PROGRAM}

The HEC- 6 code is used here to predict erosion and deposition based on the Pasco Basin channel configuration in a Missoula-type flood. The results of these analyses may aid us in. determining areas within the Pasco Basin of greater stability (sediment deposition) and potentially hazardous areas (entrainment of sedimentary materials).

The methodology for implementation of the HEC- 6 code involves combining the code with topographic cross-sections, sediment size distribution at each cross-section, and a water discharge versus inflowing sediment load rating table for flows entering the Pasco Basin. Only two discharges for water and sediment load need be input as long as maximum and minimum values are represented. For any value of water discharge the program will interpolate on a $\log Q$ (water discharge) versus log QS (sediment discharge) scale. Therefore, a river's hydrograph or flood hydrograph can be represented with limited sediment data available to the user as in this application.

The HEC- 6 sediment model is based upon the same equations of flow as is HEC-2 except that the HEC- 6 model determines scouring and deposition by modelling the interaction between the fluid medium, channel bedload and hydraulics of the flow. The HEC- 6 program utilizes the equations of: conservation of energy; continuity of water volume; continuity of sediment volume; and a transport function (HEC-6 Hydrologic Engineering Center, 1977). ALTERNATIVE TRANSPORT EQUATIONS

The HEC- 6 program allows the use of several transport 
equations. At present there are five options available. These are:

1.) User's transport function

2.) Toffaleti's Method

3.) Madden's Modification of Laursen's relationship.

4.) Yang's Streampower Method

5.) Duboy's Method

The user transport function allows the user to develop an equation describing sediment transport based on field data. The user transport function will not be discussed since it would be impossible to determine the coefficients needed for tine transport equation. Actual measurements of the sediment load of a Missoula-type flood and conversion of the measurements into an equation.

\section{Toffaleti's Method}

Toffaleti (1969) devised a method to estimate sediment transport based upon measurements of seven rivers and results of flume studies taken from the literacure. Data was collected from the Mississippi River at st. Louis and rivers within the lower Mississippi River basin. Other rivers included are the Rio Grande at Bernalilio, the Middle Loup, and the Niobrara River. Since Toffaleti's Method is a measure of the total bed load, the sediment concentration over the depth of flow is divided into an upper, middle, lower, and bed zone. The bed zone is defined as two grain diamecers in thickness. This method includes a variation in temperature for the calculation of fall velocities of the particles. The equations used in this method described by 
Shen (1982):

The velocity distribution is given by:

where:

$$
\mathrm{u}_{\mathrm{y}} / \mathrm{V}=\mathrm{n}_{1}(\mathrm{y} / \mathrm{D})^{\mathrm{n}}
$$

$$
\begin{aligned}
& u_{Y}=\text { point flow velocity at a distance } \mathrm{Y} \text { above the bed } \\
& \mathrm{D}=\text { flow depth } \\
& \mathrm{V}=\text { average flow velocity }
\end{aligned}
$$

and $\mathrm{n}_{1}$ and $\mathrm{n}_{2}$ are related by,

$$
\mathrm{n}_{1}=1+\mathrm{n}_{2}
$$

where $\mathrm{n}_{2}$ is a function of the water temperature and equal to the constants:

$$
\mathrm{n}_{2}=0.1198+0.00048 \mathrm{~T}
$$

\section{$\mathrm{T}=$ water temperature $1 \mathrm{n}$ degrees Fahrenheit}

The sediment concentrations of the upper ( $C$ ), middle (C), and lower ( $C$, zones are defined by the following equations for the ith cross-section:

$$
\begin{aligned}
& C_{1}=C_{\text {ui }}(y / D)^{-1.52} 1 \\
& C_{1}=C_{\operatorname{mi}}(y / D)^{-2} I_{1}-.7562 \\
& C_{1}=C_{1 i}(y / D)^{1}
\end{aligned}
$$

where the exponent 2 is defined by the following:

where:

$$
z_{1}=w_{i} V / C \text { DS }
$$

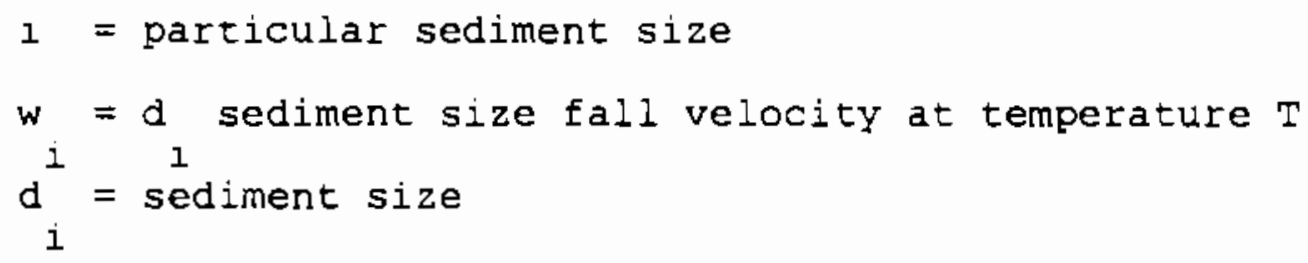




$$
\begin{aligned}
& S=\text { slope of the stream } \\
& c=260.67-0.667 \mathrm{~T}, \text { empirically derived } \\
& z=\text { depth of flow }
\end{aligned}
$$

To assure that the concentration ( $C$ ) of sediment decreases as the ratio of the distance from the bed to depth of flow increases ( $y / D)$ Toffaleti equates the value of $1.5 \mathrm{n}$ to the exponential variable $\mathrm{z}$ when less than $\mathrm{n}_{2}$.

\section{Laursen's Eormula}

Laursen's formula for total load is based upon empirical data which link the hydraulics of a river and the sediment transport parameters together. Laursen believed that the ratio of shear velocity to particle fall velocity is a good estimate of mixing due to turbulence and that this parameter should be used in the description of suspended sediment. Fall velocities were taken from flume studies and then used in the formulation of his equation.

Laursen's formula, was compared against three small streams. For one of the streams, results were very reasonable; for the other two streams results were only fair. For this analysis, a modification (Madden's) of Laursen's formula is used. Neither Laursen's formula or Madden's modification are presented in this report.

\section{Yang's Regression Curve}

Yang (1973) believed that the unit stream power (a product of average flow velocity and energy slope) is a dominant parameter in describing sediment transport rates. Through regression analyses, he expressed the average concentration of 
Ded material as a function of the following:

where:

$$
\mathrm{c}_{\mathrm{m}}=\mathrm{f}\left(\mathrm{wd} / \mathrm{v}, \mathrm{u}^{\star} / \mathrm{w}, \mathrm{vS} / \mathrm{w}-\mathrm{v}_{\mathrm{c}} / \mathrm{w}\right)
$$

$$
\begin{aligned}
c_{m} & =\text { average sediment concentration } \\
v & =\text { kinematic viscosity of water } \\
u^{*} & =\text { shear velocity } \\
v \quad & =\text { incipient flow velocity } \\
c r & =\text { fall velocity of mean sediment diameter } \\
w & =\text { mean sediment diameter } \\
d^{\prime} & =\text { average flow velocity } \\
v & =\text { energy slope }
\end{aligned}
$$

The actual formula proposed by Yang is:

$$
\begin{aligned}
& \log C_{m}=j .435-0.286 \log w d_{50} / v-0.457 \log u / w+ \\
& \left.(1.799-0.909 \log \text { wd } 50 / v) 0.314 \text { Log } u^{\star} / w\right) \\
& \log \left(V S / W-V \operatorname{cr}^{S / W}\right)
\end{aligned}
$$

Where:

$$
\begin{aligned}
& v_{\operatorname{cr}} / w=2.5 / \log \left(u^{*} d_{50} / v\right)-0.06, \\
& v_{\operatorname{cr}} / w=2.05, \\
& \text { for } u^{* d} / v>70
\end{aligned}
$$

All coefficients in the formula were based on 1093 sets of flume data and 65 sets of field data.

Du Boy's Method

Instead of a total-load sediment transport equation, Garde (1978) presents Du Boy's 1879 equation as a simple bed-1oad relationship. His method assumes a linear velocity relationship 
between the top and bottom of the movable bed surface; the movable bed being separated (divided) into parallel layers of pre-defined thicknesses: the bottom or lowermost layer having a velocity of zero. From these assumptions, a bed-load transport equation can be developed:

$$
q b=Y_{s} \operatorname{dh}(N-1) d V / 2
$$

where:

$$
\begin{aligned}
\mathrm{qb} & =\text { bed load } \\
\mathrm{Y} & =\text { specific weight of sediment } \\
\mathrm{s} & =\text { thickness of each bed layer } \\
\mathrm{d} & =\text { number of bed layers } \\
\mathrm{N} & =\text { bed layer }
\end{aligned}
$$

Since the velocity at the lower layer is equal to zero, the friction or resisting force must be equal to the tractive force:

$$
\text { to }=(Y s-Y w) \text { dh tano }
$$

where:

$$
\begin{aligned}
t_{0} & =\text { shear stress } \\
Y^{0} & =\text { specific weight of water } \\
w^{\prime} & =\text { critical slope }
\end{aligned}
$$

$\mathrm{N}$ can be determined assuming that a single layer is moving under critical conditions:

where:

$$
t_{O C}=\left(Y_{s}-Y_{w}\right) d h \operatorname{tano}
$$

$$
\tau_{o C}=\text { critical shear stress }
$$

or

$$
N=t / t
$$


Therefore,

or Du Boy's equation,

$$
q b=y_{s} d h d v t_{0}\left(t-t t_{o c}^{1 / 2 t}{ }^{2}\right.
$$

where

$$
q b=A\left(t t_{0}\right) t_{0}
$$

$$
a=y_{s} d h d v / 2 t_{o c}^{2}
$$

Shen (1982) states that further modification to Du Boy's function may be preferable for calculation of sediment movement at high transport rates and that transport functions discussed earlier are applicabie to medium to low transport rates. At high transport rates, the whole sediment bed layer may be moved. Toffaleti's relationship consists of a bed layer of only two grain diameters of thickness. Since Du Boy's method consists of multi-layers in the bed zone, more than a couple of layers of grains can be moved in one event. Shen (1982) goes on to say that a modification to the simple linear relationship between bed velocities will have to be developed before realistic results car De obtained using Du Boy's method. EROSION AT THE 200 AREAS (STEADY STATE)

To obtain reasonable estimates of sediment transport it is necessary to have some estimace of the quantity of sediment entering the system. HEC-6 requires a sediment inflow rating table; the inflow hydrographs for both water and sediments are necessary. Since it is impossible to measure the discharge of a Missoula flood we have made some assumptions in order that we might obtain a reasonable estimate of sediment inflow into the Pasco Basin.

The first assumption was that the volume of sediment 
currently in the Pasco Basin (Pasco Gravels) was deposited by one flood event. In the event of another flood it is assumed that all the materials associated with this unit would be scoured and transported out of the system through Wallula Gap. We have devised a concept of equilibrium transport for the Missoula sediments: the amount entering the Pasco Basin through one flood event is the same for each Missoula flood event.

To estimate the volume of sediment within the Pasco Basin we used the average sediment thicknesses (Pasco Gravels and Quaternary units) calculated from the sediment data from the Rockwell well-logs $(37 \mathrm{~m})$. This value was then multiplied by an area representing the extent of Lake Lewis in the Pasco Basin. This area was planimetered using a computer program. Different areas were used based upon the elevation we believed to represent the base level of Lake Lewis. Table 5.1 is a breakdown of the volume of sediment estimated to be within the Pasco Basin in each elevation increment. The sediment load in tons/day must be input to HEC-6. It is based on an assumed flow duration of 2 weeks proposed by Bretz (1969, p. 511, par. 1) and then used by Baker (1973) in his effort to characterize the flood flows; it was assumed that a constant discharge occurred for this duration to develop the estimate of sediment transport race.

Using the above methodology, an estimate of the maximum inflowing sediment load. The HEC-6 program requires at least two points to place on the sediment/water discharge rating curve for the program to be able to interpolate a sediment discharge. Therefore, estimates from modern day (large) rivers were used. 
estimates from modern day (large) rivers. As a minimum water discharge and sediment load, the modern day values recorded for the Mississippi River were used. As the intermediate discharges, data from the Amazon River were used (Shen, 1970). Values of water discharges and sediment loads for these two rivers are located in Table 5.2 .

TABLE 5.1. Estimate of sediment load for a Missoula flood oased on volume of sediment in the Pasco Basin.

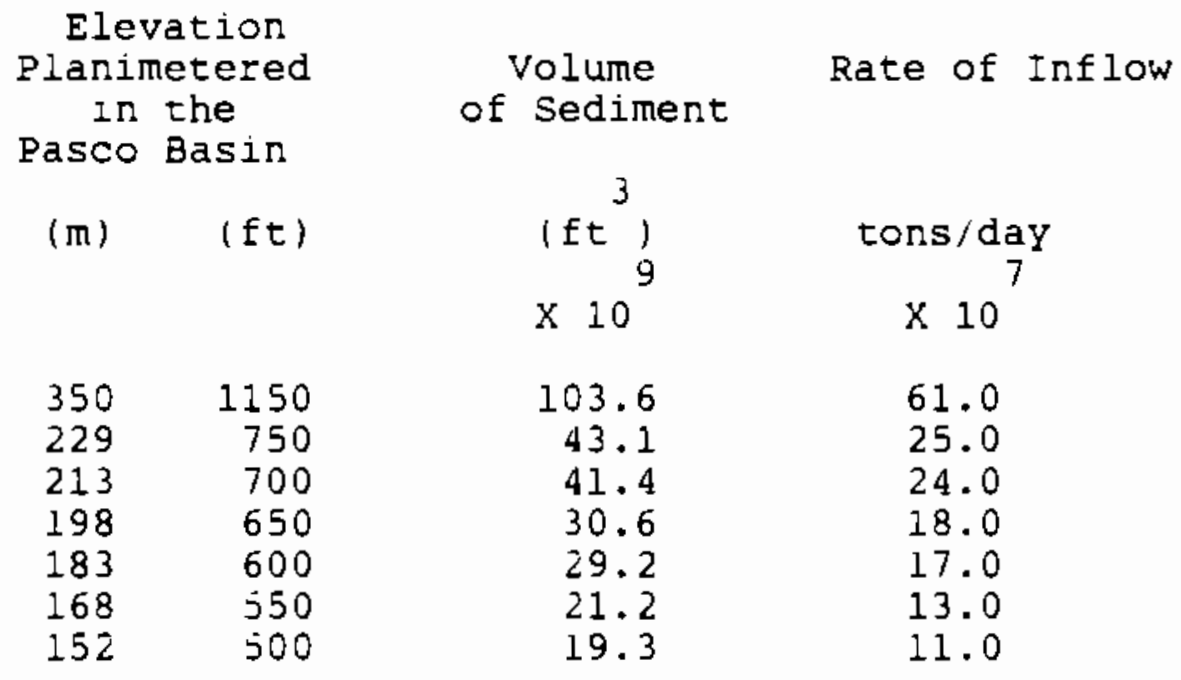

TABLE 5.2. Modern sediment loads from two rivers.

$\begin{array}{lcc}\text { River } & \begin{array}{c}\text { Water } \\ \text { cfs }\end{array} & \text { Sed Q } \\ & \times 10^{3} & 3 \\ & \times 10 & 3 \\ \text { Mississippi } & 530 & 942 \\ \text { Amazon } & 6400 & 1090\end{array}$

The HEC- 6 code requires a sediment size input along each cross-section for each analysis. Since this would require knowledge of the sediment load for each grain-size we have decided it is only practical to use one grain-size. Estimates of 
sediment load for each grain-size could have been utilized but it was believed that this method was not warranted due to the large uncertainty in the data. From analysis of the well-log information, the modal grain-size of the Pasco Basin consists of the sand class (Chapter 2). We will therefore assume that a single grain-size describes the sediment distribution. Since gravel and sand are both common in the Pasco Basin the results using both grain-size classes will be reported.

Baker (1973) estimated the maximum duration of a Missouia flood event to be 14 days. For a first cut at using HEC-6, this value (14 days) is the duration for flood flows used. It was also assumed that discharge was constant throughout the duration of the flood event (14 days). Therefore, flow was treated as if it met the requirements of steady-state conditions.

The major assumptions involved in these runs are.

1.) Greatest amoune of sediment. This is inherent to the development of our Q-Qs racing table.

2.) The sediment distribution of the entire Pasco Basin may be characterized by one grain-size lutilizing both gravel $(64 \mathrm{~mm})$ and sand (2 $\mathrm{mm}$ ) grain sizes in separate analyses).

3.) Elow is steady and gradually-varied. THE STEADY-STATE METHODOLOGY Gravel Size Particles

A grain size of $64 \mathrm{~mm}$ was used to describe the sediment distribution in the Pasco Basin to determine how HEC- 6 would handle the large grains. The inflowing sediment load was arbitrarily set to $9.9 \times 10$ tons/day at a maximum water 
discharge of 10 million cms. The minimum sediment load was set to the value corresponding to the water and sediment discharges of the Mississippi River (Table 5.2). For these analyses using the HEC- 6 code, the inflowing sediment load would be interpolated based upon a specified water discharge and the minimum and maximum sediment load values. For these analyses, using gravel as the bed's sediment size, water discharges of 7.5 militon cms and 2.2 million cms were chosen. A discharge of 7.5 million cms was chosen because this was the water discharge at which maximum flow through sentinel Gap occurred when flow through multiple channels converged on the Pasco Basin; 2.2 million cms was chosen Decause flow would be more channelized and possibly produce scour to a greater depth. Results implementing each of the four transport equations with the above initial conditions and allowing the computer code to scour up to $30 \mathrm{~m}$ can be found in Tables 5.3 and 5.4. A discussion of the results for each transport function follows. For cross-section locations refer to Figure 4.5 .

Du Boy's Method

At the upstream cross-sections near and within the sentinel Gap constriction (cross-sections 34-27), the allowable depth of erosion occurred at a discharge of $7.5 \mathrm{million} \mathrm{cms}--$ scour of 30 $\mathrm{m}(100 \mathrm{ft})$. Deposition of $140 \mathrm{~m}(459 \mathrm{ft})$ at cross-section 26 occurred, $11 \mathrm{~m}$ ( $36 \mathrm{ft}$ ) occurred at cross-section 23 and relatively little of the bed material moved downstream over the site. Analyses using a discharge of $2.2 \mathrm{million} \mathrm{cms}$ produced similar results but with more bed movement occurring downstream 
(Tables 5.3 and 5.4 ).

Toffaleti's Method

At this large water discharge and inflowing sediment load (7.5 million cms), Toffaleti's method showed deposition of $744 \mathrm{~m}$ ( $2440 \mathrm{ft})$ at cross-section 34 , the bottleneck of the constriction. Relatively little disruption of the sediment occurred downstream of this section over the site. Lowering the discharge to 2.2 million cms decreased the amount of deposition at cross-section 34 to $143 \mathrm{~m}$ (468 ft).

\section{Yang's Relationship}

Yang's relationship produced similar results to Du Boy's at 7.5 million cms with 30 m of erosion at the upstream crosssections and deposition occurring at cross-section 10 . Here $32 \mathrm{~m}$ (105 ft) of sediment was deposited. Greater depths of scour occurs at the downstream cross-sections by lowering the discharge co 2.2 million cms. Still little disruption of the sediment occurs over the repository.

Madden's Modification of Laursen's Relationship

Madden's method produced similar results to Toffaleti's relationship at a discharge of 7.5 million cms. Deposition of $308 \mathrm{~m}$ (1011 ft), occur at cross-section 32 , just upstream the narrowest cross-section within the constriction of Sentinel Gap. The 200 areas were undisturbed. Little change occurs by lowering the discharge to 2.2 million $\mathrm{cms}$.

\section{Sand Size particles}

Using the methodology above, little if any disruption of material occurred over the 200 areas. When one variable was changed, gram-size, the results changed drastically. For the 
TABLE 5.3. Aggradation ( + ) and degradation (-) values for each cross-section in the sentinel Gap analyses at a water discharge of 7.5 million cms using gravelsize (64 mm) particles.

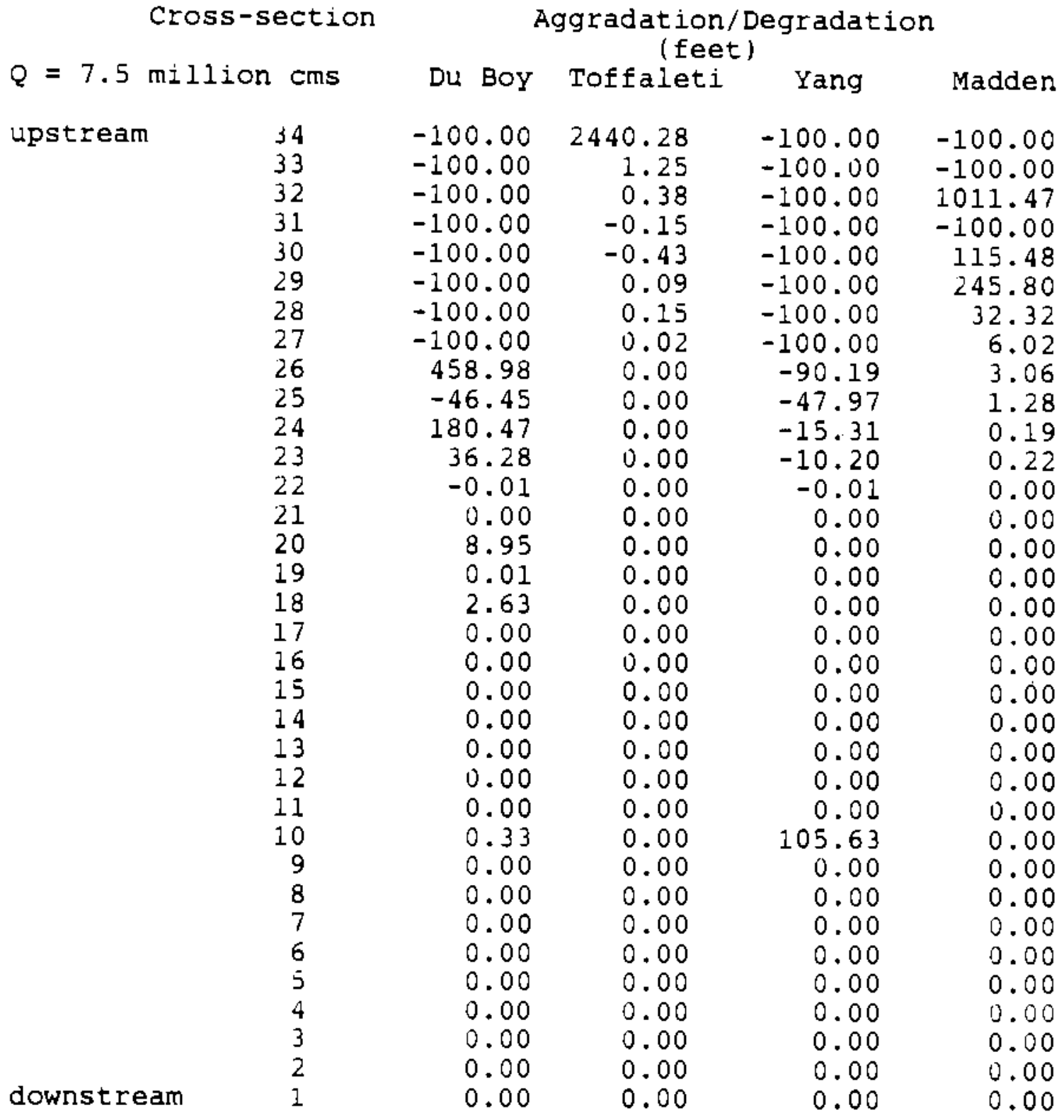


Table 5.4. Aggradation $(+)$ and degradation $(-)$ values for each cross-section in the Sentinel Gap analyses at a water discharge of 2.2 million cms using gravelsize $(64 \mathrm{~mm})$ particles.

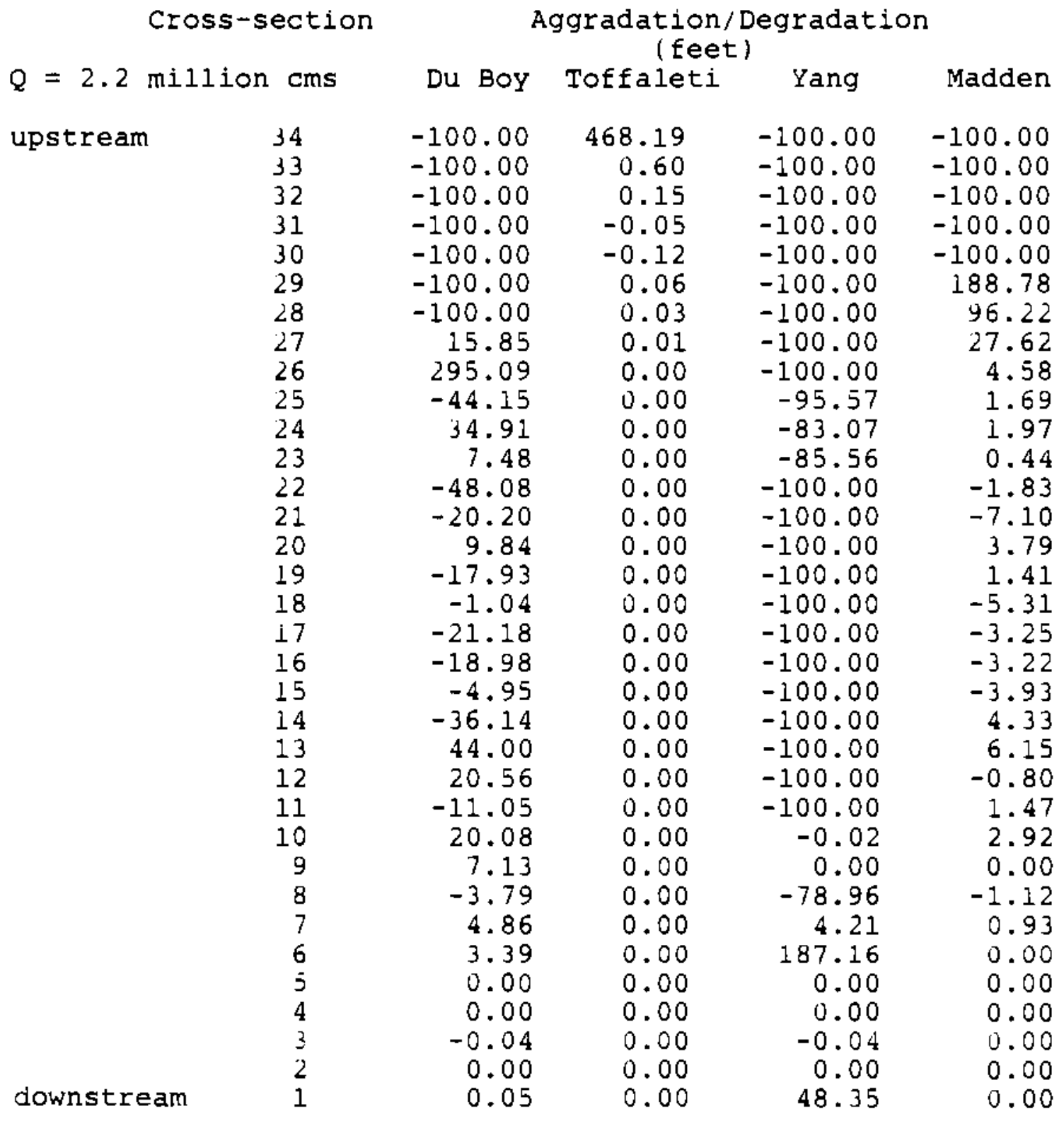


next set of runs using each transport function, sand-size (2 mn) particles are used to describe the sediment distribution of the Pasco Basin. From the results mentioned earlier, sand-size grains are the most abundant of the three studied so it is appropriate to use this grain-size in the characterization of the sediment in the Pasco Basin. These runs were computed from a discharge of 2.5 million cms since greater depths of erosion occurred at a lower discharge in the previous analyses. Results from this analysis are located in Table 5.5 .

\section{Du Boy's Method}

After the 14 day duration of the flood, erosion was evident at many cross-sections throughout the Pasco Basin area. The maximum scour allowed $(30 \mathrm{~m})$ occurred from cross-section 34 to cross-section 13. Deposition occurred as flows widened into the Pasco Basin. Over the site, $4 \mathrm{~m}(12 \mathrm{ft})$ to $9 \mathrm{~m}(31 \mathrm{ft})$ of scour occurred.

\section{Toffaleti's Method}

Toffaleti's method showed a little more interaction between the water and sediment as a function of the grain-size distribution in the Pasco Basin. Toffaleti's method is supposed to work well with sand-size particles (HEC Hydrologic Engineering Center, 1976). The results obtained still seem unrealistic with deposition of $101 \mathrm{~m}$ (331 ft) of sediment at cross-section 34 . Erosion using this transport function was negligible.

\section{Yang's Method}

Results were similar to Du BoY's method but scour was not as extensive upstream of the site. Over the site, $3 \mathrm{~m}$ (11 ft) to 4 m (14 ft) of scour occurred. 
TABLE 5.5. Aggradation $(+)$ and degradation (-) values for each cross-section in the sentinel Gap analyses at a water discharge of 2.5 million cms using gravelsize ( $2 \mathrm{~mm})$ particles.

\section{Cross-section}

$Q=2.5$ million cms

\begin{tabular}{|c|c|}
\hline dounctras & $\begin{array}{r}34 \\
33 \\
32 \\
31 \\
30 \\
29 \\
28 \\
27 \\
26 \\
25 \\
24 \\
23 \\
22 \\
21 \\
20 \\
19 \\
18 \\
17 \\
16 \\
15 \\
14 \\
13 \\
12 \\
11 \\
10 \\
9 \\
8 \\
7 \\
6 \\
5 \\
4 \\
3 \\
2 \\
1\end{array}$ \\
\hline
\end{tabular}

Aggradation/Degradation (feet)

Du Boy Toffaleti Yang Madden

$-100.00$

331.16

$-4.89$

$-2.96$

0.68

0.98

$-0.41$

$-0.32$

0.30

1.17

$-0.53$

0.33

0.14

$-0.34$

$-0.01$

0.07

$-0.08$

0.04

$-0.11$

0.03

0.03

$-0.13$

0.05

0.04

$-0.08$

0.00

0.06

0.03

$-0.03$

0.14

0.00

$-0.08$

$-0.01$

0.01

0.08
$-100.00$

$-100.00$

$-100.00$

$-100.00$

$-100.00$

$-100.00$

$-100.00$

$-100.00$

$-100.00$

$-100.00$

$-100.00$

$-83.26$

$-100.00$

$-100.00$

$-74.64$

$-17.27$

$-78.28$

$-98.91$

$-100.00$

$-88.49$

$-34.59$

178.30

6.45

16.21

152.74

30.00

$-45.66$

44.36

20.92

$-0.79$

$-14.17$

$-10.99$

11.18

15.83
$-100.00$

$-100.00$

$-100.00$

$-100.00$

$-100.00$

$-100.00$

$-100.00$

$-100.00$

153.85

$-12.70$

55.00

11.65

$-45.82$

$-83.08$

28.73

5.39

$-65.63$

$-91.94$

$-100.00$

$-91.74$

$-13.50$

172.24

1.27

18.27

57.21

3.86

$-11.47$

10.38

1. 31

$-0.01$

$-0.50$

$-0.99$

0.85

0.42 
Madden's Modification of Laursen's Relationship

Changing the particle-size distribution affected the results of this method; up to $30 \mathrm{~m}$ (100 ft) of erosion occurred in the cross-sections upstream of the 200 areas. The results are similar to those obtained with Yang's method with the gravel size. Scour of $.33 \mathrm{~m}(1 \mathrm{ft})$ occurred over the site. LIMITATIONS AND UNCERTAINTIES

These initial analyses were completed under a static steadystate assumption; flow occurs for a 14 day period without the hydraulic conditions changing. This assumption is far from realistic since scour of over $30 \mathrm{~m}$ (100 ft) occurs using Yang's and Du Boy's transport functions. This change would drastically alter the channel hydraulics. Also, an arbitrary maximum inflowing load of $9.9 \times 10^{7}$ tons/day at a discharge of 10 million cms was utilized for all transport functions. For these reasons it was decided to use a quasi-dynamic methodology. This involves the development of a flood hydrograph for which discharge is maintained for a certain time period (steady state) and then increased or decreased to represent the change in discharge through time. It also involves the development of a methodology by which estimates of inflowing sediment load for each transport equation may be defined. These methods will be discussed in Chapters 6 and 7 . 


\section{THE HYDROGRAPH OF A MAJOR FLOOD}

\section{ASSUMPTIONS EMPLOYED}

Because of the difficulties of the steady flow assumption for calculation of erosion and transport capacity of a Missoula flood, it is desirable to employ a more correct assumption. In this case, the correct assumption is that the water discharge is a time-varying, unsteady flow. Exact determination of the characteristics of such a flood would require solution of an unsteady flow code starting at Lake Missoula itself. Solutions for any shorter portion of the flow path requires specification of the boundary conditions. In this case the boundary conditions chat must be specified include the time-varying inflow hydrograph at Sentinel Gap. If other inflow points were allowed, inflow hydrographs would have to be specified there also. No such Inflow hydrographs have yet been published.

Baker (1973) has made a first step in this direction by calculating the duration of a flood within the Pasco Basin using his estimate of the maximum discharge at Wallula Gap. That calculation ignored the time-varying nature of the discharge at wallula Gap and did not provide an estimate of such time-varying discharge. This again is the equivalent of the steady flow assumption used earlier. Thus, it is not sufficient for our purposes. The alternatives before us are: (1) to attempt the synthesis of such a hydrograph de novo or, (2) to attempt integration of the relevant unsteady flow equations beginning at the area of dam failure. The second alternative is preferred, but we have experienced problems of numerical instability in such solutions to date. Making one simplifying assumption about the 
flood behavior and confining our attention to the scenario of floods limited to the Columbia River valley, we are able to synthesize a reasonable hydrograph for the Pasco Basin. The procedure is described below.

The discharge hydrograph of jokulhlaups observed nistorically follows a nearly symmetric distribution. The peak of the flows occurs about halfway through the discharge sequence and discharges decine regularly after that. They are characterized by a single peak in flow. Flows last on the order of days to perhaps a week. An example of such a hydrograph is lllustrated in Figure 6.1. Hydrologic theory also tells us that flood hydrographs tend to decrease in amplitude downstream. This phenomena is known as attenuation of the wave and has been described by Ponce (1982). We will attempt to synthesize a nydrograph that displays such characteristics.

We assume that the discharge hydrograph at each location is nearly symmetric and can be described by a single parameter function, the Poisson function. The parameter of the function varies with location. This allows representation of the attenuacion of the flood wave.

Use of this approach to synthesize a hydrograph at sentinel Gap requires knowledge of the maximum discharge at Sentinel Gap. Solution of the hydrograph at wallula Gap requires knowledge of the volume of water held in the Pasco Basin at the maximum level of the floodwaters. Both of these values can be estimated from independent lines of evidence. Baker (1973) has estimated the volume of water held in Lake Lewis at its maximum elevation (260 


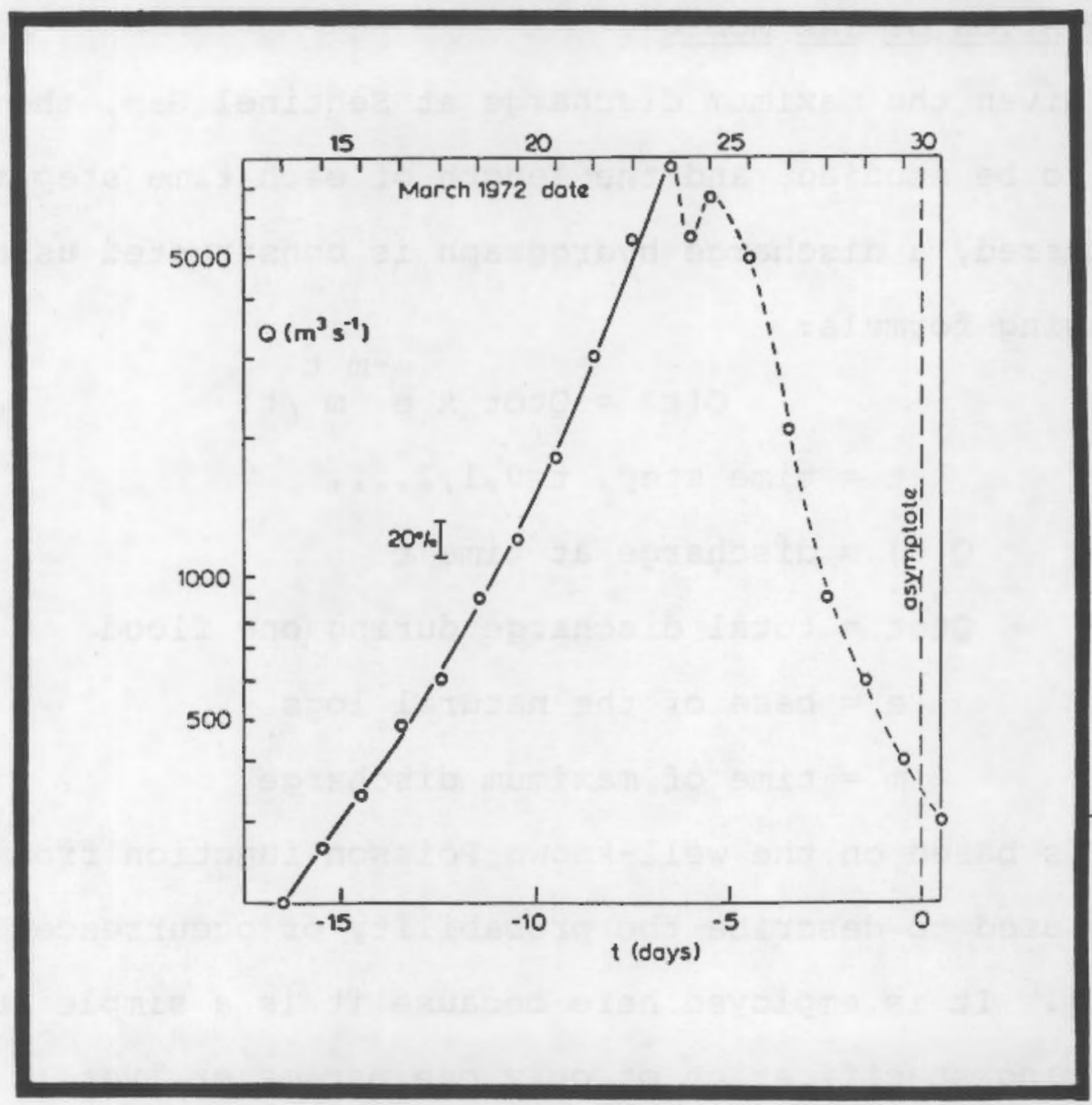

FIGURE 6.1. A typical hydrograph for a jokulhlaup. The tlood observed in Iceland at Vatnajokul in 1954. From. Nye $(1976$, p.194). 
cubic miles) and Craig (Craig, Singer and Underberg, 1983, their

Table 8 ) has provided a table showing that volume for any

elevation of the lake from its minimum to maximum elevations at $10 \mathrm{~m}$ increments.

FORMULATION OF THE MODEL

Given the maximum discharge at sentinel Gap, the length of time to be studied, and the length of each time step to be considered, a discharge hydrograph is constructed using the following formula:

$$
Q(t)=\text { Qtot } x e^{-m t} m / t !
$$

Where:

$$
\begin{aligned}
t & =\text { time step, } t=0,1,2, \ldots \\
Q(t) & =\text { discharge at time } t \\
\text { Qtot } & =\text { total discharge during one flood } \\
e & =\text { base of the natural logs } \\
m & =\text { time of maximum discharge }
\end{aligned}
$$

This is based on the well-known Poisson function from statistics. It is used to describe the probability of occurrence of rare events. It is employed here because it is a simple function requiring specification of only one parameter, yet it is capable of generating distributions reminiscent of those suggested for flood events such as jokulhlaups. As will be seen, this function appears to generate hydrographs fitting quite closely the constraints of the field data.

A second hydrograph can be generated for the discharge at Wallula Gap using the same approach. Since the flood wave has a finite velocity and tends to lose energy due to friction and turbulence, it is expected that the peak discharge at wallula Gap will occur later than, and be of less magnitude than, the 
discharge at Sentinel Gap. Indeed, it is known from field evidence that a significant volume of water accumulated in the Pasco Basin during at least some of these floods. Such accumulation can only occur when the discharge at wallula Gap is less than the inflow into the Basin. Since we are only interested in flows which are confined to the Columbia River, all Inflow to the Pasco Basin will be through sentinel Gap. We must investigate the magnitude and timing of hydraulic ponding in that scenario.

Field evidence suggests that the maximum level of hydraulic ponding in the Pasco Basin produced water levels to $350 \mathrm{~m}$ (1150 $\mathrm{ft})$ or possibly $366 \mathrm{~m}(1200 \mathrm{ft})$. It is entirely possible that these levels were never reached by floods which were confined to the Columbia River. Floods down the Columbia that did not produce such ponding must be of lower discharge. Thus, we take as a worst case scenario that there were (and can be in the future) floods, entirely confined to the columbia River, which are of sufficient discharge to produce ponding to $350 \mathrm{~m}$ (1150 ft) or $366 \mathrm{~m}(1200 \mathrm{ft})$.

We can use that information to compute the maximum discharge at Wallula Gap and the delay in that maximum beyond the time of the maximum at Sentinel Gap. For this we assume that the discharge hydrograph of Wallula Gap also follows a Poisson function. That function will tell us the discharge at wallula Gap at each time step, just as was computed for sentinel Gap. Whenever the discharge at Wallula Gap is less than the discharge at Sentinel Gap, we assume that water is accumulating in the 
Pasco Basin. If we sum, time step by time step, the volume of water that accumulates, we will have an estimate of the maximum volume of Lake Lewis during a flood.

That estimate can be directly compared to previously computed estimates of the maximum volume of Lake Lewis. Baker (1973) planimetered $15^{\prime}$ topographic maps of the Pasco Basin to estimate the volume held below the $350 \mathrm{~m}(1150 \mathrm{ft})$ level. He computed that to be 175 cubic miles. Craig (Craig, singer and Underberg, 1983) used a computer algorithm and a digital elevation model to estimate the volume of water that could be neld in the Basin at $10 \mathrm{~m}$ increments of water depth from $0 \mathrm{~m}$ to above the maximum recorded lake level (Figure 6.2). At approximately $350 \mathrm{~m}(1150 \mathrm{ft})$, the Basin can hold 666 cubic kilometers (or about 160 cubic miles) of water. Since the parameter of the Poisson changes the shape of the hydrograph, it affects the estimate of the total volume of water that will accumulate. Thus, the parameter (of the Wallula Gap function) can be varied until it produces an estimate of lake volume that agrees with the maximum estimated from the field evidence. Matching the functional forms in this way affects the estimated maximum discharge of Wallula Gap. It also determines the time lag between the maximum at sentinel Gap and the maximum at Wallula Gap. Furthermore, it fixes the rate at which the Pasco Basin will empty of water and therefore the total duration of the flood in the Pasco Basin. This latter figure has already been estimated by Baker (1973) to be 7 to 14 days. Thus, the results of such parameter fitting can be tested with an independent set of data. This procedure was used to estimate the 


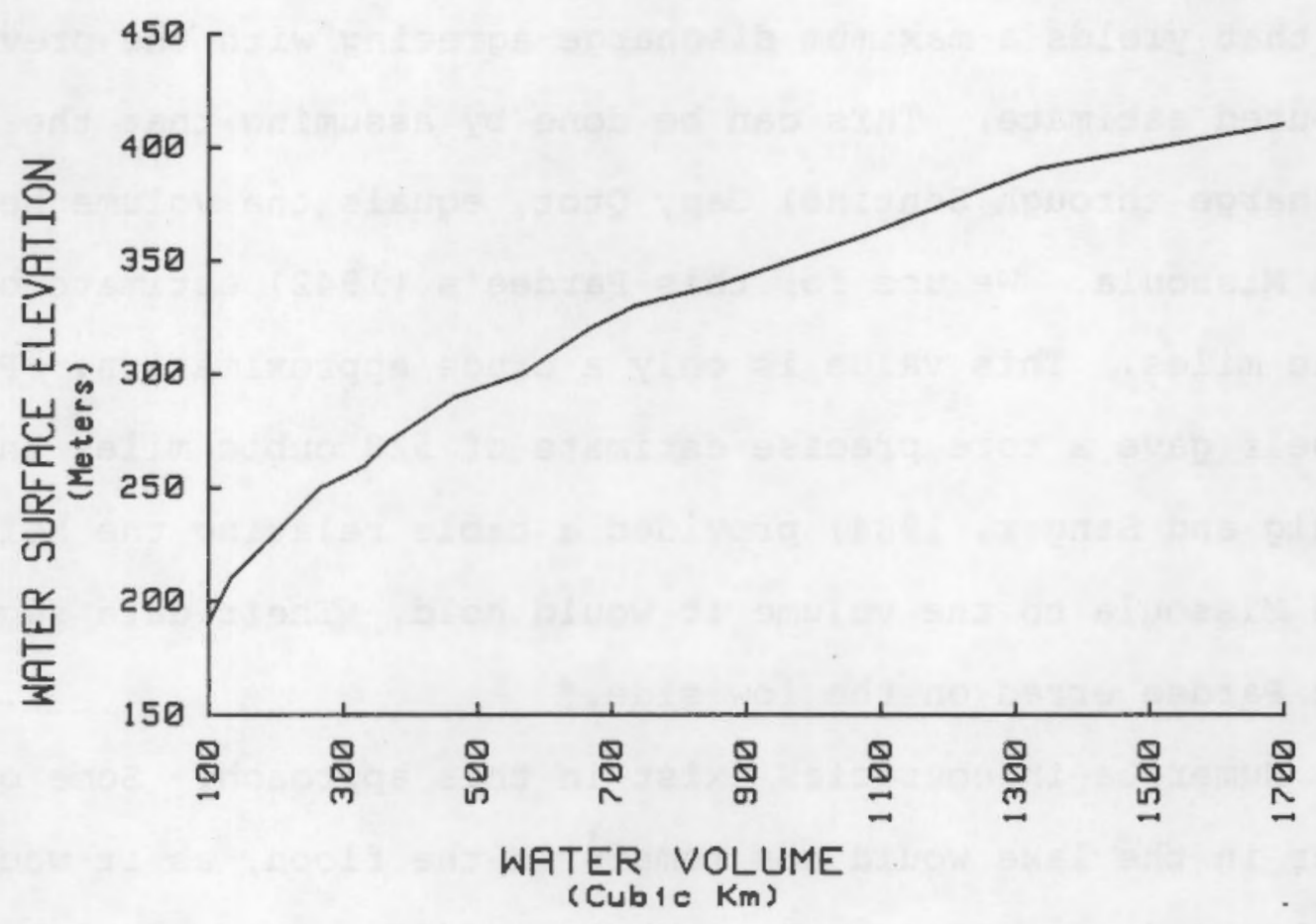

FIGURE 6.2. Relation between water surface elevation of Lake Lewis and the volume of water that would be held in that lake (from: Craig, Singer and Underberg, 1983, Table 8). 
discharge hydrographs for Sentinel Gap and for Wallula Gap. ITERATIVE SOLUTION OF THE HYDROGRAPH

'To sets of iterations are required to apply this approach. First, we must find the parameter of the function for sentinel Gap that yields a maximum discharge agreeing with the previously computed estimate. This can be done by assuming that the total discharge through Sentinel Gap, Qtot, equals the volume held by Lake Missoula. We use for this Pardee's (1942) estimate of 500 cubic miles. This value is only a crude approximation. Pardee nimself gave a more precise estimate of 520 cubic miles and craig (Craig and Singer, 1984) provided a table relating the height of Lake Missoula to the volume it would hold. Their data suggest that Pardee erred on the low side.

Numerous inaccuracies exist in this approach. Some of the water in the lake would not remain in the flood, as it would fill in closed depressions or be left behind in saturated sediments. Thus, we accept Pardee's crude estimate as a starting point. Some investigation of the effects of the assumption are warranted.

The HEC-2 analysis reported earlier provides an estimate of the maximum discharge through sentinel Gap. We accept the figure of 353.1 million cfs (Table 4.4) as our best estimate. For the HEC-6 analyses reported above, we estimated (using HEC-2) that it would take as much as 5.23 hours for a parcel of water to completely traverse the distance from Sentinel Gap to Gable Mountain. To ensure that material would move through on one time step we choose six hours as a reasonable value of $t$ in the analyses. 
Six hours is also the time step chosen for the hydrograph analyses since the data are to be applied to further HEC-6 runs. We multiply the maximum discharge for Sentinel Gap computed using HEC-2 ( 353.1 million cfs) by six hours $(6 \times 60 \times 60=14400$ seconds) to compute the volume of water that would pass through sentinel Gap in one time step $(5,084,640$ million $c f)$. We further compute that would amount to approximately $7 \%$ of the total discharge 1500 3 $\mathrm{mi}=73,599,000$ million $\mathrm{cf}$ ) in a flood. With that figure, we Iterate on the parameter value until the Poisson function yields that value for discharge during the time step corresponding to peak flow (Figure 6.3). Once that value is determined, the entire hydrograph is fixed. Only integer values were considered (Table 6.1) since we will use only integer time steps in the HEC6 analysis. An exact fit could be obtained with non-integer values. The value chosen (15 time steps, or 3.75 days) represents that time at which maximum discharge would be observed once flooding began. Continuing solution of the function for later times shows that the entire flood will have passed through Sentinel Gap (discharge less than 0.005 above normal) after nine days. Significant flooding still is occurring downstream.

Once the hydrograph at sentinel Gap is established it can be used to fix the hydrograph at Wallula Gap. That is done by iterating on the Wallula Gap parameter until the resulting function gives a cumulative volume of Lake Lewis matching that estimated from the field evidence (Figure 6.4). Again, only integer values were considered. The best match was achieved with $m=19$ time steps (Table 6.2 ). This implies that the maximum 


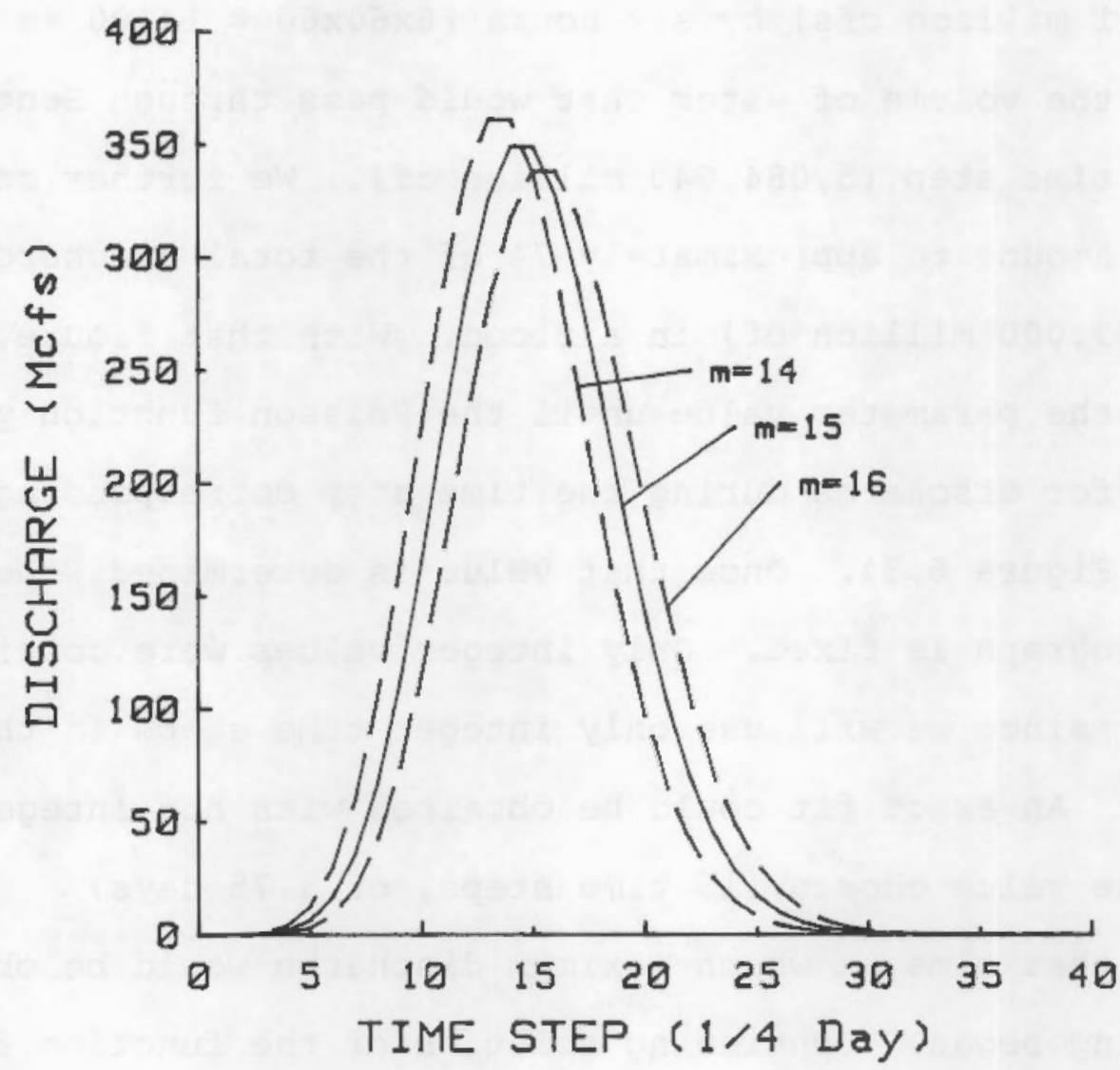

FIGURE 6.3. Iterative solutions of the Poisson Eunction provide different estimates of the flood hydrograph at

Sentinel Gap. The final hydrograph chosen $(m=15)$ is given by the solid line. 
TABLE 6.1. Results of iterative solution of the flood hydrograph for Sentinel Gap during a Scabland flood.

\begin{tabular}{c|c} 
M(Sentinel) & $\begin{array}{c}\text { Q } \\
\text { (Mcfs) }\end{array}$ \\
\hline 10 & 426.29 \\
11 & 406.76 \\
12 & 389.69 \\
13 & 374.60 \\
14 & 361.14 \\
$15^{\star}$ & 349.04 \\
16 & 338.07 \\
17 & 318.92 \\
18 & 310.49 \\
19 &
\end{tabular}

* Final value chosen 


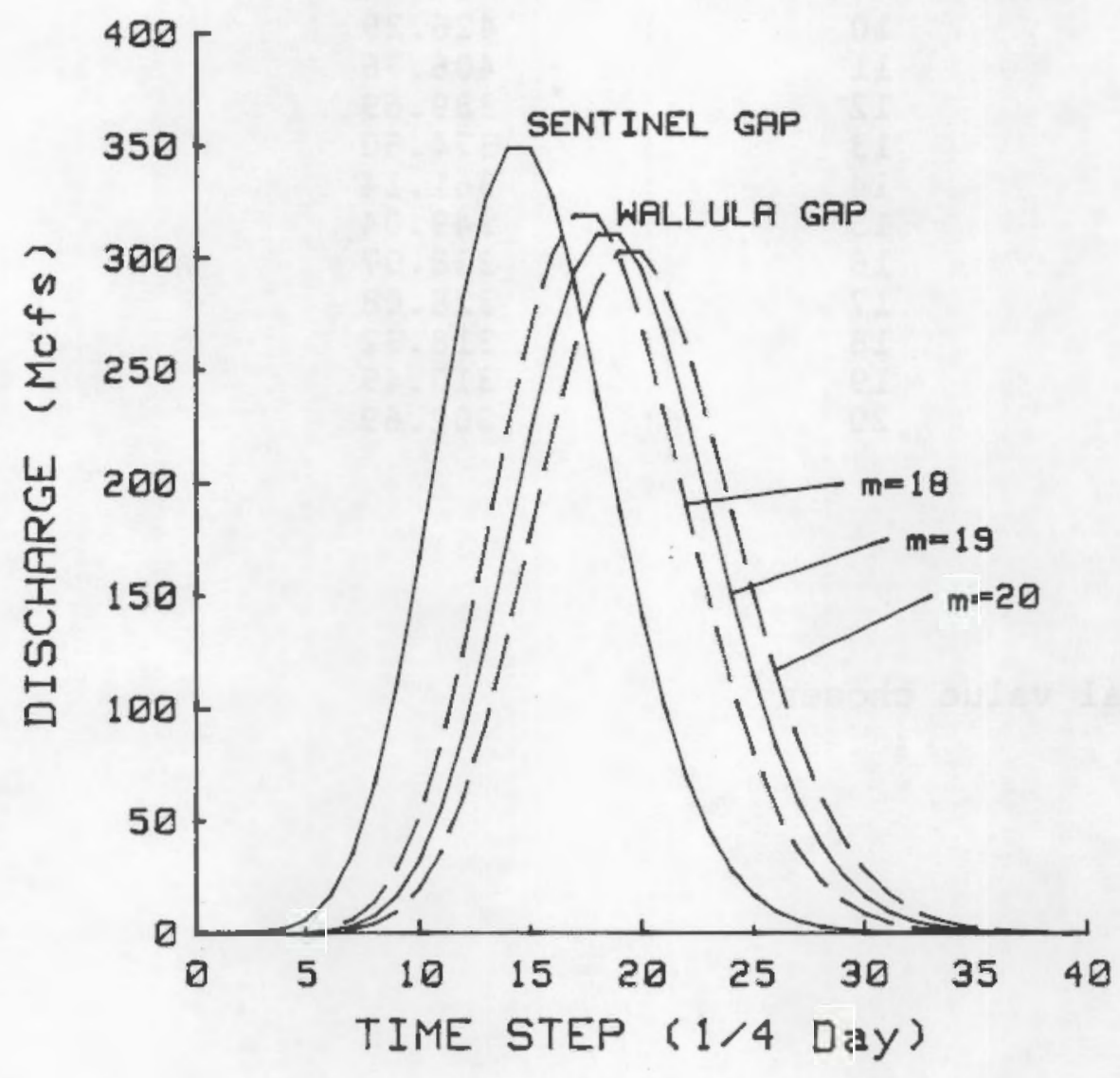

FIGURE 6.4. Illustration of the method of iteration used to select the appropriate hydrograph for Wallula Gap. 
TABLE 6.2. Results of iterative solution of the flood hydrograph for Wallula Gap during a Scabland flood. Solution is made using the final hydrograph for Sentinel Gap as illustrated in Figure 6.3.

\begin{tabular}{c|c}
$M$ (wallula) & $\begin{array}{c}\text { Cumulative } \\
\text { Ponding }\end{array}$ \\
\hline 16 & 50.67 \\
17 & 98.32 \\
18 & 144.54 \\
$19 *$ & 186.04 \\
20 & 225.92 \\
21 & 260.95 \\
22 & 293.49 \\
23 & 322.35 \\
24 & 347.48
\end{tabular}

* Final value chosen 
discharge at Wallula Gap occurred four (six hour) time steps, or one day, after the maximum at Sentinel Gap. Again, this appears to be a reasonable number since the computed velocities would require about 20 hours for a parcel of water to pass through the Basin and friction and turbulence would further slow down the propagation of the wave form. Each value of $\mathrm{m}$ produces a different estimate of the volume of water that would be ponded in the Pasco Basin.

The final estimate for the volume of water that would be ponded is 178 cubic miles. The fit to the published values is not exact. This is for two reasons: (1) non-integer values of time step were not considered and (2) there is not complete agreement in the correct value to apply. Use of non-integer values would allow an exact fit. These were not used because it was felt that the uncertainty in the field data and the representation of the problem did not warrant such accuracy. Maximum discharge at Wallula Gap occurs one day after the maximum at Sentinel Gap. During that time water continues to accumulate in the Pasco Basin. Following the time of maximum discharge at wallula Gap, discharge only slowly declines. These discharges will be controlled by the elevation of Lake Lewis which in turn is fixed by the volume of water in that lake. Since water is still entering the Pasco Basin through Sentinel Gap, the lake drains only slowly. Rate of decrease of the lake level is controlled by the relative rates of inflow and outflow. Inflow at Sentinel Gap continues for another eight days before complete discharge of the Lake Missoula waters. The rate of discharge at Wallula Gap continues to decrease as the water level 
In the Pasco Basin declines. Thus, complete drainage of Lake Lewis occurs very slowly. It is 10 days after the maximum at Wallula Gap before discharges there return to their pre-flood levels. The entire flood lasts 11 days in the Pasco Basin. The level of the lake in the Pasco Basin exerts a strong control upon the rate of emptying of that lake. The level of that lake also fixes the time during which the 200 Areas remain Inundated and subject to erosion. Thus, it is of some interest to calculate the changing elevation of the lake during a flood. That calculation is possible since the relation between volume of water held in Lake Lewis and the elevation of the lake has previously been obtained (Craig, Singer and Underberg, 1983, Table 8, p. 93) and is illustrated in Figure 6.2. The relation has been added to the hydrograph synthesis program (Appendix B) and results for the canonical flood are reported in Figure.6.5. These values are assumed to represent the elevation of the lake in its center, approximately the location of Gable Mountain and the 200 Areas. This is correct if one assumes that the water surface elevation varies linearly with distance between the two gaps and that the shape of the basin is regular with respect to the center. Deviations from those assumptions are probably not sufficient to create significant errors of interpretation. More exact calculations are possible at minor expense in computations. Examination of Figure 6.5 shows that, under this scenario, the lake will remain at depths sufficient to inundate the 200 Areas for approximately 4.25 days. During this time, water depths above the 200 Areas will vary from $0 \mathrm{~m}$ to $150 \mathrm{~m}$. 


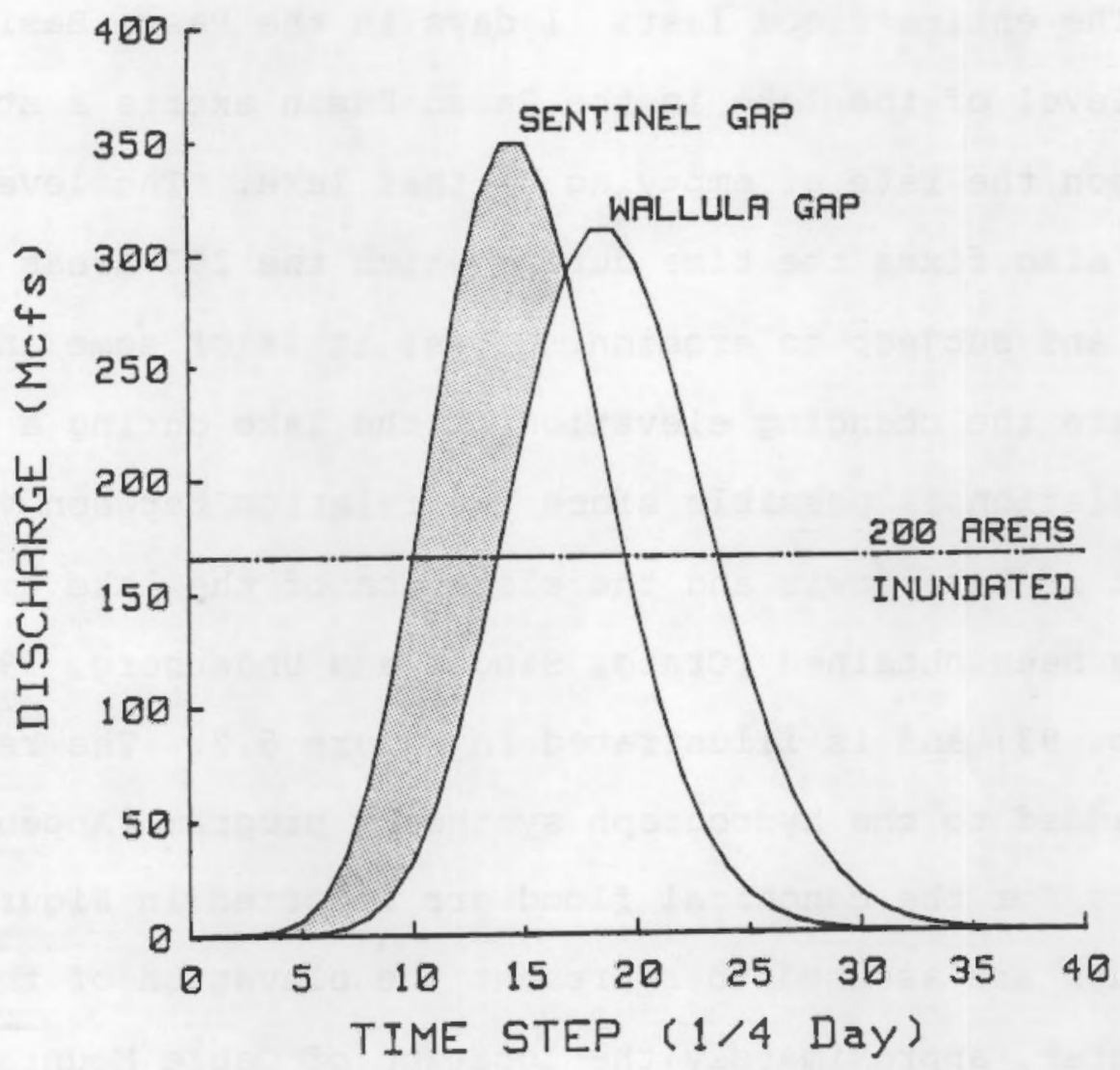

FIGURE 6.5. Final hydrograph pair chosen to represent the worst case flood scenario considered. The shaded area represents the volume of water that would be ponded in the Pasco Basin. 
DYNAMICS AT THE INLET AND OUTLET

The discharges computed allow estimates of the velocities of the water using the rating curve developed with the HEC-2 analyses. The rating curve developed for Sentinel Gap (Figure 4.9) has been added to the hydrograph computer code. Once the discharge at the gap has been computed, that value is used to interpolate the appropriate velocity at the gap. The interpolation routine is based on the assumption that the velocity varies linearly between the points at which it has actually been solved. Table 6.3 reports the final computed values of depth and velocity at both gaps for each time step during the flood.

The resulting velocity values can be applied in several ways. On the one hand, it can be used to estimate the erosion regime at the gap. Alternatively, the velocity can be used to establish boundary conditions for an unsteady flow model. Once that value has been established, it is possible to solve the dynamics of flows within the Pasco Basin using a relatively sophisticated model.

LIMITATIONS AND UNCERTAINTIES

Construction of a discharge hydrograph is possible if one assumes knowledge of the functional form of the discharge hydrograph so that only the parameters of that function need be estimated. The functional form employed is a very simple one chosen only because it is capable of producing desired distribution form over a reasonable domain of integer values and requires specification of only one parameter. There is no other justification for its use. Thus, it can be expected that more 
TABLE 6.3. Velocity and depth at Sentinel and Wallula Gaps for each (six hour) time step of a scabland flood in which flood waters are confined to the Columbia River valley.

\begin{tabular}{|c|c|c|c|c|c|c|c|c|c|}
\hline $\begin{array}{l}\text { TI IHE } \\
\text { STEF } \\
\text { (GIYC) }\end{array}$ & \multicolumn{3}{|c|}{$\begin{array}{l}\text { SENTINEL GAP } \\
\text { TOTAL }\end{array}$} & WALLU & $(m \in r \in)$ & $\begin{array}{l}\text { POHDI HG } \\
\text { (EU ai }\end{array}$ & $\begin{array}{c}\text { SUM } \\
\text { PONDIHG } \\
\text { s }\end{array}$ & $\begin{array}{l}\text { LAKE } \\
\text { ELEY } \\
(r 2)\end{array}$ & $\begin{array}{l}\text { SENT. } \\
\text { GHP } \\
\text { VEL. } \\
\text { (FL/S) }\end{array}$ \\
\hline 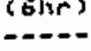 & $1 \%$ & $x^{\prime}$ & $6 m 6120$ & & & - & ---1 & & $=---=$ \\
\hline 1 & .00000 & $: 00$ & .02 & - gase & .06 & .00 & .00 & 328 & 1.96 \\
\hline 2 & .08503 & .01 & .12 & . 6060 & .00 & - 42 & 42 & $\begin{array}{l}325 \\
375\end{array}$ & $\begin{array}{l}1.07 \\
1.55\end{array}$ \\
\hline $\begin{array}{l}3 \\
4\end{array}$ & Oดी!? & .00 & .59 & . 0003 & .92 & $\begin{array}{l}.08 \\
.31\end{array}$ & $\begin{array}{r}10 \\
.41\end{array}$ & 933 & $\begin{array}{l}1.55 \\
3.26\end{array}$ \\
\hline 4 & $\begin{array}{r}.00085 \\
.019194\end{array}$ & $\begin{array}{r}.01 \\
.016\end{array}$ & $\begin{array}{l}2.20 \\
6.60\end{array}$ & .0000 & .18 & .91 & 1.32 & 344 & 7.70 \\
\hline 5 & c004st & 01 & 16.49 & . 0004 & 1.25 & 2.24 & 3.56 & 372 & 17.82 \\
\hline 7 & .01037 & .02 & 35.34 & .0910 & 3.39 & 4.69 & 8.24 & 430 & 37.11 \\
\hline 8 & .01944 & .04 & 66.25 & .0024 & $\begin{array}{r}8.94 \\
.98\end{array}$ & 0.54 & 16.79 & 935 & 47.76 \\
\hline 9 & .53241 & .07 & 110.42 & - 965日 & 16.98 & 13.71 & 30.50 & $* ?$ & 50.87 \\
\hline 10 & $6+8=1$ & .12 & 105.53 & .0075 & 32.25 & 19.57 & $50.0 ?$ & $7 E 3$ & 64,81 \\
\hline $\begin{array}{l}11 \\
12\end{array}$ & .46529 & $\begin{array}{r}18 \\
27\end{array}$ & 225,86 & $\begin{array}{l}.0164 \\
.0254\end{array}$ & $\begin{array}{l}55.71 \\
88.21\end{array}$ & $\begin{array}{l}24.97 \\
29.49\end{array}$ & 29.04 & $\begin{array}{l}946 \\
935\end{array}$ & $\begin{array}{l}72.95 \\
77.89\end{array}$ \\
\hline $\begin{array}{l}12 \\
13\end{array}$ & $\begin{array}{l}08580 \\
.03501\end{array}$ & $\begin{array}{l}.27 \\
.35\end{array}$ & $\begin{array}{l}252.33 \\
325.77\end{array}$ & .0373 & $\begin{array}{r}83.21 \\
126.93\end{array}$ & $\begin{array}{l}28.49 \\
28.68\end{array}$ & $\begin{array}{l}103.52 \\
132.41\end{array}$ & 951 & $\begin{array}{l}77.89 \\
89.53\end{array}$ \\
\hline 14 & .10244 & +47 & 349.04 & .61514 & 174.47 & 25.54 & 157.55 & 1045 & 02,16 \\
\hline 15 & .10244 & .37 & 349.94 & .0650 & 221.63 & 13.73 & 176.65 & 1084 & 82.15 \\
\hline $\begin{array}{l}18 \\
17\end{array}$ & . 190603 & $\begin{array}{r}.56 \\
.75\end{array}$ & $\begin{array}{l}327.22 \\
288.72\end{array}$ & $\begin{array}{l}.0772 \\
.8863\end{array}$ & $\begin{array}{l}263.13 \\
294.15\end{array}$ & $\begin{array}{l}9.40 \\
-.80\end{array}$ & $\begin{array}{l}185.04 \\
135.25\end{array}$ & $\begin{array}{l}1693 \\
1693\end{array}$ & $\begin{array}{l}51.81 \\
78.36\end{array}$ \\
\hline 18 & . 07061 & .82 & $\begin{array}{l}238.12 \\
240.64\end{array}$ & .3911 & 310.49 & $\begin{array}{r}-.050 \\
-13.26\end{array}$ & 174.99 & 1081 & 78.20 \\
\hline 19 & .05575 & .88 & 109.85 & .8911 & 310,48 & -17.69 & 157.31 & 1044 & 68.05 \\
\hline 20 & .04331 & $\begin{array}{r}.92 \\
05\end{array}$ & 142,45 & $\begin{array}{r}.0866 \\
0783\end{array}$ & $\begin{array}{l}294.96 \\
266.97\end{array}$ & $\begin{array}{l}-22.38 \\
-24.23\end{array}$ & $\begin{array}{l}134.93 \\
119.70\end{array}$ & $\begin{array}{l}984 \\
949\end{array}$ & \\
\hline $\begin{array}{l}21 \\
22\end{array}$ & $\begin{array}{l}.82906 \\
.02036\end{array}$ & $\begin{array}{l}.95 \\
.97\end{array}$ & $\begin{array}{r}101.76 \\
69.30\end{array}$ & .0793 & $\begin{array}{l}266.07 \\
230.96\end{array}$ & $\begin{array}{l}-24.23 \\
-23.64\end{array}$ & $\begin{array}{r}119.76 \\
37.86\end{array}$ & $\begin{array}{l}949 \\
393\end{array}$ & $\begin{array}{l}35.37 \\
48.77\end{array}$ \\
\hline 23 & .01328 & .98 & 45.25 & .0559 & $\begin{array}{l}190.49 \\
150.73\end{array}$ & $-21,30$ & 65.76 & 826 & 40.50 \\
\hline 24 & .00830 & +.99 & 28.23 & $\begin{array}{l}.13442 \\
.0335\end{array}$ & $\begin{array}{l}150.73 \\
114.56\end{array}$ & $\begin{array}{l}-17.97 \\
-14.32\end{array}$ & $\begin{array}{l}47.79 \\
33.47\end{array}$ & $\begin{array}{l}754 \\
695\end{array}$ & 29.90 \\
\hline $\begin{array}{l}25 \\
26\end{array}$ & .00478 & $\begin{array}{r}99 \\
.99\end{array}$ & $\begin{array}{r}15.97 \\
9.79\end{array}$ & $\begin{array}{l}.0335 \\
.62+6\end{array}$ & $\begin{array}{r}114.56 \\
83.71\end{array}$ & $\begin{array}{l}-14.32 \\
-10.85\end{array}$ & $\begin{array}{l}33.47 \\
22.62\end{array}$ & $\begin{array}{l}693 \\
647\end{array}$ & $\begin{array}{l}10.32 \\
10.77\end{array}$ \\
\hline $\begin{array}{l}26 \\
27\end{array}$ & , 빌ㄴ? & 1.00 & $\begin{array}{l}9.73 \\
5.44\end{array}$ & $\begin{array}{l}.62+6 \\
.0173\end{array}$ & $\begin{array}{l}83.71 \\
58.91\end{array}$ & $\begin{array}{r}-10.85 \\
-7.35\end{array}$ & $\begin{array}{l}32.62 \\
14.76\end{array}$ & $\begin{array}{l}0+16 \\
010\end{array}$ & $\begin{array}{r}10.57 \\
6.52\end{array}$ \\
\hline $\begin{array}{l}27 \\
28\end{array}$ & $\begin{array}{r}00100 \\
900 z 5\end{array}$ & $\begin{array}{l}1.00 \\
1.00\end{array}$ & $\begin{array}{l}5.44 \\
2.91\end{array}$ & . & $\begin{array}{r}38.91 \\
39.97\end{array}$ & $\begin{array}{l}-7.35 \\
-5.44\end{array}$ & $\begin{array}{r}14.16 \\
9.34\end{array}$ & $4+3$ & $\begin{array}{l}6.32 \\
3.93\end{array}$ \\
\hline 28 & $\begin{array}{r}90035 \\
.909+4\end{array}$ & 1.90 & 2.71 & .0077 & 26.19 & -3.62 & 5.72 & 399 & 2.49 \\
\hline 30 & .00022 & 1. $0 \mathrm{E}$ & .75 & .0047 & 16.59 & -2.32 & 3.39 & 370 & 1.72 \\
\hline $\begin{array}{l}3 ! \\
32\end{array}$ & .00111 & $1.9 B$ & .36 & . 6030 & 10. 17 & -1.44 & 1.95 & 352 & 1.32 \\
\hline $\begin{array}{l}32 \\
33\end{array}$ & . 6ubs: & 1.00 & .17 & $\begin{array}{r}\text {. } 3013 \\
\text { 9018 }\end{array}$ & $\begin{array}{l}6.04 \\
3.48\end{array}$ & -.86 & $\begin{array}{r}1.09 \\
.99\end{array}$ & $\begin{array}{r}343 \\
-4\end{array}$ & 1.12 \\
\hline $\begin{array}{l}33 \\
3+1\end{array}$ & .08602 & 1.90 & .08 & $\begin{array}{r}.0010 \\
0006\end{array}$ & $\begin{array}{l}3.48 \\
1.94\end{array}$ & $=.50$ & .59 & 35 & 1.03 \\
\hline $\begin{array}{l}31 \\
35\end{array}$ & . ดิ日0) & 1. & . a3 & .0306 & 1. 94 & -.28 & .31 & 334 & 1.00 \\
\hline $\begin{array}{l}35 \\
36\end{array}$ & . 40000 & 1.06 & .01 & .0003 & 1.05 & -.15 & .16 & 33 & 1.56 \\
\hline $\begin{array}{l}36 \\
37\end{array}$ & .001000 & 1.90 & .01 & .0002 & 150 & - . & .85 & 327 & 1 1 \\
\hline $\begin{array}{l}37 \\
39\end{array}$ & . 以0勺日月 & 1.06 & . $\mathrm{AB}$ & .0001 & .29 & -.04 &.$\dot{0} 4$ & 323 & 5.06 \\
\hline $\begin{array}{l}30 \\
39\end{array}$ & .30000 & 1.00 & .06 & 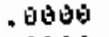 & .14 & -.02 & .02 & 328 & 1.00 \\
\hline $\begin{array}{l}39 \\
+6\end{array}$ & 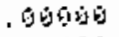 & 1.09 & .90 & .61313 & .87 & -.01 & .01 & 328 & 1,00 \\
\hline$+\overline{0}$ & . Bด600 & 1. 64 & .90 & . G501 & .03 & -.00 & . & 328 & $1.0 \overline{0}$ \\
\hline
\end{tabular}


powerful functions could be specified.

Use of the Poisson function requires an independent estimate of the maximum discharge at sentinel Gap. That value is only known in a gross approximation. It has been computed under the assumption that flows are completely confined to the Columbia River and that these floods were responsible for the high water marks that are observed at the Frenchman Hills. Since there is little data constraining the nature of such floods, the estimates of maximum discharge are crude at best.

Use of this procedure also requires independent specification of the total discharge through Sentinel Gap. We nave used Pardee's estimate of the volume of Lake Missoula as the volume that would pass through Sentinel Gap and the Pasco Basin. This value is only approximately known. It is also far from clear that a flood confined entirely to the Columbia River valley would have this volume. The uncertainty in this number must be at least $25 \%$. The value specified impacts the entire calculation. The value of total discharge affects the estimate of the hydrographs at both gaps. Thus, it is an important parameter.

As indicated, only integer values of the parameter of the Poisson function were considered. This sets a limit on the accuracy of the calculations. This accuracy could be improved through the use of shorter time steps in the calculations. For this analysis the time step length was set at six hours. This was chosen so that the resulting calculations would be directly applicable to the needs of the HEC- 6 runs to be reported below. It would be of interest to consider the use of shorter time steps. 
EROSION POTENTIAL FOR A MAJOR FLOOD

\section{EQUILIBRIUM SEDIMENT TRANSPORT}

Introduced earlier (Chapter 5) was the idea of equilibrium sediment transport. We will now alter this concept for these analyses. The new idea behind this concept is that the amount entering the Pasco Basin through Sentinel Gap equals the amount leaving the system. We are treating this as if it were a "black box" and input to the "black box" equals the output, no matter what has taken place within the environment of the "black box". With the HEC-6 model, we are able to monitor the inflowing load to the Pasco Basin and compare that value to the amount exiting the system during a flood event. For these analyses, the hydrograph computed for Wallula Gap in chapter 6 is used.

Requiring the inflow to equal the outflow we adjust the maximum value for sediment load of the inflowing sediment load rating rable to arrive at the equilibrium conditions. We iterate through inflowing sediment loads to converge upon equilibrium conditions. This procedure is be repeated for each sediment transport function used for the entire flood hydrograph. Results of iterations for all transport functions are presented below (Table 7.1$)$

\section{SELECTION OF THE TRANSPORT EQUATION}

Three of the four transport equations available to us through the HEC- 6 program are based on the total sediment load of a river. As mentioned earlier, Shen (1982) believes that the total sediment load equations are not applicable to high transport rates because these rates may produce extensive scour of the bed material; the equations will not be able to represent 
TABLE 7.1. Convergence procedure used to obtain inflowing sediment load for each transport function in the HEC-6 analyses.

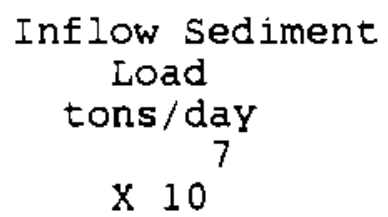

Toffaleti
3.59
0.12
HIGH
HIGH
51.5
1.8
$\star 4.2$
1.8

Du Boy's Method

$\begin{array}{rrrr}18.2 & \text { LOW } & 2160.0 & 38400.0 \\ 1820.0 & \text { LOW } & 158000.0 & 38400.0 \\ 6820.0 & \text { HIGH } & 555000.0 & 38400.0 \\ 3820.0 & \text { LOW } & 319000.0 & 38400.0 \\ 4820.0 & \text { HIGH } & 399000.0 & 38400.0 \\ 4600.0 & \text { LOW } & 381000.0 & 38400.0 \\ 4680.0 & \text { HIGH } & 388000.0 & 38400.0 \\ 4640.0 & \text { EQUAL } & 384000.0 & 38400.0\end{array}$

Madden's Modification of Laursen's Relationship

$\begin{array}{rrrr}4640.0 & \text { HIGH } & 38400.0 & 51.5 \\ 40.0 & \text { HIGH } & 442.0 & 51.5 \\ 4.0 & \text { HIGH } & 56.6 & 51.5 \\ 3.5 & \text { LOW } & 50.5 & 51.5 \\ 3.6 & \text { HIGH } & 51.7 & 51.5 \\ 3.55 & \text { LOW } & 51.1 & 51.5 \\ 3.575 & \text { LOW } & 51.4 & 51.5 \\ 3.585 & \text { EQUAL } & 51.5 & 51.5\end{array}$

Yang's Streampower Method
1820.0
18.2
HIGH
15800.0
216.0
216.0
216.0

* could not use a lower sediment load to converge on on equilibrium condition. A lower value would have been less than the sediment load in the Amazon used as the intermediate estimate in the $Q$ vs. Qs rating curve for inflowing sediment. 
such scour due to the assumptions inherent to their formulation. For example, results from implementing Toffaleti's method show that relatively little scour or deposition occurs within the Pasco Basin. Table 7.1 , is constructed of iterations for the sediment inflowing rating curve. To obtain equilibrium conditions, the amount of sediment transported into the basin would be less than the amount of sediment currently transported within the Amazon River. Since the velocities within the constriction at sentinel Gap reach $25 \mathrm{~m} / \mathrm{sec}$ and presumably would move large volumes of material, we believe that this method is not useful in determining the sediment transport capabilities of chis flood.

Inherent to Toffaleti's method is a maximum thickness of the channel bed. The bed material is assumed to consist of a single layer only two grain-sizes in thickness. This assumpeion produces the minute amounts of erosion and the large quantity of deposition at the entrance to the Pasco Basin at Sentinel Gap.

Shen (1982) suggests the use of Du Boy's method for high transport rates since this method utilizes a simple linear function relating velocities to bed layer to move multiple multiple of material. He also states that to obtain reasonable results with this method, the linear relationship should be modified. Using this function for the Missoula flood discharges, results were unrealistic. Through the beginning stages of the flood, massive erosion was evident. As the flood stage and discharge increased, a mound of sediment was deposited in the upstream portion of the channel. As flooding progressed to larger discharges, this mound grew and moved in the downstream 
direction, eventually rising to over $2133 \mathrm{~m} \mathrm{(7000} \mathrm{ft}$ ) above the water surface elevation. It could be described as a wave (mountain) of sediment moving through the system. A possible explanation for this occurrence is that as scouring took place within the upstream portion of the channel, (scour to $37 \mathrm{~m}$ or 121 ft), the channel hydraulics were changing drastically. Velocities that were $25 \mathrm{~m} / \mathrm{sec}(80 \mathrm{ft} / \mathrm{sec})$ drop to between 4.8 and $6.1 \mathrm{~m} / \mathrm{sec}(16$ and $20 \mathrm{ft} / \mathrm{sec})$.

The hydrograph developed for the Missoula flood was based on the assumption that for every steady state discharge, enough time had elapsed to allow the water to move through the system. The time factor used in the HEC-6 analysis was based upon velocities from HEC-2 analyses, which include, of course, a non-movable bed. Since the velocities have decreased by such great amounts, the flow for each discharge does not make it entirely through the system. The sediment is evidently dumped where it is when time nas elapsed. As discharges are increased, the velocities in the channel increase, moving the "wave" of sediment further downstream, constantly being eroded and redeposited until it has exited the system.

Two other total load sediment transport equations; Madden's Modification of Laursen's Relationship and Yang's Streampower Method produce consistent results. The rate at which sediment enters the Pasco Basin (using the iterative procedure in Yang's analysis, Table 7.1) corresponds to a range of values estimated determining a rate of inflow to the Pasco Basin based on equilibrium flow conditions ( 14 day period) and sediment volume 
(Table 6.1). These values for inflowing sediment load are presented in Table 7.2 for both methodologies. Therefore, Yang's transport equation may be the most reasonable procedure to determine the sediment transport of a Missoula-type flow but results using either transport equation (Madden's and Yang's) seem reasonable for the region of the Pasco Basin.

Since the results using Toffaleti's and Du Boy's methods are considered unrealistic, the results using Madden's and Yang's relationship are emphasized. Madden's method allows up to 0.061 $m$ of erosion over the the site; Yang's allows for $0.915 \mathrm{~m}$ of erosion. In both cases the amount of erosion is minimal directly over the site. Further upstream (cross-sections 34-25) erosion is much more extensive; up to the full $37 \mathrm{~m}$ allowed for erosion in this analysis occurred (refer to Figure 4.7 ). 
TABLE 7.2. Estimated sediment transport rates for various assumed sediment volumes for a fixed discharge in the Pasco Basin (a) and equilibrium sediment transport rates (b) computed with four sediment transport functions (Table $7.1)$ and the hydrograph of chapter 6 .

(a) Constant Discharge Method -- 14 day duration (see chpt. 5)

\section{Elevation}

Planimetered

in the

Pasco Basin

(m) (ft)

$350 \quad 1150$

$229 \quad 750$

$213 \quad 700$

$198 \quad 650$

$183 \quad 600$

$168 \quad 550$

152

\section{Volume \\ of Sediment}

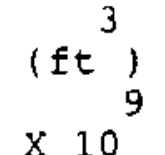

$\times 10$

103.6

43.1

41.4

30.6

29.2

21.2

19.3
Rate of Inflow

tons / day

$\times 10$

61.0

25.0

24.0

* 18.0

17.0

13.0

11.0

(b) Hydrograph Method - 10 day duration (this chapt.)

$\begin{array}{lc}\begin{array}{l}\text { Transport } \\ \text { Function }\end{array} & \begin{array}{r}\text { Rate of Inf } \\ \text { tons/day } \\ \end{array} \\ & \times 10^{7} \\ \text { Toffaleti } & <.12 \\ \text { Du Boy } & 4640.0 \\ \text { Madden } & 3.585 \\ \text { Yang } & 18.2\end{array}$

* Most similar computed values. 
TABLE 7.3. Maximum erosion at each cross-section for the Sentinel Gap data set using the computed wallula Gap hydrograph from Table 6.3.

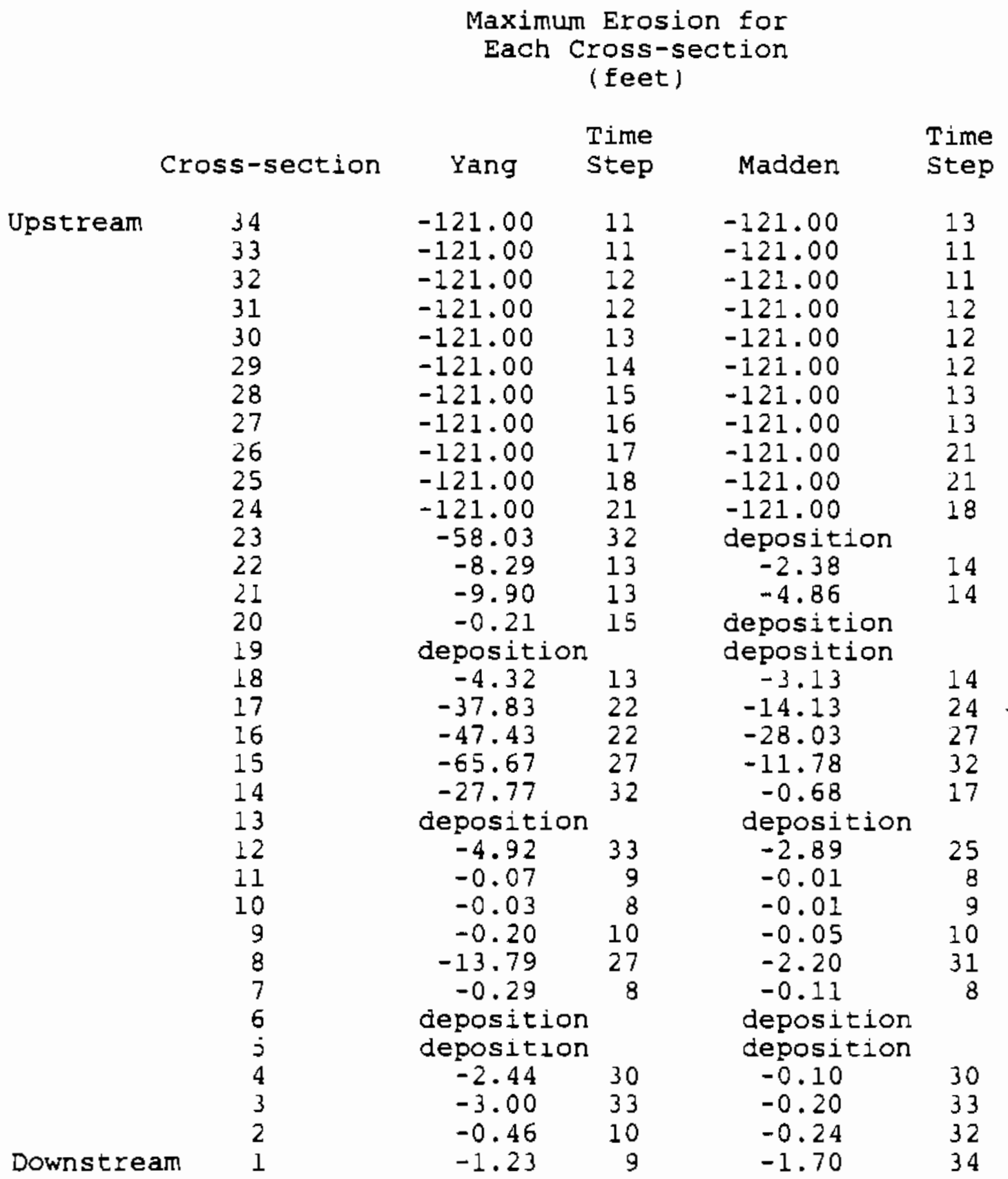




\section{REPRESENTING THE DYNAMICS OF A MAJOR FLOOD}

\section{THE GOVERNING EOUATIONS}

The previous chapters have described the solutions of the flood characteristics that can be obtained under the assumption that flow is one-dimensional and either steady or nearly so. We nave thus obtained first order estimates of sediment transport during such floods. Unfortunately, neither of these assumptions, (one-dimensional flow or steady flow) are very reasonable in the case of the Scablands floods. Some of the difficulties with these assumptions are discussed in section three. A more reasonable assumption is that the flows are two-dimensional and that they are unsteady. Unlike the case of one-dimensional, steady flows, a standard computer code for the solutions of unsteady, two-dimensional flow problems is not available. Such a computer code has been developed in this project and is described next. We begin with a review of the appropriate equations and show how they appear when phrased in two-dimensional, unsteady form. From this, the solution procedure is derived and the coding philosophy is given. The computer code itself is given in Appendix C.

There are two fundamental equations that must be considered. The first describes the conservation of mass, the second the conservation of momentum. For the purposes of this study, it is assumed that the process is isothermal. Thus, we do not consider problems related to the equation of state (the laws of thermodynamics). The conservation of momentum must be expressed for each of three dimensions; thus, three equations are required. First we show how the three-dimensional form of the continuity 
equation can be simplified to two-dimensional form. Following this, we show how the three equations of conservation of momentum can be reduced to two equations and simplified to two-dimensional form.

VERTICAL INTEGRATION OF THE CONTINUITY EQUATION

The continuity equation given below represents the conservation of mass in three dimensions when there is constant density (an incompressible fluid). Even the very high velocities of the Missoula floods are not sufficient to produce significant density changes in water. Thus, the assumption of incompressibility appears to be satisfactory. The equation is then:

$$
\frac{\delta u}{\partial x}+\frac{\delta v}{\delta y}+\frac{\delta w}{\delta z}=0
$$

Because we are interested only in the horizontal components of flow during these floods we will simplify the equations to avoid consideration of motions parallel to the vertical axis. Equation (1) is integrated from the bottom of the flow $(z=-d)$ to the free surface $(z=n)$. It is assumed that $u$ and $v$ are functions of $x, y$ and $t$ only. This yields:

$$
\int_{-d}^{n} \frac{\delta u}{\delta x}+\frac{\delta v}{\delta y}+\frac{\delta w}{\delta z} d z=0
$$

Considering each term separately, we have

$$
\int_{-d}^{n} \frac{\delta u}{\delta x} d z=(n+d) \frac{\delta u}{\delta x}
$$




$$
\int_{-d}^{n} \delta y=d z=(n+d) \frac{\delta v}{--}
$$

$$
\int_{-d}^{n} \delta w d z=w:{ }^{n} \delta
$$

Substituting (3), (4) and (5) into (2) yields:

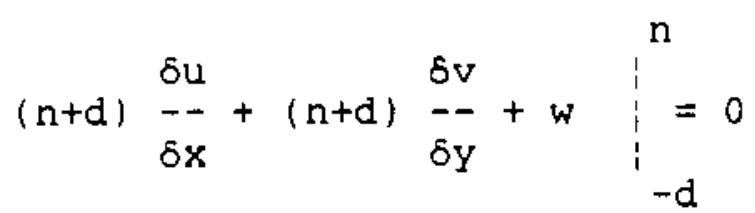

Solving the last term we get

$$
\left.w\right|_{-d} ^{n}=w(n)-w(-d)
$$

and

$$
\begin{aligned}
& w(n)=\frac{d n}{d t}=\frac{\delta n}{\delta t}+u \frac{\delta n}{\delta x}+v \frac{\delta n}{\delta y} \\
& w(-d)=\frac{d(-d)}{d t}=\frac{\delta(-d)}{\delta t}+u \frac{\delta(-d)}{\delta x}+v \frac{\delta(-d)}{----}
\end{aligned}
$$

It is assumed that the channel bottom remains fixed through time and so is a function of $x$ and $y$ only. Therefore,

$$
\frac{\delta(-d)}{b t}=0
$$

and

$$
w(-d)=u \frac{\delta(-d)}{\delta x}+v \frac{\delta(-d)}{\delta y}
$$


Substituting (10) and (8) into (6) gives:

$$
\begin{aligned}
(\mathrm{n}+\mathrm{d}) \frac{\delta \mathrm{u}}{\delta \mathrm{x}}+(\mathrm{n}+\mathrm{d}) \frac{\delta \mathrm{v}}{\delta \mathrm{y}}+\left[\frac{\delta \mathrm{n}}{\delta \mathrm{t}}+\mathrm{u} \frac{\delta \mathrm{n}}{\delta \mathrm{x}}+\mathrm{v} \frac{\delta \mathrm{n}}{\delta \mathrm{y}}-\right. \\
\left.\mathrm{u} \frac{\delta(-\mathrm{d})}{\delta \mathrm{x}}-\mathrm{v} \frac{\delta(-\mathrm{d})}{\delta \mathrm{y}}\right]=0
\end{aligned}
$$

Gathering similar terms yields:

$$
\begin{gathered}
(n+d) \frac{\delta u}{\delta x}+(n+d) \frac{\delta v}{\delta y}+\frac{\delta n}{\delta t}+u \frac{\delta}{\delta x}(n+d)+ \\
v \frac{\delta}{\delta y}(n+d)=0
\end{gathered}
$$

We can use the relationships:

$$
(n+d) \frac{\delta u}{\delta x}+u \frac{\delta}{\delta x}(n+d)=\frac{\delta}{\delta x}[u(n+d)]
$$

and

$$
(n+d) \frac{\delta v}{\delta y}+v \frac{\delta}{\delta y}(n+d)=\frac{\delta}{\delta y}[v(n+d)]
$$

Substituting (13) and (14) into (12) yields:

$$
\frac{\delta n}{\delta t}+\frac{\delta}{\delta x}[u(n+d)]+\frac{\delta}{\delta y}[v(n+d)]=0
$$

Letting $\mathrm{n}+\mathrm{d}=\mathrm{h}=$ depth of flow

$$
\frac{\delta(d)}{\delta t}=0
$$

therefore.

$$
\frac{\delta h}{\delta t}+\frac{\delta}{\delta x}(h u)+\frac{\delta}{\delta y}(h v)=0
$$


VERTICAL INTEGRATION OF THE THREE-DIMENSIONAL MOMENTUM EQUATION

\section{WITH FRICTION}

In the same way we will simplify the momentum equations to avoid the necessicy of considering flow momentum paraliel to the vertical axis. We begin with the three-dimensional momentum equation in the $u$ (or $X$ ) axis with a term, $f$, to represent friction:

$$
p\left(\frac{\delta u}{\delta t}+u \frac{\delta u}{\delta x}+v \frac{\delta u}{\delta y}+w \frac{\delta u}{\delta z}\right)=\frac{-\delta p^{\star}}{\delta x}-f
$$

Based on the properties of differentials, we can write:

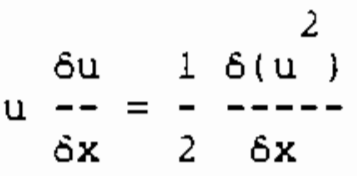

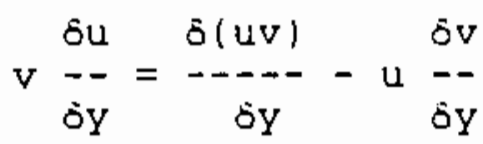

$$
\begin{aligned}
& w \frac{\delta u}{\delta z}=\frac{\delta(u w)}{\delta z}-u \frac{\delta w}{\delta z}
\end{aligned}
$$

Substituting (2), (3) and (4) into (1) yields:

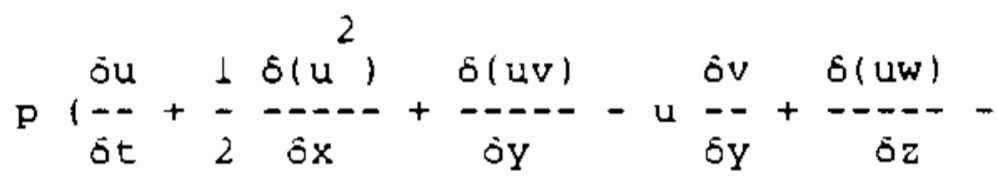

$$
\begin{aligned}
& u \frac{\delta w}{\delta z}=-\frac{\delta p^{*}}{\delta x}-\mathrm{f}
\end{aligned}
$$

By assuming the fluid to be incompressible, we can write:

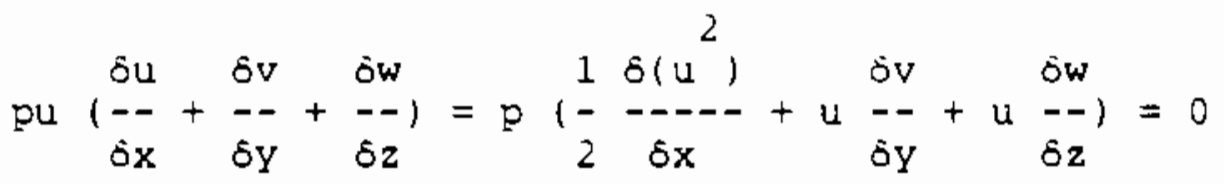

Adding (6) to (5) does not change the equality and gives: 


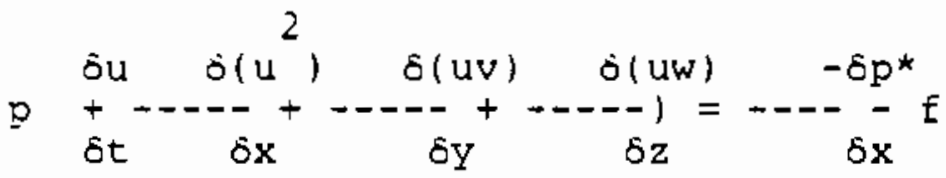

It is assumed that pressure along the z-axis is hydrostatic; therefore,

$$
\mathrm{p}^{\star}=\mathrm{pgh}
$$

where $h$ is the depth of flow. Substituting (8) into (7) gives:

$p\left(\frac{\delta u}{\delta t}+\frac{\delta\left(u^{2}\right)}{\delta x}+\frac{\delta(u v)}{\delta y}+\frac{\delta(u w)}{\delta z}=-p g \frac{\delta h}{\delta x}-1\right.$

Dividing by p gives:

$$
\frac{\delta u}{\delta t}+\frac{\delta\left(u^{2}\right)}{\delta x}+\frac{\delta(u v)}{\delta y}+\frac{\delta(u w)}{\delta z}=-g \frac{\delta h}{\delta x}-\frac{f}{p}
$$

Now we integrate both sides of the equation from the base of the flow, $z=0$, to the top of the flow, $z=h$ :

$$
\begin{aligned}
& \int_{0}^{n} \frac{\delta u}{\delta t}+\frac{\delta\left(u^{2}\right)}{\delta x}+\frac{\delta(u v)}{\delta y}+\frac{\delta(u w)}{\delta z} d z= \\
& =\int_{j}^{n}-g \frac{\delta h}{\delta x} d z-\int_{0}^{n} \frac{f}{p} d z
\end{aligned}
$$

It is assumed that $u$ and $v$ are functions of $x, y$, and $\tau$ only. Therefore,

$$
\int_{0}^{n} \frac{\delta u}{\delta t} \quad \frac{\delta\left(u^{2}\right)}{\delta x}+\frac{\delta(u v)}{\delta y}+\frac{\delta(u w)}{\delta z} d z=
$$




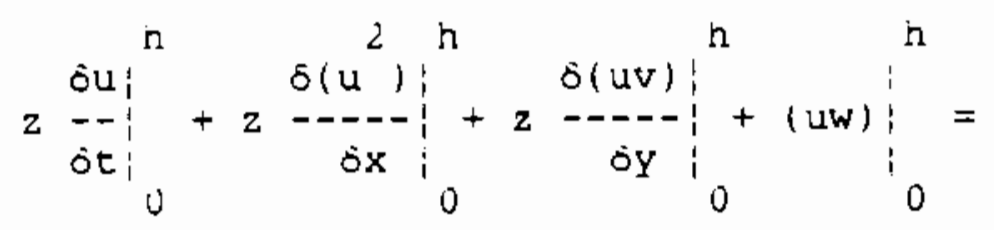

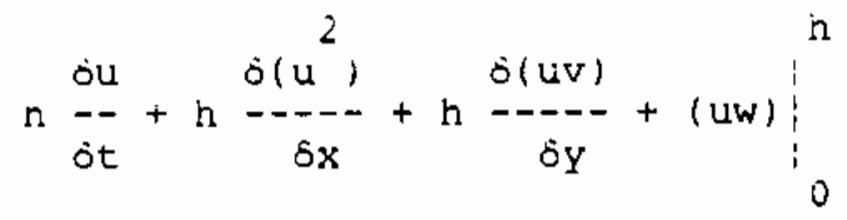

Evaluating the last term, we have

$$
(u w): \begin{gathered}
n \\
\vdots \\
0
\end{gathered}=u \cdot w=u \cdot(w(h)-w(0))
$$

By the definition of velocity, and implementation of the chain rule,

$$
\begin{aligned}
& w(h)=\frac{d h}{d t}=\frac{\delta h}{\delta t}+u \frac{\delta h}{\delta x}+v \frac{\delta h}{\delta y} \\
& w(0)=\frac{d(0)}{d t}=0
\end{aligned}
$$

Hence, the integral in (12) is equal to

$$
h \frac{\delta u}{\delta t}+h \frac{\delta\left(u^{2}\right)}{\delta x}+h \frac{\delta(u v)}{\delta y}+u \frac{\delta h}{\delta t}+u \frac{2 h}{\delta x}+u v \frac{\delta h}{\delta y}
$$

Now $\delta$ h/6t can be replaced by the two-dimensional Ivertically Integrated) continuity equation:

$$
\begin{aligned}
& \begin{array}{cc}
\delta \mathrm{h} \\
\overline{\delta t}
\end{array}=-\frac{\delta(\mathrm{uh})}{\delta \mathrm{x}} \quad \frac{\delta(\mathrm{vh})}{\delta \mathrm{y}} \\
& =-\mathrm{u} \frac{\delta \mathrm{h}}{-\mathrm{\delta}}-\mathrm{h} \frac{\delta \mathrm{u}}{\delta \mathrm{x}}-\mathrm{v} \frac{\delta \mathrm{h}}{\delta \mathrm{y}}-\mathrm{h} \frac{\delta \mathrm{v}}{--}
\end{aligned}
$$


Substituting (17) into (16) gives:

$$
\begin{aligned}
& n \frac{\delta u}{\delta t}+2 h u \frac{\delta u}{\delta x}+h \frac{\delta(u v)}{\delta y}-u \frac{\partial h}{\delta x}-u \frac{\delta u}{\delta x} \\
& -u v \frac{\delta h}{\delta y}-h u \frac{\delta v}{\delta y}+u \frac{2 h}{\delta x}+u v \frac{\delta h}{\delta y}
\end{aligned}
$$

which can be simplified to

$$
h \frac{\delta u}{\delta t}+h u \frac{\delta u}{\delta x}+h \frac{\delta(u v)}{\delta y}-h u \frac{\delta v}{\delta y}
$$

from (3) we have

$$
\frac{\partial(u v)}{\delta y}-u \frac{\delta v}{\delta y}=v \frac{\delta u}{\delta y}
$$

Substituting (20) into (19) gives:

$$
n \frac{\delta u}{\delta t}+h u \frac{\delta u}{\delta x}+h v \frac{\partial u}{\delta y}
$$

Evaluating the integrais on the right-hand side of (11):

$$
\int_{0}^{h}\left[-g \frac{\delta h}{\delta x} d z\right]-\int_{0}^{n} \frac{f}{p} d z=-g h \frac{\delta h}{\delta x}-\frac{h f}{p}
$$

Equating (22) and (21) gives the vertically integrated twodimensional momentum equation for the $x$-direction:

$$
\mathrm{h} \frac{\delta u}{\delta t}+h u \frac{\delta u}{\delta x}+h v \frac{\delta u}{\delta y}=-g h \frac{\delta h}{\delta x}-\frac{h f}{p}
$$

Dividing by $h$, we obtain:

$$
\frac{\delta u}{--}+u \frac{\delta u}{\delta t}+v \frac{\delta u}{\delta x}=-g \frac{\delta h}{\delta x}-\frac{f}{p}
$$


Likewise, for the $\mathrm{y}$-direction:

$$
\begin{aligned}
& \frac{\delta v}{\delta t}+u \frac{\delta v}{\delta x}+v \frac{\delta v}{\delta y}=-g \frac{\delta h}{\delta y}-\frac{f}{-\frac{f}{\partial y}} \\
& \text { If } f=\frac{p v\left(u^{2}+v^{2}\right)^{1 / 2} m^{2} g}{R^{4 / 3}}
\end{aligned}
$$

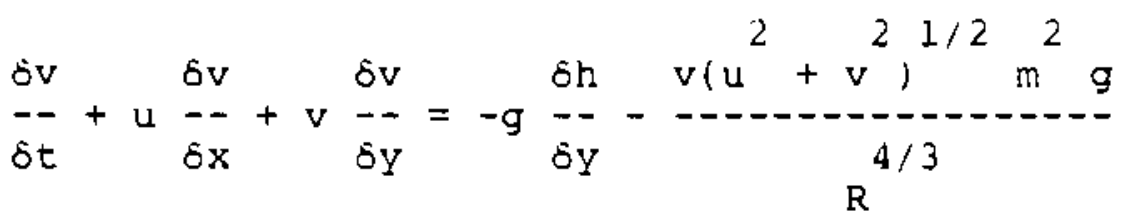

where:

$$
\begin{aligned}
& m=\text { Manning's Roughness coefficient } \\
& \mathrm{R}=\text { hydraulic radius }
\end{aligned}
$$

and, similarly:

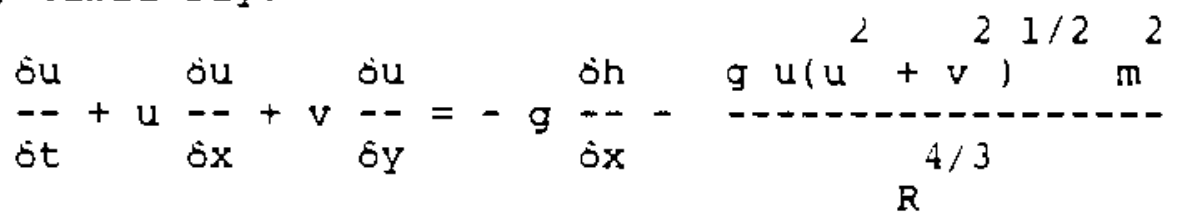

\section{THE DEPTH-AVERAGED EQUATIONS}

Rather than assume that the flow in the $X-Y$ (or horizontal) dimension is constant at all levels of the $z$ (or vertical) axis, we prefer to avoid that assumption and consider the mean behavior of flows in the $X-Y$ plane. The form of the appropriate equations is very similar to those derived above; however, it now includes terms describing the effective shear stresses introduced by differential $X-Y$ motions in the various 2 planes. Conservation of mass:

$$
\frac{\delta \mathrm{h}}{\delta \mathrm{t}}+\frac{\delta(\mathrm{h} \overline{\mathrm{u}})}{\delta \mathrm{x}}+\frac{\delta(h \bar{v})}{\delta \mathrm{y}}=0
$$




$$
\begin{aligned}
& \text { Conservation of momentum: } \\
& \mathrm{x} \text {-momentum: }
\end{aligned}
$$

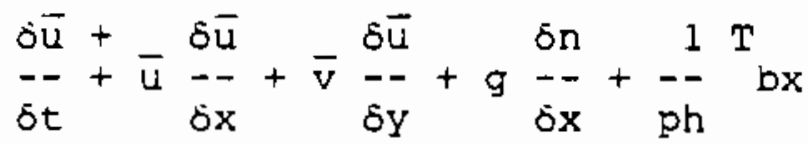

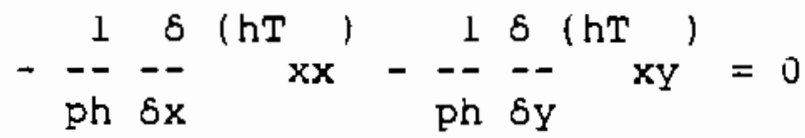

$$
\begin{aligned}
& y \text {-momentum: }
\end{aligned}
$$

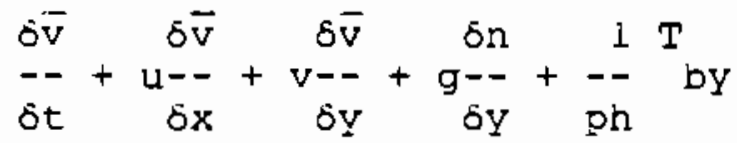

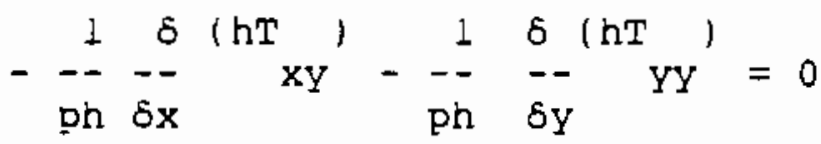

where:

$$
\begin{aligned}
\overrightarrow{\mathrm{u}}, \overrightarrow{\mathrm{v}} & =\text { depth-averaged velocities } \\
\tau & =\text { time } \\
\mathrm{x}, \mathrm{y} & =\text { coordinate directions } \\
\mathrm{g} & =\text { gravitational acceleration } \\
\mathrm{n} & =\text { water elevation ( } \mathrm{n}=\mathrm{h}+\mathrm{z}_{\mathrm{b}}^{\prime} \\
z_{\mathrm{D}} & =\text { bottom elevation } \\
\underline{\mathrm{D}} & =\text { fluid density } \\
\mathrm{T}_{\mathrm{Dx}}, \mathrm{T}_{\mathrm{by}} & =\text { bottom shear stress }
\end{aligned}
$$$$
\mathrm{T}_{\mathrm{XX}},{ }^{\mathrm{T}}{ }_{\mathrm{XY}}{ }^{\mathrm{T}} \mathrm{YY}_{\mathrm{Y}}=\text { effective shear stresses }
$$

Effective Shear Stresses

In this development, the effective shear stresses are not included explicitly in the equation set. Instead, they will be introduced in a velocity-averaging routine which simulates the 
contribution of the effective stresses. The averaging procedure is written:

$$
\begin{aligned}
& \overline{\mathrm{u}}_{j, k}^{\star}=\bar{u}_{j, k}(1-a)+a\left(\bar{u}_{j-1, k}+\bar{u}_{j, k-1}+\bar{u}_{j, k+1}+\bar{u}_{j+1, k} 1 / 4\right. \\
& \bar{v}_{j, k}^{*}=\bar{v}_{j, k}(1-a)+a\left(\bar{v}_{j-1, k}+\bar{v}_{j, k-1}+\bar{v}_{j, k+1}+\bar{v}_{j+1, k}^{1 / 4}\right.
\end{aligned}
$$

where,

$$
\begin{aligned}
& \bar{u}_{j, k}=\text { spatially averaged } \bar{u}_{j, k} \\
& \bar{v}_{j, k}=\text { spatially averaged } \bar{v}_{j, k} \\
& a=\text { weighting factor, } 0<=a<=1 \\
& j, k=\text { spatial indices }
\end{aligned}
$$

and

$$
\begin{aligned}
& T=\frac{i}{n} \int_{z}^{n}\left[2 p v-\frac{u}{x}-p{\overline{u^{\prime}}}^{2}-p(u-\bar{u})^{2}\right] d z \\
& T_{x y}=T_{y x}=\frac{i}{h} \int_{z}^{n}\left[p v\left(\frac{u}{y}+\frac{v}{x}\right)-p \overline{u^{\prime} v^{\prime}}-p(u-\bar{u})(v-\bar{v})\right] d z \\
& T_{y Y}=-\int_{z}^{n}\left[2 p v-p \bar{v}^{2}-p(v-\bar{v})^{2}\right] d z
\end{aligned}
$$

where: $u^{\prime}, v^{\prime}=$ random fluctuation

These equations are not actualiy solved directly, instead, we simulate the contribution of the effective stresses with an averaging procedure applied after each new set of dependent variables has been generated. The formula used are: 


$$
\begin{aligned}
& \overline{\mathrm{u}}_{j, k}^{*}=\bar{u}_{j, k}(1-a)+\frac{a}{4} \bar{u}_{j-1, k}+\bar{u}_{j, k-1}+\bar{u}_{j, k+1}+\bar{u}_{j+1, k}{ }^{\prime} \\
& \bar{v}_{j, k}^{*}=\bar{v}_{j, k}(1-a)+\frac{a}{4} \bar{v}_{j-1, k}+\bar{v}_{j, k-1}+\bar{v}_{j, k+1}+\bar{v}_{j+1, k}{ }^{\prime}
\end{aligned}
$$

\section{Bottom Shear Stresses}

Here, the Chezy expression is used:

$$
\begin{aligned}
& T_{b x}=p f \quad \bar{u}\left(\bar{u}^{2}+\bar{v}^{2}\right) 1 / 2 \\
& T_{b y}=p f \quad \bar{v}\left(\bar{u}^{2}+\bar{v}^{2}\right) 1 / 2 \\
& f=\frac{g}{2} \\
& C
\end{aligned}
$$

where,

$$
\begin{aligned}
& f=\text { the dimensionless friction factor } \\
& \mathrm{C}=\text { the Chezy coefficient }
\end{aligned}
$$

This is the form of the Navier-Stokes equations that has been applied in solutions of two-dimensional, unsteady flow in this analysis. These equations have been re-expressed in an implicit, finite difference form to allow solutions. The method of solution is called the Alternating Direction Implicit procedure. Solutions are first achelved in the $x$-direction using an implicit method to solve for the $x$-momentum and the water surface elevation. Then the $y$-velocity is solved in that direction using an explicit procedure. Following this, solutions are obtained in the y-direction of the grid. In this case, solutions of the $y$-momentum and water surface elevation are 
obtained with an implicit method and the $x$-momentum is obtained with an explicit procedure.

Grid system

To solve the six equations that result, a finite difference scheme is developed. To simplify the solution procedure, a separate grid system is defined for each of the variables $u, v, n$, and $\mathrm{z}$ (for convenience, the overbarred notacion is dropped). The four grid systems are staggered by one-half steps of $E x$ and $E Y$ in space as shown below (Figure 8.1). In these systems, $\varepsilon x=\varepsilon y$, because the representation of the effective shear stress used in the model depends on this assumption. It is also important to note that the solutions from the continuity equation produce the water surface elevation, rather than the water depth. This leads to some inconvenience in solutions for floods in areas of irregular topography such as the Pasco Basin.

\section{Finite Difference Approximations}

A centered difference approximation is used for the spatial derivatives because it provides a higher order accuracy (second order) than either the forward or backward difference schemes. A Forward difference approximation is used for the temporal derivatives because the more accurate centered difference scheme would result in two time levels of unknowns. The nonlinear terms in the governing equarions are formulated in an approximate, linear representation by "judicious" specification of known and unknown values in the difference equations. 


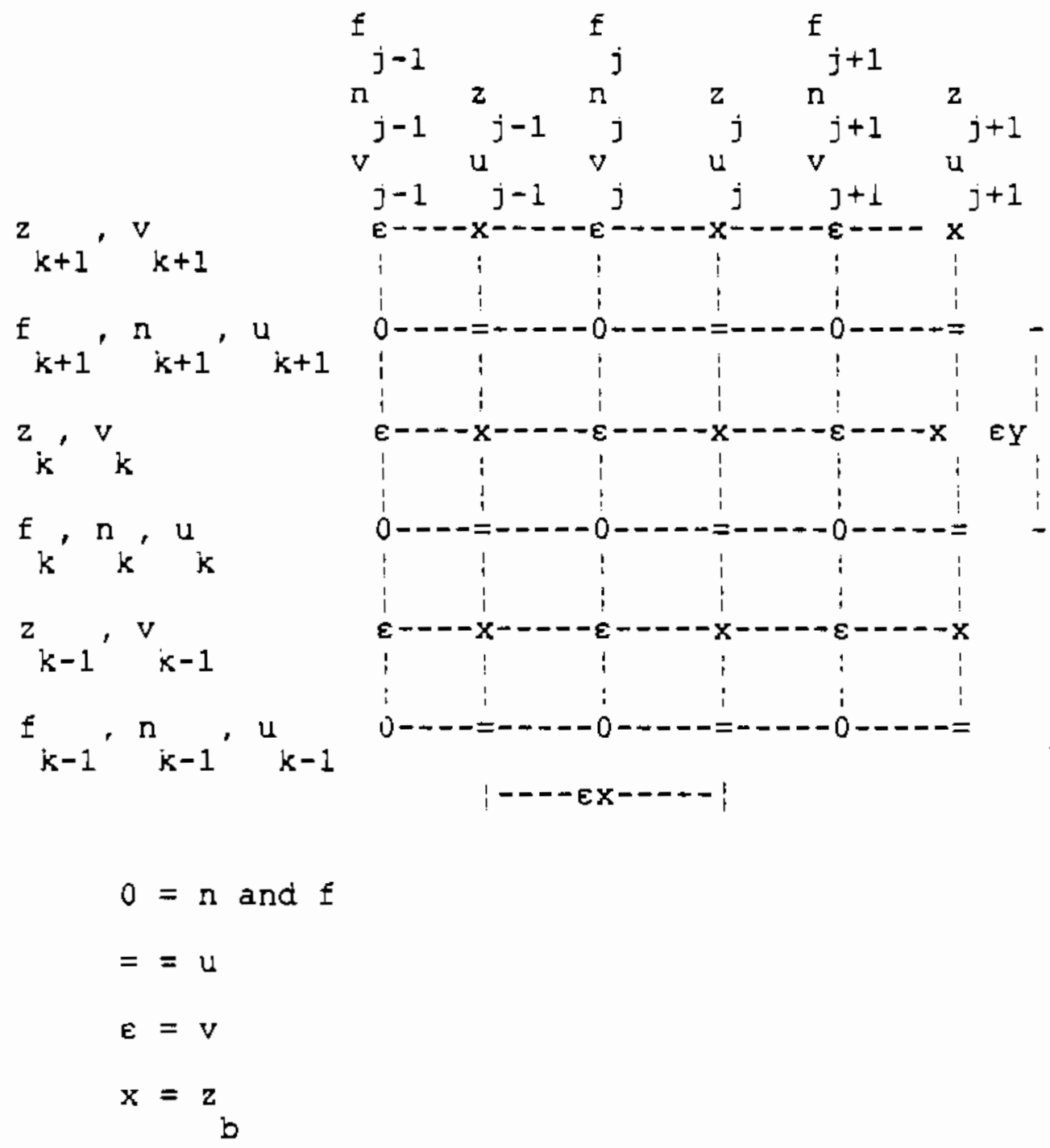

Figure 8.1. The staggered grid representation of variables used in the alternating direction implicit method of solution of the Navier-stokes equations.

The grid can be thought of as four separate grids, superimposed and staggard in space. In the formulations which follow, each variable ( $n, f, u, v$, and $z$ ) is subscripted with respect to its own grid coordinates, not the grid coordinates of the reference point for the difference formulae. 
A multioperational solution procedure is used. The method is based on a modification of the alternating-direction implicit (ADI) procedure. This modified ADI method was presented by Leendertse (1967) and later described by Ponce and Yabusaki (1981). In this procedure, each time step, $\varepsilon t$, is divided into two half-time steps. In the first half-time step, the x-momentum equation and the continuity equation are solved implicitly for $u$ and $\mathrm{n}$, and the $\mathrm{y}$-momentum equation is solved explicitly for $\mathrm{v}$. The two implicit equations, taken together, form a tridiagonal coefficient matrix for each row of the difference grid. Thus, solution proceeds one row at a time. At the end of the second half-time step, the $y$-momentum equation and the continuity equation are solved implicitly for $\mathrm{v}$ and $\mathrm{n}$, and the $\mathrm{x}$-momentur equation is solved explicitly for $u$. In this stage, the two implicit equations, taken together, form a tridiagonal coefficient matrix for each column of the difference grid. Thus, solution proceeds one column at a time.

The ADI procedure offers the following advantages:

1. Rows and columns are evaluated separately, thus greatly reducing the amount of computer core storage required.

2. By alternating the implicit and explicit procedures within a time step, errors created during one half-time are compensated for by errors incurred during the second nalf-time step.

For the $x$-momentum equation, the reference node for the difference scheme is the node occupied by $u_{j k}$. The reference node for the difference scheme in the $y$-momentum equation is the 
node occupied by $v_{j k}$. For the continuity equation, the reference node is at $\mathrm{n}$.

The finite difference forms of the components of the three governing equations are:

Stage 1:

x-momentur (Implicit):

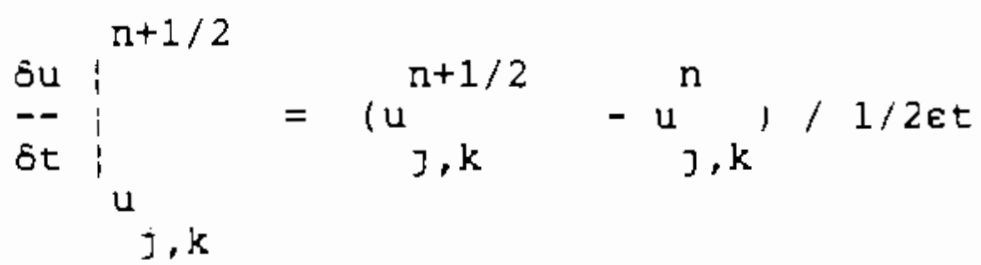

$$
\begin{aligned}
& \underset{s u}{\delta x} \underbrace{n+1 / 2}_{j, k}=u_{j, k}^{n+1 / 2} \quad\left[u_{j+1, k}^{n}-u_{j-1, k}^{n} j / 2 \in x\right.
\end{aligned}
$$

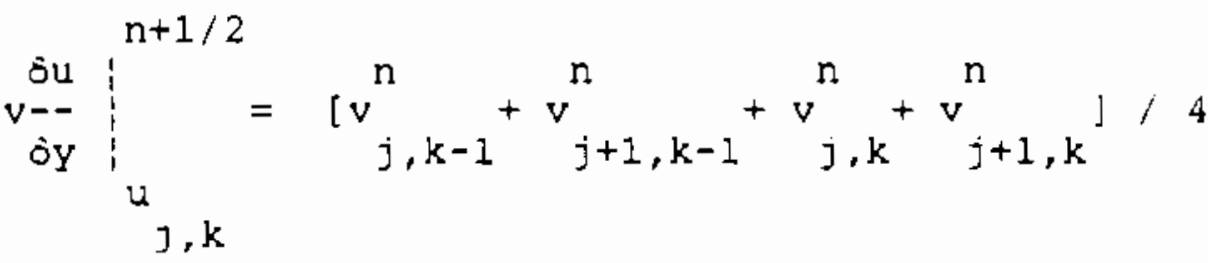

$$
\begin{aligned}
& \left.x \quad u_{j, k+1}^{n}-u_{j, k-1}^{n}\right\rfloor / 2 \varepsilon y
\end{aligned}
$$

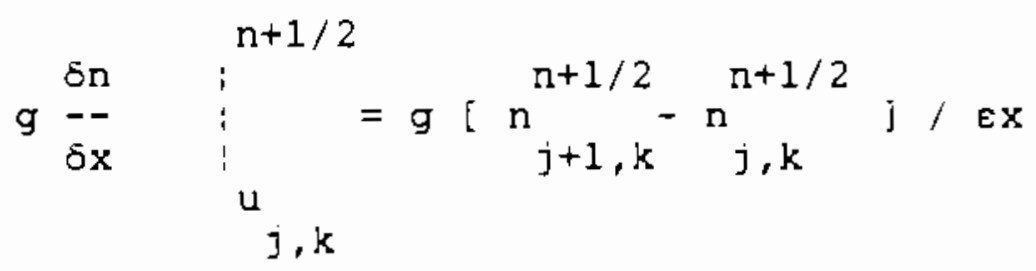

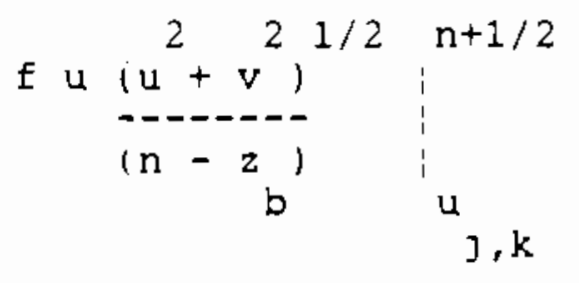




$$
\begin{aligned}
& =\left[( f _ { j , k } + f { } _ { j + 1 , k } , / 2 ] \left\langleu _ { j , k } ^ { n + 1 / 2 } \left[\left(u_{j, k}^{n}\right)^{2}+\right.\right.\right. \\
& \left.\left.\left(\left(v_{j, k-1}^{n}+v_{j+1, k-1}^{n}+v_{j, k}^{n}+v_{j+1, k}^{n}\right) / 4\right)^{2}\right\}^{1 / 2}\right\} / \\
& {\left[\left(\left(n_{j+1, k}^{n}+n_{j, k}^{n}, / 2\right)-\left(\left(z_{j, k}+z_{j, k-1}\right) / 2\right)\right]\right.}
\end{aligned}
$$

Continuity (Implicit):

$$
\text { on }{ }_{\text {ot }} \sum_{j, k}^{n+1 / 2}=\left(n_{j, k}^{n+1 / 2}-n_{j, k}^{n}\right) /(1 / 2 \varepsilon t)
$$

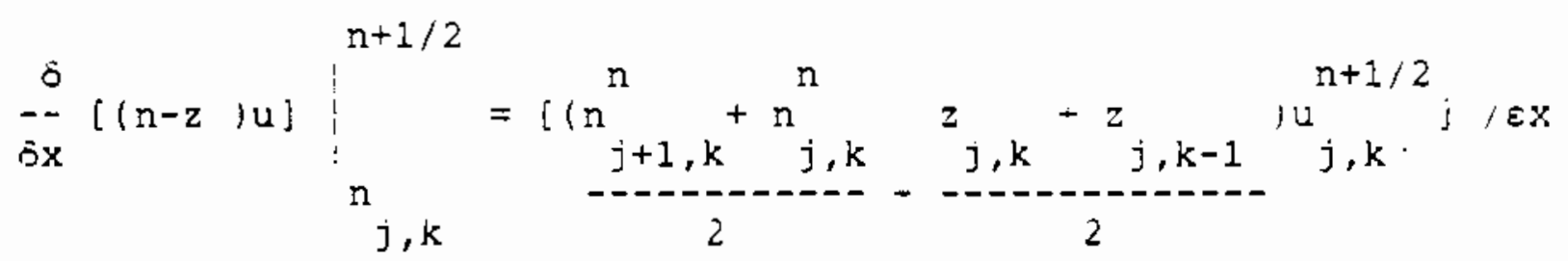

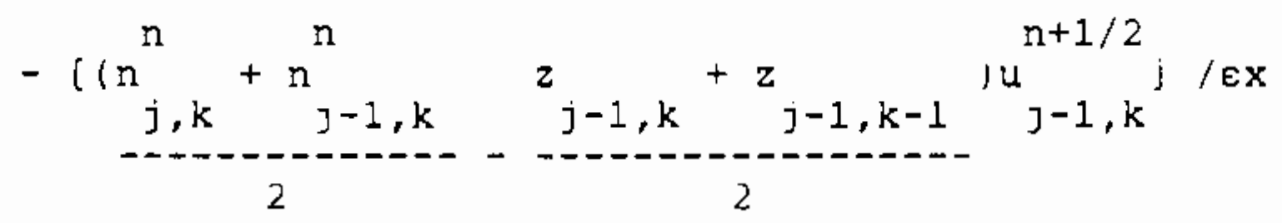

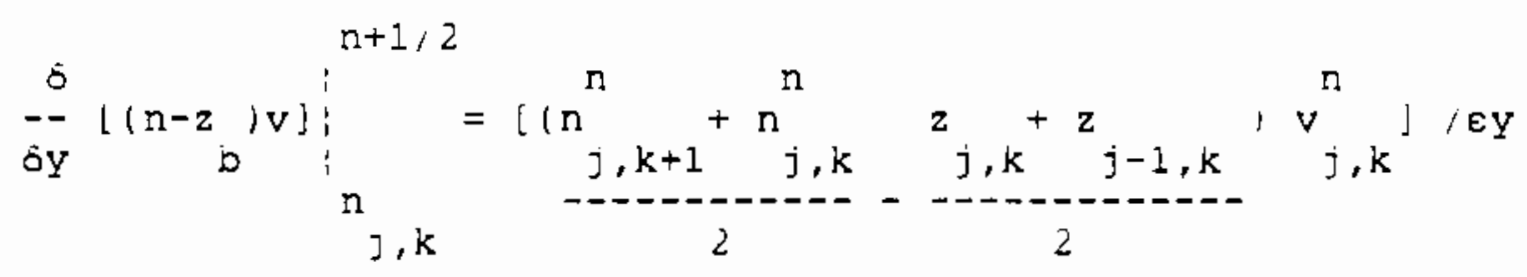

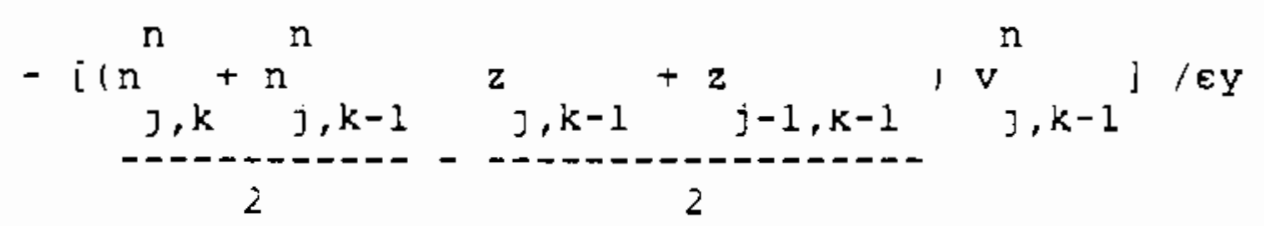


y-Momentum (Explicit)

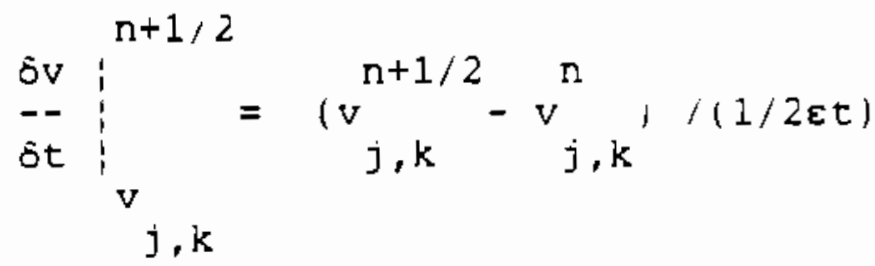

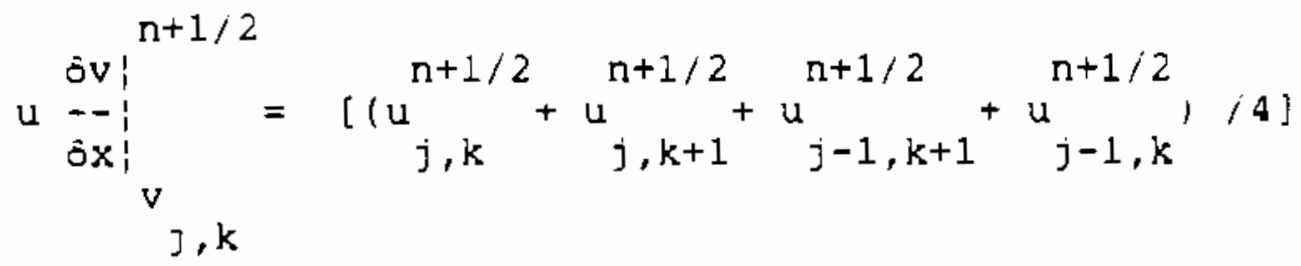

$$
\begin{aligned}
& x\left[\left(v_{j+1, k}^{n}-v_{j-1, k}^{n}\right)\right] / 2 \varepsilon x
\end{aligned}
$$

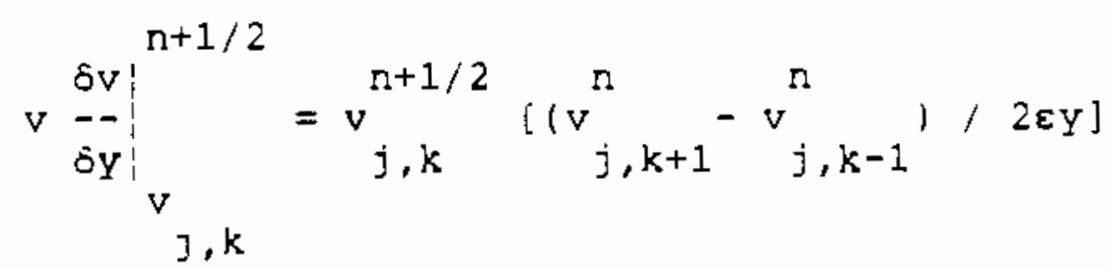

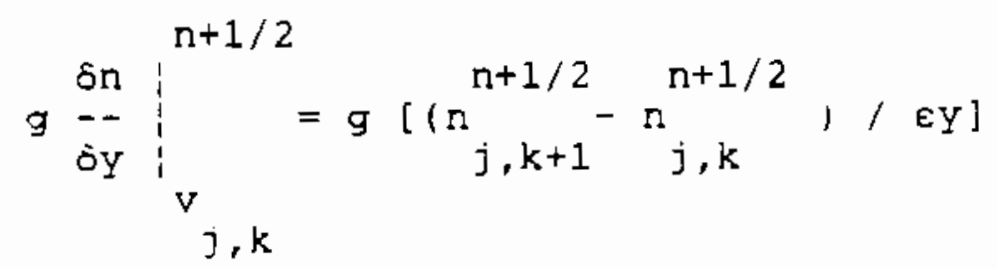

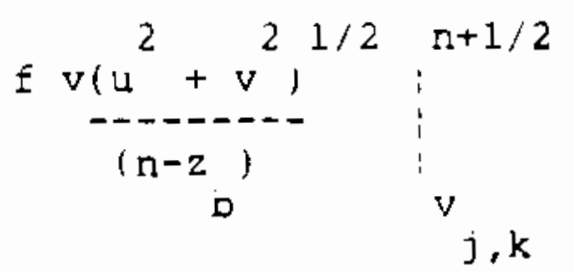

$$
\begin{aligned}
& =\left[\left(f_{j, k}+f_{j, k+1}\right) / 2\right]\left\{v _ { j , k } ^ { n + 1 / 2 } \left[\left(v_{j, k}^{n}\right)^{2}+\right.\right.
\end{aligned}
$$




$$
\begin{aligned}
& \left.\left(\left(u_{j, k}^{n+1 / 2}+u_{j, k+1}^{n+1 / 2}+u_{j-1, k}^{n+1 / 2}+u_{j-1, k+1}^{n+1 / 2}, / 4\right)^{2}\right]^{1 / 2} j\right) \\
& {\left[\left(\left(n_{j, k+1}^{n+1 / 2}+n_{j, k}^{n+1 / 2}, / 2\right)-\left(\left(z_{j, k}+z_{j-1, k}\right) / 2\right)\right]\right.}
\end{aligned}
$$

\section{Stage 2:}

y-momentum (Implicit):

$v_{j, k}^{\delta v+1}=\left[v^{n+1}-v_{j, k}^{n+1 / 2}\right] / 1 / 2 \varepsilon t$

$u=\frac{\delta v}{\delta x} \underbrace{n+1}_{j, k}=\left[\left(u_{j, k}^{n+1 / 2}+u_{j, k+1}^{n+1 / 2}+u_{j-1, k+1}^{n+1 / 2}+u_{j-1, k}^{n+1 / 2}, / 4\right]\right.$

$$
\left.x \quad v_{j+1, k}^{n+1 / 2}-v_{j-1, k}^{n+1 / 2}\right) / 2 \varepsilon x
$$

$v \underbrace{n v+1}_{j, k v}=v_{j, k}^{n+1} i v_{j, k+1}^{n+1 / 2}-v_{j, k-1}^{n+1 / 2} j / 2 \varepsilon Y$

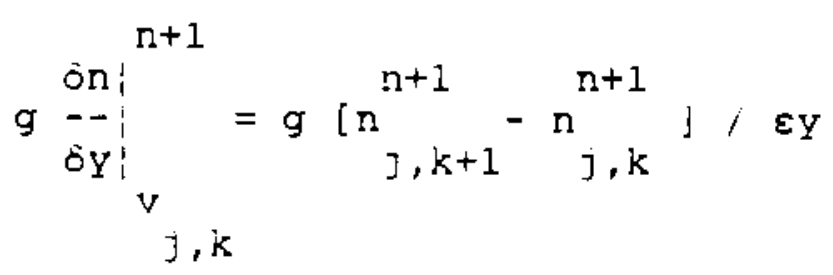




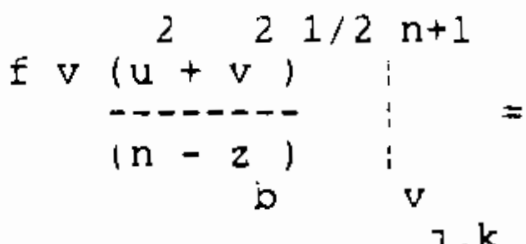

$$
\begin{aligned}
& i(f \underset{\jmath, k}{f}+f, k+1)\left[v _ { j , k } ^ { n + 1 } \left[\left(v_{j, k}^{n+1 / 2}\right)^{2}+\right.\right. \\
& \left.\left.\left(u^{n+1 / 2}+u_{j, k}^{n+1 / 2}+u^{n+1 / 2}+u_{j-1, k^{n+1 / 2}}^{j-1, k+1}\right) / 4\right)^{2} j^{1 / 2}\right\} ; \\
& {\left[\left(\left(n_{j+1, k}^{n+1 / 2}+n_{j, k}^{n+1 / 2}, / 2\right)-\left(\left(z_{j, k}+z_{j, k+1}\right) / 2\right)\right]\right.}
\end{aligned}
$$

Continuity (Implicit):

$$
\left.\cos _{j, k}^{n+1}=i n_{j, k}^{n+1}-n^{n+1 / 2}\right] /(1 / 2 \varepsilon t)
$$

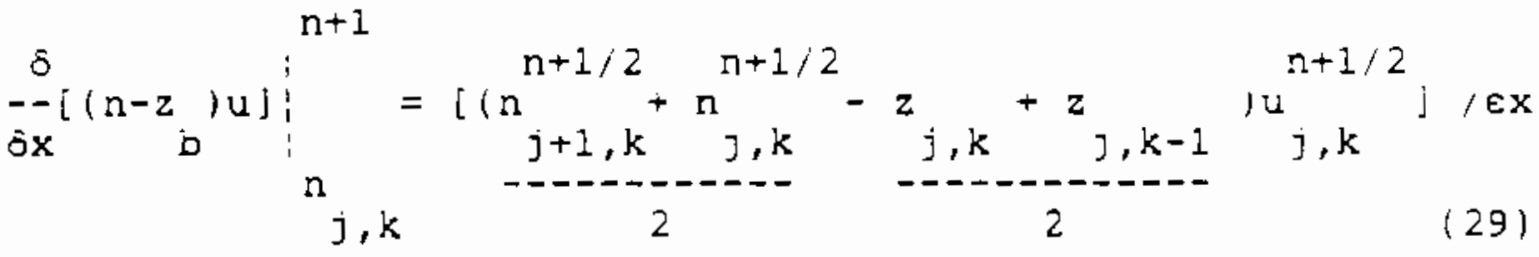

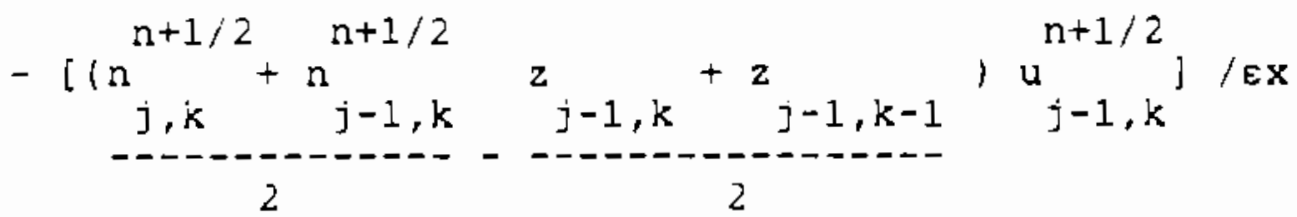




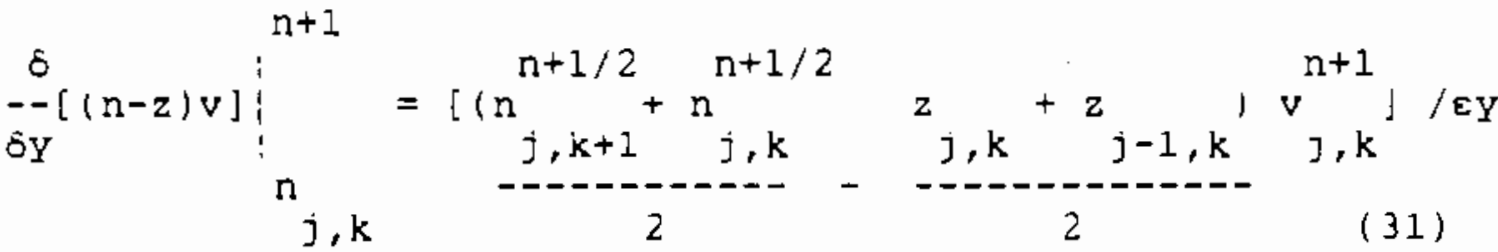

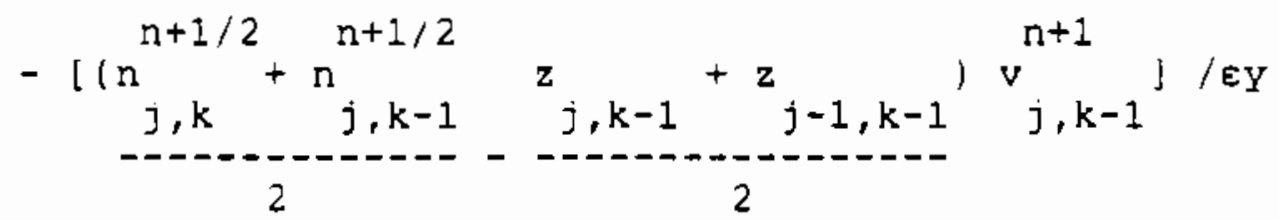

x-momentum (explicit)

$$
\cos _{j, k}^{n+1}=\left[u_{j, k}^{n+1}-u_{j, k}^{n+1 / 2}\right] / 1 / 2 \varepsilon t
$$

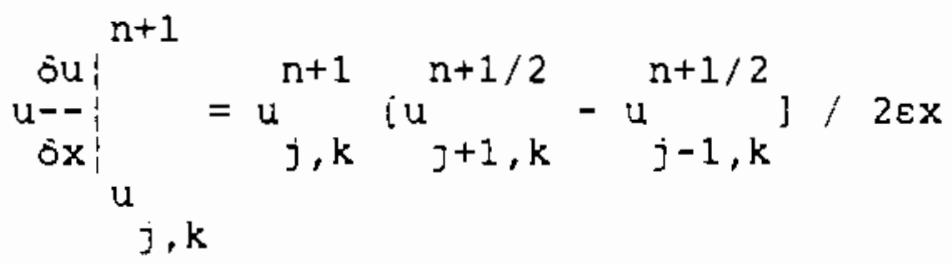

$$
\underset{u_{j, k}}{\delta u_{j}^{n+1}}=\left[v_{j, k-1}^{n+1}+v_{j+1, k-1}^{n+1}+v_{j, k}^{n+1}+v_{j+1, k}^{n+1}\right] / 4
$$

$$
\left.x_{j, k+1}^{\left[u_{j, k-1}^{n+1 / 2}\right.}-u_{j, 1 / 2}^{n+1}\right] / 2 \in y
$$

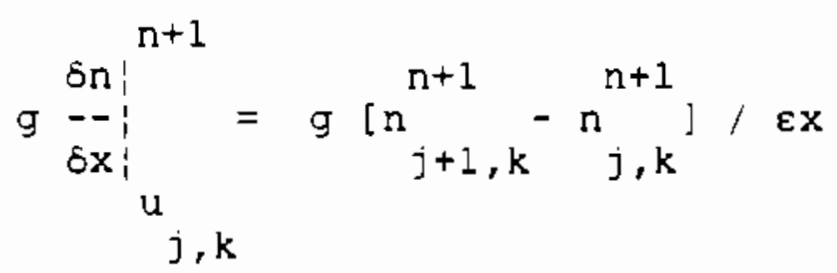




$$
\begin{aligned}
& \begin{array}{c:c}
u^{2}\left(u^{2}+v^{2}\right)^{1 / 2} & n+1 \\
\hdashline(n-z) & u_{j, k}
\end{array} \\
& =\left[\left(f f_{j, k}+f_{j+1, k}\right) / 2\right\} \quad\left\{u _ { j , k } ^ { n + 1 } \left[\left(u_{j, k}^{n+1 / 2}\right)^{2}+\right.\right. \\
& \left.\left(\left(v_{j, k-1}^{n+1}+v_{j+1, k-1}^{n+1}+v_{j, k}^{n+1}+v_{j+1, k}^{n+1}\right) / 4\right)^{21 / 2} !\right) \\
& \left(\left(\left(n_{j, k+1}^{n+1}+n_{j, k}^{n+1 / 2}, / 2\right)-\left(\left(z_{j, k}+z_{j-1, k}\right) / 2\right)\right]\right.
\end{aligned}
$$

The difference equations for stage 1 can now be written as follows:

x-momentum (Implicit)

$$
\begin{aligned}
& \left.\left(u_{j, k}^{n+1 / 2}-u_{j, k}^{n}\right) /(1 / 2 \varepsilon t)\right]+u_{j, k}^{n+1 / 2}\left[\left(u_{j+1, k}^{n}-u_{j-1, k}^{n}\right) / 2 \varepsilon x\right] \\
& +\left[\left(v_{j, k-1}^{n}+v_{j+1, k-1}^{n}+v_{j, k}^{n}+v_{j+1, k}^{n}\right) \frac{n}{n} \int_{j, k+1}^{n}-u_{j, k-1}^{n}, / 2 \varepsilon y j\right. \\
& +g\left[\left(n^{n+1 / 2}-n_{j, k}^{n+1 / 2}, / \in x\right]\right. \\
& \left.\left.+u_{j, k}^{n+1 / 2} i(f)+f j, k\right) / 2\right]\left\{\left[\left(u_{j, k}^{n}\right)^{2}+\right.\right.
\end{aligned}
$$




$$
\begin{aligned}
& \left.i\left(v_{j, k-1}^{n}+v_{j+1, k-1}^{n}+v_{j, k}^{n}+v_{j+1, k}^{n}, / 4\right)^{2}\right\}^{1 / 2}, \\
& {\left[\left(\mathrm{n}_{j+1, k}^{\mathrm{n}}+\mathrm{n}_{j, k}, / 2\right)-\left(\left(^{z} b_{j, k}+\mathrm{b}_{j, k-1}, / 2\right)\right]=0\right.}
\end{aligned}
$$

In order to simplify manipulation of the above equation, the following notation is introduced:

$$
\begin{aligned}
& v_{j, k}^{=n}=\left[v_{j, k-1}^{n}+v_{j+1, k-1}^{n}+v_{j, k}^{n}+v_{j+1, k}^{n} j / 4\right. \\
& \vec{F}_{j, k}^{=n}=\left[\left(\mathrm{f}_{j, k}+\mathrm{f}_{j+1, k}, / 2\right] \underset{j, k}{\left[\left(\mathrm{u}^{\mathrm{n}}, !^{2}\right.\right.}+\right. \\
& \left.\left(v^{n}+v_{j-1}^{n}+v_{j+1, k-1}^{n}+v_{3, k}^{n}+v_{j+1, k}^{n}, / 4\right)^{2,1 / 2}\right) \\
& \left.\left.\left(\mathrm{ln}_{j+1, k}^{\mathrm{n}}+\mathrm{n}_{j, k}^{\mathrm{n}}, / 2\right)-\left(\mathrm{z}_{\mathrm{j}, \mathrm{b}}+\mathrm{b}_{j, k-1}\right) / 2\right)\right]
\end{aligned}
$$


Substituting Equations (40) and (41) into Equation (39) gives the following more simplified version of the $x$-momentum difference for the lst half-time step:

$$
\begin{aligned}
& \left(u_{j, k}^{n+1 / 2}-u_{j, k}^{n}, /(1 / 2 \varepsilon t)+u_{j, k}^{n+1 / 2}\left\{u_{j+1, k}^{n}-u_{j-1, k}^{n}\right) / / 2 \varepsilon x\right] \\
& +v_{j, k}\left[\left(u_{j, k+1}^{n}-u_{j, k-1}^{n}\right) / 2 \varepsilon y\right]+g\left[\left(n_{j+1, k}^{n+1 / 2}-n_{j, k}^{n+1 / 2}\right) / e x\right] \\
& +u_{j, k}^{n+1 / 2} \cdot F_{j, k}^{=n}=0
\end{aligned}
$$

We wish to rearrange the equation to put all of the knowns on the right-hand side of Equation (42) and all of the unknowns on the left-hand side. Multiplying by $1 / 2 e t$ and separating the waterlevel derivative:

$u_{j, k}^{n+1 / 2}-u_{j, k}^{n}+1 / 2 \varepsilon t u_{j, k}^{n+1 / 2}\left[u_{j+1, k}^{n}-u_{j-1, k}^{n}\right\rfloor / 2 \varepsilon x$

$$
\begin{gathered}
+1 / 2 \varepsilon t v_{j, k}^{=n}\left[\left(u_{j, k+1}^{n}-u_{j, k-1}^{n}, 1 / 2 \varepsilon y\right]+1 / 2 \varepsilon t g\left[\left(n_{j+1, k}^{n+1 / 2}, / \varepsilon x\right]\right.\right. \\
-1 / 2 \varepsilon t g\left[\left(n_{j, k}^{n+1 / 2}\right) / \varepsilon x\right]+1 / 2 \varepsilon t u_{j, k}^{n+1 / 2}={ }_{j, k}=0
\end{gathered}
$$

Rearranging the terms in Equation (43) gIves:

$$
u_{j, k}^{n+1 / 2}+1 / 2 \varepsilon t u_{j, k}^{n+1 / 2}\left[u_{j+1, k}^{n}-u_{j-1, k}^{n}\right] / 2 \varepsilon x+1 / 2 \varepsilon \operatorname{tgn}{ }_{j+1, k}^{n+1 / 2} / \varepsilon x
$$




$$
\begin{aligned}
& -1 / 2 \varepsilon \operatorname{tg} n_{j, k}^{\mathrm{n+1} / 2}, \varepsilon x+1 / 2 \varepsilon t u_{j, k}^{\mathrm{n+1} / 2}=\mathrm{n} \\
& =u_{j, k}^{n}-2 / 2 \varepsilon T v_{j, k}^{=n}\left[u_{j, k+1}^{n}-u_{j, k-1}^{n}\right] / 2 \varepsilon y \\
& \text { Factoring out } u_{j, k}^{n+1 / 2} \text { gives: } \\
& \begin{array}{l}
u_{j, k}^{n+1 / 2}\left\{1+1 / 2 \varepsilon t\left[\left(u_{j+1, k}^{n}-u_{j-1, k}^{n}\right) / 2 \varepsilon x+F_{j, k} j\right\}\right. \\
+\left(1 / 2 \frac{\varepsilon t}{\varepsilon x} g\right) n_{j+1, k}^{n+1 / 2}-\left(1 / 2 \frac{\varepsilon}{\varepsilon x} g\right) n_{j, k}^{n+1 / 2} \\
=u_{j, k}^{n}-1 / 2 \varepsilon t v_{j, k}\left[u_{j, k+1}^{n}-u_{j, k-1}^{n}\right] / 2 \varepsilon y
\end{array}
\end{aligned}
$$

There is one such equation for every $u_{j, k}$ node in the domain. Let,

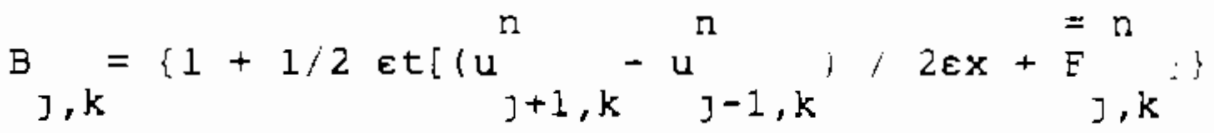

$$
\begin{aligned}
& A_{j, k}=-1 / 2 \frac{\varepsilon t}{\varepsilon x} g \\
& c_{j, k}=1 / 2 \underset{\varepsilon x}{E t}-g
\end{aligned}
$$




$$
P_{j, k}=u_{j, k}^{n}-1 / 2 \in t v_{j, k}^{=n} i u_{j, k+1}^{n}-u_{j, k-1}^{n} j / 2 \varepsilon Y
$$

Substituting Equarions (4ja-d) into Equation (45) gives:

$$
A_{j, k} n_{j, k}^{n+1 / 2}+B_{j, k} u_{j, k}^{n+1 / 2}+c_{j, k} n_{j+1, k}^{n+1 / 2}=P_{j, k}
$$

Continuity (Implicit):

$$
\begin{aligned}
& \left(n_{j, k}^{n+1 / 2}-n_{j, k}^{n}\right) /(1 / 2 \varepsilon t) \\
& +\left\{i\left(\left(n_{j+1, k}^{n}+n_{j, k}^{n}, / 2\right)-\left(l_{b}^{z}+{ }_{j, k}^{z} b_{j, k-1}, / 2\right)\right\} u_{j, k}^{n+1 / 2}, / \varepsilon x\right. \\
& -\left\{\left[\left(\left(n_{j, k}^{n}+n_{j-1, k}^{n}, / 2\right)-\left(\left(^{2} b_{j-1, k}+{ }^{2} b_{j-1, k-1}^{\prime} / 2\right) j u_{j-1, k}^{n+1 / 2} ; ; z x\right.\right.\right.\right. \\
& +\left\{\left[\left(\left(n_{j, k+1}^{n}+n_{j, k}^{n}\right) / 2\right)-\left(\left(_{b}^{z}+z_{j, k}^{z}, j / 2\right)\right] v_{j, k}^{n}\right\} / \varepsilon Y\right.
\end{aligned}
$$

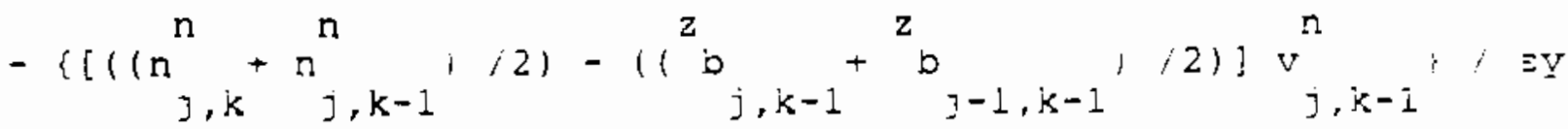

$$
\begin{aligned}
& =0
\end{aligned}
$$

Let,

$$
\left(\bar{D}_{1}^{n}\right)=\left[\left(n_{j, k}^{n}+n_{j+1, k}^{n}, / 2\right]-\left[\left(^{z} b_{j, k}+{ }^{z} b_{j, k-1}\right) / 2\right] \quad(47 a)\right.
$$




$$
\begin{aligned}
& \left(\tilde{D}_{2}^{n}\right)_{j, k}=\left[\left(n_{j, k}^{n}+n_{j-1, k}^{n}\right) / 2\right]-\left[\left(^{z} b_{j-1, k}+b_{j-1, k-1}^{2}\right) / 2\right] \\
& \left(\bar{D}_{3}^{n}\right)_{j, k}=\left[\left(\mathrm{n}_{j, k+1}^{\mathrm{n}}+\mathrm{n}_{j, k}^{\mathrm{n}}, / 2\right]-\left[\left(^{\mathrm{z}} \mathrm{b}_{j, k}+{ }^{z} \mathrm{~b}_{j-1, k}\right) / 2\right] \quad(47 \mathrm{c})\right. \\
& \left(\bar{D}_{4}^{n}\right)=\left[\left(n_{j, k}^{n}+n_{j, k-1}^{n}\right) / 2\right]-\left[\left(^{z} b_{j, k-1}+b_{j-1, k-1}^{z}\right) / 2\right]
\end{aligned}
$$

Substituting Equations ( 47 a-d) into Equation (46) produces:

$$
\begin{aligned}
& \left(n_{j, k}^{n+1 / 2}-n_{j}^{n}\right) /(1 / 2 \varepsilon t) \\
& \left.+\left[\left(\left(\bar{D}_{1}^{n}\right), j, u_{j, k}^{n+1 / 2}\right) / \varepsilon x\right]-\left[\left(\bar{D}_{2}^{n}\right), u_{j-1, k}^{n+1 / 2}\right) / \varepsilon x\right] \\
& +\left[\left(\left(\bar{D}^{n}\right), j v_{j, k}^{n}\right) / \varepsilon y\right]-\left[\left(\left(\bar{D}_{4}^{n}\right), v_{j, k}^{n}\right) / \varepsilon y\right]=0
\end{aligned}
$$

Multiplying by $1 / 2$ et gives:

$$
\begin{aligned}
& n_{j, k}^{n+1 / 2}-n_{j, k}^{n}+1 / 2 \frac{\varepsilon t}{\varepsilon x}\left(\bar{D}_{1}^{n}\right), u^{n+1 / 2}-1 / 2 \frac{\varepsilon t}{-(}{ }^{n}\left(\bar{D}^{n}\right), u^{n+1 / 2}
\end{aligned}
$$

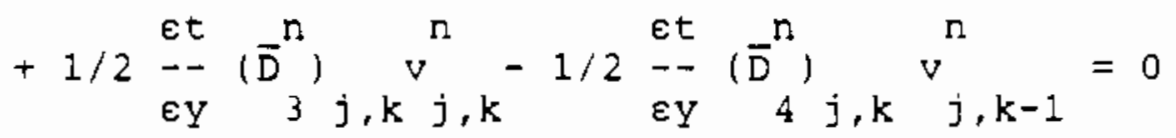

Putting the knowns on the right-hand side and the unknowns on the left-hand side gives:

$$
n_{j, k}^{n+1 / 2}+1 / 2 \underset{\varepsilon x}{--}\left(\bar{D}^{n}\right), u^{n+1 / 2}-1 / 2 \frac{\varepsilon t}{n^{2}}-\left(\bar{D}^{n}\right) u_{j, k}^{n+1 / 2}
$$




$$
=n_{j, k}^{n}-1 / 2{ }_{\varepsilon y}^{\varepsilon t}\left(\bar{D}_{3}^{n}\right), k+1 / 2 \underset{\varepsilon y}{E t}\left(\bar{D}_{4 j, k}^{n}{ }_{j, k-1}\right.
$$

There is one such equation for every $n$ node in the domain. Let,

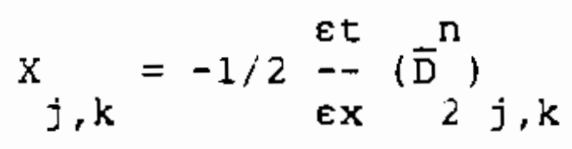

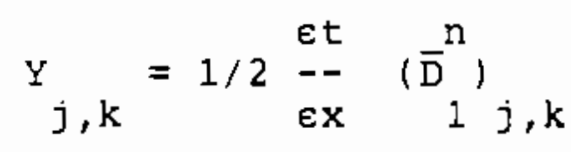

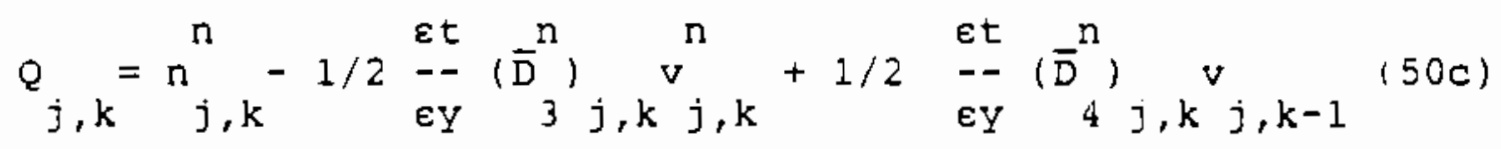

Substituting Equations (50 a-d) into Equation (50) gives:

$$
x_{j, k} u_{j-1, k}^{n+1 / 2}+\sum_{j, k}^{n+1 / 2}+y_{j, k} u_{j, k}^{n+1 / 2}=Q_{j, k}
$$

\section{y-Momentum (Explicit)}

$$
\begin{aligned}
& \left(v_{j, k}^{n+1 / 2}-v_{j, k}^{n}, /(1 / 2 \epsilon t)\right. \\
& +\left[u_{j, k}^{n+1 / 2}+u_{j, k+1}^{n+1 / 2}+u_{j-1, k+1}^{n+1 / 2}+u_{j-1, k}^{n+1 / 2}, v_{j+1, k}^{n}-v^{n}+1, k\right. \\
& +v_{j, k}^{n+1 / 2}\left[\left(v_{j, k+1}^{n}-v_{j, k-1}^{n}\right) / 2 \varepsilon y\right]+g\left[\left(n_{j, k+1}^{n+1 / 2}-n_{j, k}^{n+1 / 2}\right) / \varepsilon y\right] \\
& +v_{j, k}^{n+1 / 2}\left\{\left[(\mathrm{f}]_{j, k}+\mathrm{f}_{j, k+1}\right) / 2\right] \quad\left[\left(\mathrm{v}_{j, k}^{\mathrm{n}}\right\}^{2}\right.
\end{aligned}
$$




$$
\begin{aligned}
& +\left(\left(u_{j, k}^{n+1 / 2}+u_{j, k+1}^{n+1 / 2}+u_{j-1, k}^{n+1 / 2}+u_{j-1, k+1}^{n+1 / 2}, / 4\right)^{2,1 / 2} ;\right) \\
& {\left[\left(n_{j, k+1}^{n+1 / 2}+n_{j, k}^{n+1 / 2}\right) / 2-\left(b_{j, k}^{2}+b_{j-1, k}\right) / 2\right]=0}
\end{aligned}
$$

iet,

$$
\begin{aligned}
& u_{j, k}^{n+1 / 2}=\left(u_{j, k}^{n+1 / 2}+u_{j, k+1}^{n+1 / 2}+u_{j-1, k}^{n+1 / 2}+u_{j-1, k+1}^{n+1 / 2}\right) / 4
\end{aligned}
$$

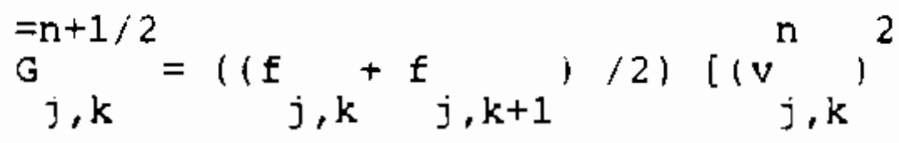

$$
\begin{aligned}
& +\left(\left(u_{j, k}^{n+1 / 2}+u_{j, k+1}^{n+1 / 2}+u_{j-1, k}^{n+1 / 2} u_{j-1, k+1}^{n+1 / 2}, / 4\right)^{21 / 2}\right. \\
& \left.\left.\operatorname{in}_{j, k+1}^{n+1 / 2}+n_{j, k}^{n+1 / 2}\right) / 2-\left(b_{j, k}+b_{j-1, k}\right) / 2\right]
\end{aligned}
$$

Substituting Equations (52) and (53) into Equation (51) gives:

$$
\begin{aligned}
& \left.\left(v^{n+1 / 2}-v_{j, k}^{n}\right) /(1 / 2 \varepsilon t)+u_{j, k}=n+1 / 2 v_{j-1, k}^{n}-v_{j-1, k}^{n} j / 2 \varepsilon x\right] \\
& +v_{j, k}^{n+1 / 2}: v_{j, k+1}^{n}-v_{j, k-1}^{n} J / 2 \varepsilon y \\
& +g\left[\left(n^{n+1 / 2}-n_{j, k+1}^{n+1 / 2}\right) / j_{j, k}\right]+[v_{j, k}^{n+1 / 2} \underbrace{=n+1 / 2}_{j, k}]=0
\end{aligned}
$$


Multiplying by $1 / 2$ et gives

$$
\begin{aligned}
& v_{j, k}^{n+1 / 2}-v_{j, k}^{n}+1 / 2 \text { et }{ }_{j, k}^{=n+1 / 2}\left[v_{j+1, k}^{n}-v_{j-1, k}^{n}[/ 2 \varepsilon x]\right. \\
& +1 / 2 \varepsilon t v_{j, k}^{n+1 / 2}\left[\left(v_{j, k+1}^{n}-v_{j, k-1}^{n}\right) / 2 \varepsilon y\right]+1 / 2 \varepsilon t g\left[n_{j, k+1}^{n+1 / 2}-n_{j, k}^{n+1 / 2}, / \varepsilon y\right] \\
& +\left[1 / 2 \varepsilon t v_{j, k}^{n+1 / 2} \cdot \mathrm{G}_{j, k}^{=n+1 / 2}\right]=0
\end{aligned}
$$

Rearranging Equation (55) so that all of the knowns are on the right-hand side and all of the unknowns are on the left-hand side gives:

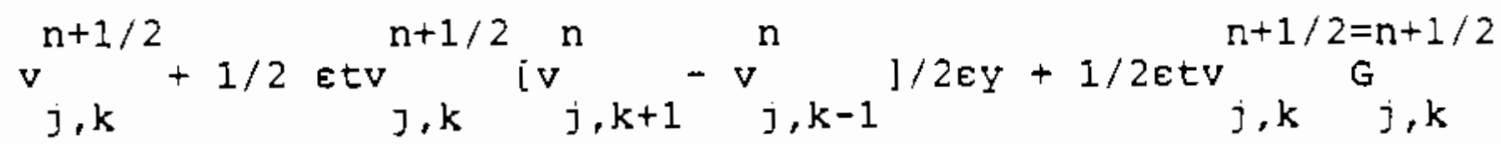

$$
\begin{aligned}
& =v_{j, k^{n}}^{n}-1 / 2 \varepsilon t u^{n+1 / 2} i\left(v_{j+1, k}^{n}-v_{j-1, k}^{n} j / 2 \varepsilon x\right] \\
& -1 / 2 \operatorname{etg}\left[\left(\mathrm{n}_{j, k+1}^{\mathrm{n}+1 / 2}-\mathrm{n}_{j, k}^{\mathrm{n}+1 / 2} / \mathrm{ey}\right]\right. \\
& \text { Eactoring out } v^{n+1 / 2} \text { gives } \\
& v_{j, k}^{n+1 / 2}\left\langle 1+1 / 2 \operatorname{et}\left\{\left(\left(v_{j, k+1}^{n}-v_{j, k-1}^{n} \mid / 2 \varepsilon y\right)+G_{j, k}^{n+1 / 2}\right]\right\}\right. \\
& =v_{j, k}^{n}-1 / 2 \varepsilon t u_{j, k}^{=n+1 / 2} \underset{i\left(v^{n}\right.}{n}-v_{j-1, k^{n}}^{n} k^{1 / 2 \varepsilon x]}
\end{aligned}
$$




$$
-1 / 2 \operatorname{etg}\left[\left(n_{j, k+1}^{n+1 / 2}-n_{j, k}^{n+1 / 2}\right) /\right. \text { ey] }
$$

Hence, $v_{j, k}^{n+1 / 2}$ can be solved for directly.

The difference equations for stage $\# 2$ can now be written as follows:

y-Momentum (Implicit):

$$
\begin{aligned}
& \left(v_{j, k}^{n+1}-v_{j, k}^{n+1 / 2}\right)(1 / 2 \varepsilon t)+\left[\left(u_{j, k}^{n+1 / 2}+u_{j, k+1}^{n+1 / 2}+u_{j-1, k+1}^{n+1 / 2}+u_{j-1, k}^{n+1 / 2} 1 / 4\right]\right. \\
& {\left[\left(v_{j+1, k}^{n+1 / 2}-v_{j-1, k}^{n+1 / 2} 1 / 2 \varepsilon x\right]+v_{j, k}^{n+1}\left[v_{j, k+1}^{n+1 / 2}-v_{j, k-1}^{n+1 / 2}\right]\right.} \\
& +g\left[\left(n_{j, k+1}^{n+1}-n_{j, k}^{n+1}\right) / \varepsilon y\right]+\left((f_{j, k}+\underbrace{}_{j, k+1}) / 2\right)\left\{v_{j, k}^{n+1} i\left(v_{j, k}^{n+1 / 2}\right)^{2}\right. \\
& +\left(\left(u_{j, k}^{n+1 / 2}+u_{j, k+1}^{n+1 / 2}+u_{j-1, k}^{n+1 / 2}+u_{j-1, k+1}^{n+1 / 2}, 1 / 4\right)^{21 / 2},\right. \\
& :\left(n_{j+1, k}^{n+1 / 2}+n_{j, k}^{n+1 / 2} 1 / 2-i_{j, k}^{z}+b_{j, k-1}^{z} 1 / 2\right\}=0
\end{aligned}
$$

Let,

$$
\begin{aligned}
& u_{j, k}^{n+1 / 2}=\left[\left(u_{j, k}^{n+1 / 2}+u_{j, k+1}^{n+1 / 2}+u_{j-1, k+1}^{n+1 / 2}+u_{j-1, k}^{n+1 / 2}\right) / 4\right] \\
& =n+1 / 2=\left[\left(f_{j, k}+f_{j, k+1}\right) / 2\right]\left[v_{j, k}^{n+1 / 2}\right)^{2}
\end{aligned}
$$




$$
\begin{gathered}
\left.+\left(u_{j, k}^{n+1 / 2}+u_{j, k+1}^{n+1 / 2}+u_{j-1, k}^{n+1 / 2}+u_{j-1, k+1}^{n+1 / 2}\right) / 4\right)^{2} j^{1 / 2} / \\
\left.i\left(n_{j+1, k}^{n+1 / 2}+n_{j, k}^{n+1 / 2}\right) / 2-\left(b_{j, k}+b_{j, k-1}\right) / 2\right]
\end{gathered}
$$

Substituting Equations (59) and (60) into Equation (58) gives:

$$
\begin{aligned}
& \left.v_{j, k}^{n+1}-v_{j, k}^{n+1 / 2}\right)\left((1 / 2 \varepsilon t)+u_{j, k}^{=n+1 / 2}\left[\left(v_{j+1, k}^{n+1 / 2}-v_{j-1, k}^{n+1 / 2}\right) / 2 \varepsilon x\right]\right. \\
& +v_{j, k}^{n+1 / 2}\left[\left(v_{j, k+1}^{n+1 / 2}-v_{j, k-1}^{n+1 / 2}\right) / 2 \varepsilon y\right]+g\left[\left(n_{j, k+1}^{n+1}-n_{j, k}^{n+1}\right) / \varepsilon y\right] \\
& +v_{j, k}^{n+1} \stackrel{F}{j, k}_{j, 1 / 2}^{=}=0
\end{aligned}
$$

Multiplying by $1 / 2$ et and separating the difference formula for the water elevation gives:

$$
\begin{aligned}
& v_{j, k}^{n+1}-v_{j, k}^{n+1 / 2}+1 / 2 \varepsilon t u_{j, k}^{=n+1 / 2}\left[v_{j+1, k}^{n+1 / 2}-v_{j-1, k}^{n+1 / 2}\right] / 2 \varepsilon x
\end{aligned}
$$

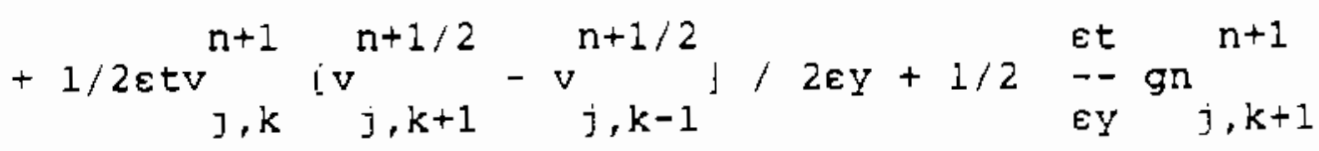

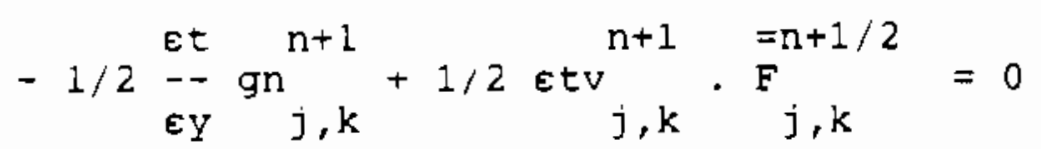

Rearranging terms to get all of the knowns on the right hand side and all of the unknowns on the left-hand side gives:

$$
v_{j, k}^{n+1}+1 / 2 \varepsilon t v^{n+1} i\left(v_{j, k+1}^{n+1 / 2}-v_{j, k-1}^{n+1 / 2} 1 / 2 \varepsilon y\right]+1 / 2 \text { et } v_{j, k}^{n+1} \underbrace{=n+1 / 2}_{j, k}
$$




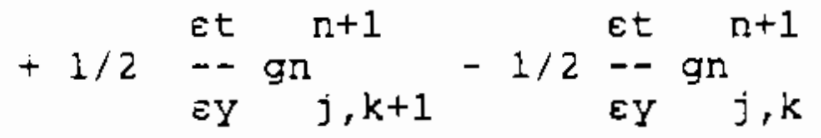

$$
\begin{aligned}
& =v_{j, k}^{n+1 / 2}-1 / 2 \varepsilon t u_{j, k}^{=n+1 / 2}\left[v_{j+1 / k}^{n+1 / 2}-v_{j-1, k}^{n+1 / 2}\right\rfloor / 2 \varepsilon x \\
& \text { Factoring out } v_{j, k}^{n+1} \text { gives: } \\
& v_{j, k}^{n+1}\left\{1+1 / 2 \varepsilon t\left[\left(v_{j, k+1}^{n+1 / 2}-v_{j, k-1}^{n+1 / 2}, / 2 \varepsilon y+E_{j, k}^{=n+1 / 2}\right]\right\}\right.
\end{aligned}
$$

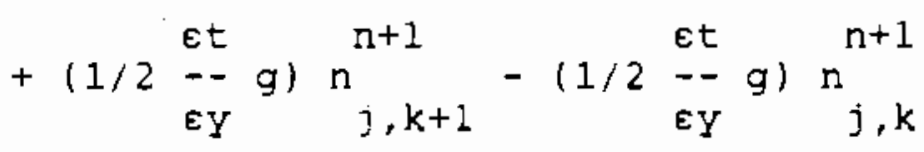

$$
\begin{aligned}
& =v_{j, k}^{n+1 / 2}-1 / 2 \varepsilon t u_{j, k}^{n+1 / 2}\left[v_{j+1, k}^{n+1 / 2}-v_{j-1, k}^{n+1 / 2}\right\rfloor / 2 \varepsilon x
\end{aligned}
$$

Let,

$$
\begin{aligned}
& A_{j, k}=\left(-1 / 2 \begin{array}{l}
\epsilon t \\
-\overline{E Y}
\end{array}\right) \\
& B_{\jmath, k}=\left\{1+1 / 2 \in\left[\left\{v_{j, k+1}^{n+1 / 2}-v_{j, k-1}^{n+1 / 2}, 1 / 2 \varepsilon y+F_{j, k}^{=n+1 / 2}\right]\right\}\right. \\
& c_{j, k}=\left(1 / 2 \begin{array}{l}
\epsilon t \\
-\overline{\varepsilon Y}
\end{array}\right) \\
& P_{j, k}=v_{j, k}^{n+1 / 2}-1 / 2 \varepsilon t u_{j, k}^{n+1 / 2} \quad v_{j+1, k}^{n+1 / 2}-v_{j-1, k}^{n+1 / 2} j / 2 \varepsilon x
\end{aligned}
$$


Thus, Equation (64) becomes:

$$
A_{j, k} \mathrm{n}_{j, k}^{\mathrm{n}+1}+\mathrm{B}_{j, k} \mathrm{v}_{j, k}^{\mathrm{n}+1}+\mathrm{C}_{j, k} \mathrm{n}_{j, k+1}^{\mathrm{n}+1}=\mathrm{P}_{j, k}
$$

Continuity (Implicit):

$$
\begin{aligned}
& \left(n_{j, k}^{n+1}-n_{j, k}^{n+1 / 2}\right) /(1 / 2 \varepsilon t) \\
& +\left[\left(n_{j+1, k}^{n+1 / 2}+n_{j, k}^{n+1 / 2}\right) / 2-i_{j, k}^{z}+b_{j, k-1}^{z}\right) u_{j, k}^{n+1 / 2} / \varepsilon x \\
& -\left[\left(n_{j, k}^{n+1 / 2}+n_{j-1, k}^{n+1 / 2}\right) / 2-\left(b_{j-1, k}+b_{j-1, k-1}^{z}\right) u_{j-1, k}^{n+1 / 2} / \in x\right. \\
& +\left[\left(n_{j, k+1}^{n+1 / 2}+n_{j, k}^{n+1 / 2}\right) / 2-\left(b_{j, k}^{2}+b_{j-1, k}^{2}\right) / 2\right] v_{j, k}^{n+1} / \varepsilon y . \\
& -\left[\left(n_{j, k}^{n+1 / 2}+n_{j, k-1}^{n+1 / 2}\right) / 2-\left(b_{j, k-1}^{z}+b_{j-1, k-1}^{z}\right) / 2\right] v_{j, k-1}^{n+1} / \varepsilon y=0
\end{aligned}
$$

Let,

$$
\begin{aligned}
& \left(\bar{D}_{i}^{n}\right)_{j, k}=\left[\left(n_{j+1, k}^{n+1 / 2}+n_{j, k}^{n+1 / 2}\right) / 2-\left(b_{j, k}+b_{j, k-1}^{z}\right)(70 a)\right. \\
& \left.\left(\bar{D}_{2}^{n}\right)_{j, k}=\left(n_{j, k}^{n+1 / 2}+n_{j-1, k}^{n+1 / 2}\right) / 2-\left(b_{j-1, k}+{ }^{z} b_{j-1, k-1}\right) / 2\right]
\end{aligned}
$$




$$
\begin{aligned}
& \left.\left(\bar{D}_{3}^{n}\right)=\left[\left(n_{j, k+1}^{n+1 / 2}+n_{j, k}^{n+1 / 2}\right) / 2-i_{j, k}^{z}+b_{j-1, k}\right) / 2\right] \\
& \left(\bar{D}_{4 j, k}^{n}=\left[\left(n_{j, k}^{n+1 / 2}+n_{j, k-1}^{n+1 / 2}\right) / 2-i_{j, k-1}^{z}+b_{j-1, k-1}^{z}\right) / 2\right]
\end{aligned}
$$

Substituting Equations (70a-d) into Equation (69) gives:

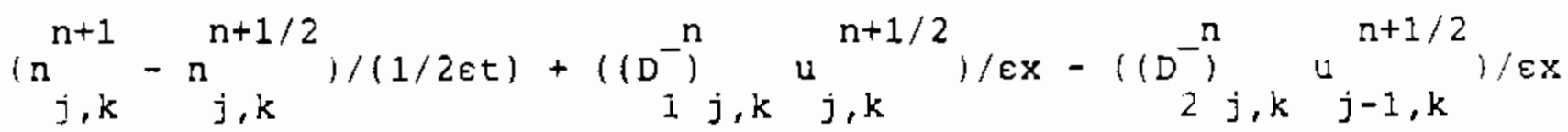

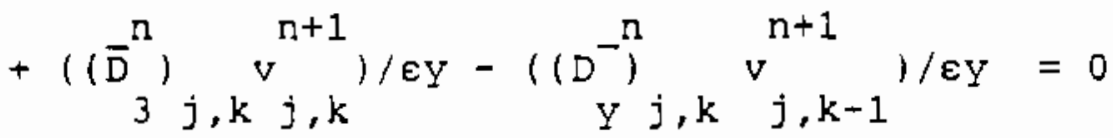

Multiplying by $1 / 2 \varepsilon t$ gives:

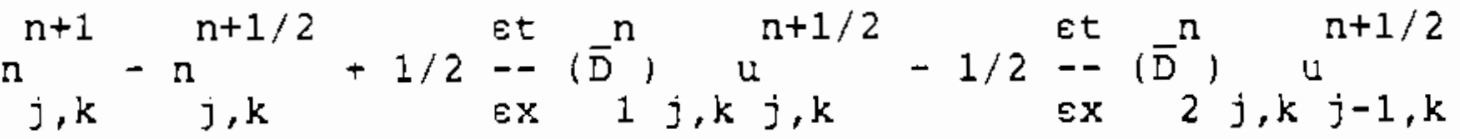

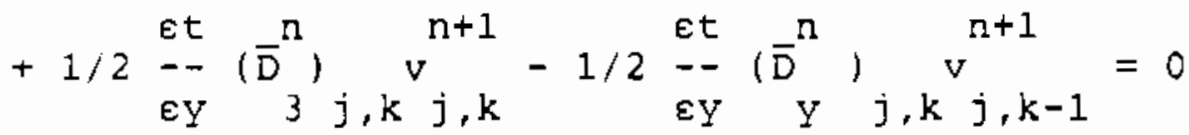

Putting all of the knowns on the right-hand side and all of the unknowns on the left-hand side gives:

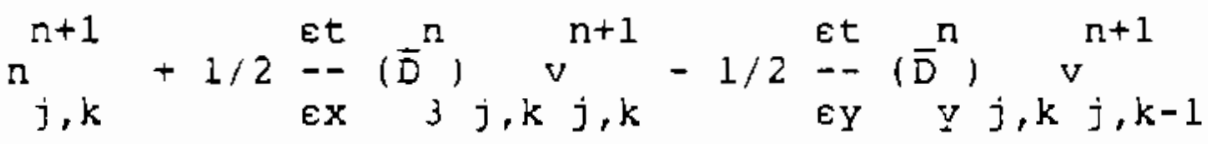

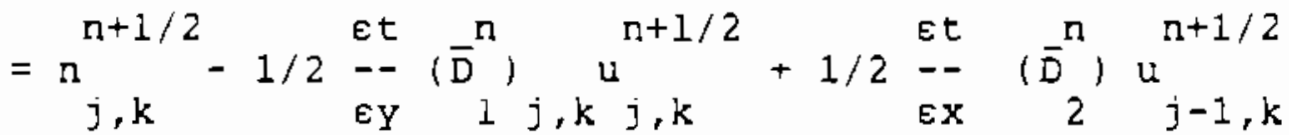


Let,

$$
\begin{aligned}
& x_{j, k}=\left(-1 / 2 \operatorname{EY}_{\mathrm{EY}}^{\varepsilon}\left(\bar{D}^{\mathrm{n}}\right)_{j, k}\right) \\
& Y_{j, k}=\left(1 / 2 \begin{array}{c}
\varepsilon t \\
-\overline{E Y}
\end{array}\left(\bar{D}^{\mathrm{n}}\right), j, k\right)
\end{aligned}
$$

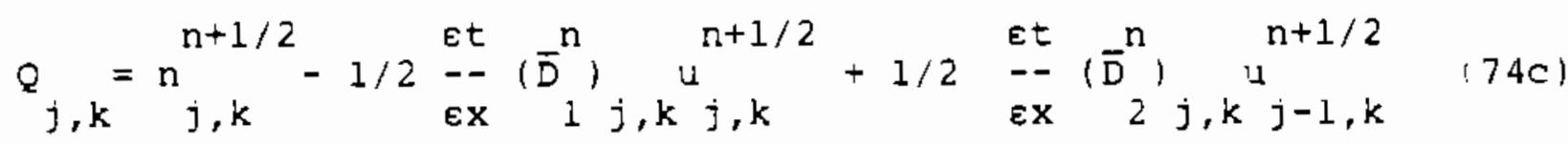

Then, Equation (73) becomes:

$$
x_{j, k} v_{j, k}^{n+1}+n_{j, k}^{n+1}+y_{j, k} v_{j, k}^{n+1}=Q_{j, k}
$$

x-momentum (Explicit)

$$
\begin{aligned}
& \left(u_{j, k}^{n+1}-u_{j, k}^{n+1 / 2}\right) /(1 / 2 \varepsilon t)+u_{j, k}^{n+1} \underbrace{n+1 / 2}_{j+1, k}-u_{j-1, k}^{n+1 / 2} j / 2 \in x \\
& \left.+[\left(v_{j, k-1}^{n+1}+v_{j+1, k-1}^{n+1}+v_{j, k}^{n+1}+v_{j+1, k}^{n+1}\right) \underbrace{n+4]\left(u_{j, k-1}^{n+1 / 2}\right.}_{j, k+1}-u^{n+1 / 2}) / 2 \varepsilon y\right] \\
& +g \ln _{j+1, k}^{n+1}-n_{j, k}^{n+1} j / \varepsilon x
\end{aligned}
$$

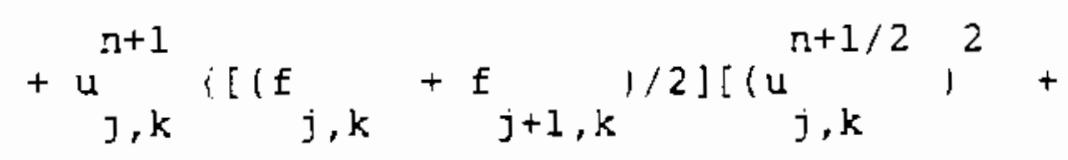

$$
\begin{aligned}
& \left.\left(v_{j, k-1}^{n+1}+v_{j+1, k-1}^{n+1}+v_{j, k}^{n+1}+v_{j+1, k}^{n+1}(1 / 4)^{21 / 2}\right\}\right)
\end{aligned}
$$




$$
\begin{aligned}
& \left.\left[n_{j, k+1}^{n+1}+n_{j, k}^{n+1 / 2}\right)+2-\left(_{j, k}+b_{j-1, k}^{z}\right) / 2\right]=0 \\
& \text { Let, } \\
& v_{j, k}^{=n+1}=\left[v_{j, k-1}^{n+1}+v_{j+1, k-1}^{n+1 n}+v_{j, k}^{n+1}+v_{j+1, k}^{n+1}\right] / 4
\end{aligned}
$$

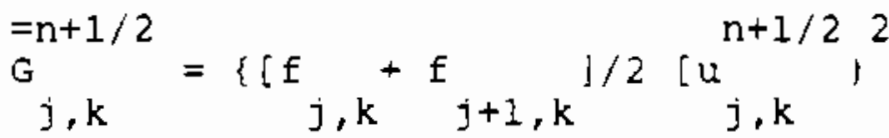

$$
\begin{aligned}
& \left.\left.+\left(\left(v^{n+1}+v_{j, k-1}^{n+1}+v_{j+1, k-1}^{n+1}+v_{j, k}^{n+1}\right) j_{j+1, k}\right) / 4\right)^{2 / 2}\right]^{1 / 2}, \\
& {\left[n_{j, k+1}^{n+1}+n_{j, k}^{n+1 / 2} 1 / 2-\left(b_{j, k}+b_{j-1, k}\right) / 2\right]}
\end{aligned}
$$

Substituting Equations (77) and (78) into Equation (76) gives:

$$
\begin{aligned}
& \begin{array}{c}
n+1 \\
(u \\
j, k
\end{array}-\underset{j, k}{u+1 / 2}, /(1 / 2 \varepsilon t)+u_{j, k}^{n+1} i u_{j+1, k}^{n+1 / 2}-u_{j-1, k}^{n+1 / 2} 1 / 2 \varepsilon x \\
& { }^{=n+1} v_{\jmath, k}^{n+1 / 2}-u_{\jmath, k+1}^{n+1 / 2}-u_{\jmath, k-1}^{n / 2 \varepsilon y}+g \ln _{j+1, k}^{n+1}-n_{j, k}^{n+1} j / \varepsilon x \\
& +u_{j, k}^{n+1} \cdot \mathrm{G}_{\jmath, k}^{=n+1 / 2}=0
\end{aligned}
$$

Multiplying by $1 / 2$ et gives:

$$
u_{j, k}^{n+1}-u_{j, k}^{n+1 / 2}+1 / 2 \in t u_{j, k}^{n+1} i_{j+1, k}^{n+1 / 2}-u_{j-1, k}^{n+1 / 2} j / 2 \varepsilon x
$$




$$
\begin{aligned}
& \underbrace{=n+1}_{j, k} \operatorname{lu}_{j, k+1}^{n+1 / 2}-u_{j, k-1}^{n+1 / 2} j / 2 \varepsilon y+1 / 2 \text { etg }\left[n_{j+1, k}^{n+1}-n_{j, k}^{n+1} j / \varepsilon x\right. \\
& +1 / 2 \varepsilon t u_{j, k}^{n+1}{ }_{j, k}^{=n+1 / 2}=0
\end{aligned}
$$

Rearranging Equation (80) to get all the knowns of the right-hand side and all the unknowns on the left-hand side gives:

$$
\begin{aligned}
& u_{j, k}^{n+1}+1 / 2 \varepsilon t u_{j, k}^{n+1} i_{j+1, k}^{n+1 / 2} u_{j-1, k}^{n+1 / 2} j / 2 \varepsilon x+1 / 2 \varepsilon t u_{j, k}^{n+1}=n+1 / 2 \\
& =u_{j, k}^{n+1 / 2}-1 / 2 \in t v_{j, k}^{=n+1}\left[u_{j, k+1}^{n+1 / 2}-u_{j, k-1}^{n+1 / 2}\right] / 2 \varepsilon y \\
& -1 / 2 \operatorname{etg}\left[n_{j+1, k^{n+1}}^{n+n^{n+1}} j / \varepsilon x\right.
\end{aligned}
$$

$$
\text { Factoring out } u_{j, k}^{n+1} \text { gives: }
$$$$
u_{j, k}^{n+1}\left\{1+1 / 2 \varepsilon t\left[\left(u_{j+1, k}^{n+1 / 2}-u_{j-1, k}^{n+1 / 2}\right\} / 2 \varepsilon x+G_{j, k}\right]\right\}
$$$$
=u_{j, k}^{n+1 / 2}-1 / 2 \varepsilon v_{j, k}^{=n+1} \underbrace{n+1 / 2}_{j, k+1}-u_{j, k-1}^{n+1 / 2} j / 2 \varepsilon y
$$$$
-1 / 2 \operatorname{etg}\left[n_{j+1, k}^{n+1}-n_{j, k}^{n+1}\right] / \varepsilon x
$$

Hence, $u_{j, k}^{n+1}$ can be solved for directly. 


\section{BASIC ALGORITHM}

A. Read in initial values of $n_{j, k},{ }^{2} b_{j, k}, u_{j, k}, v_{j, k}$ and $f_{j, k}$ for all $j, k$ where $j$ denotes the column and denotes the row.

B. For each time step, $\varepsilon t$, do the following:

1. Begin stage 1. There is a tridiagonal coefficient matrix to be solved for each row, $k$. Therefore, do the following for each row. The subscript $k$ can be dropped in the solution matrix coefficients.

1.1. For each column, $j$, compute the following:

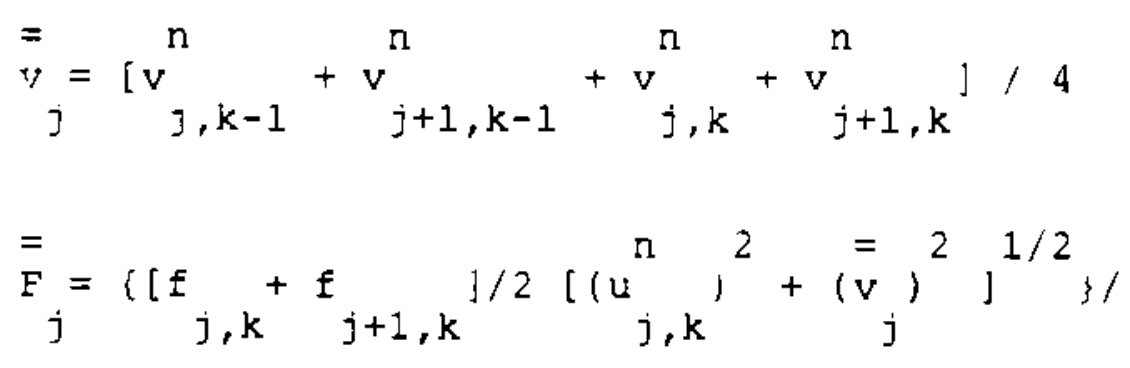

$$
\left[\left(n_{j+1, k}^{n}+n_{j, k}^{n} 1 / 2-i_{j, k}^{z}+b_{j, k-1}^{z} 1 / 2\right]\right.
$$$$
\left.B_{j}=\left\{1+1 / 2 \varepsilon t\left[u_{j+1, k}^{n}-u_{j-1, k}^{n}\right) / 2 \varepsilon x+F_{j}\right]\right\}
$$$$
P=u_{j, k}^{n}-1 / 2 \varepsilon t v \underset{j}{\left[u_{j, k+1}\right.}-u_{j, k-1}^{n} j / 2 \varepsilon y
$$

$$
\begin{aligned}
& \left.\left(\bar{D}_{i j}\right)=\left[n_{j+1, k}^{n}+n_{j, k}^{n}\right] / 2-i_{j, k}^{z}+b_{j, k-1}^{z}\right] / 2 \\
& \left(\bar{D}_{2}\right)_{j}=\left[n_{j, k}^{n}+n_{j-1, k}^{n}\right] / 2-\left[b_{j-1, k}^{z}+{ }^{z} b_{j-1, k-1}\right] / 2
\end{aligned}
$$




$$
\begin{aligned}
& \left(\bar{D}_{3}\right)_{j}=\left[n_{j, k+1}^{n}+n_{j, k}^{n}\right] / 2-\left[b_{j, k}^{z}+b_{j-1, k}^{z} 1 / 2\right. \\
& \left(\bar{D}_{4}\right)=\left[\mathrm{n}_{j, k}^{\mathrm{n}}+\mathrm{n}_{j, k-1}^{\mathrm{n}} j / 2-\mathrm{l}^{2} \mathrm{~b}_{j, k-1}+\mathrm{b}_{j-1, k-1} j / 2\right. \\
& x_{j}=-1 / 2 \underset{\varepsilon x}{=-(\bar{D})} \sum_{j} j \\
& Y_{j}=1 / 2 \underset{\varepsilon x}{--}(\bar{D})_{j}
\end{aligned}
$$

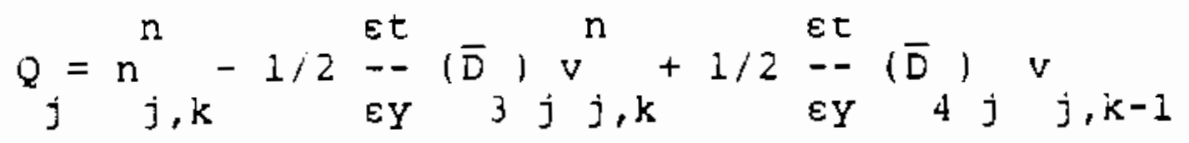

1.2 Calculate

$$
\begin{aligned}
& \mathrm{A}_{\mathrm{j}}=-1 / 2 \underset{\varepsilon \mathrm{x}}{--g} \\
& \mathrm{j}_{j}=1 / 2 \underset{\mathrm{Ex}}{-\overline{\mathrm{E}}} \mathrm{g}
\end{aligned}
$$

1.3. Put coefficients and constant vector into proper arrays for the matrix solver.

1.4. Call subroutine TRIDIA.

Begin next row.

Stage 1: one matrix for every row, $k$ : 


\begin{tabular}{|c|c|c|c|c|c|c|c|c|c|}
\hline & & ${ }^{\mathrm{n}} \mathrm{i}, \mathrm{k}$ & ${ }^{\mathrm{u}}, \mathrm{k}$ & ${ }^{n}, k$ & ${ }_{2, k}$ & $\mathrm{n}_{3, \mathrm{k}}$ & $\mathrm{u}_{3, \mathrm{k}}$ & $\mathrm{n}_{4, \mathrm{k}}$ & ${ }_{4}^{u}, k$ \\
\hline$j=1$ & 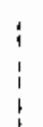 & 1 & ${ }_{1}^{Y}$ & 0 & 0 & 0 & 0 & 0 & 0 \\
\hline$j=1$ & 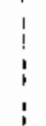 & ${ }_{1}^{A}$ & ${ }_{1}^{B}$ & $\mathrm{C}_{1}$ & 0 & 0 & 0 & 0 & 0 \\
\hline$j=2$ & 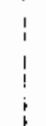 & 0 & $\mathrm{x}_{2}$ & 1 & $Y_{2}$ & 0 & 0 & 0 & 0 \\
\hline$j=2$ & 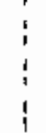 & 0 & 0 & $\mathrm{~A}_{2}$ & ${ }_{2}$ & $c_{2}$ & 0 & 0 & 0 \\
\hline$j=3$ & 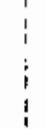 & 0 & 0 & 0 & $x_{3}$ & 1 & $Y_{3}$ & 0 & 0 \\
\hline$j=3$ & 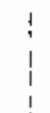 & 0 & 0 & 0 & 0 & $\mathrm{~A}_{3}$ & ${ }_{3}$ & $c_{3}$ & 0 \\
\hline$j=4$ & $\begin{array}{l}1 \\
1 \\
1\end{array}$ & 0 & 0 & 0 & 0 & 0 & $x_{4}$ & 1 & $Y_{4}$ \\
\hline$j=4$ & 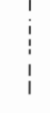 & 0 & 0 & 0 & 0 & 0 & 0 & ${ }_{4}$ & ${ }_{4}$ \\
\hline
\end{tabular}

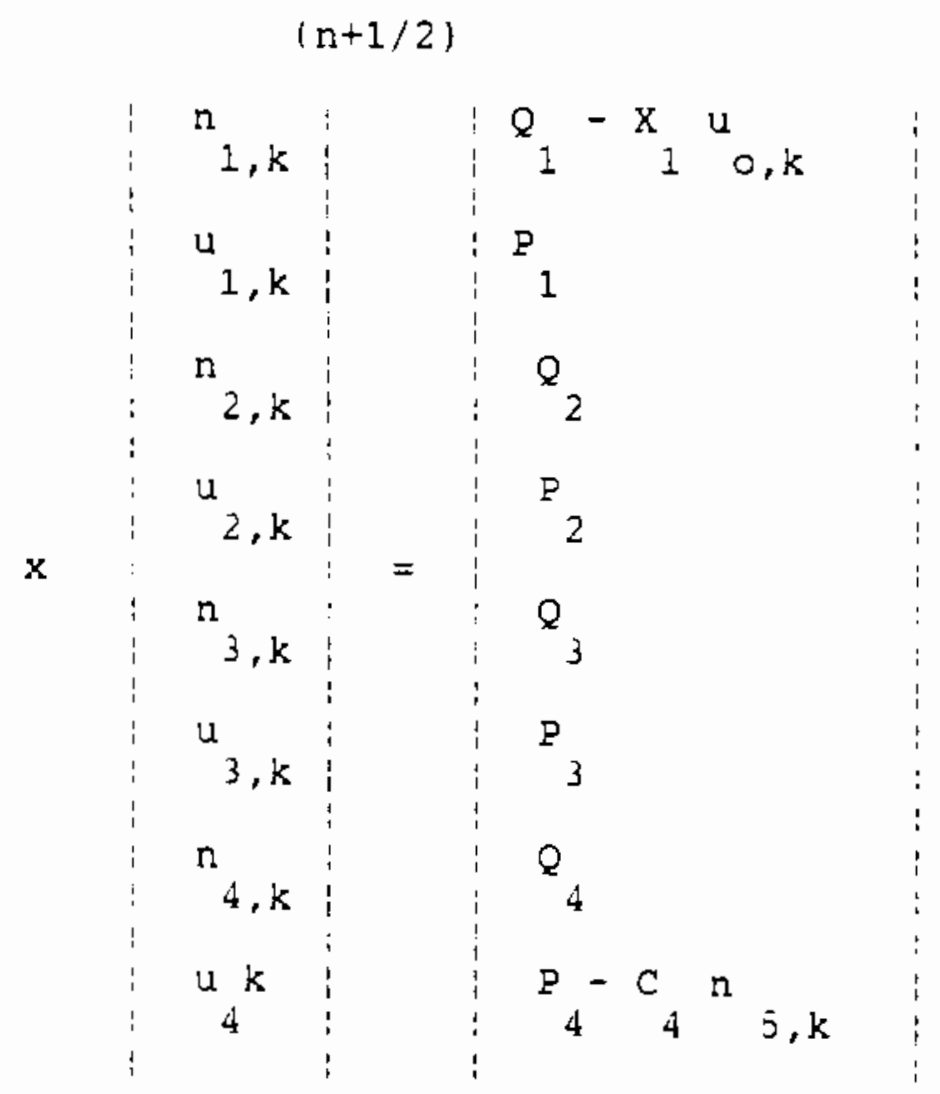


2. Solve for all $\mathrm{v}$ explicitly

ij

2.1 Do $k=1$, \# of rows

Do $j=1$, \# of columns

$\left.=u_{j, k}^{n+1 / 2}+u_{j, k+1}^{n+1 / 2}+u_{j-1, k}^{n+1 / 2}+u_{j-1, k+1}^{n+1 / 2}\right) / 4$

$\left.\bar{F}=\left\{\left[f f_{j, k}+f_{j, k+1}\right] / 2\left[\left(v_{j, k}^{n}\right)^{2}+(u)\right)^{2}\right\}\right\}$,

$\left[\left(n_{j, k+1}^{n+1 / 2}+n_{j, k}^{n+1 / 2}\right) / 2-\left(b_{j, k}^{z}+{ }^{z} b_{j-1, k}\right) / 2\right]$

$A=\left\{1+1 / 2 \varepsilon t\left[\left(v_{j, k+1}^{n}-v_{j, k-1}^{n}, / 2 \varepsilon y+F\right]\right\}\right.$

$B=-1 / 2 \varepsilon t u_{j}\left[v_{j+1, k}^{n}-v_{j-1, k}^{n}\right] / 2 \varepsilon x$

$c=-1 / 2 \operatorname{tg}\left[n_{j, k+1}^{n+1 / 2}-n_{j, k}^{n+1 / 2}, / \varepsilon y\right.$

$v_{j, k}^{n+1 / 2}=\left(v_{j, k}^{n}+B+C\right) / A$

3. Begin Stage 2: there is a tridiagonal coefficient matrix to De solved for each column, j. Therefore, do the following for each column. The subscript $j$ can be dropped from the entries in the coefficient matrix and constant vector. 
3.1. For each row, $k$, compute the following:

$$
\begin{aligned}
& =u_{k}=\left[u_{j, k}^{n+1 / 2}+u_{j, k+1}^{n+1 / 2}+u_{j-1, k}^{n+1 / 2}+u_{j-1, k+1}^{n+1 / 2}\right] / 4 \\
& \left.\bar{E}_{k}=\left\{(\mathrm{f}\}_{j, k}+\mathrm{f}_{j, k+1}\right)\left[\left(\mathrm{v}_{j, k}^{\mathrm{n}+1 / 2}\right)^{2}+\underset{\left(u_{k}\right)}{=}\right)^{1 / 2}\right\} / \\
& {\left[\left(n_{j+1, k}^{n+1 / 2}+n_{j, k}^{n+1 / 2}\right) / 2-\left(b_{j, k}+b_{j, k-1}^{z} 1 / 2\right]\right.}
\end{aligned}
$$$$
B_{k}=\left\{1+1 / 2 \in t\left[\left(v_{j, k+1}^{n+1 / 2}-v_{j, k-1}^{n+1 / 2}, / 2 \varepsilon y+F_{k}\right]\right\}\right.
$$

$$
P_{k}=v_{j, k}^{n+1 / 2}-1 / 2 \varepsilon t u_{k}\left[\left(v_{j+1, k}^{n+1 / 2}-v_{j-1, k}^{n+1 / 2}\right) / 2 \varepsilon x\right.
$$$$
(\vec{D})_{k}=\left[n_{j+1, k}^{n+1 / 2}+n_{j, k}^{n+1 / 2}\right] / 2-\left[b_{j, k}^{2}+b_{j, k-1}^{z}\right] / 2
$$$$
(\bar{D})_{2 k}=\left[n_{j, k}^{n+1 / 2}+n_{j-1, k}^{n+1 / 2}\right] / 2-\left[b_{j-1, k}^{z}+b_{j-1, k-1}^{z} 1 / 2\right.
$$$$
\left(\bar{D}_{3 k}\right)=\left[n_{j, k}^{n+1 / 2}+n_{], k}^{n+1 / 2} j / 2-\left[b_{j, k-1}^{2}+{ }^{z} b_{-1, k-1}^{1 / 2}\right.\right.
$$$$
(\vec{D})_{4 k}=i_{j, k}^{n+1 / 2}+n_{j, k-1}^{n+1 / 2} j / 2-\left[b_{j, k-1}^{z}+b_{j-1, k-1}^{z} 1 / 2\right.
$$

$$
\begin{aligned}
& x_{k}=-1 / 2 \frac{E \tau}{E Y} \quad(\bar{D})_{4 k} \\
& Y_{K}=1 / 2 \underset{\varepsilon Y}{\varepsilon t} \quad(\bar{D})_{k}
\end{aligned}
$$


$Q=n_{j, k}^{n+1 / 2}-1 / 2 \frac{\varepsilon t}{\varepsilon x}(\bar{D}){ }_{1 k j, k}^{n+1 / 2}+1 / 2 \frac{\varepsilon t}{\varepsilon x}(\bar{D})_{2 k} u^{n+1 / 2}$

3.2 Calculate

$$
\begin{aligned}
& { }_{\mathrm{K}}=-1 / 2 \frac{\varepsilon \mathrm{t}}{\varepsilon \mathrm{y}} \mathrm{g} \\
& c_{\mathrm{x}}=1 / 2 \stackrel{\varepsilon t}{-\overrightarrow{\varepsilon Y}} \mathrm{~g}
\end{aligned}
$$

3.3 Put entries of the coefficient matrix and the constant vector into the proper arrays for the matrix solver.

\subsection{Call subroutine TRIDIA.}

Begin next column.

\begin{tabular}{|c|c|c|c|c|c|c|c|c|}
\hline & $\mathrm{n}_{j, 1}$ & $v_{j, 1}$ & $\mathrm{n}_{j, 2}$ & $v_{j, 2}$ & $\mathrm{n}_{j, 3}$ & $v_{j, 3}$ & $\mathrm{n}_{j, 4}$ & $v_{j, 4}$ \\
\hline $\mathrm{k}=1$ & 1 & $\Psi_{1}$ & 0 & 0 & 0 & 0 & 0 & 0 \\
\hline$k=1$ & ${ }_{i}^{A}$ & ${ }_{1}^{B}$ & $c_{i}$ & 0 & 0 & 0 & 0 & 0 \\
\hline$k=2$ & 0 & $x_{2}$ & i & $Y_{2}$ & 0 & 0 & 0 & $0:$ \\
\hline$s=2$ & 0 & 0 & $\dot{A}$ & $B_{2}$ & $c_{2}$ & 0 & 0 & 0 : \\
\hline$k=3$ & 0 & 0 & 0 & $x_{3}$ & 1 & $\mathrm{Y}_{3}$ & 0 & 0 \\
\hline$k=3$ & 0 & 0 & 0 & 0 & $A_{3}$ & ${ }_{3}^{B}$ & $c_{3}$ & 0 \\
\hline $\mathrm{k}=4$ & 0 & 0 & 0 & 0 & 0 & $x_{4}$ & 1 & \begin{tabular}{l|l}
$Y_{4}$ &
\end{tabular} \\
\hline $\mathrm{K}=4$ & 0 & 0 & 0 & 0 & 0 & 0 & $\mathrm{~A}_{4}$ & $\mathrm{~B}_{4}$ \\
\hline
\end{tabular}

Stage 2: One matrix for every column, $j$ : 


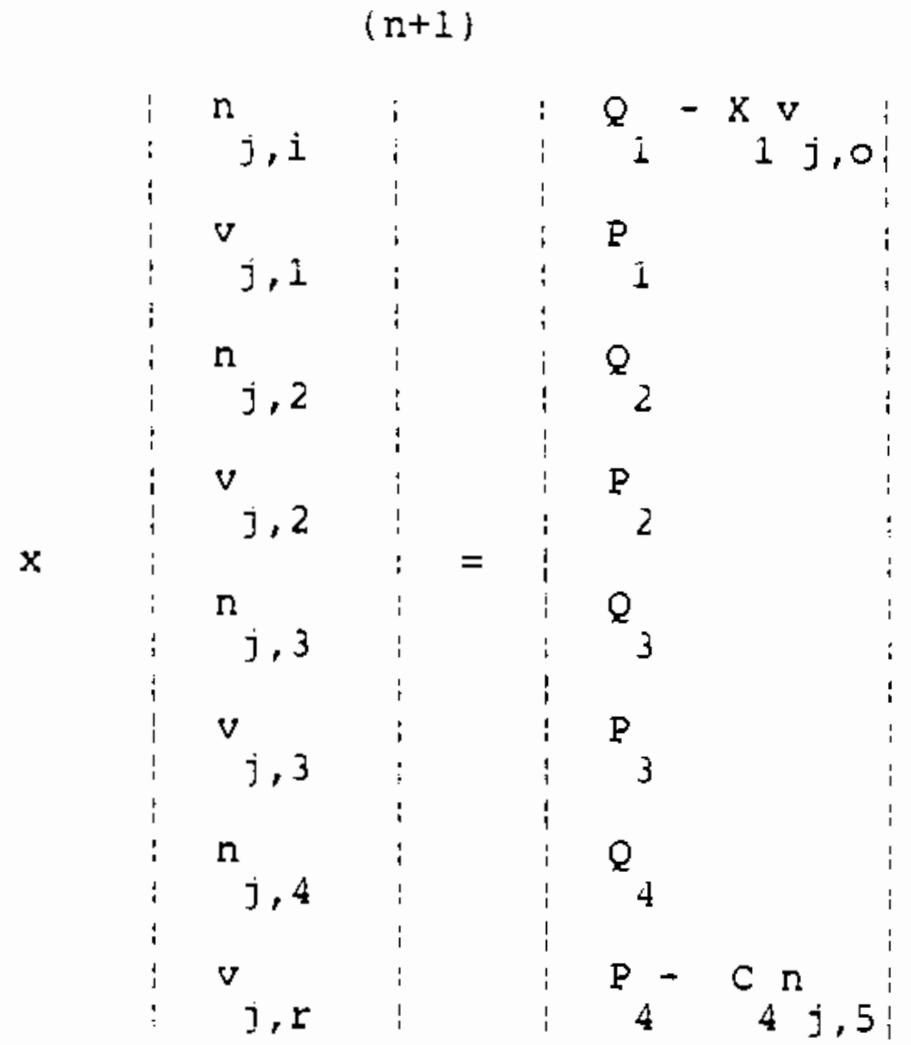

4. Solve for all u, explicity:

4.1 Do $k=1$, \# of rows.

Do $j=1$, \# of columns.

$\vec{v}=\left(v_{j, k-1}^{n+1}+v_{j+1, k-1}^{n+1}+v_{j, k}^{n+1} v_{j+1, k}^{n+1}\right) / 4$

$\left.\vec{F}=\left\{\left[f_{j, k}+f_{j+1, k}\right] / 2\left[\left(u_{j, k}^{n+1 / 2}\right)^{2}+(\vec{v})^{2}\right]^{1 / 2}\right\}\right)$

$i\left(n_{j, k+1}^{n+1}+n_{j, k}^{n+1 / 2} 1 / 2-i_{j, k}+b_{j-1, k} j / 2\right]$

$A=\left\{1+1 / 2 \operatorname{et}\left[\left(u_{j+1, k}^{n+1 / 2}-u_{j-1, k}^{n+1 / 2}, / 2 e x+F\right]\right\}\right.$ 


$$
\begin{aligned}
& B=-1 / 2 \varepsilon t v\left[u_{j, k+1}^{n+1 / 2}-u_{j, k-1}^{n+1 / 2}\right] / 2 \varepsilon y \\
& c=-1 / 2 \operatorname{etg}\left[n_{j+1, k}^{n+1 / 2}-n_{j, k}^{n+1}\right\rfloor / \varepsilon x \\
& u_{J, k}^{n+1}=\left(u_{j, k}^{n+1 / 2}+B+C\right) / A
\end{aligned}
$$


ESTIMATING THE EROSION DYNAMICS

MEYER-PETER AND MEULLER'S EQUATION

Due to the questionable results using HEC-6, a decision was made to utilize a more flexible approach to computing sediment transport. The method used is sometimes referred to as the "Swiss Formula" or the Meyer-Peter and Meuller formula (MeyerPeter and Meuller, 1948). This formula is usually used for rivers that move coarse grain sizes because it was developed from experiments utilizing a coarse grain fraction. The following are the range of conditions under which the equation was developed (Yalin, 1976):

$$
\begin{aligned}
& 1 \mathrm{~cm}<\mathrm{h}<120 \mathrm{~cm} \\
& 0.0004<S<0.020 \\
& 0.4 \mathrm{~mm}<D<30 \mathrm{~mm} \\
& 0.25<\mathrm{Y}<3.2
\end{aligned}
$$

h $=$ depth of flow

$S=$ water surface slope

$\mathrm{D}=$ grain size diameter

$Y=$ specific weight of sediment

except for "h", the values of these variables used fall within these ranges. The value of "h" differs by several orders of magnitude. Gessler (1970) restated Meyer-Peter and Meuller's equation:

$$
G s=c 2\left(t a u-t_{c}\right)^{3 / 2}
$$

where,

$$
\begin{aligned}
\mathrm{Gs} & =\operatorname{bed} \text { sediment load }(\mathrm{kg} / \mathrm{m} / \mathrm{sec}) \\
\mathrm{C} 2 & =8^{*}(\mathrm{~g} / \mathrm{Y}) \\
\mathrm{w} & =\operatorname{acceleration}^{2} \\
\mathrm{~g} & =\mathrm{af}^{2} \text { gravity }\left(\mathrm{m} / \mathrm{sec}^{2}\right)
\end{aligned}
$$




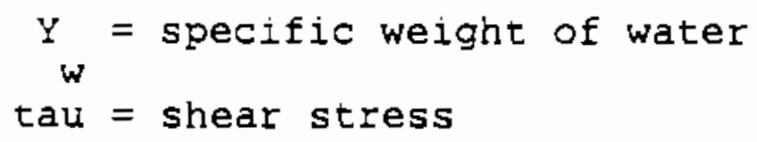

A computer program (Appendix D) was developed to calculate che amount of degradation/aggradation using this formula for the area of interest (location of the storage tanks directly east of the 200 E region). The methodology is taken from chapter 8 of the course notes on River Mechanics by Gessler, 1970.

FORMULATION AS $\underline{\text { A COMPUTER ALGORITHM }}$

Much of the input data needed for calculation of aggradation/degradation can be taken from the HEC-2 analyses over the range of discharges developed for the Pasco Basin. Water surface gradient, depth of flow and top width of the channel are utilized.

Since backwater curves were developed in the analyses using HEC-2, reasonable estimates of the depths of flows in the Pasco Basin over a range of discharge values were obtained. Shear stress is a function of the hydraulic radius of the channel. In order that reasonable estimates of shear stress are computed, use of depth of flow and channel width as variables in our estimace of hydraulic radius are used. The equation that relates these ¿wo variables to hydraulic radius is as follows:

$$
n r=D * W /(w+2 D)
$$

$$
\begin{aligned}
& \text { nr }=\text { hydraulic radius } \\
& D=\text { depth of flow } \\
& W=\text { channel width } \\
& \text { If the channel width is more than } 20 \text { times that of the }
\end{aligned}
$$


channel depth, the channel depth is a reasonable estimate of the

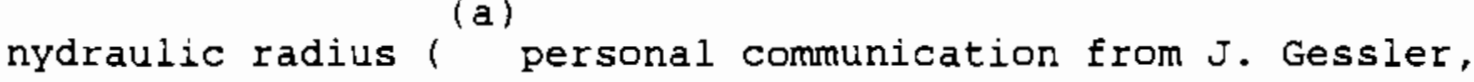
1985). This assumption is appropriate for Missoula-type flows for the wide cross-sections in the region of the 200 areas. To minimize error in the computations of sediment transport, calculation of the hydraulic radius is based on the equation presented above. If depth of flow were used directly as an estimate of hydraulic radius, only $2 \%$ error would be introduced into computations of shear stress.

The next step in the program is the calculation of the shear stress at each cross-section. Bed shear stress was calculated using the following equation:

where,

$$
\operatorname{tau}=\mathrm{Y}_{W} \mathrm{rS}
$$

$$
\begin{aligned}
\text { tau } & =\text { bed shear stress } \\
Y & =\text { specific weight of water }\left(\mathrm{kg-sec} / \mathrm{m}^{3}\right) \\
W & =\text { hydraulic radius } \\
S & =\text { slope of the water surface }
\end{aligned}
$$

Critical shear stress for a particular grain-size is computed by:

where,

$$
\tau_{c}=0.047\left(Y_{S}-Y_{W}\right) D
$$

$$
\begin{aligned}
0.047 & =\text { dimensionless constant } \\
Y & =\text { specific weight of sediment } \\
\mathrm{S} & =\text { specific weight of water } \\
\mathrm{W} & =\text { diameter of the particle }
\end{aligned}
$$

With this information, the bed-load (G) may be computed:

$$
\mathrm{G}_{\mathrm{s}}=\mathrm{c} 2\left(\mathrm{tau}-\mathrm{tau}_{\mathrm{c}}\right)^{\mathrm{s} / 2}
$$


Once the bed-load for each cross-section has been computed, we must apply the continuity equation for sediment load to obtain values of aggradation or degradation:

where,

$$
\mathrm{dGs} / \mathrm{dx}=-\mathrm{C} 3 \mathrm{dz} / \mathrm{dt}
$$

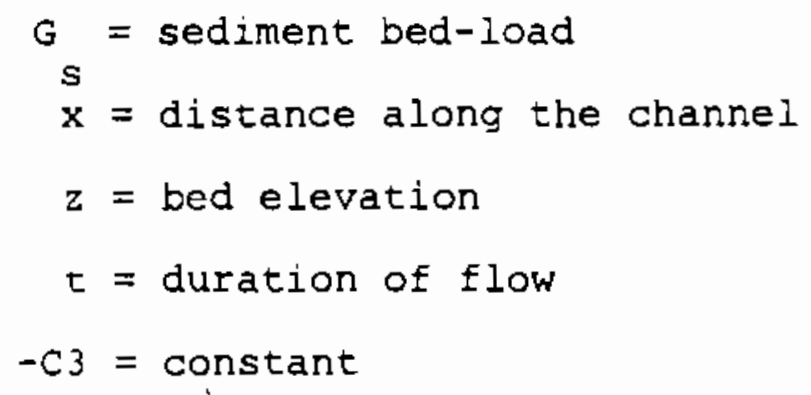

The equation is then solved for the value of $\mathrm{dz}$ and transformed into finite difference form:

$$
\mathrm{d} z=2((\mathrm{G}(\mathrm{k}-1)-\mathrm{G}(\mathrm{k})) / \mathrm{dx})^{*} \mathrm{t}^{\star} \operatorname{coefficient}
$$

where the coefficient converts weight into a volume (units of inverse density). A value of aggradation ( + ) or degradation (-) is computed for each cross-section.

\section{QUASI-DYNAMIC APPLICATION}

In the estimates presented earlier in this report, aggradation and degradation values were based upon the steadystate assumption. For this application, (use of Meyer-Peter and Meuller's equation) we've attempted to simulate an unsteady scenario. For all practical purposes, the methodology used to model sediment transport is, at best, quasi-dynamic.

The methodology used to create this quasi-dynamic approach involves the use of the dual hydrographs for both Sentinel Gap and Wallula Gap (Figure 6.6) in the Pasco Basin. To simulate the flood wave passing through the basin, the discharges and corresponding water surface elevations from the HEC-2 analyses 
for both hydrographs were used as initial input to the model. At roughly the half-way point in the Pasco Basin, near Gable Mountain, the stage of the flow was changed to represent the changing dynamics of the system. This method is a rather crude differencing scheme using Gable Mountain, central Pasco Basin, as a focal point or hinge point as the central node. To simulate the dynamics of the system, the projected water surface elevations used for the Wallula Gap hydrograph were input as the starting conditions for flow coming through sentinel Gap. The results from runs of the HEC-2 program such as water surface elevation, depth of flow, and width of the channel for each discharge value, served as input to the computer code using the Meyer-Peter and Meuller equation. Therefore, this method allowed simulation of sediment transport over an entire flood hydrograph (consisting of individual steady-state events) with modified input parameters creating the quasi-dynamic dimension of the Missoula flood flows.

\section{RESULTS}

Appendix E contains the results of aggradation and degradation values estimated using the methodology mentioned above for the entire flood hydrograph. Estimates have been made for cross-sections 1 through 9 in Figure 4.5. The total amount of sediment moved in meters is summarized below in Table 9.1 for each cross-section. From Table 9.1 it is evident that crosssections 1 and 2 have been affected by the boundary condition that no erosion occurs at cross-section one. The code is set up similarly to the HEC programs in that it works from downstream to 
TABLE 9.1. Summation of aggradation $(+)$ or degradation $(-)$ for the region of the 200 areas using the Meyer-peter and Meuller equation.

$\begin{array}{ccc} & \begin{array}{c}\text { Amount } \\ \text { of }\end{array} \\ \text { Cross-Section } & \begin{array}{c}\text { Aggradation } / \text { Degradation } \\ (\mathrm{m})\end{array} & \\ & 0.000 & \text { downstream } \\ 1 & -51.038 & \\ 2 & 2.031 & \\ 3 & -19.088 & \\ 4 & -3.474 & \\ 5 & -3.392 & \\ 7 & 0.549 & \\ 8 & 0.594 & \text { upstream } \\ 9 & 13.829 & \end{array}$

upstream. Based on the differences in sediment load from crosssection to cross-section and the gradient of the water surface a value of aggradation or degradation is computed. It appears as though the code compensates for this boundary condition by scouring the cross-section upstream from it, cross-section two. Since it is reasonable to assume that the value reporced for cross-section two is due to the boundary effect it is reasonable to use cross-section three as the first cross-section that would give reasonable results.

Over the entire duration of the flood (10 days) large quantities of sediment are transported through the system with large amounts of degradation occurring over the 200 areas (Tank Earms containing nuclear waste). The values reported above are the summation of aggradation/degradation values over the floods duration. Looking more closely at each time step (Appendix E), a majority of the degradation at cross-section four occurs before the repository site is inundated (almost $12 \mathrm{~m}$ ). This still 
leaves over 6 meters that were eroded while the repository was Inundated by flood waters. This is a significant amount since it would only require about 3 meters of erosion before the Tank Farms (200 Areas) would be exposed at the surface. Since large fluctuations occur in the results using the Meyer-Peter and Meuller equation we believe that the mean value computed for cross-sections 3 through 7 (excluding 1 and 2,8 and 9 because of che boundary affect) is a more reasonable estimate of the amount of degradation; mean $=-4.675$, standard deviation $=8.413$, variance $=70.771$.

\section{LIMITATIONS AND UNCERTAINTIES}

As with the HEC-6 results of aggradation/degradation, sources of uncertainty in the methodology are very similar. The major source of uncertainty would have to be in the sediment transport function. Based upon the amount of error between methods of sediment transport in a natural setting (typical nonflood stage rivers), a minimum error of a factor of 2 or 3 can be assessed to these results ( ${ }^{(a)}$ personal commuication from Gessler, 1985). This error does not include the error due to extrapolation to floods of this magnitude. It should also be stressed that the methods developed by Gessler were deveioped for illustration of a concept in degradation in modern day canals. According to Gessler, the algorithm simulated experimental results within 2 or 3 orders of magnitude; which he believed to be adequate. For evaluation, these estimates do not take into (a)

personal communication from J. Gessler, Colorado state University, October, 1985, phone conversation (303)491-1101. 
account the amount of error that may be introduced due to extrapolation of these equations and concepts to a flood of the magnitude of a Missoula-type flood. Also, error is introduced by not utilizing more than one graln-size in these analyses and rreating the flood event as a one-dimensional steady-state process has not been considered. 


\section{CONCLUSIONS}

It is now generally agreed that there have been many floods of the Missoula type within the Scablands of Washington during the last glaciation (the Fraser). Moreover, their have been more than one flood sequence. Other floods have occurred in glaciations older than the Fraser. Evidence preserved within the Pasco Basin itself shows that ac least one of these floods reached an elevation of 1050 feet. Each of the many floods which occurred was probably different from the other floods in at least some of its characteristics. For example, there were probably variations in: volume of water released, ice margin posicion, obstacles in the path of the flood, and chance events leading to cumulative variations in flood behavior. The evidence of flooding within the Pasco Basin, and within the Scablands in general, is time transgresive within a flood and between fioods. It is not certain to which flood to assign evidence preserved at specific localities. Thus, it is dangerous to reconstruct the detailed characteristics of a single flood from the combined field evidence. Some reconstruction of flood behavior has been achieved. This includes especially the contribution of Bretz, Baker, and Patton. Complete understanding of the characteristics of these floods has not been achieved. To do so would require the creation of a three-dimensional unsteady flow dynamic model of the pluvial dynamics. Such a model is not available. In this work we have achieved one-dimensional steady and quasi-steady modelling and have begun creation the of two-dimensional unsteady code sufficient to describe certain characteristics of the dynamics of these floods. 
At least 15 localities within the Pasco Basin and its environs preserve evidence of variations in water level during such Missoula floods (Table 2.1). Analysis of well-logged data obtained by Rockwell Hanford Operations on the Hanford site show that approximately $46 \%$ of the deposits within the Pasco Basin. consist of sand-sized particles, $36 \%$ are gravel-sized and $18 \%$ are finer than sand-sized. The mean thickness of sediments within the Hanford Reservation is approximately 39 meters and the scandard deviation is more than 83 meters.

A one-dimensional steady-state analysis of flood dynamics in the upper Pasco Basin was achieved using the HEC-2 code. This work began with a development of a rating curve for Wallula Gap. At wallula Gap, it was assumed that the flow was critical at the downstream section. To achieve the high water marks at walluia Gap requires a discharge of approximately 12.5 Mcms.

With these data available a rating curve was deveioped Sentinel Gap using three different methods. The first was a slope-area method in which it was assumed that the slope of the water surface equals the bed slope, approximately 0.004 . With chis method it was found that to achieve the high water marks at Sentinel Gap would require a discharge of $34.6 \mathrm{Mcms}$. This discharge greatly exceeds any estimated discharge for Missoula floods at any point in the flood system. It is unlikely that such a discharge occurred at Sentinel Gap. Rather, we conclude that high water marks at Sentinel Gap were achieved in a backwater relation set up by ponding in Wallula Gap. It did not arise from high discharges of water passing unimpeded through 
Sentine1 Gap.

To convey the effects of such a backwater situation, a second method was used to estimate discharge characteristics in the upper Pasco Basin. The elevation of the water surface at the downstream end of the cross-sections used at Sentinel Gap is fixed. The water surface was fixed at an elevation of 350 meters which corresponds to Baker's estimate of the high water marks at Wallula Gap. This is equivalent to projecting a horizontal water surface from the upper end of the Wallula Gap area to Gable Mountain. The resulting M1 curve showed that a discharge of 7.5 Mcms was required in order to produce the high water marks of 366 meters at sentinel Gap. This lead to a discharge of $16 \mathrm{~m} / \mathrm{sec}$ at the Gap.

A more realistic method of estimating discharge in sentinel Gap during backwater ponding was also used. In this case we projected the slope of the water surface at the upper end of Wallula Gap back to the downstream cross section at Gable Mountain. This was used as a starting condition for computation of water surface gradient up to sentinel Gap itself. This lead to an estimate of a discharge of 9.5 Mcms required to produce the high water marks of $366 \mathrm{~m}$ at Sentinel Gap. We believe that this is the most realistic estimate available. We conclude from this that the maximum floods that would occur strictly down the Columbia River would be a discharge of less than 9.5 Mcms.

We use the HEC-6 steady state code to compute sediment cransport characteristics in the upper Pasco Basin. Four separate transport equations were applied. The inflow sediment curve used in this computation was based on the assumption that 
all sediments currently in the Pasco Basin were deposited by a single Missoula flood. This is equivalent to assuming that the amount deposited in each flood is a constant. We used a fixed discharge, Baker's estimate of the maximum at wallula Gap, for a 14 day period in order to estimate the sediment transport characteristics during a flood. A single grain size was used in the analyses. Two separate analyses were done. One with a grain size of $64 \mathrm{~mm}$ and the second with a grain size of sand. The four sediment transport equations that were used were those of DuBoys, Toffaletti, Yang, and Madden's modification of Laursen's method.

In general, with the larger grain size (gravel) very little activity was observed at the 200 Areas. Indeed, Yang's equation estimated that deposition up to 10 meters would occur at that site. Using a grain size of sand, which is the more common grain sized observed in the Pasco Basin, all of the sediment transport equations computed some amount of scour in the 200 Areas. The DuBoys function estimated as scour in the range four to nine meters. Yang's equation estimated three to four meters of scour, Toffaletti's method estimated very little scour, an amount hardly observable, and Madden's modification of Laursen's method estimated scour in the range of one-third of a meter. We assume that the analyses using sand size are more reailstic. These still represent a minimum amount of scour that would occur within the area. Computations that were done were not the most realistic available, further modifications are discussed below. In order to achieve a more reasonable estimate of the fluid dynamics during such a flood, a hydrograph was synthesized using 
an assumption that the water discharge follows the form of a Poisson function over the duration of the flood. Using this procedure we found that the maxima of the flood would occur after 90 hours within the flood at Sentinel Gap. It would occur at 114 hours at Wallula Gap. Thus, there is approximately a one day lag in the system between the maxima at the two gaps. During this time water continues to accumulate within the Pasco Basin. Approximately 186 cubic kilometers of water finally accumulate within the Pasco Basin. During this time velocities at the 200 Areas are probably fairly low. The 200 areas will remain Innundated for approximately four days and six hours. This represents the period of time during which erosion and transport of sediment would occur at the 200 Areas.

Using this information a quasi-dynamic sediment transport computation was achieved using the same HEC- 6 code. In this case, in order to estimate the sediment transport inflow, an assumption that the amount of sediment entering the Pasco Basin equals the amount of sediment leaving the Pasco Basin over the cumulative period was made. We modified the inflow sediment nydrograph in order to achieve this assumption. The computation showed that the methods of Toffaletti and DuBoys are not reliable at these high discharges. In the case of Toffaletti, the sediment transport amounts were too little to be considered realistic. In the case of DuBoys, the sediment transport amount was much too great to be considered realistic. It is known from the iiterature that the DuBoys equation must be modified in order to apply it to high sediment and water transport rates.

The results of use of Madden's modification of the Laursen 
method and of using Yang's transport equation agreed fairly closely. The former estimated an erosional amount of approximately 0.61 meters. The latter estimated the erosion would be on the order of 0.915 meters. These agree as closely would be considered reasonable. We still consider this to be a minimum amount of erosion within the area. We note that the amount of erosion is highly variable between cross sections in the sequence that were analyzed. These results approximately agree with the earlier methods using the steady state assumption. A high degree of variability between cross sections suggests to us that the amount of erosion at any one site would be variable through time and it would probably be more safe to use the maximum erosion that was observed at any one cross section as the best estimate of the amount of erosion that could occur at the 200 Areas. This suggests that total scouring to the base of the Hanford Formation could occur during a flood. This will involve a great deal of reworking of sediment and redeposition of that sediment within the Pasco Basin.

In order to achieve a more realistic estimate of flood characteristics, a two-dimensional unsteady flow model has been defined and a multi-operational method invoked in order to achieve solutions. Preliminary analyses have been done and they suggest that useful solutions of flood dynamic characteristics within the Pasco Basin can be achieved through the use of a combined hydrograph as synthesized for Sentinel Gap and wallula Gap. We believe that this work should continue in order to estimate transport characteristics within the Pasco Basin. 
A final analysis that was done was to incorporate another set of transport equations, the Meyer-Peter and Meuller equations into a new set of computer code. Solution of the Meyer-Peter Meuller equations was achieved through the use of the discharge characteristics computed with the HEC-2 code. We found that the results of this analysis was very comparable to the quasi-dynamic analysis using HEC-6. Slightly less than 1 meter of net scour was observed within the 200 areas. More extensive erosion was achieved during particular time steps of this analysis suggesting again that a great deal of re-working of sediment would occur within the Pasco Basin during a Missoula flood.

We conclude from these analyses that instability of at least the top meter of surface material would occur during a Missoula flood. We consider quite likely that greater depths of sediment would be involved in transport during such a flood and tnere 15 some probability that all of the material in the Pasco Basin would be re-worked at least a small degree during each Missoula flood that would occur. We believe that more sophisticated sediment transport models coupled to a dynamic model oî twodimensional flood behaviour would be required in order to achieve more useable results. 


\section{DISCUSSION}

Net erosion at the 200 areas during a scablands flood may be as little as $1 \mathrm{~m}$ or as great as $40 \mathrm{~m}$. There could be as much as several orders of magnitude error in the computations of sediment transport, even for simple flood problems. This range of estimates illustrates the uncertainty of calculations for Missoula-scale floods. That uncertainty will have an important effect on conclusions concerning the stability of the site. Three separate approaches to the computations of sediment transport have been done. The results have been reasonably consistent.

There is some difficulty resolving the small amount of erosion at the lower end of our estimates with our understanding of the sedimentological evidence in the Pasco Basin. There is very little evidence of multiple flood deposits within tne 200 areas. It appears as if these sediments are the deposits of only a single flood. This must be resolved with evidence that there were many scablands floods which passed through the Pasco Basin. The simplest explanation is that each flood entrains all of the material which is already there, removes it or reworks it, and then deposits a new layer to replace it.

If there was only one flood which reached the elevations of the 200 areas, deposition by that flood of all existing sediment would be reasonable explanation of the lack of multiple flood layers. It is possible that there were multiple floods but only one which reached the elevation of the 200 areas. However, there is no evidence of the kind of terracing or stratification that would be expected in the Pasco Basin if the various floods were 
of markedly different discharges. On the basis of the analyses of the discharges from Lake Missoula (Craig, Singer and Underberg, 1983), there is no reason to believe that there would only be one flood with such a large magnitude. It is much more likely that there would be many floods large enough to reach that level.

These analyses suggest that the total volume of sediment in the Pasco Basin is probably a fairly close approximation -- as much as 50 용 -- of the material entrained within a single flood and passing through wallula Gap. If that is the case, there may be a lot of reworking of sediment within the Pasco Basin. Once a flood deposits the material, the next flood moves the material around within the Pasco Basin but does not necessarily transport It out of the Basin. It just reworks it and leaves it fairly close to its original place. This is the favored scenario based on these analyses. Probably only a small fraction of the sediment would leave the Pasco Basin and a much smaller part would get down as far as Portland, Oregon. Perhaps, a negligibly small part.

Significant net deposition in each flood is not a iikelihood. The evidence suggests multiple floods through the Basin. If there had been a tendency for deposition in that area, one might expect differentiable strata in the 200 area. Such multiple flood layers (of different ages) are not recognized. If chere is reworking, there might also be net deposition, with sediment thickness slowly increasing over time. We don't have enough evidence to suggest that is probable. The amount of 
material that could be expected to accumulate during one flood can be estimated (present thickness/number of floods $=39 \mathrm{~m} / 40<$ Im). It would undoubtedly be added near the end of a flood, after some erosion had occurred.

If there is significant net deposition at the 200 areas, it is not deposition in the sense of a layer deposited on top of what is already present. It would be net deposition in the sense of additional sediments mixed with, and thoroughly reworked with, the materiais which are already there. On average, only a little more sediment would end up there in each flood. There would still be a net transport of the actual material which was at the 200 area.

The depth of scouring is greater than the erosion estimate given earlier $(1 \mathrm{~m}$ to $10 \mathrm{~m})$. Probably all of the unconsolidated materials down to, but not including, the Ringold Fm. would be entrained to a sufficient extent to rework the material and probably destroy any existing sedimentary structures in it. New structures would be formed and it would look like a new deposit, out the amount of entraiment and how far that sediment was cransported may not be very great.

Total reworking is a more likely case based on the uncertalnties in the calculation and the known flood record and probable scenarios. Deep scouring seems likely despite the fact that the calculations suggest a most probable net scouring of 2 to 4 meters. Because of this reworking, a great portion of the sediment undergoes some net movement. It no longer remains within the 200 area. We must assume that the entire mass will move. It is just a question of the extent -- it may be a very 
small amount of motion. The material may not move out of the 200 area; if may only move a meter or two. But it is likely that it will move.

The concept of reworking has some basis in standard theory of stream transport. Current notions suggest that stream transport occurs intermittently. Sediment may be transported primarily in large events, then stored a short distance downstream until the next large event (Schum, 1977). The toral amount of motion involved is probably not that great. The majority of the sediment does move, but is quickly redeposited, so it is not an effective scouring.

Great amounts of erosion do occur at some locations within the Pasco Basin. This is a function of the different hydraulics (super-cricical flow and cavitation) that occur at constrictions like wallula Gap. In the very broad areas of the Pasco Basin, extreme erosion is quite unlikely. It appears fairly certain that during the greatest discharges waters in the 200 area were probably relatively placid. The greatest amount of work goes on in the very early stages of the flood at any given site. Later in the flood, the whole cross- section that inciudes the 200 areas and Gable Mountain would probably have little active transport compared to what occurs at the gaps themselves. The initial surge down the Columbia River will almost surely reach the level of the 200 areas. It probably would not inundate the site to a great depth; it would still involve quite high velocities. The high velocities are apparently short lived, so the net transport is not that great, at least with the formulas 
we have been using.

Some sediment will be entrained and transported for a great distance. This is especially true of the upper meter or two because it is scoured in the early stages. The water then quickly backs up from wallula Gap, creating a lake. Velocities drop off quickly enough so that reworking of the sediment becomes the dominant process. The sediment lower in the section, below the top few meters, may be transported for a relatively small distance.

Although the total amount of material transported during a flood is perhaps no more than twice the volume of material in the Pasco Basin, a flood could conceivably remove all of the sediment In the Pasco Basin. The sediments now there may be totally new material deposited by the last flood. It is not possible to state how the reworking goes on without a fuily couplea-model of sediment and water. At present we have the water hydrograph and a separate analysis of sediment transport. The sediment could all go; but, in the most likely case, most of the sediment now in the Pasco Basin would not leave the Pasco Basin. It would still be there, but it may be in a very different location in the pasco Basin.

These results differ from earlier estimates of total sediment transport during a flood because they make use of a more dynamic model of the flood behavior. We have not had such a model before. The variations in hydraulics during a flood are quite important. Normal hydrologic analyses -- such as the HEC-6 model -- are actually equilibrium models. They provide an idea of what the erosion would be like if flows continue at a 
discharge for an indefinite period. We have tried to represent the fact that it does not continue at that very high magnitude. Analyses with less exact approaches have given the impression of enormous amounts of transport involved in one of these floods. One of the limitations of this analysis is that we must assume a single sediment size. The mean sediment size within the area was used. For a worst case scenario, a much smaller sediment size might be used. The well logs from Rockwell were used to characterize the Hanford Formation. The HEC- 6 code is not capable of handling anything more sophisticated chan a single grain size. It has been run several times using different sizes. But even that is not the best answer, because the mixture of sizes is important in the behavior of the flood. Obviously, use of the mean size, cannot represent what could happen if material were covered with a rip-rap of a larger median diameter. The resuits suggest that a storage system might be engineered that could be expected to survive. Because of uncertainties in the analysis, this is not a firm conclusion. If the tanks have not disintegrated, there could be concentration of fow and the exact design would be of importance. We have done the analysis on the assumptions that the canisters corroded and the material had the characteristics of the typical surrounding sediments. 


\section{REFERENCES}

Atwater, B.F. 1984. "Periodic Floods from Glacial Lake Missoula Into the Sanpoil Arm of Glacial Lake Columbia, Northeastern washington." Geology. 12:464-467.

Baker, V.R. 1973. "Paleohydrology and Sedimentology of Lake Missoula Flooding in Eastern Washington." Geol. Soc. America Special Paper 144:1-73.

Baker, V.R. 1978a. "Paleohydraulics and Hydrodynamics of Scabland Floods." In The Channeled Scablands, eds. V.R. Baker and D. Numnedal, pp, 59-79. National Aeronautics and Space Administration, washington, D.C.

Baker, V.R. 1978b. "Large-Scale Erosional and Depositional Features of the Channeled Scabland." In The Channeled Scablands, eds. V.R. Baker and D. Numedal, pp, 81-115. National Aeronautics and Space Administration, washington, D.C.

Baker, V.R. 1978c. "Quaternary Geology of the Channelled Scabland and Adjacent Areas." In The Channeled Scablands, eds. V.R. Baker and D. Numedal, pp, 17-35. National Aeronautics and Space Administration, Washington, D.C.

Baker, V.R., and R.C. Bunker, 1985. "Cataclysmic Late Pleistocene Flooding from Lake Missoula: A Review." quaternary Science Reviews. $4: 1-41$.

Bjornstad, B.N. 1980. Sedimentology and Depositional Environment of the Touchet Beds, Walla walla River Basin, Washington. RHO-WHI-SA-44, Rockwel1 Hanford Operations, Richland, washington.

Bretz, J.H. 1923a. "Glacial Drainage on the Columbia Plateau." Geol. Soc. of Am. Bul1. 34:573-608.

Bretz, J.H. 1923b. "The Channeled Scablands of the Columbia Plateau." J. 요 Geol. 31:617-649.

Bretz, J.H. 1924. "The Dalles Type of River Channel." J. of Geol. 32:139-149.

Bretz, J.H. 1925. "The Spokane Flood Beyond the Channeled Scablands I." J. of Geol. 33:97-115.

Bretz, J.H. 1926. "The Spokane Flood Beyond the Channeled Scablands II." J. of Geol. 33:236-259.

Bretz, J.H. 1927a. "Channeled Scabland and the Spokane Flood." Washington Academy Science Journal. 17(8):200-211.

Bretz, J.H. 1927b. "The Spokane Flood: A Reply." J. of Geol. $35: 461-468$. 
Bretz, J.H. 1928b. "Bars of the Channeled Scabland." Geol. Soc. of Am. Bull. 39:643-702.

Bretz, J.H. 1929. "Valley Deposits Immediately East of the Channeled Scablands of washington I and II." J. of Geol. $37: 393-427,505-541$.

Bretz, J.H. 1930a. "Lake Missoula and the spokane Flood." Geol. Soc. of Am. Bull. 41:461-468.

Bretz, J.H. 1930b. "Valley Deposits Immediatley west of the Channeled Scablands." J. of Geol. 38:385-422.

Bretz, J.H. 1932. "The Grand Coulee." Am. Geog. Soc. Spec. Pub. $15: 89$.

Bretz, J.H., H. Smith, and G. Neff. 1956. "Channeled Scabland of Wahington: New Data and Interpretations:" Geol. Soc. of An. Bull. 67:967-1049.

Bretz, J.H. 1959. "Washington's Channeled Scabland." Wash. Dept. Conserv., Div. Mines and Geology Bull. 45:57.

Bretz, J.H. 1969. "The Lake Missoula Floods and the Channeled Scabland." J. of Geol. 77:505-543.

Chambers, R.L. 1971. Sedimentation in Glacial Lake Missoula. Unpublished Master's Dissertation. Univ. of Montana.

Clarke, G.K., W. Mathews and R. Pack. 1984. "Outburst Floods from Glacial Lake Missoula." Quat. Res. 22:289-299.

Chow, V.T. 1959. Open-Channel Hydraulics. New York, McGrawHill Book Company, 680 pp.

Craig, R.G., M. Singer and G. Underberg. 1983. Analysis of IceAge Flooding from Lake Missoula. Prepared for Battelle Memorial Institute, Pacific Northwest Labs under contract B-F7204-A-H.

Craig, R.G., M. Singer. 1984. "A Theoretical Study of Lake Missoula Jokulhlaups in the Late Pleistocene." Geol. Soc. of Am. Abstracts with Programs. 16:276-277.

Fecht, K.R., and J.T. Lillie. 1982. A Catalog of Borehole Lithologic Logs from the 600 Area, Hanford Site. RHO-LD158 , Informal Report, Rockweli hanford Operations, Richland, washington.

Garde, R.J., and K.G. Ranga Raju. 1978. Mechanics of Sediment Tranportation and Alluvial Stream Problems. Wiley Eastern Limited, $483 \mathrm{pp}$. 
Gessler, J. 1970. "Aggradation and Degradation." Chapter 8. In River Mechanics, ed. Hsieh Wen Shen, Colorado state University.

HEC-2. Hydrologic Engineering Center. 1982. Water Surface Profiles. (HEC-2) User's Manual. $290 \mathrm{pp}$.

HEC-6. Hydrologic Engineering Center. 1977. Scour and Deposition in Rivers and Reservoirs. (HEC-6) User's Manual. $168 \mathrm{pp}$.

HEC. Hydrologic Engineering Center. 1976-1982. Video Cassette Support Documentation of the HEC-2 and HEC-6 Computer Programs.

Meyer-Peter, E., and R. Meuller. 1948. "Formulas for bed-Ioad transport." Proc. of 2nd Congress, IAHR, Stockholm.

Nye, J.F. 1976. "Water Flow in Glaciers: Jokulhlaups, Tunnels and Veins." J. of Glaciology. 17(6):181-207.

Pardee, J.T. 1942. "Unusual Currents in Glacial Lake Missoula." Geol. Soc. Am. Bul1. 53:1570-1599.

Patton, P.C., and V.R. Baker. 1978. "Origin of the CheneyPalouse Scabland Tract." In The Channeled Scabland, eds. V.R. Baker and D. Nummedal, pp. 117-130. National Aeronautics and Space Administration, Washington, D.C.

Ponce, V.M. 1982. "Kinematic Dynamic and Inertial Waves." In Applied Sedimentation and River Engineering, College of Extended Studies, Professional Development, San Diego State University, Jan. 17-20, 1984.

Shen, H.W. 1970. "Introduction." Chapter 1. In River Mechanics, ed. H.W. Shen, Colorado State University.

Shen, H.W. 1982. "Wash Load and Bed Load." In Chapters 8 and 9 of Fluvial Processes Short course notes.

Singer, M., and R.G. Craig. 1984. "Volume-Area-Depth Relations in the Lake Missoula Basin." Geol. Soc. of Am. Abscracts With Programs. $16: 333$.

Tallman, A.M., J.T. Lillie and K.R. Fecht. 1981. "Suprabasalt Sediments of the Cold Creek Syncline Area." In Subsurface Geology of the Cold Creek Syncline. RHO-BWI-ST14, Rockwell Hanford Operations, Richland, Washington.

Tallman, A.M., and K.R. Fecht. 1978. Bergmounds Along the Western Margin of the Channeled Scablands, South Central Washington. RHO-EWI-SA-11, Rockwell Hanford Operations, Richland, washington. 
Toffaleti, F.B. 1969. "Definitive Computations of Sand Discharge in Rivers." A.S.C.E. J. of the Hydraulics Div. $95: 225-248$.

Underberg, G.L. 1983a. Revisions to a Geomorphic Events Simulation Model for a Hypothetical Nuclear waste Disposal Site in the Columbia plateau, Washington. Report to Argonne National Laboratory, Argonne, Illinois.

Underberg, G.L. 1983b. Revisions to a Geomorphic Events Simulation Model for a Hyoothetical Nuclear Waste Disposal Site in the Columbia Piateau, Washington. Unpublished Master's Dissertation, Kent State University.

Waitt, Richard B. 1979. "Forty Late-wisconsin Catastrophic Lake Missoula Back Floodings of the Walla Walla and Lower Yakima Valleys, Southern Washington." In Geol. Soc. Am. Abstracts With Programs. 11:133.

Waitt, Richard B. 1980. "About Forty Last-Glacial Lake Missoula Jokulhlaups Through Southern Washington." J. of Geol. $88: 653-679$.

Waitt, Richard B. 1983. Tens of Successive, Colossal Missoula Floods at North and East Margins of Channeled Scabland. U.S. Geological Survey Open-File Report 83671, Friends of the pleistocene, Rocky Mountain Cell.

Waitt, Richard B. 1984. "Periodic Jokulhlaups from Pleistocene Glacial Lake Missoula - New Evidence from Varved Sediment in Northern Idaho and Washington." Quat. Res. 22:46-58.

Waitt, Richard B. 1985. "Case for Periodic, Colossal Jokuihlaups from the Pleistocene Glacial Lake Missoula." Geol. Soc. of Am. Bull. 96(10):1271-1286.

Yalin, M.S. 1976. Mechanics of Sediment Transport: Pergamon Press, 297p.

Yang, C.T. 1973. "Incipient Motion and Sediment Transport." A.S.C.E J. of the Hydraulics Div. 99:1679-1704. 


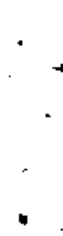

"

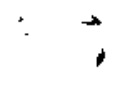

$-$

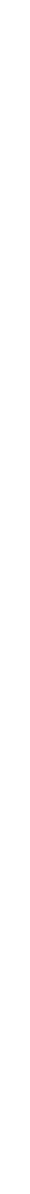


APPENDIX A

SEDIMENT SIZE DISTRIBUTION FOR THE HANFORD RESERVATION 


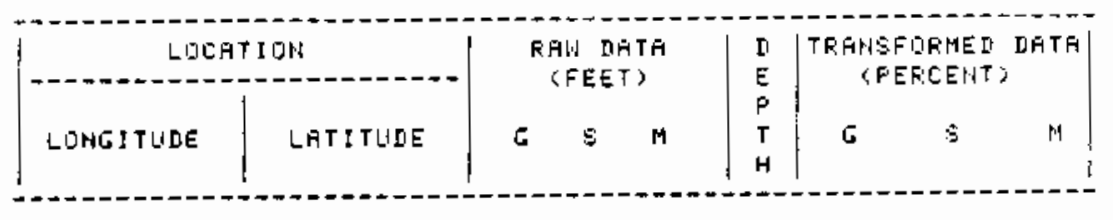

\begin{tabular}{|c|c|c|c|c|c|c|c|c|c|c|c|c|}
\hline 119 & 35 & 20.5 & 45 & 38 & 18.0 & 56 & 5 & $2 !$ & 65 & 5.5 .9 & 9.4 & 24.7 \\
\hline $11 \%$ & 39 & $6 . \bar{\theta}$ & $4:$ & $\$ 7$ & 58.0 & 27 & $1:$ & $2+$ & $7 \overline{1}$ & 83.8 & $25 . ?$ & 34.5 \\
\hline $1: 9$ & 17 & $27 . \overline{0}$ & 46 & $2 !$ & 59.6 & 17 & 17 & $1 \because$ & 45 & 37.0 & 37.0 & 25.9 \\
\hline 115 & 16 & 56.9 & 46 & 21 & 28.6 & 23 & 23 & 0 & +5 & 50.5 & $50 . \overline{1}$ & $\overline{0} . \overline{6}$ \\
\hline 110 & 1 is & 33.5 & 45 & $\approx 1$ & 45.0 & 19 & 34 & 3 & 55 & 30 & 51.5 & 4. 5 \\
\hline 19 & 25 & 3.5 & 40 & 22 & 39.4 & 1.5 & $1 \bar{y}$ & 5 & 29 & 50.6 & 32.3 & 17.2 \\
\hline 19 & 18 & 44.0 & $4 E$ & 23 & E. B. & '吅 & 38 & 8 & 75 & $+5,15$ & 50.6 & $1 \overline{0} 0$ \\
\hline 13 & 22 & $\Xi 2 . \overline{4}$ & $4 E$ & 25 & 15.6 & 1.5 & $\dot{E}$ & 15 & 95 & 15.5 & 5.2. & 15.3 \\
\hline 119 & 24 & $27 . \overline{0}$ & 45 & 25 & 57.6 & 0 & 100 & 8 & $1 \overline{1} \overline{1}$ & 1. & 156.5 & 音. \\
\hline 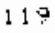 & ZE & 45, & 48 & 24 & 27.6 & $\bar{b}$ & 5 & $E$ & 15 & 1. & 50.5 & 55.5 \\
\hline 19 & 16 & 50.5 & 45 & 24 & 33.1 & $2: 3$ & $E$ & $E$ & 35 & 56.7 & 15.7 & 10.7 \\
\hline 115 & 38 & 52.5 & 48 & 43 & 6.5 & 10 & 21 & $1:$ & 43 & 32.6 & $40:$ & 24.3 \\
\hline 119 & 30 & 51.0 & $4 E$ & 43 & 7.0 & 13 & 16 & 13 & 41 & 30.5 & $3: 2$ & इ \\
\hline 119 & 30 & 54.6 & 46 & 43 & $? .5$ & 2 घี & 20 & 7 & +7 & 42.5 & 42.6 & 14.5 \\
\hline 19 & 29 & 46.5 & 48 & 42 & 23.5 & 18 & 15 & 3 & 45 & 40.7 & 40.7 & 18.5 \\
\hline 119 & 31 & 12.0 & $40^{\circ}$ & 42 & 16.0 & 23 & 23 & 15 & Eต & $3 \overrightarrow{7} .5$ & 37.5 & 25.5 \\
\hline 119 & 23 & 56.8 & 46 & 35 & $1 \mathbf{s}, \overline{0}$ & 43 & 37 & 5 & 79 & 53.8 & 46.2 & b. 9 \\
\hline 119 & 17 & 4.8 & 46 & 15 & 53.0 & 20 & 22 & 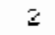 & 44 & 45.5 & $56 . \overline{0}$ & 4.5 \\
\hline 119 & 38 & 17.8 & 48 & 44 & 4.5 & $a$ & 10 & 0 & 16 & 0.5 & 1 ยั. & Б. \\
\hline 113 & 16 & 50.6 & 46 & 15 & $3+.6$ & 17 & 12 & 5 & 33 & 54.5 & 35.4 & 14.2 \\
\hline 119 & 16 & 57.5 & 45 & 15 & 11.8 & 13 & 0 & $B$ & 13 & 100.5 & 0.0 & $5 . \overline{5}$ \\
\hline 119 & 17 & 4.0 & $4 \hat{0}$ & 15 & 33.0 & 12 & 15 & $\overline{3}$ & 35 & 34.3 & $4 \approx 2$ & 22.9 \\
\hline 119 & 17 & 4.0 & 45 & 15 & 43.0 & 25 & 37 & 10 & 76 & 32.5 & 52.9 & 14.3 \\
\hline 119 & +3 & 30.6 & 46 & 34 & 37.0 & 11 & 20 & $2 \overline{1}$ & 50 & 23.0 & $3+6$ & 39.5 \\
\hline 115 & 17 & 34.6 & 40 & 16 & 25.0 & 23 & 55 & $\mathfrak{b}$ & 77 & 25.2 & 70.6 & $\bar{\theta} . \overline{0}$ \\
\hline 119 & 17 & 3.5 & 46 & 16 & 24.0 & 1 & 15 & 15 & 31 & 3.2 & 48.4 & 43.4 \\
\hline 115 & 17 & 16,0 & 46 & 16 & $3 \% .0$ & 38 & 19 & $! 1$ & 68 & 55,5 & 27.7 & $1 \in .7$ \\
\hline 119 & I 7 & 3.0 & $4 \hat{E}$ & 16 & 34.0 & 6 & 6 & 0 & $1 !$ & 50,5 & 30.0 & 6.8 \\
\hline $11 \%$ & +3 & 31.0 & 45 & 34 & 37.0 & 0 & 0 & 5 & 5 & 0.0 & 0.0 & 100.0 \\
\hline 119 & 16 & 46.8 & $4 E$ & 15 & 33.0 & 23 & $2: 3$ & 0 & 51 & 45.1 & 54,9 & 0.6 \\
\hline 119 & $1 ?$ & 28.0 & 40 & 16 & 50.0 & 48 & 36 & $\theta$ & 84 & 57.1 & 42,9 & घ. 0 \\
\hline 119 & 17 & 28.8 & 45 & 16 & 50.6 & 34 & 37 & 6 & 70 & 47.9 & 52.1 & 6.3 \\
\hline 119 & $1 ?$ & 2.0 & 46 & 16 & 52.0 & $\hat{0}$ & 12 & 6 & 12 & 8.5 & $1 \dot{\bar{b}}, \bar{b}$ & a. $\bar{v}$ \\
\hline 115 & 15 & 11.0 & 45 & 21 & 18.0 & $\dot{v}$ & 2 & 3 & $z$ & $\overline{0 .} \overline{1}$ & 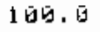 & 5.0 \\
\hline 119 & 15 & 56.0 & 45 & 18 & 8.0 & 5 & 8 & $\overline{1}$ & 5 & 109.5 & 0.0 & $\hat{6} .6$ \\
\hline 119 & 15 & 34.0 & 46 & 18 & 19.6 & 13 & 10 & 6 & 21 & 54.8 & 45.2 & 8.0 \\
\hline 119 & 10 & 1.51 & 45 & 18 & 28.5 & 28 & 26 & $\bar{a}$ & 53 & 51.9 & $+\vec{e} .1$ & 0.0 \\
\hline$: 19$ & 17 & 9.5 & +6 & 18 & +3.13 & 19 & $1 E$ & 8 & 38 & 5 घี. & 43.13 & 6.1 \\
\hline 19 & 17 & 1.6 & 45 & 18 & +2.0 & 18 & $2 \%$ & is & 40 & +3.8 & $5 E .3$ & $\ddot{\theta} . \bar{\theta}$ \\
\hline 117 & 15 & 56.4 & 46 & 13 & $3 E .0$ & 11 & 18 & 0 & 59 & 27.5 & ELE & 1.1 \\
\hline 119 & 15 & 51.5 & 45 & 15 & 30.0 & 40 & 35 & 6 & 73 & $5+.5$ & +5.2 & 8. \\
\hline 119 & $: 5$ & $5+.6$ & $40^{\circ}$ & 18 & 35.0 & 22 & $1 \mathrm{E}$ & $\because$ & +1 & $52 .+$ & $4 \geq . ?$ & 4.5 \\
\hline 117 & 15 & 50.0 & $4 \hat{0}$ & $: \xi$ & 30.4 & 26 & +5 & $\breve{b}$ & PG & 36.4 & $5 \%, 5$ & 0.5 \\
\hline 119 & 15 & 50.0 & 45 & 15 & 40.5 & 22 & 23 & $\overline{0}$ & 44 & +3.9 & 51.1 & घ. \\
\hline 119 & 15 & 57.9 & 46 & 20 & 59.0 & 8 & 80 & 5 & 27 & 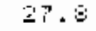 & 72.0 & $\theta .0$ \\
\hline 115 & $10^{\circ}$ & $\therefore 9.6$ & +6 & 15 & 50.0 & 30 & 31 & ij & $0 E$ & 53.5 & 45.2 & $\overline{0} . \overline{0}$ \\
\hline 119 & $1 \hat{0}$ & 23.6 & $4 E$ & 19 & 37.0 & 20 & 33 & 2 & 83 & 44.7 & $52 . ?$ & 2. ? \\
\hline $1 ! 9$ & $! \dot{t}$ & 58.6 & 45 & 21 & 23.4 & 25 & 55 & $\overline{1}$ & 50 & 50.0 & 50.5 & $\overline{0} . \bar{v}$ \\
\hline 119 & 18 & 40.3 & 45 & 18 & 47.9 & 5 & 23 & aे & רי & 16.7 & :3.3 & 0.6 \\
\hline 119 & $1 ?$ & 38.0 & 46 & 19 & 23.0 & 20 & $1 \overline{7}$ & 2 & 48 & 50.0 & 40.3 & 3.8 \\
\hline 119 & 16 & 23.0 & 46 & 19 & 37,13 & 32 & 27 & 12 & 71 & 45,3 & 33.3 & 16.4 \\
\hline 119 & 17 & 54.15 & 46 & 19 & 35.0 & 20 & 15 & 5 & 40 & 50,0 & 37.5 & 12.5 \\
\hline 119 & 17 & 44,5 & 46 & 14 & $4 \hat{4} . \dot{0}$ & 32 & 50 & 3 & 44 & 72.7 & 21.0 & 5.7 \\
\hline 119 & 16 & 27.6 & $4 E$ & 19 & +6.5 & 29 & 38 & $\bar{u}$ & $E T$ & 43.3 & $5 \in .7$ & 0.0 \\
\hline 119 & 16 & 22,1 & $4 E$ & 19 & 43.0 & 38 & 18 & 5 & EE & ET. & 32.1 & $\overline{\mathbf{u}} \cdot \overline{\mathrm{b}}$ \\
\hline 11 & 10 & 19.0 & 45 & 26 & $5 . \overline{1}$ & 54 & 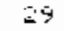 & $\mathfrak{1}$ & 83 & ES. 1 & 34.9 & 0.5 \\
\hline 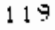 & $1 \dot{8}$ & 22,4 & 45 & 19 & 50.0 & 45 & 23 & $\overline{\mathbf{v}}$ & 73 & $E 1.6$ & 39.6 & 0.6 \\
\hline
\end{tabular}




\begin{tabular}{|c|c|c|c|c|c|c|c|c|c|c|c|c|}
\hline 119 & 15 & 53.0 & $4 \hat{E}$ & 20 & 43.15 & 19 & 10 & 0 & 28 & $E \in .1$ & 33.9 & 0.0 \\
\hline 119 & 17 & 0.0 & 45 & 13 & 59.0 & 57 & $\exists$ & $\bar{G}$ & 56 & 30.4 & 13.6 & B. 0 \\
\hline 119 & 16 & 21.0 & $4 \epsilon$ & 15 & 50.6 & 36 & $3 \dot{15}$ & $\dot{\theta}$ & 80 & 50,0 & 50.6 & 0.0 \\
\hline 119 & 16 & 49.0 & 46 & 19 & 58.6 & 11 & 47 & 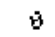 & 53 & $19 . \overline{0}$ & 81.6 & $\overline{0} . \overline{6}$ \\
\hline 119 & 15 & 33.0 & 40 & 13 & 57.5 & 22 & 23 & 0 & 43 & 56.0 & 50.0 & 6.6 \\
\hline 19 & 17 & a. a & $4 E$ & 19 & 57.0 & 51 & 7 & 1 & $E G$ & 3.5 .6 & 12.2 & 2.2 \\
\hline 19 & 25 & 27.0 & 46 & 36 & 47.0 & 29 & 24 & 9 & 61 & $46 . ?$ & 38.5 & $1+\varepsilon$ \\
\hline 19 & 31 & 37.6 & $40^{\circ}$ & 36 & +3.0 & 11 & 13 & 2 & 25 & +2.7 & 50.7 & $\epsilon .7$ \\
\hline 115 & 32 & 41.0 & 45 & 36 & 44,0 & 30 & 32 & $\ddot{z}$ & 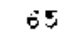 & $48 . ?$ & 48.7 & 2.6 \\
\hline 119 & 23 & 20,6 & 46 & 36 & 45.0 & 80 & 49 & 2 & $11 \overrightarrow{0}$ & 54.1 & 44.1 & $1 . z$ \\
\hline 115 & 41 & 5.0 & 46 & 36 & 49.0 & 80 & 38 & 0 & 117 & 67.9 & 30.1 & 0.0 \\
\hline 119 & 31 & 30.0 & 46 & 37 & 4.6 & 42 & 57 & 2 & 101 & $4 !, 8$ & $5 \in . \theta$ & 1.7 \\
\hline 119 & 33 & 36.0 & 48 & 27 & ఈ. & 79 & 53 & 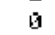 & 133 & 57.2 & 42.8 & 0.5 \\
\hline 119 & 35 & 20.5 & +8 & 37 & 5.0 & $E \bar{y}$ & 44 & $\vec{z}$ & 115 & 00.1 & 38.4 & 1.5 \\
\hline 19 & 25 & 1.6 & $4 \hat{E}$ & 37 & 14.6 & 21 & 3 & $\dot{y}$ & 40 & $5+.2$ & 22.9 & 22.3 \\
\hline 19 & 28 & 36.0 & 4 & 37 & $15 . \overline{6}$ & 10 & 15 & 7 & 27 & 36.4 & 35.4 & $\approx 7.1$ \\
\hline 19 & 28 & 57. & 40 & 27 & $1 \in .0$ & $\dot{\xi}$ & 9 & 6 & 17 & 50.0 & 50.0 & B. \\
\hline 19 & 36 & 15.0 & 4 & 37 & +7.6 & 15 & 47 & 24 & $B E$ & 17.8 & 54.5 & 27.5 \\
\hline 119 & 31 & 49,0 & 46 & 37 & 28.6 & 25 & 74 & $20^{\circ}$ & 155 & 20.1 & 53.7 & 20.7 \\
\hline 1 & +1 & $2 \theta, 0$ & 45 & 38 & 18.0 & 45 & 15 & 9 & 60 & $>5 . \overline{0}$ & 25.9 & 0.0 \\
\hline 19 & 25 & 4.6 & 46 & 38 & 38.0 & $1=$ & 20 & (1) & 3.5 & 42.3 & 57.1 & ย. 0 \\
\hline 19 & 30 & 3.5 & 45 & 39 & 37.0 & 43 & 8 & 0 & 50 & 85.0 & 15.6 & 5,4 \\
\hline 119 & +2 & 55.0 & 46 & 37 & 20.0 & 23 & +1 & $20^{\circ}$ & 35 & 29.3 & 43.5 & 27.7 \\
\hline 119 & 26 & 46.4 & 46 & 38 & 7.0 & 25 & 0 & 5 & 25 & 100.8 & 0.5 & 0.0 \\
\hline 119 & 32 & 1.0 & 46 & 38 & $\overrightarrow{9}, \overrightarrow{\mathfrak{v}}$ & 52 & 47 & 17 & 115 & 45.2 & 40.4 & 14.3 \\
\hline 119 & $3 ?$ & 54.6 & 46 & 38 & $\theta .0$ & 42 & 37 & 27 & $1 \overline{6} 5$ & 39.7 & 34.9 & 25.4 \\
\hline 119 & 30 & 59.0 & 46 & 38 & $1 \pm, \overline{0}$ & 73 & 13 & $\overline{\mathbf{u}}$ & 55 & 35.3 & 14.7 & घ. 8 \\
\hline 113 & 28 & 3.0 & $4 E$ & 39 & 1.0 & 37 & 3 & $\overline{3}$ & +0 & 92.5 & 7.5 & $0, \dot{0}$ \\
\hline 11 & 32 & 25.0 & 40 & 35 & $3 . \overline{1}$ & $\theta 3$ & 5 & 3 & 56 & $91 . ?$ & $5 . E$ & 2.8 \\
\hline 119 & $3 \mathrm{a}$ & 58.0 & $4 E$ & 30 & 35.0 & 3 & 37 & 31 & 105 & 35.2 & 3.5 .2 & 29.5 \\
\hline 115 & $1 \%$ & 59.0 & 40 & 21 & $1 \pm .0$ & 35 & 55 & 3 & 95 & 38.7 & 58.5 & 2.7 \\
\hline 11 & 17 & 15.0 & 46 & 32 & $2+.0$ & 19 & 20 & $1: 3$ & 53 & उE. 5 & 38.4 & 25.2 \\
\hline 118 & 16 & 11.0 & 40 & 22 & 7.0 & 17 & 3 & घ & 19 & 86.8 & 13.2 & 0.0 \\
\hline 119 & 27 & 50.0 & 46 & 48 & 13.0 & 18 & 18 & 3 & 35 & 50.0 & 50.0 & 5.0 \\
\hline$i 1$ & 30 & 51.0 & 45 & 33 & 12.0 & 61 & 137 & 98 & 295 & & 46.3 & 33.1 \\
\hline i 1 & 26 & 27.0 & 46 & 35 & 34.0 & 27 & 36 & 5 & 70 & 37.9 & 51,4 & 10.7 \\
\hline 119 & 31 & $\$ 3.0$ & 46 & 32 & 56.0 & 79 & 164 & 92 & 305 & 23.6 & $\$ 9.0$ & 27,4 \\
\hline 113 & 32 & 21.0 & 46 & 32 & 16.0 & 132 & 143 & 62 & 336 & 39.1 & 42.4 & 18,5 \\
\hline 11 & 35 & 56.0 & 45 & 30 & 59.9 & 15 & 14 & 0 & 29 & 93.4 & 46,6 & 0.0 \\
\hline 113 & 16 & 14.0 & 46 & 23 & 15.0 & 15 & 24 & 5 & 47 & 39.4 & 50.6 & $1+\epsilon$ \\
\hline 11 & 34 & 22.0 & 46 & 39 & 14.0 & +3 & 1 & 9 & 44 & 97.7 & 2.3 & ט. \\
\hline 1: & 28 & 41.0 & $4 E$ & 34 & 32.0 & ت & 4 & i & $+\bar{y}$ & $\$ 0.0$ & $10 . \overline{6}$ & 0.0 \\
\hline 11 & 25 & $+\& .0$ & 40 & $3 \overline{4}$ & $2 \dot{9}, \dot{1}$ & $3 \overline{9}$ & 1 & 7 & $+\hat{\theta}$ & 97.5 & 2.5 & $0 . \overline{0}$ \\
\hline 119 & 23 & 48.0 & 45 & 5 & 36.0 & 27 & 12 & 4 & +2 & 83.1 & 27.4 & 9.5 \\
\hline 119 & 29 & $+8,0$ & $4 E$ & 34 & $35 . \overline{4}$ & 33 & 3 & 3 & 40 & さふ.3 & 8.5 & 8.3 \\
\hline 119 & 20 & 48.6 & 46 & 39 & 31.0 & +0 & 0 & $\bar{y}$ & 40 & $1 \overline{1} \bar{b}, \bar{y}$ & ต. $\overline{\mathrm{u}}$ & 0.6 \\
\hline 11 & 33 & $20, \overline{0}$ & 45 & 39 & +5.0 & 13 & 3 & 3 & 20 & 80.7 & 16.7 & 15.7 \\
\hline 11 & 50 & $+4,6$ & +5 & +0 & $3, \mathrm{u}$ & $a$ & 30 & 0 & 30 & 0.8 & $1 \dot{y} \bar{y} . \overline{9}$ & 5. \\
\hline 11 & 33 & 40.0 & 45 & $4 \bar{a}$ & 32.5 & 15 & 11 & 3 & 30 & 51.1 & 37.8 & 11.1 \\
\hline 119 & 27 & 52.6 & 40 & 41 & $\bar{g}, \overline{\mathrm{u}}$ & 30 & 5 & 5 & +0 & 75.0 & 12.5 & 12.5 \\
\hline 119 & 20 & 30.0 & 48 & 36 & 39.0 & 24 & 71 & $\overrightarrow{\mathrm{b}}$ & 95 & 25.3 & 74.7 & $6 . \overline{5}$ \\
\hline 11 & 34 & 55.0 & 40 & 23 & 31.6 & 15 & 33 & 17 & $E$ & 24,8 & $5 \overline{0} \overline{3}$ & 25.4 \\
\hline 11 & 32 & 20.9 & 48 & 85 & 5.0 & 8 & +8 & 41 & 40 & 3.8 & 50.0 & 42.2 \\
\hline 119 & 21 & 48.0 & 46 & 32 & 3.0 & +3 & 54 & $\bar{Z}$ & 116 & 37.4 & 55.0 & 7.0 \\
\hline 11 & 30 & 26.8 & $4 E$ & 34 & 19.6 & 30 & +7 & 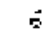 & $\bar{y} \bar{v}$ & 40.4 & 5.0 & 7.9 \\
\hline 11 & 25 & 16.9 & 40 & 34 & 25.0 & 32 & 105 & 11 & $1+5$ & 21,7 & 71.0 & 7.2 \\
\hline 113 & 25 & 0.0 & 40 & 34 & 39.0 & 15 & 18 & 3 & 35 & 42.9 & $50, \overline{5}$ & 7.1 \\
\hline 119 & 38 & 26.0 & 48 & 34 & 23.0 & $2 E$ & 17 & + & +7 & 55.7 & รE. & 7.8 \\
\hline$: 1$ & 42 & 15.0 & 46 & 34 & 37.6 & $E 3$ & 82 & 25 & 170 & 37,6 & 48.4 & $14 . E$ \\
\hline 119 & 29 & 34.6 & 48 & 34 & 40.0 & $3 E$ & 3 & $\hat{u}$ & $3 \theta$ & 93,4 & $\varepsilon .5$ & 0.0 \\
\hline 119 & 26 & +1.0 & $4 E$ & 34 & 39.0 & 41 & 9 & 50 & 160 & 41,3 & 3.2 & 49.7 \\
\hline 11 & 39 & $4+.0$ & 48 & 34 & 40.5 & 35 & 21 & 3 & $\$ 4$ & 54.4 & 33.5 & 13.0 \\
\hline 11 & 43 & 31.0 & 48 & 34 & 37.6 & $\div 4$ & 34 & ${ }_{5}$ & D日 & & 57.5 & 6.7 \\
\hline 11 & 43 & 30.0 & $4 E$ & 34 & $37 . \overline{6}$ & $2 \dot{b}$ & 23 & 7 & $+\hat{3}$ & $4 \overline{\mathrm{B}}, \overline{\mathrm{\sigma}}$ & $4+4$ & 14.6 \\
\hline 11 & 34 & $37 . \overline{9}$ & +6 & 34 & 54.6 & 125 & 37 & 5 & 109 & 75,4 & 21.3 & 2.7 \\
\hline 1 & 37 & 30.0 & 46 & 34 & +7.0 & yu & 5 & $\overline{\mathbf{y}}$ & 35 & 94.7 & 5.3 & B. 5 \\
\hline
\end{tabular}




\begin{tabular}{|c|c|c|c|c|c|c|c|c|c|c|c|c|}
\hline 119 & 27 & 91.0 & 46 & 35 & 9.5 & 4 & 22 & $a$ & 25 & 14.0 & $\Xi \varepsilon .0$ & 0.0 \\
\hline 119 & 32 & 41.3 & 45 & 35 & $9 . \overline{0}$ & 75 & 92 & 25 & $18 ?$ & 40.3 & 49.1 & $10 . \overline{0}$ \\
\hline 119 & 32 & 41.0 & 45 & 35 & 5.5 & 68 & 119 & 3 & 190 & 36.8 & 62.3 & 1.8 \\
\hline 19 & 33 & 4.0 & $4 \sigma$ & 35 & 22.0 & 140 & 11 & $E$ & 158 & $8 s .8$ & ?.2 & 4.8 \\
\hline 19 & 24 & 58.0 & 46 & 35 & 32.0 & 18 & 23 & 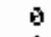 & $4 \bar{B}$ & 43.8 & 56.3 & 9. \\
\hline 19 & 31 & 29.0 & 46 & 35 & 28.0 & 26 & 18 & \$ & 43 & 59.3 & $4 \bar{\theta} . ?$ & 9.3 \\
\hline 19 & 20 & 45.5 & 46 & 35 & 22.6 & 34 & 10 & 5 & 44 & 53.8 & 35.6 & 16.5 \\
\hline 119 & 31 & 31.5 & 46 & 3ड & 23.0 & 25 & 22 & 13 & ס̄ & 41,1 & 37.6 & 22.5 \\
\hline 17 & 31 & 28.3 & 46 & 35 & 28.0 & 30 & 19 & 7 & 55 & 53.9 & 39.9 & 12.1 \\
\hline 19 & 33 & 54.0 & 46 & 35 & 30. & 168 & $\mathfrak{6}$ & $G$ & 163 & 100.0 & 5.0 & घ. \\
\hline 19 & 33 & 54,7 & 46 & 35 & 33.0 & 153 & 13 & 9 & 170 & 99.7 & 1 घ. 3 & $\bar{y} . \bar{g}$ \\
\hline 119 & 35 & 15.9 & 46 & 35 & 33.0 & 57 & 19 & 24 & 160 & 56.8 & 19.3 & 23.8 \\
\hline 119 & 37 & 48.0 & 46 & 35 & $30 . \hat{0}$ & 92 & 32 & 0 & 113 & 72.1 & 27.9 & 0.9 \\
\hline 119 & 42 & 13.0 & 46 & 3.5 & 32.0 & 140 & $E 0$ & B & 200 & 75.0 & 30.0 & $\dot{\theta} \cdot \theta$ \\
\hline 119 & 35 & 21.0 & 45 & 35 & 51.0 & $E 2$ & $5 ?$ & 39 & 155 & 39.1 & 36.6 & 24.9 \\
\hline 119 & 35 & 32.4 & 45 & 36 & $14 . \overline{0}$ & $3 \varepsilon$ & 30 & 2 & 77 & 48.7 & 43.7 & 2.2 \\
\hline 119 & $3: 3$ & 32.0 & 40 & 36 & $15 . \hat{0}$ & 23 & 52 & 2 & 77 & 29.6 & EP. & $\Xi .9$ \\
\hline 119 & 29 & 21.6 & 46 & 36 & $3 \bar{y} . \bar{y}$ & 4 & 27 & 9 & 40 & 10,4 & 56.7 & 22.7 \\
\hline 119 & 27 & 11.0 & $4 \div$ & 35 & 15,0 & 32 & 34 & 5 & 6.5 & $4 \& .5$ & 51.5 & E. 0 \\
\hline 119 & 33 & 3.0 & $46^{\circ}$ & 35 & 21,0 & 45 & 45 & 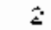 & $\dot{y \in}$ & 51.8 & 40.5 & 2.1 \\
\hline 119 & 35 & 12.0 & 46 & 36 & 29.0 & $7 E$ & 26 & 3 & $1 \overline{05}$ & 72.2 & $24 . E$ & 3.2 \\
\hline 119 & 34 & 23.6 & 45 & 36 & 24.0 & $a \overline{8}$ & 43 & 1 & 132 & $66 . \overline{8}$ & 32.7 &. \\
\hline 119 & 27 & 2.0 & 46 & 36 & 40.0 & 37 & 39 & 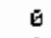 & 75 & 48.7 & 51.3 & 0.0 \\
\hline 119 & 29 & 46.0 & 46 & $30^{\circ}$ & 36.0 & 45 & 22 & b & 60 & E7. 4 & 32.6 & 0.0 \\
\hline 119 & 29 & 46.0 & 46 & 36 & $40 . \overline{0}$ & 38 & 30 & 5 & 59 & 50.0 & 50.0 & 0.6 \\
\hline 119 & 29 & 43.0 & 45 & 36 & 40.0 & 39 & 29 & (1) & 67 & 57.5 & 42.5 & 0.0 \\
\hline 119 & 29 & 42.0 & $4 E$ & 35 & 40.0 & 20 & 42 & 5 & 67 & 29.9 & 62.7 & 7.5 \\
\hline 119 & 29 & 43.0 & $4 \theta$ & 36 & 40.0 & 56 & 16 & b) & 56 & 75.8 & 24.2 & 0.6 \\
\hline 15 & 29 & 44.0 & 46 & 36 & 40.0 & 35 & 8 & b & 43 & 81.4 & 18.5 & घ. B \\
\hline 119 & 29 & 44.6 & $4 \sigma$ & 36 & 39.5 & 40 & 20 & 10 & 70 & 57.1 & 28.6 & 14.3 \\
\hline 119 & 29 & 44.0 & 46 & 36 & 46.0 & $4 \overline{1}$ & 24 & 0 & 54 & $=2.5$ & 37.5 & $\ddot{\theta} . \dot{b}$ \\
\hline 119 & 29 & 45.19 & 45 & 36 & 40.0 & 57 & 7 & y & EH & 37.1 & 18.9 & 0. \\
\hline 119 & 29 & 44.6 & 46 & $30^{\circ}$ & 39.0 & 30 & 38 & $B$ & $\overline{8}$ & 44.1 & 55.9 & $0, \theta$ \\
\hline 119 & 29 & 45.0 & 45 & 36 & $40 . \overline{1}$ & 56 & 11 & (3) & $E 6$ & 84.1 & 15.9 & $\overline{0}$ \\
\hline & 29 & 44.0 & 46 & 36 & 39.0 & 3 & 58 & อ & 68 & 4.2 & 95.8 & 0.0 \\
\hline 119 & 16 & 49. 0 & 45 & 19 & 58.0 & 32 & 31 & 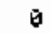 & 62 & 50.8 & 49.2 & 0.0 \\
\hline 11 & 16 & 10.0 & 45 & 25 & 20.0 & 35 & 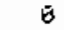 & $a$ & 36 & 100.0 & 0.0 & อ. \\
\hline 119 & 15 & 21.0 & 46 & 35 & 14.8 & 35 & 1) & $\hat{\mathrm{H}}$ & 36 & 100.5 & $\dot{\Delta . b}$ & 0.0 \\
\hline 119 & 16 & 21.5 & $4 E$ & 25 & 14.0 & 31 & 4 & $\hat{\boldsymbol{\theta}}$ & 35 & $\overrightarrow{88}, \vec{E}$ & 11.4 & 0.8 \\
\hline 119 & 18 & 54.0 & 40 & 25 & 19.5 & 20 & 49 & $?$ & 77 & 26.4 & 54,1 & 5.5 \\
\hline 119 & 18 & 47.5 & 46 & 25 & 14.0 & 19 & 17 & 14 & 50 & 39.3 & 3.3 .3 & 28.3 \\
\hline 119 & 13 & 50.0 & 46 & 25 & 23.0 & 27 & 29 & $\dot{y}$ & 50 & 35.1 & 48.6 & 15.3 \\
\hline 119 & 18 & 51.0 & 45 & 25 & 15.5 & 29 & 25 & 5 & $6 \theta$ & 45.8 & 45,8 & E. 3 \\
\hline 119 & 18 & 48.0 & $45^{\circ}$ & 25 & 14.0 & 28 & 20 & 3 & 50 & 55,0 & 40.0 & 5.6 \\
\hline 11 & 18 & 44.0 & 48 & 25 & 12.5 & 32 & 19 & $\xi$ & 60 & 52.3 & 32.0 & 15.3 \\
\hline 119 & 18 & 52.0 & 46 & 25 & 40.0 & 15 & 27 & 4 & 45 & 33.3 & 58.9 & 7.8 \\
\hline 119 & 10 & 29.0 & 45 & 26 & 34.0 & 52 & 2 & 2 & 65 & 94.9 & 2.5 & 2.6 \\
\hline 119 & 15 & 12.0 & 40 & $2 \hat{0}$ & 37.4 & 23 & 30 & 5 & こே & 37.5 & 50.5 & 12.5 \\
\hline 11 & 27 & 16.0 & 45 & 27 & 41.6 & 33 & 10 & 2 & 130 & -3.7 & PS. & 1.1 \\
\hline 11 & 19 & 8.3 & 45 & 27 & 44.5 & $1 \Xi$ & 15 & 13 & 4.5 & 38.7 & $3 \overline{3} 3$ & 27.8 \\
\hline 119 & 16 & 50.0 & 46 & 27 & 57.0 & 35 & 17 & 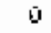 & 5.5 & 70.6 & $3 \overline{0} . \overline{0}$ & $6 . \overline{6}$ \\
\hline 119 & 32 & 26.6 & 46 & 28 & $\bar{E} . \overline{1}$ & 0 & 34 & 43 & $? ?$ & 0.6 & 44.2 & 55.3 \\
\hline 119 & 34 & 55.6 & 45 & 28 & 31.0 & $1 \%$ & $=9$ & 25 & E5 & 13.5 & 43.5 & 37.7 \\
\hline 11 & 19 & 23.6 & te & 28 & 34.8 & 83 & 53 & $\bar{v}$ & 135 & E1.1 & 38.9 & 0.6 \\
\hline 11 & 18 & 22.0 & 46 & 38 & 35.6 & 6? & 35 & b & 105 & 63.8 & 35.2 & 9.8 \\
\hline 11 & 15 & 32,6 & 45 & 29 & 35.0 & 76 & 35 & 19 & 113 & E. 8 & 33.2 & $\overline{1} . \bar{v}$ \\
\hline 1! & 18 & $2 \div 0$ & 45 & 25 & 35.0 & 60 & $3 \overline{8}$ & B & 97 & $61 . \overline{3}$ & 38.7 & $\ddot{B} . \dot{b}$ \\
\hline $1 \div 9$ & 18 & 22.0 & 45 & 26 & $\overline{3} \overline{0} . \overline{0}$ & 53 & 45 & 5 & 98 & 54,1 & +5.9 & $\dot{B} \cdot \dot{\theta}$ \\
\hline 11 & 30 & 57.0 & 45 & 29 & 39.8 & 12 & 93 & $8: 3$ & 177 & 6.8 & $46^{\circ} . E$ & $\Delta \in . \epsilon$ \\
\hline 119 & 28 & +3.2 & 46 & 28 & 44,0 & 0 & 55 & 55 & 110 & 0.0 & 50.6 & 50.0 \\
\hline 11 & 23 & 14.0 & 45 & 23 & 48.6 & 24 & 72 & 89 & 105 & $1+.6$ & 43,4 & 41.9 \\
\hline 11 & 23 & 17.0 & $4 E$ & 36 & 23.5 & 0 & 20 & 20 & 40 & & $5 \emptyset .0$ & 50.0 \\
\hline & 22 & 47.6 & 48 & 41 & 29.0 & 2 & 2 & v & 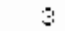 & $5 \overline{0} . \overline{8}$ & 50.0 & 0.0 \\
\hline & 38 & +5.0 & +5 & 37 & $53 . \overline{0}$ & 33 & 38 & $\dot{y}$ & 80 & $41 . \vec{b}$ & 47.3 & 11.7 \\
\hline & $3: 3$ & 46.0 & 45 & 37 & 59.0 & 45 & 27 & 0 & 72 & 53.2 & 35.8 & $\bar{\theta} . \bar{\sigma}$ \\
\hline & 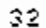 & & 46 & 41 & 35.0 & 28 & 33 & 28 & 89 & 31.3 & 35,9 & 31.8 \\
\hline
\end{tabular}




\begin{tabular}{|c|c|c|c|c|c|c|c|c|c|c|c|c|}
\hline 119 & 26 & 14.0 & 46 & 39 & 20.0 & $\theta$ & $\begin{array}{l}48 \\
28\end{array}$ & 0 & $\begin{array}{l}55 \\
65\end{array}$ & 13.6 & 86,4 & $\begin{array}{l}0.0 \\
0.0\end{array}$ \\
\hline 119 & 26 & 22.0 & $A E$ & 39 & 38.8 & $\begin{array}{l}37 \\
39\end{array}$ & $\begin{array}{l}28 \\
23\end{array}$ & 5 & 55 & $\begin{array}{l}56.9 \\
52.3\end{array}$ & $\begin{array}{l}43.1 \\
37.7\end{array}$ & $\begin{array}{l}0.6 \\
0.8\end{array}$ \\
\hline t & $\begin{array}{l}20 \\
26\end{array}$ & $\begin{array}{l}18.0 \\
48.9\end{array}$ & dE & 39 & 24.6 & 25 & 17 & 8 & 50 & 49.7 & 33.7 & 16.7 \\
\hline 19 & 26 & 57.0 & $4 E$ & 39 & 18.6 & 17 & 27 & 0 & 44 & 38.6 & $E 1.4$ & 0,0 \\
\hline $1 \%$ & 25: & 55.1 & $40^{\circ}$ & 39 & 20.0 & $2 \theta$ & 27 & 5 & 52 & 49.0 & 51.8 & 6. 5 \\
\hline 19 & 29 & 1.0 & 45 & 42 & $2, \overline{1}$ & 20 & 15 & 15 & $5 \pi$ & 45.6 & 30.0 & $3 \overline{0}, 0$ \\
\hline 19 & 20 & 37.0 & 46 & 42 & 5.6 & 25 & 25 & $\hat{\theta}$ & $5 \sqrt{1}$ & 50.8 & 50.6 & 6.8 \\
\hline 19 & 25 & 47.13 & 46 & 42 & 10.0 & 26 & 23 & $\mathfrak{G}$ & 47 & 33,1 & 46.9 & 0.0 \\
\hline 19 & 35 & 47.0 & 46 & 39 & 17.0 & 0 & 3 & 0 & 3 & 0.0 & 100.0 & 0.0 \\
\hline 19 & 35 & 56.0 & $4 E$ & 30 & 59.13 & $2 \overrightarrow{6}$ & 14 & 4 & 37 & 52.7 & 36.5 & $15, E$ \\
\hline 19 & 3.5 & 58.19 & 45 & 30 & 7.0 & 26 & 13 & 8 & 47 & 59.6 & 40.4 & घ. \\
\hline 9 & 35 & 44.8 & $4 E$ & 39 & 17.6 & 32 & 13 & 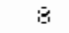 & 53 & 56.4 & 24.5 & 15.1 \\
\hline 19 & 33 & 57,0 & $4 E$ & $+\overline{1}$ & $37 . \overline{1}$ & 30 & $\because$ & B & 5 & 52.7 & 47.3 & 19. \\
\hline $1 \%$ & 34 & 0.0 & 45 & $4 B$ & 39.0 & 50 & 27 & 4 & 83 & 47.3 & $45 . E$ & 6.9 \\
\hline 9 & 35 & 49.0 & 46 & 45 & 34.8 & 32 & 28 & 5 & 60 & 54.2 & 45.6 & $\overline{0.0}$ \\
\hline 9 & 33 & 56.0 & $4 E$ & 40 & 35.6 & 23 & 23 & $\dot{y}$ & 50 & 55.0 & 45.6 & 0.5 \\
\hline 9 & 33 & +2.5 & $4 \hat{\theta}$ & $4 \theta$ & 34.5 & 21 & 3 & 4 & 27 & 75.3 & 11.1 & 13.5 \\
\hline 15 & 33 & 43.0 & 46 & 40 & 31.0 & 14 & 14 & $\hat{0}$ & 27 & 50.5 & $5 \overline{.0}$ & 0.0 \\
\hline 19 & 33 & 59.19 & 46 & 45 & 43.0 & 10 & 5 & 8 & 15 & 66.7 & 33.3 & 0.8 \\
\hline 19 & 33 & 59.0 & $4 E$ & 45 & 43.0 & 21 & $\dot{0}$ & 5 & $\geq 1$ & 100.0 & 0.0 & $\bar{b}, \mathcal{G}$ \\
\hline 17 & 33 & $59, \overline{19}$ & 40 & 40 & 43.0 & 14 & 6 & 5 & 14 & 100.07 & 0.0 & घ. 尚 \\
\hline 19 & 33 & $5 \% .0$ & 45 & 40 & 43.0 & 24 & 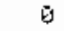 & $\hat{\mathbf{u}}$ & 24 & $1 \bar{B}, \overline{4}$ & เ1. $\theta$ & 5.0 \\
\hline I & 34 & 0.8 & 40 & 40 & $+3 . \bar{v}$ & 10 & 3 & $\theta$ & 21 & $85 . ?$ & 14.3 & 6.5 \\
\hline 19 & 33 & 41.0 & 45 & 40 & 53.0 & 23 & 23 & 0 & +5 & 50.6 & 50.0 & 0.0 \\
\hline 19 & 33 & 55.0 & 46 & 90 & 28.0 & $1 E$ & 10 & $\bar{\theta}$ & 32 & 56.5 & 50.6 & 0.0 \\
\hline 19 & 32 & 18.0 & 45 & 32 & 19.1 & 61 & $1 \in \bar{x}$ & 110 & 331 & 1 日. 4 & 48,8 & 33.2 \\
\hline 15 & 32 & 21.0 & $4 \theta$ & 32 & 16.0 & 107 & 123 & 125 & 355 & 30.1 & 34.6 & 35.3 \\
\hline 19 & 32 & 21.0 & $40^{\circ}$ & 32 & $19 . \overline{0}$ & 68 & 156 & 107 & 331 & 29.6 & 47.2 & 32.2 \\
\hline 19 & 32 & 23.0 & 46 & 32 & 19.0 & 123 & 115 & 115 & 353 & 34.8 & 32,6 & 32.6 \\
\hline 19 & 32 & 21.0 & 46 & 32 & 16.0 & 73 & 186 & 87 & 345 & $21 \cdot 1$ & 53.3 & 25.1 \\
\hline 19 & 32 & 23.8 & 46 & 32 & 17.13 & 113 & 140 & 105 & 352 & 32.0 & 35.5 & 28.4 \\
\hline 19 & 32 & 31.8 & 46 & 32 & 17.0 & 85 & 263 & 5 & 352 & 24.0 & 74.7 & 1.3 \\
\hline 19 & 32 & 34.8 & 45 & 32 & 16.0 & 78 & 172 & 110 & 359 & 21.7 & 47.8 & 30,5 \\
\hline 1 & 32 & 33.0 & 46 & 32 & 26.0 & 116 & $2 ! 4$ & 22 & 352 & 33.8 & 60.8 & 6.2 \\
\hline 13 & 32 & 40,0 & 46 & 32 & 14.8 & 76 & 250 & 1.3 & 338 & 22.3 & 74.0 & 3.7 \\
\hline 9 & 32 & 31.0 & 46 & 32 & 13.0 & $8 !$ & 259 & $\ddot{\theta}$ & 340 & 23.8 & 76.2 & 8.0 \\
\hline 19 & 32 & 41.6 & 46 & 32 & 11.0 & 75 & 246 & 15 & 330 & 22.7 & 72.7 & 4.5 \\
\hline 5 & 32 & 31.0 & $A B$ & 32 & У. & 44 & 275 & 12 & 331 & 13.3 & 83.1 & 3.5 \\
\hline 19 & 32 & +5.0 & 46 & 32 & 22.0 & 53 & $18 \varepsilon$ & 166 & 345 & 15.5 & 53.9 & 38.7 \\
\hline 1. & 32 & $5 \mathrm{~A} . \overline{\mathrm{u}}$ & 46 & 32 & 18.0 & 32 & 215 & 75 & 322 & 10.5 & 66.7 & 23.2 \\
\hline 19 & 32 & 41.6 & 45 & 32 & 17.0 & 27 & 175 & 139 & 358 & 10.0 & 49.5 & 39.6 \\
\hline 9 & 32 & 47.9 & 46 & 32 & 13.6 & $6 !$ & 103 & 122 & 34.5 & 17.8 & 47.2 & 35.3 \\
\hline 9 & 32 & 44.9 & $+\pi$ & 32 & 13.6 & 33 & 191 & $18 ?$ & 336 & 10.8 & 57.7 & 32.3 \\
\hline 19 & 32 & $37 . \overline{9}$ & 46 & 32 & 6. & 30 & 193 & 106 & 325 & 7.9 & 59.5 & 32.6 \\
\hline 1 & 32 & 21.0 & 46 & 32 & 13.0 & 16 & 175 & $11 \%$ & 310 & 5.1 & SE. 5 & 30.4 \\
\hline 17 & 30 & 38,0 & 46 & 32 & +5.0 & 31 & $1+2$ & 137 & 310 & 10.0 & +5.9 & 44.2 \\
\hline 18 & 30 & 22.6 & +5 & 32 & $51 . \overline{0}$ & $E+$ & 125 & $1 \mid 1$ & ริธ̄ติ & 21.4 & 41.6 & 36.9 \\
\hline 119 & 31 & 10.6 & $4 E$ & 32 & 50.0 & 27 & $2 \in \theta^{\circ}$ & 33 & 325 & 8.2 & $51 . E$ & 18.2 \\
\hline 119 & 31 & 5.0 & $4 \theta$ & 32 & 50.0 & 43 & 288 & 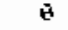 & 330 & 12.9 & 37.1 & $\overline{0.9}$ \\
\hline 119 & 31 & 8.0 & $40^{\circ}$ & 32 & 50.6 & 49 & 264 & 25 & 337 & 14.4 & 78.3 & 7.4 \\
\hline 119 & 31 & 9.8 & 45 & 33 & 19. & 67 & 194 & 74 & 335 & 19.9 & 58.00 & 22.6 \\
\hline 119 & 31 & $10, \hat{0}$ & 45 & 32 & 41.0 & +6 & 294 & $\overline{\mathbf{u}}$ & 340 & 13.5 & 36.5 & B. $\overline{0}$ \\
\hline 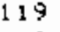 & 31 & 11.0 & $4 E$ & 32 & 47.0 & 5 & 5 & ติ & 10 & 50.0 & 50.0 & 19.6 \\
\hline $1 !$ & 31 & 21.6 & $4 E$ & 32 & 51.0 & 67 & 272 & $\dot{0}$ & 335 & 19.7 & 90.3 & $\dot{0} . \dot{0}$ \\
\hline 11 & 32 & 14,0 & $45^{\circ}$ & 33 & 0.6 & 52 & $19 \hat{y}$ & $7 \%$ & 330 & 15.7 & 86,4 & 24.6 \\
\hline 119 & 31 & 14.0 & 45 & 32 & $54 . \overline{0}$ & 33 & 153 & 93 & 220 & $1 \overline{0} .4$ & 60.4 & 29.2 \\
\hline 11 & 31 & 16.6 & 46 & 32 & 54.5 & $40^{\circ}$ & $2 \Xi 1$ & 16 & 337 & 13.6 & 83.4 & 3.5 \\
\hline 11 & 31 & 7.6 & 45 & 33 & $1 \mathrm{a}, \overline{0}$ & 86 & 214 & 5 & 303 & 26.2 & 72.1 & $1 . ?$ \\
\hline 11 & 31 & 9.0 & 46 & 33 & 11.8 & 100 & 198 & 0 & 257 & 33.5 & 60.5 & 0.0 \\
\hline 119 & 31 & 7.0 & 46 & 32 & 53.0 & 47 & 262 & 21 & 335 & 14,1 & 79.4 & 6.4 \\
\hline 19 & 31 & 13.0 & $4 E$ & 32 & 54.5 & 30 & $1 ? 5$ & 90 & 255 & 10.1 & 59.4 & 30.0 \\
\hline 11 & 31 & 21.0 & $4 \hat{E}$ & 32 & 54.10 & 55 & 283 & 3 & 340 & 16.2 & 83.1 & .7 \\
\hline 11 & 31 & 1.0 & 46 & 33 & 11.0 & 35 & 195 & 73 & 305 & 11.3 & 54.0 & 23.9 \\
\hline 11 & 31 & 16.0 & 46 & 32 & 53.8 & +4 & 152 & 164 & 310 & 14.2 & 52.2 & 33.5 \\
\hline 1 & 30 & 59.0 & 45 & 33 & 11.0 & 29 & $18 \theta$ & 94 & 250 & 7 & 57.8 & 32.5 \\
\hline & 30 & 48.0 & 46 & 32 & 59.5 & $5 E$ & 209 & 46 & 316 & 17.4 & 67.3 & 14.8 \\
\hline
\end{tabular}




\begin{tabular}{|c|c|c|c|c|c|c|c|c|c|c|c|c|}
\hline 119 & 30 & 44.0 & 46 & 33 & 16.0 & 67 & 179 & 25 & 270 & 24.6 & 66.1 & 9.3 \\
\hline 119 & 30 & 43.8 & 46 & 33 & 16.8 & 134 & 139 & $\theta$ & 272 & 49.1 & 59.3 & 9.6 \\
\hline 119 & 30 & 43. 19 & 45 & 33 & 15.5 & 121 & 143 & 13 & 276 & 43.8 & 51,6 & 4.5 \\
\hline 119 & 3 & 40.0 & 46 & 33 & 16.0 & 130 & 145 & 0 & 275 & 47.3 & 52.7 & 6.0 \\
\hline 119 & 30 & 36.0 & 45 & 33 & 16.0 & 62 & 154 & 54 & 270 & 22.9 & 57.5 & 25.1 \\
\hline 119 & 30 & 32.0 & 46 & 33 & 17.0 & 111 & 162 & 3 & 275 & 40,4 & 58,7 & .5 \\
\hline 119 & 30 & +7.0 & 46 & $3 \hat{3}$ & 19.0 & $16 \epsilon$ & 73 & 31 & $27 b$ & 61.4 & 37.3 & 11.4 \\
\hline 19 & 30 & 36.4 & 46 & 32 & $5 \in, \overline{0}$ & 79 & 130 & $9 \overline{10}$ & 306 & 26.4 & 43.4 & 30.1 \\
\hline 19 & 30 & 29.10 & 46 & 32 & 53.0 & 62 & 119 & 115 & 295 & 21.0 & 46.2 & 38.8 \\
\hline 19 & 30 & 53,9 & 46 & 33 & 15.0 & 25 & 136 & 14.5 & 300 & 3.3 & 43.3 & 48.3 \\
\hline 19 & 31 & 0.0 & 46 & 33 & 11.0 & 26 & 151 & 133 & 311 & 8.5 & 48.7 & 42.5 \\
\hline 19 & 22 & 47.0 & $4 \epsilon$ & 41 & 29.0 & 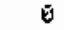 & 2 & 3 & 3 & 0.5 & 50.0 & 50.6 \\
\hline 13 & 33 & 53.0 & 46 & 41 & 37.0 & 18 & 18 & 16 & 51 & 34.3 & 34.3 & 31,4 \\
\hline 19 & 16 & 25.8 & $4 \theta$ & 22 & 25.0 & 20 & 24 & 5 & 49 & 41.2 & 49.3 & 9.5 \\
\hline 119 & 18 & 36.5 & 45 & 23 & $3 ? \cdot \overline{0}$ & 13 & $1 E$ & 1 is & 45 & 29.6 & 35.2 & 35.2 \\
\hline 19 & 10 & 25.0 & $4 E$ & 22 & 4,0 & 21 & 21 & (1) & 42 & 50.0 & 50.0 & 5.0 \\
\hline 114 & 16 & 15.0 & 46 & 22 & 26.3 & 35 & 11 & 0 & +5 & TE. 7 & 23.3 & $\bar{y} . \bar{\theta}$ \\
\hline 119 & 16 & 20.8 & 46 & 22 & 24.0 & 34 & 24 & 2 & 60 & 57.0 & 48.3 & 2.8 \\
\hline 119 & 16 & 20.0 & 46 & 22 & 21.0 & 30 & 30 & $\ddot{b}$ & 80 & 50.07 & $5 \mathrm{~B} . \mathrm{\theta}$ & 0.6 \\
\hline 119 & 10 & 41.0 & 45 & 22 & 8.6 & 20 & 29 & $\theta$ & 40 & 50.5 & 58.6 & 4.6 \\
\hline 119 & 15 & 29.0 & 46 & 22 & 12.5 & 7 & 14 & 12 & 33 & 20.7 & 41.9 & 37.4 \\
\hline 19 & 16 & $1+.0$ & 46 & $2 \hat{2}$ & $11 . \bar{\theta}$ & 12 & 12 & 12 & 25 & 33.3 & 33.3 & 33.3 \\
\hline 119 & 16 & 16.0 & 46 & 22 & 8.0 & 35 & 25 & 5 & 55 & 45.5 & 45.5 & 9.1 \\
\hline 119 & 16 & 22.0 & 46 & 22 & 7.0 & 9 & 9 & 6 & 18 & 50.6 & 50.6 & 0.0 \\
\hline 119 & $10^{\circ}$ & $25 . \theta$ & 45 & 21 & 59.6 & 21 & 21 & $2 !$ & 63 & 32.5 & 35.6 & 33.6 \\
\hline 19 & 16 & 32.8 & 45 & 22 & 2.5 & 34 & 34 & 18 & $\$ 5$ & 39.8 & 39.6 & 20.8 \\
\hline 19 & 16 & 18.0 & $4 E$ & 21 & 57.0 & 40 & 20 & is & 65 & $6 E .7$ & 33.3 & 0.6 \\
\hline 19 & 16 & 7.0 & 46 & 21 & 49.0 & 24 & 24 & 5 & 52 & 45.3 & 45.3 & .4 \\
\hline 19 & 16 & 15.0 & 46 & 22 & 5.0 & 32 & 32 & $\theta$ & 24 & 50.0 & 50.6 & ด. \\
\hline 119 & 10 & 49.0 & $4 E$ & $\geq 1$ & 59.0 & 23 & 24 & 14 & 60 & 37.8 & 39.5 & 22.8 \\
\hline 115 & 17 & 0.0 & 46 & 22 & 8.0 & 17 & 19 & 15 & 50 & 33.3 & 37.3 & 29.3 \\
\hline 119 & 15 & 56.0 & 40 & 22 & 36.9 & 23 & 26 & $1 !$ & 59 & 39.4 & 43.5 & 1E. 1 \\
\hline 119 & 20 & 24.0 & 46 & 24 & $15 . \overline{0}$ & 20 & 22 & 2 & 44 & 45.5 & 50.0 & 4.5 \\
\hline 19 & 16 & 13.5 & 46 & 25 & 17,0 & 14 & 10 & 5 & 36 & 38.7 & 48.6 & 12.5 \\
\hline 119 & 18 & 46.13 & 46 & 25 & 14.6 & $2 \theta$ & 26 & 3 & 50 & 53.0 & 40.0 & 5.6 \\
\hline 119 & 15 & 12.0 & 40 & 26 & 37.0 & $\theta$ & 8 & 8 & 15 & 0.0 & 50.0 & 50.0 \\
\hline 19 & 30 & 20,0 & 46 & 28 & 12.0 & $\vdots$ & 85 & 94 & 170 & +5 & 50.0 & 49,4 \\
\hline 19 & 29 & 32.0 & 46 & 33 & 29.0 & 37 & 72 & $4 !$ & 150 & 24,6 & 47.9 & 27.5 \\
\hline 119 & 44 & 28.0 & 45 & 33 & 34.0 & 126 & 10 & 10 & 145 & 95.3 & 6.8 & 6.8 \\
\hline 119 & 23 & 42.5 & 45 & $3 \%$ & $13, \overline{0}$ & 23 & 28 & 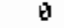 & 55 & 50.0 & 50.0 & $0 . \overline{0}$ \\
\hline 115 & 27 & 41.0 & 45 & 35 & 18.0 & 7 & 15 & $\xi$ & $3 \mathrm{~B}$ & 23.3 & 50.8 & 26.7 \\
\hline 119 & 29 & 41.0 & 40 & 35 & 21,0 & 41 & 19 & $\theta$ & $E \theta$ & 68.3 & 31.7 & .8 \\
\hline 119 & 35 & 9.6 & +5 & 35 & 32.0 & 113 & 19 & 4 & 135 & 33.7 & 13.7 & 2.6 \\
\hline 119 & 33 & 36.5 & $40^{\circ}$ & 37 & 8.0 & 57 & $5 ?$ & 32 & 135 & 42.0 & $42 . \overline{0}$ & 16.1 \\
\hline 119 & 33 & 35.5 & $4 E$ & 37 & 8.0 & $8 ?$ & 57 & 12 & 1.35 & 49.4 & 42.6 & 8. 6 \\
\hline 115 & 30 & 15.0 & 45 & 37 & 47.6 & 11 & 46 & 25 & 86 & 13.0 & 53.7 & 33.3 \\
\hline 119 & 32 & $1 . \overline{0}$ & 46 & 39 & 9.0 & 55 & 50 & 20 & 125 & +3.5 & 40.3 & .9 \\
\hline 119 & 36 & 59.0 & 46 & 39 & $18 . \overline{0}$ & 73 & 13 & $\dot{b}$ & 85 & 85.3 & 14.7 & 0.8 \\
\hline 119 & 32 & +2.0 & 46 & 40 & 41.0 & 19 & $2 \bar{v}$ & 1 & 39 & $4 ? .4$ & $56 . \overline{10}$ & 2.5 \\
\hline 119 & 23 & Sis. & +5 & 35 & 15.8 & 28 & 22 & 5 & 50 & 56.0 & 44.6 & 5.6 \\
\hline 119 & $2 !$ & 20.0 & 46 & 34 & 26.0 & 25 & 8 & 5 & $+\overline{0}$ & 62.5 & 18.8 & $18 . \overline{8}$ \\
\hline 119 & 21 & 12.0 & 46 & 34 & 21.0 & 14 & 22 & $\dot{0}$ & 36 & 38.7 & 61.1 & .9 \\
\hline 119 & 22 & 3э. & 46 & 34 & 43.0 & 35 & 4 & 2 & 40 & 86.3 & 10.0 & . 8 \\
\hline 119 & 22 & 49.0 & 46 & $3+$ & 57.5 & 28 & 4 & 4 & 35 & 80.6 & 10.0 & 10.0 \\
\hline 119 & 25 & 59.8 & 45 & 36 & 25.3 & 36 & 25 & 13 & 74 & 48.0 & 33.8 & 17.6 \\
\hline 19 & 23 & 43.6 & +6 & 35 & 3.0 & 19 & $1 E$ & $\bar{y}$ & 37 & 54.4 & 45.8 & 0.0 \\
\hline 119 & 22 & 37.5 & 40 & 34 & 51.0 & +6 & $1 E$ & 5 & $E 1$ & 74.6 & 25.4 &.$\hat{\theta}$ \\
\hline 119 & 22 & 55.0 & 46 & 34 & 53.0 & 25 & 25 & ت & $.5 \overline{\mathbf{v}}$ & 50.6 & 50.8 & 5.9 \\
\hline 119 & 23 & $24, \overline{0}$ & 45 & 35 & 42.0 & 34 & $\mathbf{5}$ & 0 & 38 & 88.2 & 11.8 & .6 \\
\hline 119 & 21 & 17.0 & 46 & 34 & 21.0 & 14 & 20 & 0 & 33 & 40.9 & 59.1 & .5 \\
\hline 119 & 23 & 58.13 & 46 & 37 & 55.0 & 84 & 2 & 0 & 85 & 98.2 & 1.8 & 1.9 \\
\hline 119 & 22 & 34.6 & 40 & 34 & 24,0 & 90 & + & 2 & $\Xi 5$ & 93.5 & 4.7 & 1.8 \\
\hline 19 & 22 & 34.5 & $4 E$ & 34 & 23.0 & 76 & 4 & 1 & $3 \hat{\mathbf{y}}$ & 94.4 & 4.4 & 1.3 \\
\hline 19 & 22 & $35 . \overline{0}$ & 46 & 34 & $23 . \bar{\theta}$ & 57 & 3 & $\theta$ & 65 & 97.7 & 12.3 & 9.0 \\
\hline 19 & 22 & 35.0 & 46 & 34 & $23 . \overline{1}$ & 54 & 22 & 8 & 70 & 71.1 & 20.5 & $\overline{6} .9$ \\
\hline 115 & 23 & 30.0 & $4 E$ & 34 & 22.8 & 50 & 3 & $\overline{\mathrm{y}}$ & 63 & 95.2 & 4.8 & 0.0 \\
\hline
\end{tabular}




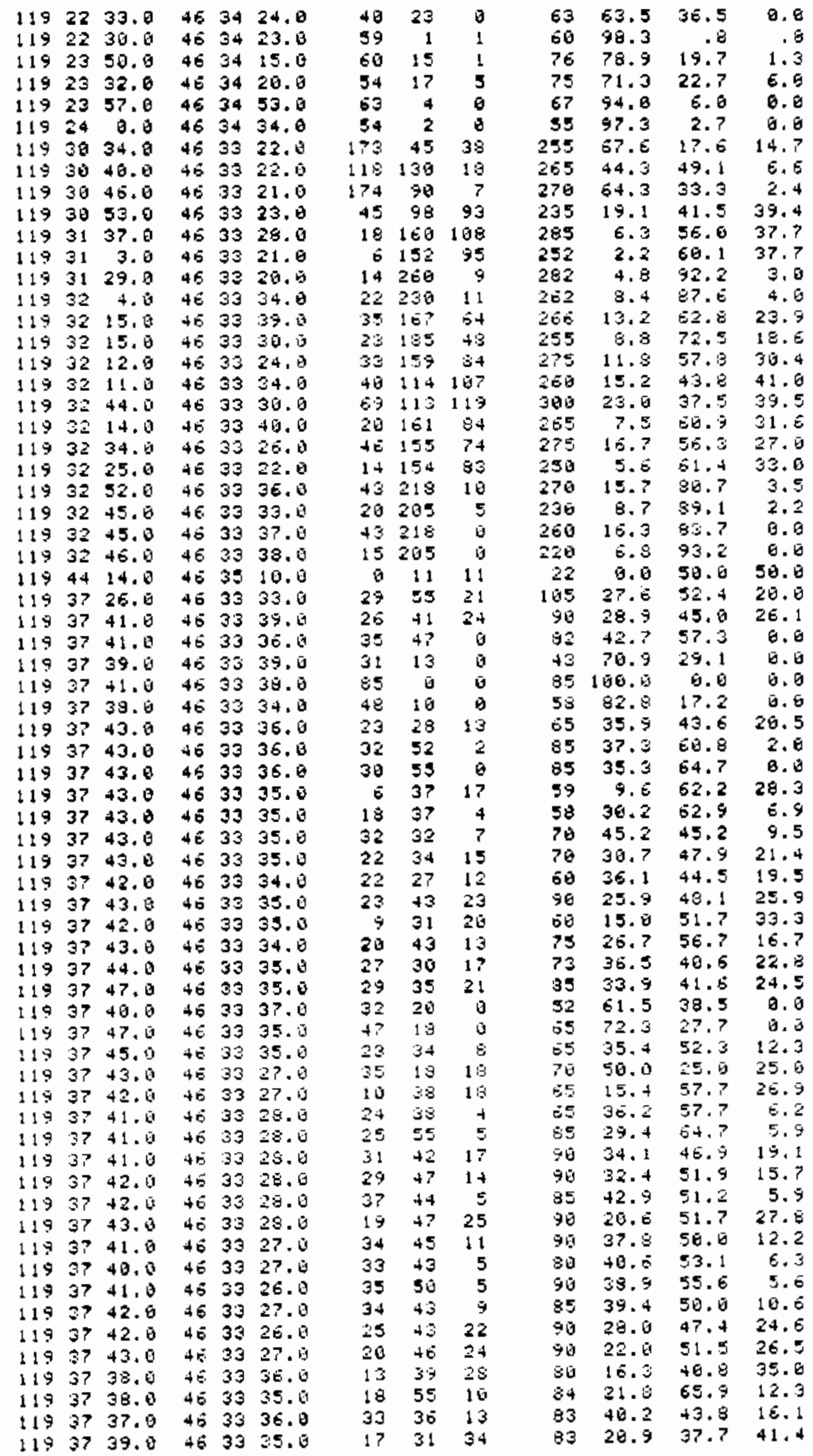




\begin{tabular}{|c|c|c|c|c|c|c|c|c|c|c|c|c|}
\hline 119 & 37 & 40.0 & 46 & 33 & 35.13 & 15 & 34 & 32 & 80 & 18.8 & 41.9 & 39.4 \\
\hline 119 & 37 & 43.0 & 46 & 33 & 28.0 & 15 & $3 \epsilon$ & 5 & 55 & 26.4 & 64.5 & 9.1 \\
\hline 119 & 37 & 46.0 & 46 & 33 & 37.6 & 32 & 35 & 8 & 75 & 42.2 & 46.5 & 10.9 \\
\hline 119 & 37 & 45.0 & 45 & 33 & 33.0 & 29 & 40 & 11 & 86 & 36.6 & 50.4 & 13.5 \\
\hline 119 & 37 & 42.0 & 46 & 33 & 35.8 & 7 & 44 & 11 & 61 & 10.9 & 71.8 & 17.5 \\
\hline 119 & 37 & 42.9 & 46 & 33 & 32.0 & 49 & 21 & 18 & 88 & 35.1 & 23.7 & 20.3 \\
\hline 119 & 37 & 50.0 & 46 & 33 & 29.0 & 57 & 32 & 2 & 90 & 63.0 & 35.2 & 1.5 \\
\hline 119 & 37 & $3 ? .1$ & 40 & 33 & 40.0 & 15 & 56 & $\$ 5$ & 85 & 17.3 & E5.5 & 17.3 \\
\hline 119 & 37 & 42.0 & 46 & 33 & 39.6 & 23 & 53 & 0 & 85 & 28.1 & 71.9 & 0.5 \\
\hline 119 & 37 & 44.0 & $4 E$ & 33 & 34.0 & 30 & 35 & 5 & 71 & 42.7 & 49.8 & 7.5 \\
\hline 119 & 37 & 42.0 & 46 & 33 & 40.0 & 10 & 46 & 26 & 82 & 12.8 & 55.9 & 32.1 \\
\hline 119 & 37 & $4 ! .1$ & 46 & 33 & 39.0 & 32 & 32 & 9 & 73 & $43.0^{\circ}$ & 43.6 & 12.8 \\
\hline 119 & 37 & 40.6 & 46 & 33 & 36.15 & 19 & 53 & 9 & 85 & 23.1 & 55.6 & 11.3 \\
\hline 119 & 37 & 37.0 & 46 & 33 & 35.6 & 17 & 54 & $y$ & 89 & 20.8 & $E 7.7$ & 11.5 \\
\hline 119 & 37 & 38.0 & $+\varepsilon$ & 33 & 35.0 & 13 & 48 & 20 & $8 \overline{1}$ & $15 . t$ & 59.4 & 25.0 \\
\hline 119 & 37 & 38.0 & 46 & 33 & 35.6 & 15 & 53 & 13 & 60 & 15.8 & $\epsilon \mathbf{E} \cdot \epsilon$ & 15.6 \\
\hline 119 & 37 & 39.0 & 46 & 33 & 35.0 & 18 & 55 & 13 & 55 & 21.2 & 6.4 .1 & 14.7 \\
\hline 119 & 37 & 40.6 & 46 & 33 & 35.0 & 22 & 43 & 16 & 80 & 26.9 & 53.1 & 20.5 \\
\hline 119 & 37 & 41.0 & 46 & 33 & 35.0 & 19 & 48 & 19 & 85 & 22.4 & 55.9 & 21.8 \\
\hline 119 & $3 ?$ & 37.5 & $4 E$ & 33 & 38.0 & 23 & 46 & 11 & 80 & 28.8 & 57.5 & 13.8 \\
\hline 119 & 37 & 38.0 & 45 & 33 & 38.5 & 5 & 37 & $\bar{y}$ & 50 & $10 . \overline{8}$ & 73.0 & 17.6 \\
\hline 119 & 37 & 38.0 & 45 & 33 & 39.5 & 15 & 59 & 3 & 31 & 23.5 & 72.8 & 3.7 \\
\hline 119 & 37 & 38.0 & 46 & 33 & 39.0 & 21 & 54 & 5 & 80 & 26.3 & 57.5 & 6.3 \\
\hline 119 & 37 & 40.0 & 46 & 33 & 37.0 & 14 & 51 & 17 & 31 & 17.3 & 62.3 & 25.4 \\
\hline 119 & 37 & 40.0 & $4 \vec{c}$ & 33 & 36.0 & 30 & 45 & 10 & 35 & 35.3 & 52.9 & 11.8 \\
\hline 119 & 37 & 39.0 & 45 & 33 & 30.0 & 25 & 45 & 10 & $\overline{85}$ & 31.3 & 56.3 & 12.5 \\
\hline 119 & 37 & 40.0 & 46 & 33 & 37.11 & 20 & 45 & $1 E$ & 31 & 24.5 & 56.6 & 19.5 \\
\hline 115 & 37 & 40.0 & $4 E$ & 33 & 37.5 & 20 & 41 & 20 & 81 & 24.7 & 56.6 & 24.7 \\
\hline 119 & 37 & 40.0 & 40 & 33 & 38.0 & 20 & 57 & 4 & 80 & 25.0 & ᄀй. 6 & 4.4 \\
\hline 119 & $3 \vec{r}$ & 41.0 & $4 E$ & 33 & 37.0 & 24 & 56 & 0 & 35 & 30.0 & $70 . \theta$ & $0 . \dot{6}$ \\
\hline 119 & 37 & 40.0 & $4 E$ & 33 & 37.0 & 28 & 40 & 21 & 80 & 24.4 & 50.0 & $25 . \pi$ \\
\hline 117 & 37 & 35.8 & 48 & 33 & 37.0 & 17 & 47 & 17 & 81 & 21.2 & 57.6 & 21.2 \\
\hline 119 & 37 & 41.0 & 46 & 33 & 37.0 & 25 & 49 & 9 & 82 & 30.5 & 59.1 & 10.4 \\
\hline$\$ 19$ & 37 & 40.0 & 46 & 33 & 38.0 & 20 & 42 & 21 & 03 & 24.1 & 50.6 & 25.3 \\
\hline 119 & 37 & 40.0 & 46 & 33 & 39.8 & 15 & $\$ 1$ & 16 & 81 & $1 \mathrm{~B}, 1$ & 62.6 & 19,3 \\
\hline 119 & 37 & 41.0 & 46 & 33 & 36.0 & 19 & 60 & 3 & 91 & 23.5 & 73.5 & 3.1 \\
\hline 119 & 37 & 39.0 & 46 & 33 & 36.8 & $2 \theta$ & 61 & b & 81 & 24.7 & 75.3 & 0.0 \\
\hline 119 & 37 & 39.0 & 46 & 33 & 30.0 & 20 & 60 & $\theta$ & 80 & 25.0 & 75.0 & 0.0 \\
\hline 119 & 37 & 40.0 & 46 & 33 & 38.0 & 33 & 43 & $B$ & 80 & 40.6 & 59.4 & 0.0 \\
\hline 119 & 37 & 39.0 & 46 & 33 & 39.0 & $3 \overline{0}$ & $5 \dot{0}$ & 0 & 30 & 37.5 & 62.5 & 0.0 \\
\hline 113 & 37 & 40.0 & 46 & 32 & 39.6 & 28 & 53 & v & 80 & 34,4 & 65.6 & 5.0 \\
\hline 119 & 37 & 40.6 & 46 & 33 & 38.6 & 33 & 48 & $\ddot{0}$ & 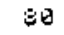 & $4 \pi .6$ & 59.4 & 0.6 \\
\hline 119 & 37 & +1.0 & 45 & 33 & 39.0 & 23 & 53 & $\overline{0}$ & $8 \ddot{\theta}$ & 28.1 & 71.9 & E. \\
\hline 119 & 37 & 38.4 & 46 & 33 & 37.0 & 23 & 50 & 3 & 80 & 34.4 & 62.5 & 3.1 \\
\hline 117 & 37 & 41.8 & 45 & 33 & 35.6 & $2 \theta$ & 45 & 15 & $3 \overline{9}$ & 25.8 & 5E. 3 & 18.8 \\
\hline 119 & 37 & 38.1 & $40^{\circ}$ & 33 & 36.0 & 23 & 28 & घ) & 51 & 45.1 & 54.5 & 0.0 \\
\hline 119 & 37 & 41.0 & 46 & 33 & 38.0 & 15 & 35 & 31 & 32 & 18.7 & 43.1 & 38.2 \\
\hline 119 & 37 & 37.0 & 46 & 33 & 37.6 & 14 & 35 & $3 \dot{8}$ & 78 & 17.3 & 44.2 & 38.5 \\
\hline 119 & 37 & 38.0 & 46 & 33 & 37.0 & 18 & 25 & 39 & 32 & 22.8 & 36.5 & 47.6 \\
\hline 119 & 37 & 20.0 & 46 & 33 & 34.0 & 19 & 60 & 51 & 130 & 14.5 & 46.0 & 39.5 \\
\hline 119 & 37 & 13.0 & 45 & 33 & 32.0 & 27 & 49 & 39 & 114 & 23.4 & 42.7 & 33.9 \\
\hline 119 & 37 & 9.0 & 46 & 33 & 32.1 & 38 & 34 & 41 & 113 & 33.9 & 29.9 & $3 \in .1$ \\
\hline 119 & 37 & 7.0 & 46 & 33 & 29.6 & 17 & 56 & 45 & 119 & 14.6 & 47.3 & 3 e. 1 \\
\hline 159 & 37 & 18.5 & 46 & 33 & 35.0 & 33 & $4 \epsilon$ & 27 & 105 & 31.1 & 43.5 & 25.4 \\
\hline $11 \%$ & 37 & 3.5 & 46 & 33 & 29.0 & 27 & 72 & 42 & 140 & 18.9 & 51.4 & 29.6 \\
\hline 119 & 35 & 46.6 & 45 & 33 & 17.0 & 41 & 64 & 10 & 115 & 35.8 & 55.4 & 8.8 \\
\hline 119 & 37 & 40.0 & 46 & 33 & 19.6 & 25 & 59 & 18 & 1 ตั ชั & 25.0 & 57.5 & 17.5 \\
\hline 119 & 37 & 39.0 & 46 & 33 & 19.0 & 27 & 72 & 2 & 100 & 26.5 & 72.0 & 1.5 \\
\hline 119 & 37 & 39.0 & 46 & 33 & $19 . \overline{0}$ & 27 & 72 & 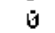 & 98 & 27.6 & 73.6 & 6.0 \\
\hline $11 \%$ & 37 & 40.0 & 45 & 33 & 19.8 & 5 & 53 & 43 & 100 & 5.8 & 52.5 & 42.5 \\
\hline 119 & 37 & 42.3 & 46 & 33 & 20.5 & 29 & 57 & 6 & $\$ 1$ & 31.3 & $E 2.6$ & 6.18 \\
\hline 119 & 36 & 38,1 & 45 & 33 & 33.0 & 34 & 58 & 45 & 138 & 24.9 & 42,3 & 32.8 \\
\hline 119 & 37 & 32.0 & $45^{\circ}$ & 33 & 20.0 & 19 & 29 & 37 & 85 & 22.6 & 34.3 & 43.1 \\
\hline 119 & 37 & 33.13 & पE. & 23 & 33.5 & 5 & 34 & 8 & 90 & 9.4 & B2.2 & 8.3 \\
\hline 19 & 37 & 0.0 & 45 & 33 & 41.0 & 58 & $50^{\circ}$ & 7 & 120 & 47.9 & 46.3 & 5.8 \\
\hline & 37 & 37.0 & 45 & 33 & Зシ. & 75 & 16 & 0 & 96 & 82.8 & 17,2 & $\dot{\theta} . \dot{0}$ \\
\hline
\end{tabular}




\begin{tabular}{|c|c|c|c|c|c|c|c|c|c|c|c|c|}
\hline 119 & 37 & 37.0 & 46 & 33 & 35.0 & 45 & 30 & $\theta$ & 74 & 60.1 & 39.9 & 0.0 \\
\hline 119 & $3 ?$ & 21.0 & 46 & 33 & 35.0 & 24 & 63 & 22 & $10 \theta$ & 22.2 & 57.5 & 19.9 \\
\hline 119 & 37 & 21.0 & 46 & 33 & 35.0 & 30 & 65 & 21 & $1: 5$ & 26.1 & 56.1 & 17.8 \\
\hline 119 & 37 & 20.0 & 46 & 33 & 35.0 & 37 & 72 & 2 & 110 & 33.2 & 65.5 & 1.4 \\
\hline 119 & 37 & 21.0 & 46 & 33 & 35.0 & 31 & 49 & 35 & 115 & 26.8 & $4 \% .5$ & 30.7 \\
\hline 119 & 37 & 22.0 & 46 & 33 & 35.0 & 25 & 59 & 29 & 113 & 22,1 & 52.2 & 25.7 \\
\hline 119 & 37 & 21.0 & 46 & 33 & 34,0 & 47 & 53 & 5 & 110 & 43. & 48.5 & B. 5 \\
\hline 119 & 37 & 21.0 & 46 & 33 & 34.6 & 22 & 77 & 10 & 198 & 19.9 & $70 . \bar{z}$ & 9.3 \\
\hline 119 & 37 & 33.0 & 46 & 33 & 35,0 & 41 & 20 & 21 & E5 & 46.4 & 29.0 & 24.6 \\
\hline $1: 9$ & 37 & $21 . \theta$ & 45 & 33 & 50.6 & 42 & 32 & 16 & $9 \overline{0}$ & 46.7 & 35.6 & 17.8 \\
\hline 119 & 37 & 40.0 & 46 & 33 & 23.6 & 0 & 23 & 23 & 46 & 0.0 & 50.0 & 50.0 \\
\hline 19 & 37 & +2. & 46 & 33 & 18.0 & $\theta$ & 27 & 27 & 53 & 0.0 & 50.0 & 50.0 \\
\hline 119 & 37 & 42.0 & 46 & 33 & 19.0 & 29 & 48 & 23 & 196 & 26.3 & 40.3 & 23.3 \\
\hline 119 & 37 & 42.0 & 46 & 33 & $2 ! \cdot 0$ & $\overline{1}$ & 24 & 24 & 47 & 0.8 & 50.0 & 50,0 \\
\hline 119 & 37 & 41.0 & 45 & 33 & 21.0 & 20 & 40 & 36 & 9.5 & 20.7 & 41.8 & 37.5 \\
\hline 119 & 57 & 44.0 & 46 & 33 & 22.0 & 18 & +6 & 36 & 160 & 18.3 & 45.5 & 35.5 \\
\hline 119 & 37 & 43.0 & 45 & 33 & E. B & 25 & 40 & 37 & 1 ต 8 & 33.3 & 42,3 & 34.6 \\
\hline 119 & 37 & 46.0 & $4 \epsilon$ & 32 & 59.6 & 72 & 42 & 2 & 115 & 62.3 & $3 \in .2$ & 1.5 \\
\hline 119 & 37 & 52.6 & 46 & 33 & 12,1 & 25 & 55 & 3 & 110 & $22 . ?$ & 50.5 & 27.3 \\
\hline 119 & 37 & 53,9 & 45 & 33 & $11 . \bar{\theta}$ & 32 & E3 & 27 & 111 & 19.8 & 58.3 & 23.9 \\
\hline 119 & 37 & 51.0 & 45 & 33 & 10.0 & \pm 5 & 54 & उE & 104 & 14,4 & 51.4 & 34.1 \\
\hline 119 & 37 & 51.0 & 46 & 33 & 10.0 & 19 & 56 & 35 & 110 & 16.8 & 50.9 & 32.3 \\
\hline 119 & 37 & $\$ 1.0$ & 45 & 33 & 10.0 & 23 & 42 & 32 & 97 & 23.4 & 43.5 & 33.2 \\
\hline 119 & 37 & 52.0 & 46 & 33 & 11.0 & 50 & 62 & 3 & 114 & 43.4 & 54.4 & 2.2 \\
\hline 119 & 37 & $\$ 2.0$ & 46 & 33 & 11.0 & $4 B$ & 50 & 0 & 108 & 44.4 & 55.6 & 8.8 \\
\hline 119 & 37 & 52.0 & 45 & 33 & 11.0 & 41 & 57 & 3 & $11 \hat{\theta}$ & 35.8 & 65.9 & 2.3 \\
\hline 119 & 37 & 45.0 & 46 & 33 & 11.0 & 11 & 54 & 35 & 100 & 11.2 & 53.7 & 35.2 \\
\hline 119 & 37 & $39, \bar{v}$ & $4 E$ & 33 & 18.0 & 17 & 44 & 44 & 104 & 16.0 & 42,0 & 42.0 \\
\hline 119 & 37 & 45.0 & 46 & 33 & 18.0 & 18 & 43 & +5 & 100 & 17.5 & 42.5 & 40.5 \\
\hline 119 & $\widehat{3} \vec{T}$ & $45 . \overline{0}$ & 46 & 33 & 20.5 & 26 & 57 & 23 & 1 EE & 24.5 & 53.8 & 21.7 \\
\hline 119 & 36 & 27.0 & 45 & 33 & 52.6 & 37 & 57 & $3 E$ & 130 & 28.6 & 43.6 & 27.8 \\
\hline 119 & 37 & 33.0 & $45^{\circ}$ & 33 & 23.0 & 9 & 34 & 27 & 7日 & 13.1 & 48.8 & 38,1 \\
\hline 119 & 37 & 34.0 & 40 & 33 & 25. & 20 & 5 & 13 & 90 & 22.2 & 63.9 & 13.9 \\
\hline 119 & 37 & 42,0 & 40 & 33 & 25,0 & 25 & 55 & 10 & 96 & 27.8 & 61.1 & 11.1 \\
\hline 119 & 37 & 52.0 & 46 & 33 & 11.0 & 31 & 69 & 8 & 107 & 29.5 & 64.0 & 7.0 \\
\hline 119 & 37 & 39,0 & 46 & 33 & 20.0 & 23 & 50 & 28 & 100 & 22.5 & 50.0 & 27.5 \\
\hline 119 & 37 & 37.0 & 46 & 32 & 15.0 & 11 & 72 & 64 & 167 & 6.5 & 43.3 & 50.2 \\
\hline 119 & 37 & 40.0 & 46 & 32 & 21.0 & 30 & 60 & 32 & 150 & 19.9 & 45.6 & 34.5 \\
\hline 119 & 37 & $3 \% .0$ & 46 & 32 & 14.0 & 15 & 78 & 13 & 105 & 13.8 & 74.3 & 11.9 \\
\hline 119 & 37 & 10.4 & 46 & 32 & $1 \varepsilon .0$ & 10 & 153 & 78 & 190 & 5.3 & 53.9 & 46.8 \\
\hline 119 & 37 & 6.0 & 46 & 32 & 17.0 & 17 & E9 & 55 & 151 & 11.5 & 45.6 & 42.9 \\
\hline 119 & 37 & 30.0 & 40 & 32 & $17 . \overline{0}$ & 32 & 183 & 36 & 170 & 18.8 & 6日. 3 & 20.9 \\
\hline 119 & 37 & 27. & $4 E$ & 32 & 17.5 & 41 & 52 & 82 & 175 & 23.0 & 29.6 & 45,8 \\
\hline 119 & 37 & 32.0 & 46 & 32 & 17.0 & 15 & 85 & 55 & 135 & 11.3 & $\$ 8.0$ & 40.7 \\
\hline 119 & 37 & 32.0 & 46 & 32 & 17.0 & 11 & 55 & 79 & $13 E$ & 6.1 & $4 \overline{6} .4$ & 51.5 \\
\hline 117 & 38 & 2.6 & 46 & 31 & $53 . \overline{0}$ & 2 & 97 & 43 & $1+2$ & 1.4 & 68.3 & $36+3$ \\
\hline 119 & 37 & 54.0 & 45 & 32 & 52.6 & 32 & 20 & 31 & 133 & 24.1 & $52 . \varepsilon$ & 23.3 \\
\hline 119 & 37 & 56.0 & 46 & 32 & 50.8 & 21 & 97 & 17 & 134 & 15.7 & 72.0 & 12.3 \\
\hline 119 & 37 & +9.0 & 46 & 32 & 55.0 & 25 & 73 & 28 & 125 & 20.0 & 58.0 & $22 . \bar{v}$ \\
\hline 119 & 37 & 52.0 & $4 E$ & 32 & 52.0 & 44 & 59 & 22 & 129 & 35.3 & 47.3 & 17,3 \\
\hline 119 & 37 & 54.0 & 46 & 30 & 53.0 & 24 & 62 & 49 & 135 & 17.9 & 45.7 & 36.4 \\
\hline 119 & 37 & 54,0 & 45 & 32 & 57.0 & 28 & 50 & 33 & 120 & 22.9 & 50.8 & 27.1 \\
\hline 119 & 37 & 55.0 & 46 & 32 & 51.0 & 32 & $E y$ & 29 & 130 & 24.4 & 53.2 & 22,4 \\
\hline 119 & 37 & 25,0 & $40^{\circ}$ & 32 & 14.8 & $3 \mathbf{G}$ & 54 & 64 & 157 & 19.1 & 40.4 & 46.4 \\
\hline 119 & 37 & 22.0 & 46 & 32 & 15.0 & 22 & 34 & 34 & 90 & 24.1 & 38.0 & 38.5 \\
\hline 119 & 37 & 33.0 & 46 & 32 & 17.5 & 15 & 54 & 87 & 156 & 9.7 & 34.4 & 55.9 \\
\hline 119 & 37 & 31.0 & te & 32 & 16.6 & 37 & 56 & Si & 135 & 19.3 & 40.3 & $4 \overline{0} .3$ \\
\hline 119 & 36 & 57.0 & 46 & 32 & 15.5 & 2 & 77 & $11 ?$ & 196 & 1.1 & 39.4 & 59.5 \\
\hline 119 & 36 & 52.0 & $4 E$ & 32 & 17.0 & 13 & 88 & 100 & 210 & & 41,7 & 50.0 \\
\hline 119 & 37 & 32.0 & 46 & 32 & 15.0 & 28 & 77 & 63 & $16 \theta$ & 16.5 & 45.9 & 37.6 \\
\hline 119 & 37 & 32.0 & 46 & 32 & 18.0 & 23 & 90 & 48 & 160 & 14.2 & 56.8 & 29.7 \\
\hline 119 & 37 & 4.0 & 46 & 32 & 23.15 & 14 & 78 & 75 & 170 & 6.4 & 45.8 & $45 . \bar{B}$ \\
\hline & 37 & 32,0 & 46 & 32 & 17.0 & $3 \mathbf{G}$ & 80 & 51 & $1 E 0$ & 18.8 & 49.7 & 31.6 \\
\hline & 37 & $32 . \overline{1}$ & 46 & $3 \%$ & 17.0 & 35 & 130 & 5 & 170 & 20.5 & 76.5 & 2.9 \\
\hline 11 & 37 & 2.0 & 4 & 32 & 23. & 23 & $? \theta$ & 65 & 157 & 14.3 & 44.3 & 41,4 \\
\hline 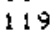 & 37 & 24.0 & 46 & 32 & 9.0 & 54 & 64 & 52 & 17日 & 31.9 & 37.7 & $3 \overline{1} .4$ \\
\hline
\end{tabular}




\begin{tabular}{|c|c|c|c|c|c|c|c|c|c|c|c|c|}
\hline$\$ 19$ & 37 & 4.0 & 46 & 32 & 4.8 & 2 & 105 & 29 & 185 & .9 & 56.8 & 42.3 \\
\hline 119 & 37 & 2.0 & 46 & 32 & 8.0 & 10 & 85 & 85 & 188 & 5.6 & 47.2 & 47.2 \\
\hline 19 & 37 & 31.8 & 46 & 32 & 17.0 & 18 & 123 & 34 & 175 & 10.5 & 70.2 & 19.3 \\
\hline 19 & 37 & 31.0 & 46 & 32 & 18.0 & 24 & 76 & 51 & $15:$ & 15.7 & 50.4 & 33.7 \\
\hline 19 & 37 & 38.0 & 46 & 32 & 17.0 & 9 & 53 & 56 & 122 & 7. & 47.5 & 45.5 \\
\hline 19 & 37 & 38.0 & 45 & 32 & 22.9 & 25 & 43 & 62 & 130 & 19.1 & 32.9 & 47.9 \\
\hline 19 & 37 & 25.0 & $40^{\circ}$ & 32 & 30.0 & 30 & 140 & 15 & 185 & 16.2 & 75.7 & B. I \\
\hline 19 & 37 & 33.4 & 45 & 32 & 17. & 18 & 13 & 33 & 55 & $2 \theta .2$ & 20.5 & 51.3 \\
\hline 19 & 37 & 24.0 & 45 & 32 & 25.0 & 29 & 97 & 59 & $1>5$ & 16.7 & 49.9 & 33.5 \\
\hline 19 & 37 & 22.5 & 40 & 32 & 24.0 & 30 & 89 & 47 & 165 & 17.9 & 53.9 & 28.2 \\
\hline 19 & 37 & 24.0 & 46 & 32 & 14.13 & 40 & 65 & 38 & 142 & 28.2 & 45.4 & 26.4 \\
\hline 9 & 37 & 23.0 & 46 & 32 & 14.0 & 14 & 109 & 33 & 155 & 9.8 & 70.0 & 21.0 \\
\hline 19 & 37 & 32.5 & 45 & 32 & 17.6 & 26 & 74 & 48 & 147 & 17.7 & 58.9 & 32.3 \\
\hline 19 & 37 & 12.0 & 46 & 32 & 24.8 & 30 & 90 & 45 & 165 & 18.2 & $5+.5$ & 27.3 \\
\hline 13 & 37 & 21.0 & 45 & 32 & 24,6 & 32 & 89 & 57 & 179 & 13.1 & 49.9 & 32.0 \\
\hline 9 & 37 & 22,0 & 46 & 32 & 22.6 & 33 & 97 & 59 & 180 & 18.5 & 48.5 & 33.0 \\
\hline 13 & 37 & 48,3 & 45 & 32 & 19.8 & 23 & 77 & +5 & 144 & 15.5 & 53.1 & 31.3 \\
\hline 19 & 37 & 45.6 & 46 & 32 & 19.6 & 27 & 75 & \pm 1 & 153 & 17.4 & 49.1 & 33.4 \\
\hline 19 & 37 & 37.4 & E & 32 & 20.0 & 10 & 84 & $7 ?$ & 170 & 5.8 & 45.4 & 45.8 \\
\hline 15 & 37 & 37.0 & 45 & 32 & 13.6 & 18 & 85 & 63 & 176 & 10.3 & 50.0 & 39.7 \\
\hline 19 & 37 & 54.8 & $4 B$ & 32 & 19.0 & 28 & 09 & 35 & 135 & 20.4 & $5 \overline{0} . ?$ & 28.9 \\
\hline 19 & 37 & 51.0 & 46 & 32 & 17.5 & 27 & 30 & 47 & 155 & 18.5 & 51.4 & 30.1 \\
\hline 19 & 37 & 25.6 & 48 & 33 & 27.15 & 6 & 19 & 17 & 42 & 14.3 & 45.2 & 46.5 \\
\hline 119 & 37 & $4 \overline{0}, \overline{0}$ & 46 & 33 & 35.0 & 13 & 35 & 35 & 32 & 15.9 & 42.1 & 42.1 \\
\hline 19 & 37 & 44.0 & 46 & 33 & 25.0 & 15 & 39 & 39 & 92 & 16.3 & 41.8 & 41,8 \\
\hline 119 & 37 & +2.0 & $46^{\circ}$ & 33 & 0,0 & 17 & 43 & 28 & 87 & 19.5 & 48.9 & 31.6 \\
\hline 119 & $3 ?$ & 39.0 & 46 & 33 & 14.0 & $2 \overline{0}$ & 47 & 24 & 90 & 22.2 & 51.7 & $2 \epsilon .1$ \\
\hline 119 & 37 & 34.9 & 46 & 33 & 39.4 & 3 & 47 & 45 & 94 & 2.7 & 58.0 & 47.3 \\
\hline 19 & 37 & 20.6 & 46 & 33 & 50.0 & 40 & 18 & 0 & 66 & 72.7 & 27.3 & 0.6 \\
\hline \pm 19 & 23 & 12.5 & $40^{\circ}$ & 28 & 49.5 & 60 & 133 & b & 198 & 33.1 & $6 \theta, 9$ & 0.6 \\
\hline 119 & 25 & 57.0 & 46 & 28 & 57.6 & 40 & 50 & 5 & 125 & 32.0 & 64.0 & 4.6 \\
\hline 119 & 22 & 42.5 & 46 & 28 & $52, \overline{5}$ & 60 & 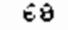 & a & 120 & 50.0 & 56.5 & 0.0 \\
\hline 19 & 20 & 44.0 & $4 E$ & 29 & 12.0 & 18 & 18 & $\tilde{\boldsymbol{b}}$ & $3 E$ & 50.0 & 50.0 & 5.9 \\
\hline 19 & 30 & 56.0 & 46 & 29 & 16.0 & 4 & 162 & 13 & 179 & 3.2 & 9ต̆.7 & 7.5 \\
\hline 119 & 36 & 20,0 & 46 & 29 & 15.13 & 23 & 21 & $4 \sqrt{3}$ & 83 & 27.1 & 24.7 & 49.2 \\
\hline 19 & 33 & 32,0 & 45 & 29 & 33.0 & 15 & 73 & 61 & 149 & 10.3 & 48.3 & 45.8 \\
\hline 19 & $\$ 0$ & 33.0 & 45 & 29 & 38.0 & 46 & $\theta$ & 19 & 65 & 70.8 & 0.0 & 29.2 \\
\hline 19 & 18 & 31,3 & 45 & 25 & 36.0 & 51 & 42 & 2 & 109 & 58.1 & 40.0 & 1,9 \\
\hline 19 & 18 & 31.3 & 40 & 29 & 37.0 & 56 & 56 & $\theta$ & 111 & $5 \overline{0} .0$ & 50.0 & $\theta, \theta$ \\
\hline 19 & 32 & 58.17 & 40 & 32 & 42.5 & 60 & 152 & 143 & 355 & 16.7 & $+2+7$ & 46.3 \\
\hline 19 & 32 & a. a & 46 & 33 & 11.0 & 33 & 180 & 93 & 297 & 11.0 & 55.9 & 32.5 \\
\hline 19 & 31 & 36.1 & 46 & 33 & 19.0 & 21 & 173 & 81 & 275 & 7.6 & 63.0 & 29.4 \\
\hline 19 & $3 !$ & +3.0 & $4 \pi$ & 32 & 50.0 & 78 & 105 & 92 & 335 & 23.3 & 49,2 & 27.5 \\
\hline 119 & 24 & 18.0 & 46 & 22 & 25.6 & 8 & 8 & 3 & 23 & 33.3 & 33.3 & 33.3 \\
\hline 119 & 37 & 18.6 & +6 & 33 & 49.6 & $4 \Xi$ & $4 E$ & 0 & 95 & 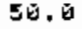 & 56.0 & 5.0 \\
\hline 119 & 37 & 17.6 & 45 & 33 & 58.0 & 50 & 30 & $3 \overline{1}$ & 116 & 45.5 & 27.3 & 27.3 \\
\hline 119 & 37 & 21.0 & 45 & 33 & $5 \overline{0} . \dot{0}$ & 34 & 49 & 12 & 95 & 36.0 & 51.8 & 12.3 \\
\hline 119 & 37 & 43.0 & 46. & 33 & 25,6 & +8 & 23 & 23 & 95 & 50.9 & 24.0 & 24,6 \\
\hline 119 & 37 & 22.5 & 45 & 33 & 48.0 & 13 & +2 & 39 & 100 & 18.3 & 42.3 & 39.3 \\
\hline 19 & 37 & 34.8 & $4 E$ & 33 & 3૭. & 19 & 49 & 23 & 89 & $21 \cdot 4$ & 53.8 & 25.5 \\
\hline 119 & 37 & 32.0 & 46 & 33 & 23.10 & 15 & 56 & 35 & 92 & 10.3 & 54.3 & 35.3 \\
\hline 119 & 37 & 40.0 & 46 & 33 & 36,0 & 18 & 33 & 36 & 35 & 18.4 & 39.0 & 42.6 \\
\hline 117 & 37 & $+1 . \overline{0}$ & 45 & $3 \hat{3}$ & 37.01 & 15 & 41 & 18 & 74 & 20.0 & 55.9 & 24.1 \\
\hline 119 & 37 & 35.6 & 46 & 23 & $14 . \overline{1}$ & $1 \bar{v}$ & 45 & 20 & :ร̄ต & 11.9 & 56.3 & 31.9 \\
\hline 119 & 37 & 33.0 & 46 & 33 & 25.18 & 18 & 58 & 8 & 75 & 23.3 & 76.7 & 0.0 \\
\hline 119 & 37 & 35,6 & 45 & 33 & 16.0 & 12 & 50 & $3 z$ & 93 & 12.4 & 53.2 & 34.4 \\
\hline 119 & 37 & 42.0 & 46 & 33 & 2.0 & 8 & $\$ 5$ & 1 घี & 20 & $B .5$ & 50.0 & 56.0 \\
\hline 19 & 37 & 52.3 & 45 & 32 & SE. & 17 & 41 & 40 & 100 & 18.7 & 41.2 & 40.2 \\
\hline 119 & 37 & 44.8 & $40^{\circ}$ & 33 & 25,0 & 27 & 57 & 10 & 93 & 29.0 & 60.8 & 10.2 \\
\hline 119 & 37 & 40.0 & 46 & 33 & 2.0 & 11 & 6.3 & 27 & 100 & 15.5 & 82.5 & 27.6 \\
\hline 19 & 37 & 51.0 & 40 & 33 & 12.5 & 32 & 80 & 10 & 162 & 31.4 & 58.8 & צ.e \\
\hline 19 & 36 & 43.0 & 45 & 33 & 3.0 & 45 & 154 & 19 & 168 & 25.8 & E1. & 11.3 \\
\hline 119 & 37 & 52.6 & 45 & 32 & 56.0 & 17 & $4 E^{-}$ & $4 E$ & 11 ตั & 15.5 & 42.1 & 42.1 \\
\hline 119 & 37 & 50.0 & $4 E$ & 32 & 13.0 & 18 & $\approx 5$ & 23 & 118 & 15.3 & 59.1 & 25.6 \\
\hline 18 & 37 & 58.1 & 40 & 33 & 14.5 & 33 & 58 & 25 & 115 & 28.3 & 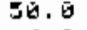 & 21.7 \\
\hline & 7 & $s$ & 45 & 32 & 50.0 & $1 \overline{9}$ & 48 & $3 E$ & 103 & $1 \bar{B} .1$ & 46.8 & 35.1 \\
\hline
\end{tabular}




\begin{tabular}{|c|c|c|c|c|c|c|c|c|c|c|c|c|}
\hline 119 & 37 & $52+0$ & 45 & 32 & 53.0 & 20 & $5 \overline{6}$ & 50 & 119 & 16.4 & 41.6 & 42.0 \\
\hline 119 & 37 & 52,0 & 46 & 32 & 56.0 & 23 & 37 & 44 & 105 & 22.2 & 35.6 & 42.2 \\
\hline 114 & 37 & 52.0 & 45 & 32 & 57.5 & 24 & 40 & 34 & 58 & 24.7 & 40.5 & 34.9 \\
\hline 119 & 37 & 52.0 & 40 & 32 & 57.8 & 22 & +7 & 48 & 117 & 18.7 & 48.6 & 41.3 \\
\hline 119 & 37 & 51.9 & 46 & 32 & 54.0 & If & 52 & 50 & 115 & 11.9 & 44.9 & 43.2 \\
\hline 119 & 37 & 53.6 & 45 & 32 & 54.0 & 13 & 49 & 49 & 112 & 11.5 & 44.6 & $44 . \overline{5}$ \\
\hline 119 & 37 & 52,0 & 45 & 32 & 55.0 & 17 & 63 & 45 & $\$ 25$ & 13.7 & 50.1 & 35.1 \\
\hline 119 & 37 & 52.9 & $4 E$ & 32 & 55.6 & 20 & 53 & 38 & 110 & $17 . ?$ & 47.7 & 34.5 \\
\hline 119 & 30 & 3.5 & 40 & 32 & 58,11 & 30 & 78 & 23 & 130 & 22.7 & $E 0.0$ & 17.3 \\
\hline 9 & 38 & 3.0 & $4 E$ & 32 & 54.0 & 13 & 91 & 22 & 125 & 16.0 & 72.4 & 17.6 \\
\hline 9 & 37 & 55,0 & 46 & 32 & 51.0 & 25 & 80 & 30 & 135 & 18.5 & 53.3 & 22.2 \\
\hline 9 & 37 & 39.0 & $4 \pi$ & $3 \hat{2}$ & 41.0 & 53 & 43 & 17 & 112 & 47.3 & 37.9 & 14.7 \\
\hline 19 & 37 & 41.0 & 45 & 32 & 45.6 & 50 & 58 & 13 & 125 & 40.5 & 46.8 & 14.6 \\
\hline$\theta$ & 37 & 40.0 & 45 & 32 & 44.0 & 50 & 43 & 24 & 123 & 40.7 & $3 \% .3$ & 19.5 \\
\hline 9 & अ? & 40.0 & 46 & 32 & 43,0 & $4 E$ & 51 & 42 & 138 & 83. & 37.0 & 36.1 \\
\hline 19 & 37 & 42.6 & +6 & 32 & 42.0 & 55 & 75 & $\ddot{\mathbf{H}}$ & 130 & 42.3 & 57.7 & 0.0 \\
\hline 19 & 37 & 50.6 & 46 & 32 & $54 . \overline{0}$ & $4 E$ & 79 & 9 & 135 & 34.3 & 52.3 & 5.3 \\
\hline 19 & 38 & 0.0 & $4 i$ & 32 & 54.6 & 30 & PE & 23 & 127 & 23.3 & 58.9 & 17.9 \\
\hline 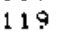 & 37 & 53.0 & 46 & 32 & 55.0 & 54 & 52 & 1 & 118 & $5+.5$ & 44.3 & 1.1 \\
\hline 119 & 37 & $58 . \hat{\theta}$ & $4 E$ & 32 & 56.4 & 16 & 109 & 0 & 125 & 12.3 & 37.2 & G. $\overline{0}$ \\
\hline 119 & 37 & 54.0 & 40 & 32 & $55, \overline{1}$ & 35 & 63 & 24 & 127 & 27.4 & 53.8 & 13.8 \\
\hline 119 & 37 & $1 . \overline{0}$ & 46 & 32 & 31.0 & 26 & 50 & 30 & 105 & $19 . \overline{0}$ & 52.7 & 28.1 \\
\hline & 37 & 36.6 & 46 & 32 & 39.6 & 38 & 46 & +1 & 125 & 30.3 & 37.1 & 32.7 \\
\hline 119 & 36 & $46 . \dot{3}$ & 46 & $3 \simeq$ & 52.6 & 44 & 91 & 35 & 159 & 25.7 & 53.3 & 29.4 \\
\hline 119 & 37 & 37.0 & 46 & 32 & 44.6 & 42 & 81 & 13 & 136 & 30.7 & 59.6 & 9.6 \\
\hline 9 & $3 ?$ & 37.0 & 46 & 32 & 41.01 & 35 & 88 & $G$ & 123 & 28.5 & 71.5 & .0 \\
\hline 9 & 37 & 4.18 & 45 & 32 & $48 . \overline{0}$ & 22 & 77 & 77 & 175 & 12.4 & 43.8 & 43.8 \\
\hline 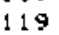 & 37 & 25.6 & 46 & 32 & 31.0 & 35 & 105 & 23 & 165 & 31.2 & EE. 2 & 13.6 \\
\hline 119 & 28 & 9.0 & 45 & 32 & 27.6 & 73 & 35 & 33 & 150 & 48.7 & 25.6 & 25,5 \\
\hline 119 & 25 & 53.6 & 46 & 31 & 35.6 & 58 & $8:$ & 58 & 210 & 32.5 & 39.7 & $27 . E$ \\
\hline 119 & 25 & 11.0 & 46 & 30 & 58.0 & 108 & 60 & 41 & 215 & 50.4 & $30 . \epsilon$ & . \\
\hline & 23 & 21.0 & 46 & 32 & 5,6 & 40 & 47 & 40 & 125 & 31.3 & 37.3 & 31.3 \\
\hline 115 & 23 & 2.0 & 46 & 31 & 48.0 & 55 & 54 & 19 & 125 & 42.7 & 42.3 & 15.0 \\
\hline 119 & 27 & 44.0 & 45 & 32 & 41.0 & 37 & 42 & 42 & 122 & 38.5 & 34.7 & 34.7 \\
\hline & 23 & 39,0 & $4 \pi$ & 34 & $\$ 7,0$ & 30 & 30 & 30 & 90 & 33.3 & 33.3 & 33,3 \\
\hline 9 & 27 & 20.0 & 46 & 32 & 54.6 & 42 & 47 & 42 & 130 & 32.1 & 35.9 & 32.1 \\
\hline 119 & 25 & 42.0 & 45 & 33 & 49.0 & 100 & 48 & 18 & 165 & 60.5 & 28.8 & 16.5 \\
\hline & 23 & 14.0 & 46 & 35 & 10,0 & 15 & 43 & +3 & 100 & $1=$ & 42,5 & \\
\hline & $2 E$ & 31.0 & 40 & 33 & 22.0 & 35 & 39 & 32 & 110 & 35.6 & 35.6 & 28,8 \\
\hline & 23 & 32.0 & 46 & 32 & 25,0 & 53 & 55 & 3 & 110 & 47.7 & 50.0 & .3 \\
\hline 11 & 36 & 33.6 & 45 & 30 & +4.0 & 54 & 102 & +4 & 200 & 27,1 & 50.2 & 22,1 \\
\hline 119 & 25 & 39.0 & 46 & 34 & 4.0 & 128 & 28 & 43 & รอิ & 64.2 & 14.2 & 21.7 \\
\hline & 24 & 1.8 & 46 & 32 & 39,0 & 53 & 83 & $1 \overline{3}$ & 130 & $\$ 1.0$ & 48.7 & \\
\hline & 24 & 43.5 & 40 & 31 & 45,0 & 75 & 70 & 15 & 160 & $46 . \overline{9}$ & 43.3 & 4 \\
\hline & 24 & 30.6 & 48 & 31 & 53.0 & 87 & 92 & +1 & $2 \theta \vec{\theta}$ & 33.7 & 45.3 & .4 \\
\hline 11 & 25 & 19.0 & +5 & 33 & 47.0 & 56 & +8 & 50 & 160 & 34.9 & 30.2 & 34.7 \\
\hline 1 & 24 & 40.1 & 46 & 33 & 13.5 & 43 & 45 & 29 & 118 & 36.6 & 39.7 & \\
\hline & 24 & 20.0 & 46 & 32 & 56.0 & 40 & $4:$ & 54 & $1+13$ & 28.7 & 31.9 & 39.4 \\
\hline & 25 & 0.0 & 4 ئ. & 33 & 30.6 & 115 & 50 & 14 & 160 & 84.5 & 27.9 & 7.6 \\
\hline 11 & 22 & 23.0 & 45 & 32 & 54.0 & \pm 0 & 50 & 15 & 160 & +1.3 & 49.7 & \\
\hline & 23 & 4.0 & $40^{\circ}$ & 32 & 32.0 & 49 & 45 & $2 z$ & 120 & +1.0 & 41.6 & 10.1 \\
\hline & 23 & 40.0 & 45 & 32 & 21.0 & 40 & 56 & 5 & 110 & 43.9 & 50.8 & 3 \\
\hline & \pm 1 & 23.0 & 45 & 33 & 25.0 & 55 & 85 & 10 & 130 & 42.3 & 50.0 & .7 \\
\hline & 24 & 10.0 & $4 E$ & 32 & 5.6 & 49 & 45 & 28 & 125 & 38.7 & 38.7 & 22.7 \\
\hline & 20 & $55 . \hat{y}$ & 45 & 33 & 43.0 & 33 & 33 & 25 & 9 & & 36.1 & $\Xi$ \\
\hline & 20 & 25.0 & 4 & 3 & 59.0 & $\hat{\varepsilon}$ & 23 & 15 & +5 & 16.7 & $5 \overline{6} .0$ & 3 \\
\hline & 25 & 20.3 & 40 & 32 & 58.6 & 45 & 55 & 70 & 170 & 26.5 & 32.4 & 41.2 \\
\hline & 25 & $58 . \overline{\mathrm{v}}$ & 40 & 34 & 31.0 & 5 & 55 & 53 & 175 & & $31 .+$ & \\
\hline & 23 & 53,0 & 40 & 33 & 35.8 & ?3 & 50 & 0 & $1>0$ & & 27.6 & \\
\hline & 23 & 29.0 & 45 & 33 & 39.0 & 57 & 45 & 24 & 130 & 43.5 & 37.6 & 18.6 \\
\hline & 25 & 17.0 & 45 & 34 & 2.0 & 53 & 53 & 63 & 185 & & 36.3 & \\
\hline & 24 & $52, \overline{1}$ & +6 & 34 & 16.0 & 55 & $E 3$ & 35 & IE日 & 34.4 & 42.2 & \\
\hline & 22 & 20. & 46 & 31 & 30.5 & $E \overline{0}$ & 8.0 & 35 & 155 & 28.7 & 3 & \\
\hline & 21 & 0.0 & 45 & 31 & $41 . \overline{8}$ & 53 & $10 \overline{5}$ & 15 & 125 & & 01.4 &.$\varepsilon$ \\
\hline & 20 & 20.6 & 4 & 32 & 5.0 & 53 & E5 & 33 & 150 & & +3.3 & 21.7 \\
\hline & 25 & 7. & $+e$ & 32 & $44 . \overline{0}$ & 39 & 47 & 44 & 130 & 30.1 & 35.4 & 34.0 \\
\hline
\end{tabular}




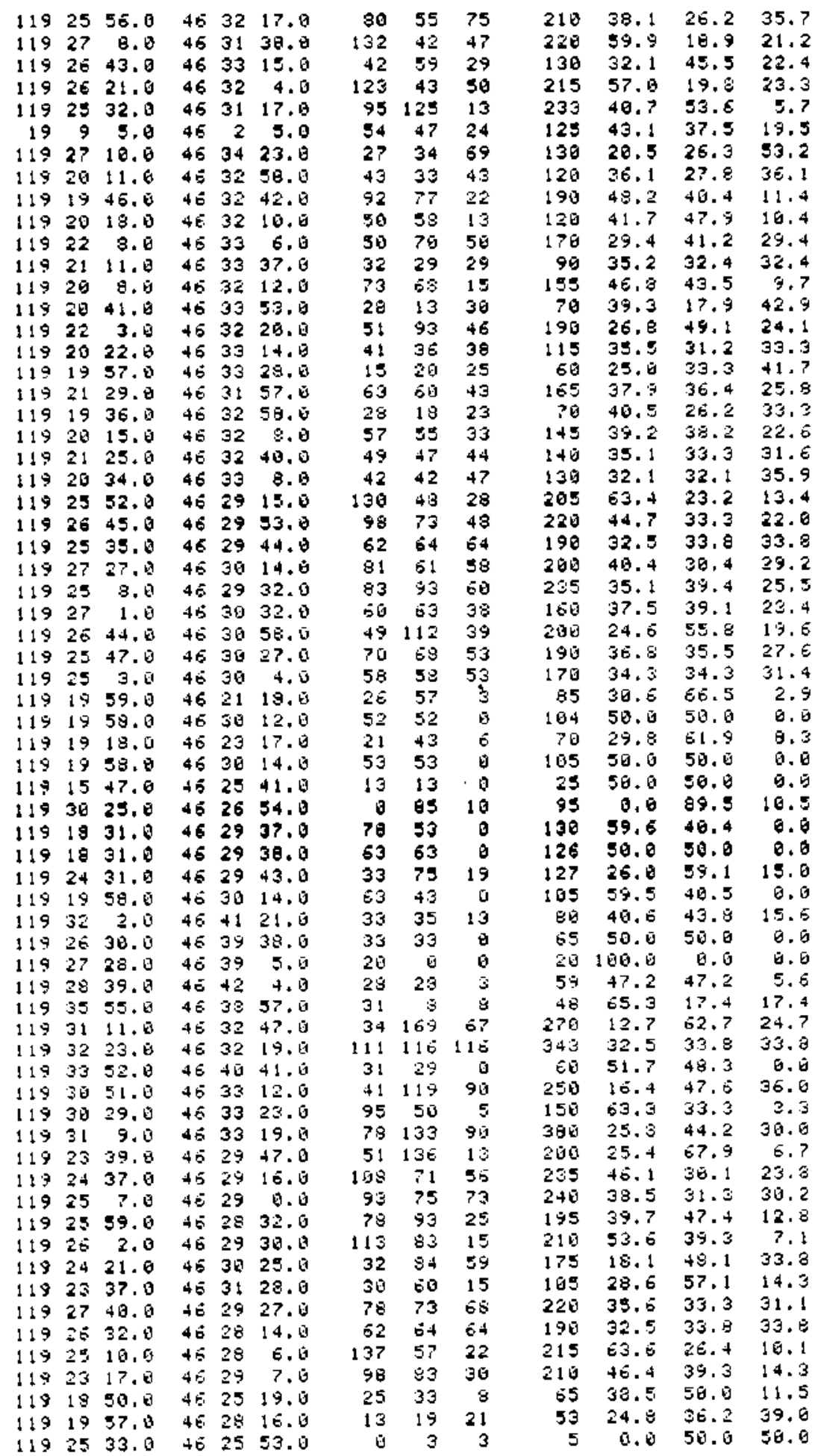




\begin{tabular}{|c|c|c|c|c|c|c|c|c|c|c|c|c|}
\hline 119 & 23 & 54.0 & 46 & 26 & 36.1 & 37 & 49 & 41 & 125 & 29.3 & 38.1 & 32.5 \\
\hline 115 & 27 & 31.0 & 40 & 26 & 41.0 & 25 & 97 & 3 & 124 & 19.8 & 78.2 & 2.0 \\
\hline$\$ 15$ & 23 & 46,0 & 46 & 27 & 43.1 & 46 & 76 & 5 & 127 & 36.5 & 59.7 & 3.8 \\
\hline 119 & 25 & 39.0 & 46 & 27 & 41,0 & 13 & 54 & 38 & 105 & 12.5 & 51.6 & 35.5 \\
\hline 119 & 32 & 2.0 & 46 & 33 & 27.0 & 34 & 175 & 48 & 256 & 13.1 & 69.2 & 18.8 \\
\hline $1: 9$ & 24 & 11.0 & 46 & 24 & 59.0 & 26 & 82 & 5 & 112 & 22.8 & 72.8 & 4,5 \\
\hline 119 & 31 & 59.9 & 46 & 33 & 39.0 & 53 & $1: 9$ & 99 & 260 & 20.2 & 45.8 & 34.0 \\
\hline 19 & 32 & 42.0 & $40^{\circ}$ & 33 & 29.6 & 49 & 216 & 3.5 & 3070 & 16.4 & 71.9 & 11.7 \\
\hline 119 & 33 & 6.0 & 45 & 34 & 5.0 & 81 & 113 & 52 & 245 & 33.1 & 45.9 & 21.6 \\
\hline 119 & 32 & 36.0 & 45 & 33 & 52.0 & 58 & 124 & 74 & 255 & 22.5 & 48,6 & 28.7 \\
\hline 19 & 37 & \pm 1.0 & 45 & 33 & 35.6 & 40 & 37 & 34 & 110 & 35.9 & 33.6 & $\approx 5.5$ \\
\hline 19 & 37 & 0.0 & $40^{\circ}$ & 33 & 35.4 & 31 & +4 & 30 & 105 & 29.7 & 42.1 & 28.3 \\
\hline 19 & 38 & 13.6 & 46 & 33 & 25.0 & 26 & $5 !$ & 49 & 125 & 20.8 & 40.4 & 38.5 \\
\hline 19 & 37 & $43 . \overline{1}$ & 46 & 32 & $58 . \overline{0}$ & 17 & 53 & 40 & 110 & 1.5 .5 & 46.2 & 36.4 \\
\hline 19 & 38 & 1.0 & 45 & 32 & 56.6 & 19 & 59 & 44 & 138 & 13.5 & 53,1 & 33.5 \\
\hline 119 & 37 & 16.0 & 45 & 32 & 41.6 & 28 & 33 & 40 & 190 & 27.5 & 32.5 & 45.6 \\
\hline 119 & 37 & 17.6 & 46 & 32 & 32.0 & 28 & 57 & 45 & 130 & 21.4 & 44.1 & 34.5 \\
\hline 119 & 36 & 33.5 & $4 E$ & 32 & 21.0 & 5 & 75 & 65 & 185 & 2.7 & 51.4 & 45.3 \\
\hline 119 & 37 & 33.4 & $4 E$ & 32 & $17 . \bar{v}$ & 14 & 57 & 56 & 125 & 11.2 & 44.8 & 44.5 \\
\hline 119 & 37 & 23.6 & 45 & 32 & $14 . \overline{0}$ & $1 E$ & $\Xi 1$ & $E ?$ & 165 & 9.5 & 49.3 & 40.8 \\
\hline 119 & 37 & 1.0 & 40 & 32 & $22+13$ & 7 & 95 & 59 & $1 \in \mathrm{b}$ & 4.1 & 59.4 & $3 \epsilon, \epsilon$ \\
\hline 119 & 37 & 24.0 & 46 & 32 & 25.0 & 27 & 67 & 10 & 16 & 24.3 & 61.5 & 14.2 \\
\hline 115 & 37 & 13.0 & 46 & 32 & 24.5 & 30 & ? 8 & 23 & 135 & 22.2 & 57.4 & 25.4 \\
\hline 119 & 16 & 33.0 & 45 & 23 & 25.0 & $2 E$ & 26 & $\exists$ & $E \bar{U}$ & 43.6 & 43.5 & 12.8 \\
\hline 119 & 16 & 54.0 & 46 & 23 & $25 . \overline{0}$ & $1 \hat{5}$ & 18 & 15 & 48 & 33.3 & 36.5 & 30.2 \\
\hline 119 & 30 & 27.0 & 46 & 17 & 58.0 & 10 & 14 & 4 & 27 & 35.2 & 56.8 & 14.8 \\
\hline 119 & 29 & 58.0 & 45 & 29 & 45.6 & 19 & 79 & 62 & 160 & 12.6 & 49.5 & 38.5 \\
\hline 119 & 19 & $58+4$ & 45 & 30 & 13.0 & 60 & 45 & $\Xi$ & 165 & 57.1 & 43.9 & 6.8 \\
\hline 119 & 27 & 35.0 & $4 E$ & 36 & 13.6 & 51 & $\dot{0} 2$ & 22 & 134 & 38,1 & 45.9 & 16.0 \\
\hline 119 & 30 & 35.0 & 45 & 35 & 21.6 & 43 & $1+2$ & 27 & 215 & 19.8 & 67.5 & 12.7 \\
\hline 119 & 32 & 47.8 & 45 & 31 & 36. & 22 & 151 & 117 & 259 & 8.3 & $4 \in .7$ & 45.8 \\
\hline 119 & 36 & 20.1 & $4 \pi$ & 30 & $30,$. & 2 & 74 & $7+$ & 150 & 1.4 & $4 \% .1$ & 49.4 \\
\hline 119 & 16 & 17.0 & 45 & 21 & $19 . \dot{0}$ & 20 & 25 & 0 & 45 & 44.4 & 55.6 & E. E \\
\hline 19 & 38 & 35.5 & 45 & 80 & 35.0 & $\dot{\mathfrak{b}}$ & b & 15 & 15 & 0.0 & $\hat{\theta} . \hat{\theta}$ & 108.0 \\
\hline 119 & 23 & 6.0 & 45 & 36 & $\$ 5.0$ & 71 & 5 & $\hat{\theta}$ & Po & 93.4 & $E, E$ & 5.5 \\
\hline 119 & 40 & 51.0 & 46 & 30 & 45.0. & 25 & 60 & 25 & 109 & $22 . E$ & 54.7 & 22.6 \\
\hline 19 & 21 & 36.0 & 40 & 30 & 47,0 & 45 & 45 & 10 & 103 & 43.2 & 47.6 & 9.2 \\
\hline 19 & 29 & 14.0 & 40 & 30 & 57.0 & 57 & 94 & 26 & 177 & 32.1 & 53,3 & 14.6 \\
\hline 13 & 32 & 44.0 & 46 & 31 & 2.0 & 5 & 137 & 125 & 266 & 1.7 & 51.3 & 47.6 \\
\hline 19 & 38 & 9.0 & 46 & 31 & 18.0 & 11 & 43 & 11 & 65 & 16.7 & 66.7 & 16.7 \\
\hline 119 & 26 & 56.0 & $40^{\circ}$ & 31 & 24.0 & 78 & 32 & 3 & 110 & 70.9 & 29.1 & 0.0 \\
\hline 119 & 32 & 15.0 & 46 & 31 & 32.0 & 23 & 205 & 53 & 231 & 8.1 & 72.9 & 19.0 \\
\hline 19 & 32 & 15.9 & 46 & 31 & 33.8 & 55 & 178 & 44 & 276 & 19.7 & 64.5 & 15.8 \\
\hline 19 & 35 & 12.0 & 46 & 31 & 28.0 & 5 & $1 I E$ & 105 & 230 & 3.8 & 50.6 & $45 . \varepsilon$ \\
\hline 1 & 24 & 52.0 & 46 & 31 & 38.5 & 68 & 80 & 3 & 150 & 45.6 & 53.3 & 1.7 \\
\hline 119 & 29 & 44.0 & $4 \epsilon$ & 31 & 45.0 & +3 & 63 & 15 & 115 & 37.0 & 54.3 & 8.7 \\
\hline 19 & 29 & 47.0 & 46 & 31 & 41.0 & 53 & +8 & $1 \overline{1}$ & 111 & 47.7 & 43.2 & 9.0 \\
\hline ! & 34 & 24.0 & 40 & 31 & $42 . \overline{6}$ & 5 & 183 & 28 & 215 & 2.3 & 84.9 & 12.8 \\
\hline 19 & 36 & 23,0 & 46 & 31 & $44 \cdot 8$ & 29 & 34 & 72 & 184 & 15,3 & 45.7 & 39.0 \\
\hline 11 & 35 & +7.0 & 45 & 31 & $48 . \theta$ & 5 & 119 & se & 190 & 2.0 & 62.6 & 34.7 \\
\hline 119 & 37 & 59.9 & $40^{\circ}$ & 31 & $41 . \bar{v}$ & 11 & 74 & 57 & 142 & 7.7 & 52.1 & 46.1 \\
\hline 119 & 29 & 41.5 & 45 & 31 & 46.0 & 23 & $\hat{E} 1$ & 31 & 115 & 20,0 & 53.0 & 27.6 \\
\hline 1 & 32 & 58.4 & 46 & 31 & 51,0 & 40 & 275 & $\overline{9}$ & 315 & 12.7 & 97.3 & $0 . \dot{6}$ \\
\hline 119 & 28 & 55.6 & 46 & 32 & $0 . \overline{0}$ & シ & $\Xi$ & $\dot{\theta}$ & 13 & 65.4 & $54 . E$ & 0.6 \\
\hline 113 & 29 & 26.0 & 46 & 32 & 2.0 & 59 & $7 \%$ & 33 & 170 & 34.5 & 46.5 & 19.5 \\
\hline 1 & 29 & 34.0 & 45 & 31 & 55.0 & 43 & -5 & 23 & 130 & 32.7 & 50.0 & 17.3 \\
\hline 1 & 25 & 9.8 & 46 & 32 & $5, \vec{v}$ & 51 & $\bar{E} \bar{U}$ & 30 & 140 & 36.1 & 42.5 & 21.4 \\
\hline 119 & 31 & 50.0 & 46 & 32 & $\overline{\mathrm{e}}, \hat{\mathrm{v}}$ & 41 & 144 & 143 & 323 & 12.4 & 43.9 & 4.3 .7 \\
\hline 19 & 35 & 17.0 & 46 & 32 & 11.0 & 35 & 125 & $\$ 10$ & 270 & 13.0 & 46.3 & 45.7 \\
\hline 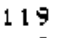 & 40 & 38.6 & $4 \pi$ & 32 & 日. & 10 & 32 & 32 & 73 & 13.7 & 43.2 & 43.2 \\
\hline 119 & 36 & 18.0 & 45 & 32 & 8.8 & $E$ & 101 & 95 & 203 & 3.1 & 49.7 & 47.2 \\
\hline $1=$ & 38 & 15.0 & 45 & 32 & 18.0 & $2 E$ & E6 & 49 & $1+0$ & 12.2 & 46.8 & 35.8 \\
\hline 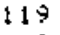 & 30 & 29,8 & 46 & 32 & 22.6 & 144 & 115 & 72 & 325 & 44.2 & 33.7 & 22.2 \\
\hline & 30 & 29.0 & 45 & 32 & 22.6 & 142 & 110 & 65 & 317 & 44.8 & 34.7 & \\
\hline 119 & 30 & 29.0 & 45 & 22 & 23.8 & 148 & 105 & Tú & 325 & 45.4 & 33.1 & 21.5 \\
\hline 10 & 34 & 5.0 & 46 & 32 & 25.0 & 15 & 150 & $130^{\circ}$ & $3 \overline{6}$ & 4.8 & 49.9 & 45 \\
\hline
\end{tabular}




\begin{tabular}{|c|c|c|c|c|c|c|c|c|}
\hline 119 & 34 & 5.0 & 46 & 32 & 26.0 & 33 & 138 & 120 \\
\hline 115 & 25 & 50.6 & +6 & 32 & 30.0 & 74 & $1+3$ & 68 \\
\hline 119 & +1 & $47 \cdot 6$ & 40 & 32 & 24.5 & 3 & 30 & 23 \\
\hline 119 & 39 & 9.6 & 46 & 32 & 35.0 & 10 & 12 & 3 \\
\hline 119 & 39 & 9,19 & 46 & 32 & $3 \%, 6$ & 10 & 5 & 5 \\
\hline 119 & 3.5 & 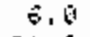 & 45 & 32 & 41.0 & 5 & 107 & 92 \\
\hline 119 & 36. & 21.0 & $4 \%$ & 32 & 43.1 & 17 & 82 & 35 \\
\hline 119 & 25 & $5 \% .6$ & $4 E$ & 32 & 49.0 & E4 & 48 & 1 \\
\hline 119 & 5 & 23,8 & 45 & 22 & $5.5 . \overline{1}$ & 40 & 41 & 7 \\
\hline 119 & 19 & 44,1 & 45 & $3 z$ & 53.5 & 65 & 35 & 2 \\
\hline 115 & 27 & 34.6 & 4 & 3 & 2,5 & 52 & 52 & 11 \\
\hline 113 & Eّ & 3.5 & +5 & 33 & 4.6 & 53 & 33 & 5 \\
\hline 115 & 34 & $1 E .8$ & 45 & 33 & 4,5 & 12 & $1+9$ & $1+4$ \\
\hline 119 & 32 & $23 . \overline{3}$ & $+\hat{E}$ & 35 & 25.5 & $5 z$ & $E$ & 5 \\
\hline 119 & 29 & $27 . \dot{0}$ & $4 E$ & 35 & \pm 9.6 & 89 & $7 E$ & $4 \%$ \\
\hline 119 & 40 & $4 \bar{B} . \dot{6}$ & 46 & 33 & 35.6 & 1 & 28 & 15 \\
\hline 119 & $+\hat{b}$ & 42,0 & $4 \hat{5}$ & 33 & 35.5 & 0 & 15 & 18 \\
\hline 119 & 34 & 47.4 & $4 E$ & 33 & +1.6 & 71 & 110 & 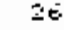 \\
\hline 119 & 24 & 30.0 & $+E$ & 33 & 57.5 & 59 & 12 & +5 \\
\hline 19 & $3 E$ & ง. & 45 & 33 & 51.0 & 43 & 33 & 59 \\
\hline & 27 & 51.8 & $4 \Sigma$ & 34 & 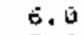 & 32 & 25 & 14 \\
\hline 19 & 27 & 51,8 & 46 & 34 & ?. 0 & 25 & 35 & 10 \\
\hline
\end{tabular}

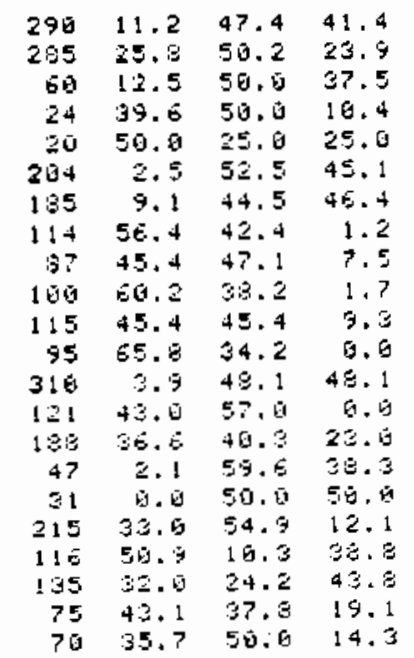




\begin{tabular}{|c|c|c|}
\hline$c$ & CONVRT.FLX & BUR00010 \\
\hline c & * & BUR00020 \\
\hline C & * TKIS PROGRAY CONVERTS PLANT, HANFORD AND RICHLAND * & BUR00030 \\
\hline C & * COORDINATES TO LAMBERT COORDINATES. & BUROOOLO \\
\hline c & SUBROUTINE LONLAT IS USED TO CONVERT THE & BURDOOSO \\
\hline c & LAMBERT COOROINATES TO GEOGRAPHIC LONGITUDE * & BUR00060 \\
\hline $\mathrm{c}$ & AND LATYTUDE COORDINATES. & BUR00070 \\
\hline c & - & BUR00080 \\
\hline C & $\Rightarrow$ OR IT CAN ALSO CONVERT IAAMBERT COORDINATES TO & BUR00090 \\
\hline $\mathrm{C}$ & $\Rightarrow \quad$ PLANT COORDINATES. & BUR00100 \\
\hline C & - & BUR00110 \\
\hline $\mathrm{C}$ & * BATTELLE NORTMWEST LABORATORIES & BUR00120 \\
\hline $\mathrm{C}$ & * WATER AND LAND RESOURCES DEPT. & BL'R00130 \\
\hline c & * RICHLAND, WASHINGTON 99352 & BUR00140 \\
\hline $\mathrm{C}$ & \# & BUROO150 \\
\hline c & * AUTHOR(S) : D.W. DAMSCHEN & BUR00160 \\
\hline $\mathrm{c}$ & $\Rightarrow \quad$ R.S. ARGO & BUR00170 \\
\hline C & " & BUR00180 \\
\hline c & * INITIAL VERSION: 20 JUL 1977 & BUR00190 \\
\hline $\mathrm{C}$ & * CURRENT VERSION: 28 AUG 1984 & BUR00200 \\
\hline c & * & BUR00210 \\
\hline $\mathrm{c}$ & 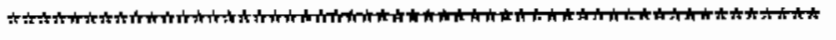 & BUR00220 \\
\hline C & & BURO0 230 \\
\hline & BYTE WELL(12), FILI (30), FILO(30), AA, BB & BUR00240 \\
\hline & BYTE $A, B, D, N, S, E, W, P, R, H, L$ & BUR00250 \\
\hline $\mathrm{C}$ & & BUR00260 \\
\hline & REAL LONDEG, LONMIN, LONSEC , LATDEG, LATMIN, IATSEC, LN, IE & BUR00270 \\
\hline C & & BUR00280 \\
\hline & COMMON RPRIME (31), LONDEG, LONHIN, LONSEC, & BUR00290 \\
\hline & LATDEG, LATMIN, IATSEC & BUR00300 \\
\hline C & & BUR00310 \\
\hline & 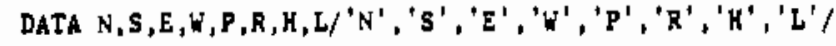 & BURO0320 \\
\hline $\mathrm{c}$ & & BUR00330 \\
\hline & $\begin{array}{l}\text { OPEN(UNIT-1, NAME='RPRIME. DAT' ,TYPE= 'OL ' , READONLY) } \\
\operatorname{READ}(1,100)(\text { RPRIHE }(I), I=1,31)\end{array}$ & $\begin{array}{l}\text { BUR00340 } \\
\text { BUR00350 }\end{array}$ \\
\hline 100 & FORHAT $(F 15.0)$ & BLR00360 \\
\hline & CLOSE (UNIT $=1$ ) & BUR00370 \\
\hline c & & BUR00380 \\
\hline & WRITE $(5,500)$ & BUR00390 \\
\hline 500 & FORMAT $\left('\right.$ \$ENTER NAME OF INPUT FILE $\left.(30 \mathrm{~A} 1)>{ }^{\circ}\right)$ & BUR00400 \\
\hline & $\operatorname{READ}(5,501)$ FILI & BUR00410 \\
\hline 501 & FORMAT (30AI) & BUR00420 \\
\hline & $\mathrm{NN}=\operatorname{ICHR}(F I L I)$ & BUR00430 \\
\hline & OPEN (UNIT $=1$, NAME $=F I L 1, T Y P E='$ OLD' , READONLY) & BURO0 440 \\
\hline C & & BUR00450 \\
\hline & WRITE $(5,502)$ & BUR00460 \\
\hline 502 & FORMAT('\$ENTER NAME OF OUTPUT FILE $(30 \mathrm{~A} 1)>1$ ') & BUR00470 \\
\hline & $\operatorname{READ}(5,501)$ EILO & BURO0 480 \\
\hline & $\mathrm{NN}=I C H R(F I L O)$ & BUR00490 \\
\hline & OPEN $\left(U N I T=2\right.$, NAME $=$ FILO, TYPE $={ }^{\prime}$ NEW' $\left.^{\prime}\right)$ & BUR00500 \\
\hline C & & BUR00510 \\
\hline C & & BUR00520 \\
\hline & $X_{1}=0.0025674589$ & BUR00530 \\
\hline & $Y_{1}=0.9999967040$ & BUR00540 \\
\hline & $z=0.77979344$ & BUR00550 \\
\hline & $V=0.62603690$ & BUR00560 \\
\hline & $U=0.99989620$ & BUR00570 \\
\hline & $T=0.01440816$ & BUR00580 \\
\hline & $Q=2295325.01$ & BUR00590 \\
\hline
\end{tabular}


FILE: CONVRT FORTRAN A1 (USR191) 12/16/85 12:21:03

$0=405302.04$

BUR00600

$G=2294636.42$

$G G=325733.14$

URITE $(5,5)$

5 FORMAT (' SELECT : ' $/$ ' (O) LAMBERT TO PLANT COORDINATES"/

+ (1) PLANT, ETC. COORDINATES TO LONGITUDE-LATITUDE'/)

READ $(5, *)$ IOPT

C

$\operatorname{IF}((0)+$ NE . (IOPT) ) GO TO 32757

C

WRITE $(2,6)$

6 FORMAT ( $/ 9 \mathrm{X}$ 'WELL LAMBERT COORDINATES' $11 \mathrm{X}$ 'PLANT COORDINATES'/

$\left.+9 X^{\prime}-\ldots-4 X, 20\left({ }^{\prime}-{ }^{\prime}\right), 9 X, 19\left({ }^{\prime}-{ }^{*}\right)\right)$

7 READ (1, 8, END=99) WELL, $Y, 8, X, A$

8 FORMAT $(1 X, 12 A 1,1 X, F 10,0, A 1, I X, F 10,0, A 1,5 X, F 10.0, A 1,1 X, F 10.0, A 1)$ IF (B.EQ.S) $Y=-Y$

IF (A.EQ.W) $X=-X$

$C 1=X-Q$

$\mathrm{C} 2=\mathrm{Y} \cdot \mathrm{O}$

$\mathrm{YY}=-\mathrm{X}_{1} * \mathrm{C} 1+\mathrm{Y} 1 * \mathrm{C} 2$

$\mathrm{XX}=\mathrm{Y} 1 * \mathrm{C} 1+\mathrm{X} 1 * \mathrm{C} 2$

$\mathrm{BB}=\mathrm{N}$

IF (.NOT. (YY.LT.O)) GO TO 32756

$\mathrm{BB}=\mathrm{S}$

$Y Y=-Y Y$

$32756 \mathrm{AA}=\mathrm{E}$

IF (.NOT. (XY.LT, O)) GO TO 32755

$A A=W$

$\mathrm{XX}=-\mathrm{XX}$

32755 WRITE $(2,8)$ WELL, Y, B, X,A,YY, BQ, XX, AA

GO TO 7

99 CONTINUE

GO TO 32758

32757 IF ((1).NE. (IOPT)) GO TO 32754

$\mathrm{C}$

C it PLANT, HANFORD, OR RICHLAND TO LAMBERT TO LONG-LAT

$\mathrm{C}$

OPEN (UNIT=4, NALE = ' LONLAT . DAT' , TYPE= 'NEW' )

HRITE $(2,200)$

200 FORHAT (1HI, 2X, 'WELL NAHE', 6X, 'PLANT COORDTNaTES', $7 \mathrm{X}$, 'LaMbert',

1 1X, 'COORDINATES', 10X, 'LONGITUDE' , 9X, 'LATITUDE'

C

$2100(1 \mathrm{H}-))$

HRITE $(4,210)$

210 FORMAT ( IH1 16X/3X, 'WELL NAKE', 5X, 'ELEV. ', 7X,

$\mathrm{C}$

$19 \mathrm{X},{ }^{\prime}$ LATITUDE $\left.^{\prime} / 1 \mathrm{X}, 54(1 \mathrm{H}-)\right)$

LINES $=2$

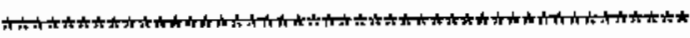

*

* blanX READ to bypass header on inpUt file *

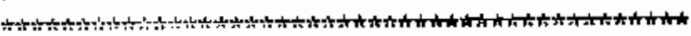

$\operatorname{READ}(1,101)$

BUR00610

BUR00620

BUR00630

BUR00640

BUR00650

BUR00660

BUR00670

BUR006́80

BUR00690

BUR00700

BUR00710

BURO0720

BURO0730

BUR00740

BUR00750

BUR00760

BUR00770

BUR00780

BUR00790

BUR00800

BURO0810

BURO0820

BUR00830

BUR00840

BURO0850

BUR00860

BUR00870

BUR00880

BUR00890

BUR00900

BUR009 10

BUROOS20

BUR00930

BUR00940

BUR00950

BUR00960

BUR00970

BUR00980

BURO0990

BURO 1000

EURO 1010

BUR01020

BURO 1030

BURO 1040

BURO 1050

BUR01060

BUR01070

BUR01080

BUR01090

BUR01100

BUR01110

BUROI 120

BURO1 130

BUR01140

BURO 1150

BURO1160

BUR01170

C

BUR01180 
FILE: CONVRT FORTRAN A1 (USR191) 12/16/85 12:21:03

PAGE 3

$\operatorname{READ}(1,101, \mathrm{END}=999)$ WELL, A, B , C, D , F, CASE

101 FORHAT ( $1 X, 12 A 1,1 \mathrm{X}, M, A 1, F 7.0,1 \mathrm{X}, \mathrm{Al}, \mathrm{F} 7.0,58,0)$

BLRO1190

BUR01200

BUR01210

IF (C.EQ.O.) GO TO 75

IF (A.EQ.P.AND,B.EQ.N.ANR T.EN,W) GO TO 10

IF (A.EQ.P.AND.B.EQ.S.AND.D.EQ.E) GO TO 20

IF (A.EQ.P.AND.B.EQ.S.AND.D.EQ.W) GO TO 30

IF (A.EQ.P.AND.B.EQ.N.AND.D.EQ.E) GO TO 40

IF (A.EQ.H) GO TO 50

IF (A.EQ.R) GO TO 70

GO TO 90

C

$F=F P$

$C=C P$

C

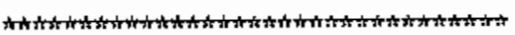

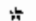

* CONVERT FROM PLANT TO IAAMBERT *

:)

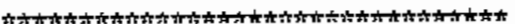

$10 \quad L N=0-F \star X I+C * Y 1$

$\left.L E=Q-F^{*}+C^{+}+X\right]$

GO TO 80

$\mathrm{C}$

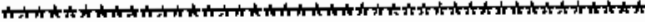

$+$

* convert plant to lameERT for negatives *

\#

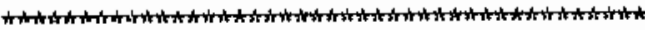

$\mathrm{LN}=\mathrm{O}-\mathrm{C}+\mathrm{Y} I+\mathrm{F}+\mathrm{XI}$

$\mathrm{LE}=\mathrm{Q}+\mathrm{F}^{\star \mathrm{Y}} \mathrm{Y}+\mathrm{C}^{\star} \mathrm{XI}$

GO TO 80

$30 \quad \mathrm{LN}=0-F \star X 1-C \star Y 1$

$\mathrm{L} . \mathrm{E}=\mathrm{Q}-\mathrm{F}^{*} \mathrm{Y} 1+\mathrm{C}^{*} \mathrm{X} 1$

GO TO 80

$40 \quad[N=0+F \div X 1+C \div Y I$

$\mathrm{LE}=\mathrm{Q}+\mathrm{F} \div \mathrm{Y} 1-\mathrm{C}+\mathrm{X} \mathrm{X}$

GO TO 80

$c$
$C$
$C$
0
0
$c$
$c$

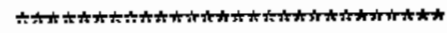

*

* CONVERT haNFORD TO PLANT *

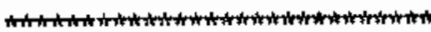

so IF (B.EQ.S) GO TO 60

$F P=12953.65 \cdot F \div Z \cdot C+Y$

$C P=52836.82-F^{*}+\mathrm{V}+\mathrm{C}+2$

GO TO 9

C

$F P=12953.65+F * Z+C \star V$

$\mathrm{GP}=52836.82+\mathrm{F}^{*} \mathrm{~V}-\mathrm{C}^{\star} \mathrm{Z}$

GO TO 9

C

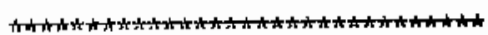

BUR01220

BURO 1230

BUR01240

BUR01250

BURO 1260

BUR01270

BURO1280

BUR0 1290

BUR01300

BUR01310

BURO 1320

BUR01330

BURO 1340

BURO1350

BUR01360

BURO1370

BURO1380

BURO1390

BUR01400

BUR01410

BURO 1420

BUR01430

BUR01440

BURO1450

BURO1460

BUR0 1470

BUR01480

BUR01490

BURO 1500

BURO1510

QUROIS20

BUR01530

BC'RO1540

BURO1550

BUR0 1560

BURO1570

BUROI580

BURO 1590

BUR01600

BURO1610

BUR01620

BUR01630

BURO1640

BUR01650

BURO1660

BUR01670

BURO 1680

BUR0 1690

BUR01700

BURO1 710

BURO 1720

BURO 1730

BURO1740

BUR01750

BUR01760

BUR01770 


\begin{tabular}{|c|c|c|}
\hline C & * & BUR01780 \\
\hline $\mathrm{C}$ & * CONVERT RICHLAND TO LAMBERT * & BUROY790 \\
\hline c & & BURO1800 \\
\hline $\mathrm{C}$ & 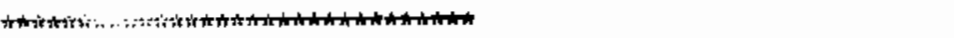 & BUR01810 \\
\hline C & & BUR01820 \\
\hline 90 & $L N=G G+F+T+C+U$ & BUR01830 \\
\hline & $L E=G+F+U-C+T$ & BUR01840 \\
\hline & GO TO 80 & BUR01850 \\
\hline C & & BUR01860 \\
\hline 75 & $L N=0$. & BUR0 1870 \\
\hline & $L E=0$ & QLRO 1880 \\
\hline & LONDEG $=0$ & BUR01890 \\
\hline & LONMIN $=0$ & BUR01900 \\
\hline & LONSEC $=0$ & BUR01910 \\
\hline & LATOEG $=0$. & BUR01920 \\
\hline & LATMIN $=0$. & BUR01930 \\
\hline & LATSEC $=0$ & BUR01940 \\
\hline & GO TO 85 & BURO1950 \\
\hline $\mathrm{c}$ & & BUR01960 \\
\hline $\mathrm{C}$ & 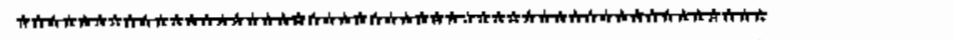 & BUR01970 \\
\hline $\mathrm{C}$ & $\star$ & BUR01980 \\
\hline C & * CALCULATE GEOGRAPHIC COORDINATES USING LONLAT * & BUR01990 \\
\hline $\mathrm{c}$ & \# $\quad \pi$ & BUR02000 \\
\hline 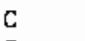 & 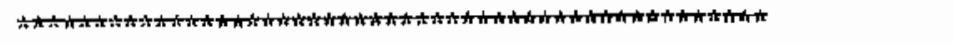 & BURO2010 \\
\hline C & & BUR02020 \\
\hline 80 & CALL LONLAT(LN,LE) & BUR02030 \\
\hline $\mathrm{C}$ & & BUR02040 \\
\hline BS & WRITE $(4,401)$ WELL, CASE, LONDEG, LONMIN, LONSEC, LATDEG, LATMIN, & BUR02050 \\
\hline & 1 LATSEG & BUR02060 \\
\hline 401 & FORMAT $(1 \mathrm{X}, 12 \mathrm{~A} 1, \mathrm{~F} 10.2,4 \mathrm{X}, 2(2 \mathrm{~F} 4.0,2 \mathrm{X}, \mathrm{F} 5.2,2 \mathrm{X}))$ & BUR02070 \\
\hline & WRITE $(2,201)$ WELL $, A, B, C, D, F, L, N, I N, E, L E$, LONDEG , LONHIN, & BUR02080 \\
\hline & LONSEC, LATDEG , LATMIN, LATSEC & BUR02090 \\
\hline 201 & FORMAT $(1 X, 12 A 1,4 X, 2 A 1, F 7.0,1 X, A 1, F 7.0,4 X, 2 A 1, F 10.2,1 X, A 1$, & BUR02100 \\
\hline & $1 \quad F 12,2,4 \times, 2(2 r 4,0,2 X, F 5,2,2 X))$ & BUR02110 \\
\hline C & LINES = LINES+1 & BUR02120 \\
\hline & $\begin{array}{l}\text { IINES = LINES+1 } \\
\text { IF (LINES.LT. 60) GO TO } 1\end{array}$ & $\begin{array}{l}\text { BUR02130 } \\
\text { BUR02160 }\end{array}$ \\
\hline C & If (LIRES . L1, OU) GO 10 & BUR02150 \\
\hline & WRITE $(2,200)$ & BURO2160 \\
\hline C & & BUR02170 \\
\hline $\mathrm{C}$ & LINES $=2$ & BUR02180 \\
\hline $\mathrm{C}$ & & BUR0 2190 \\
\hline $\mathrm{C}$ & GO TO 1 & BUR02200 \\
\hline 90 & & BUR02210 \\
\hline 601 & WRITE $(5,601)$ WELL ERROR OR OTHER MISINTERPRETATION OF DATA' & BUR02220 \\
\hline & 1 ORMA WELL ', 12A1) & $\begin{array}{l}\text { BUR02230 } \\
\text { BUR02240 }\end{array}$ \\
\hline & WRITE $(5,101)$ WELL, A, B, C, D, F & BUR02250 \\
\hline & GO TO 1 & BLR02260 \\
\hline $\mathrm{c}$ & & BUR02270 \\
\hline 32754 & CONTINUE & BUR022BO \\
\hline $\mathrm{C}$ & & BUR02290 \\
\hline 32758 & CONT INUE & BUR02300 \\
\hline 999 & CLOSE (UNIT=1) & BUR02310 \\
\hline & CLOSE (UNIT=2) & BUR02320 \\
\hline & STOP & BUR02330 \\
\hline & END & BUR02340 \\
\hline & SUBROUTINE LONLAT (LN,LE) & BUR02350 \\
\hline & & BUR02360 \\
\hline
\end{tabular}




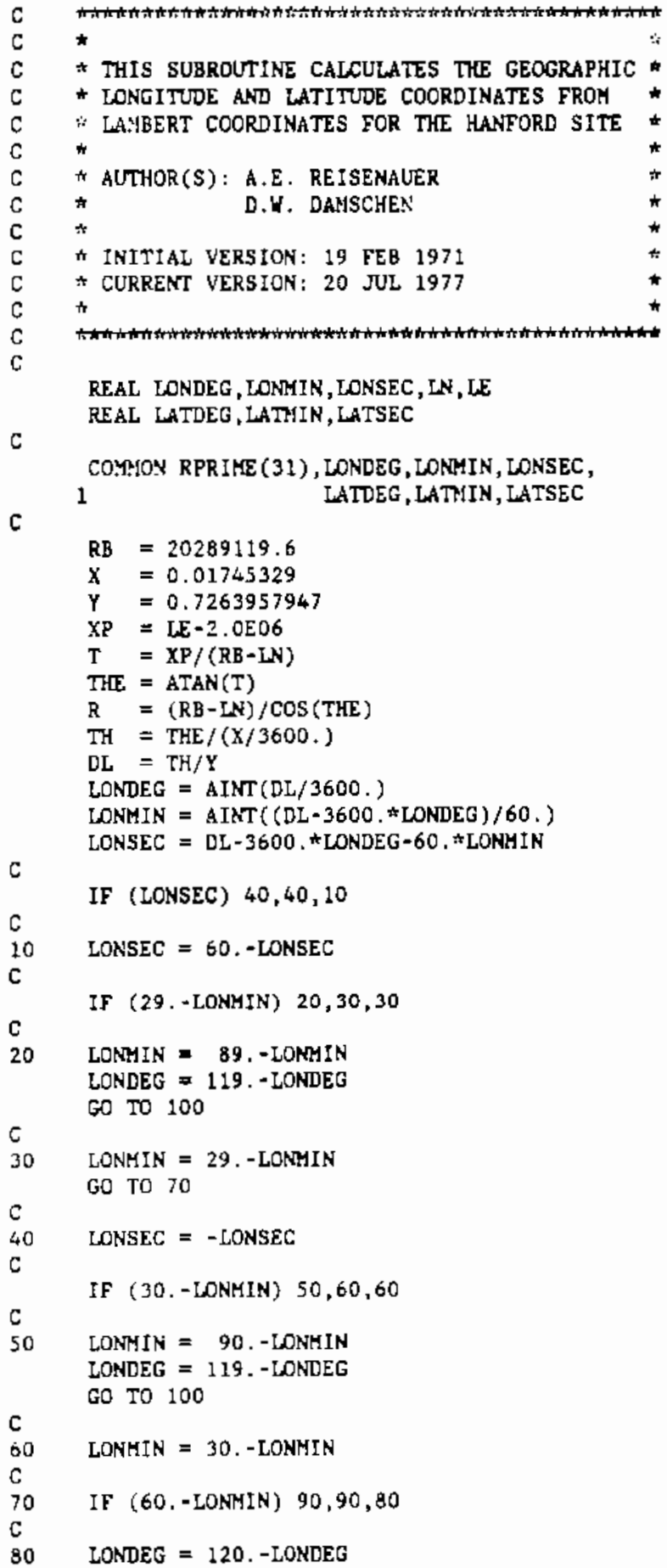

BUR02370

BUR02380

BURO2390

BUR02400

BUR02410

BURO2420

BURQ2430

BUR02440

BUR02450

BUR02460

BUR02470

ELS02480

BUR02490

BUR02500

BLR02510

BURO2520

BURO2530

BUR02540

BURO2550

BUR02560

BUR02570

BUR02580

BURO2590

QUR02600

BURO2610

BUR02620

BUR02630

BURO2640

BUR02650

BUR02660

BUR02670

BUR02680

BUR02690

BUR02700

BUR02710

BUR02720

BUR02730

BUR02740

BURO2750

BUR02760

BUR02770

BURO2780

BUR02790

BURO2800

BUR02810

SURO2820

GL'R02830

BLR02840

BUR02850

BLR02860

BURO2870

BURO2B80

BUR02890

BUR02900

EURO2910

BURO 2920

EURO2930

BURO2940

BURO2950 
FILE: CONVRT FORTRAN A1 (USR191) 12/16/85 12:21:03

BUR02980

BUR02990

C

BUR03000

100 CONTINUE

DO $32758 \quad I=1,31$

IF (R.LT.RPRIME(I)) GO TO 110

BUR03010

IF (R.EQ.RPRIME (I)) GO TO 120

BUR0 3020

BUR03030

BUR03040

IF (.NOT. (I.NE. 1)) G0 TO 32757

BUR03050

BUR03060

ADIF $=\operatorname{RPRIME}(I-1)-R$

BDIF = RPRIME (I-1)-RPRIME (I)

LATSEC $=$ ADIF*60./8DIF

GO TO 230

32757 CONTINUE

110 CONTINUE

32758 CONTINUE

120 LATSEC $=0$.

130 LATMIN $=15+I-2$

LATDEG $=46$.

$c$

RETURN

BUR03070

BUR03080

BUR03090

BUR0 3100

BUR03110

BURO 3120

BUR0 3130

BURO3140

BUR03150

BUR0 3160

BUR0 3170

BUR0 3180

END

BUR03190 
$\therefore$ 
APPENDIX B

COMPUTER CODE FOR FLOOD HYDROGRAPH 


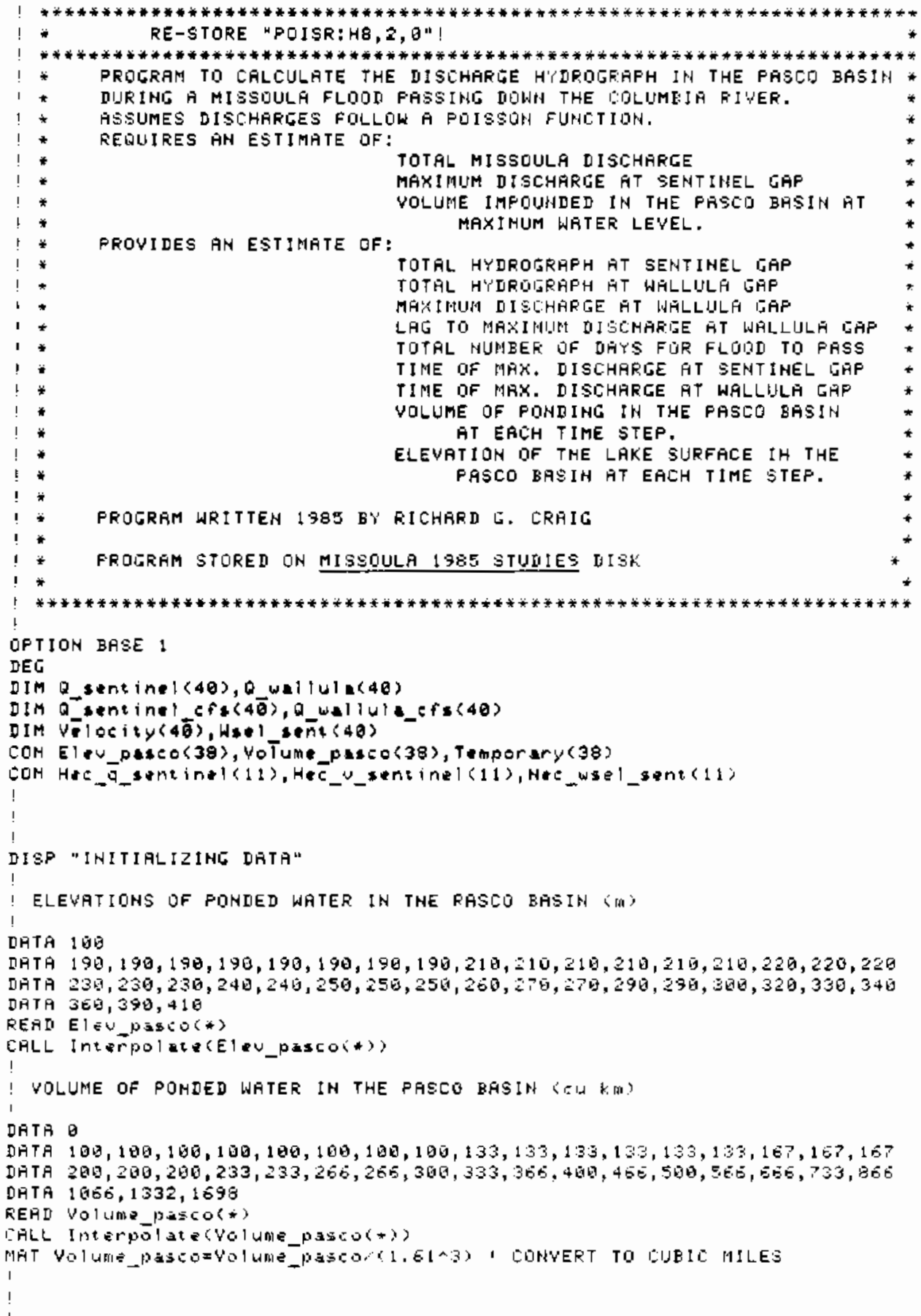




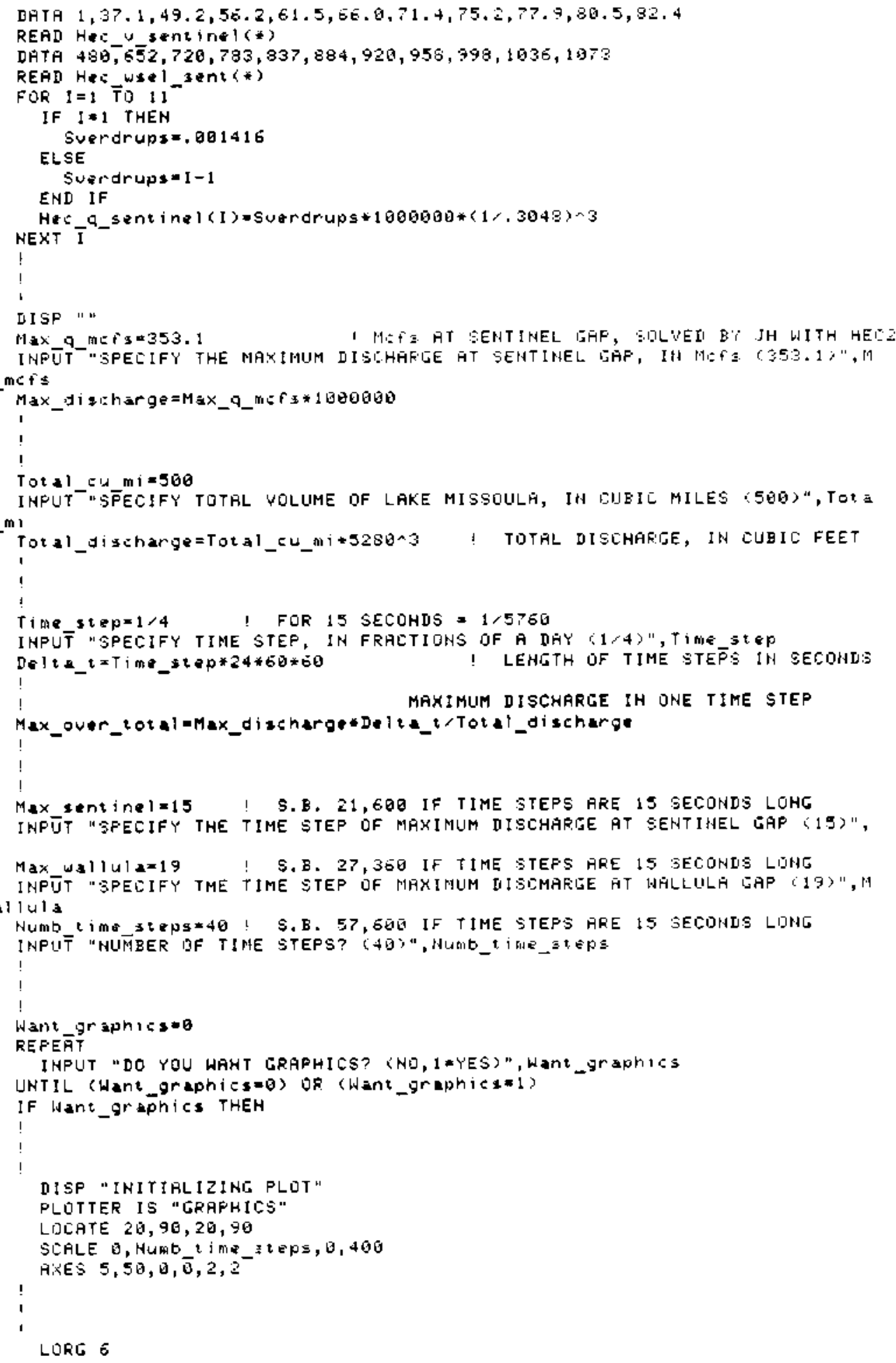




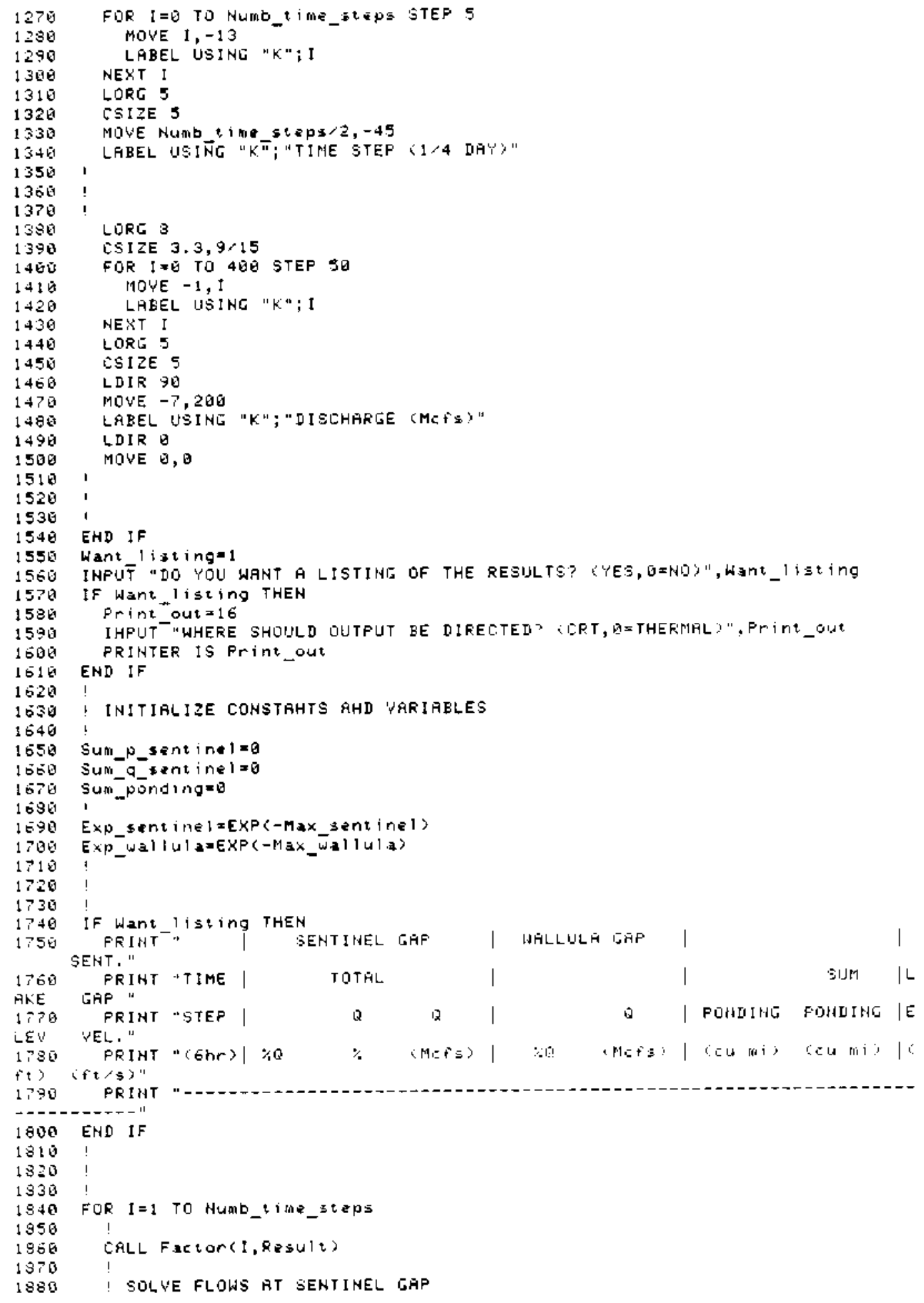




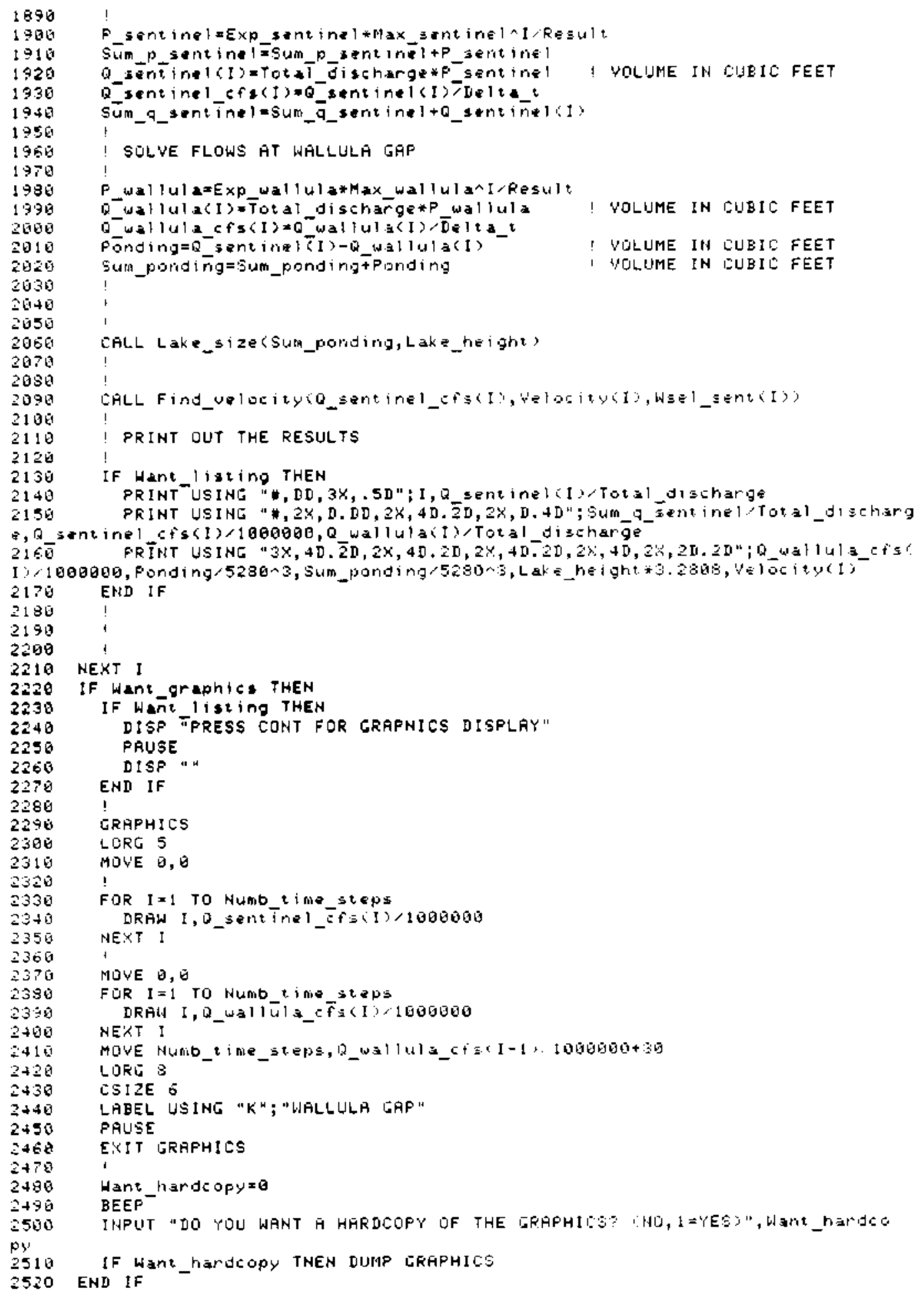




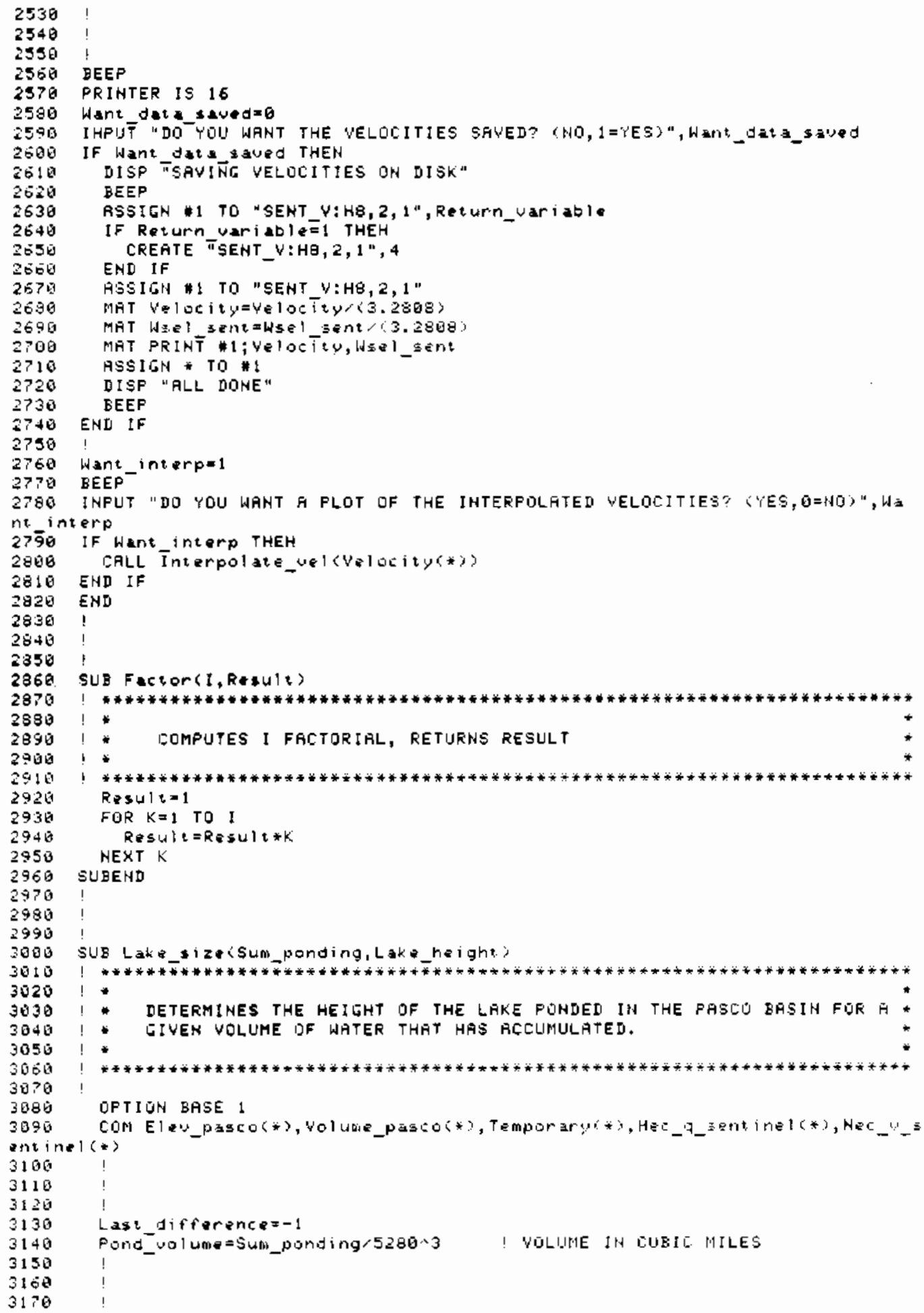




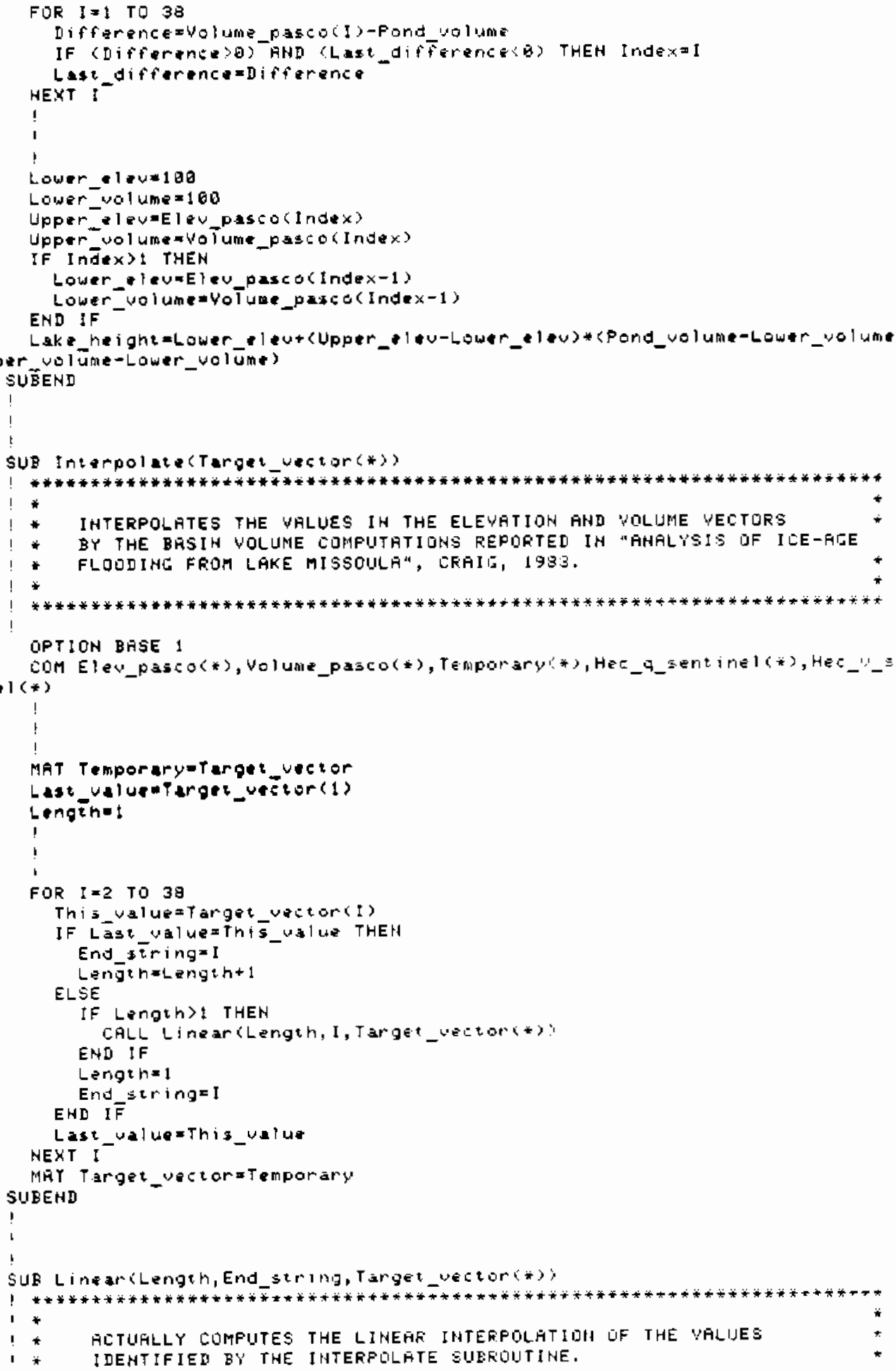




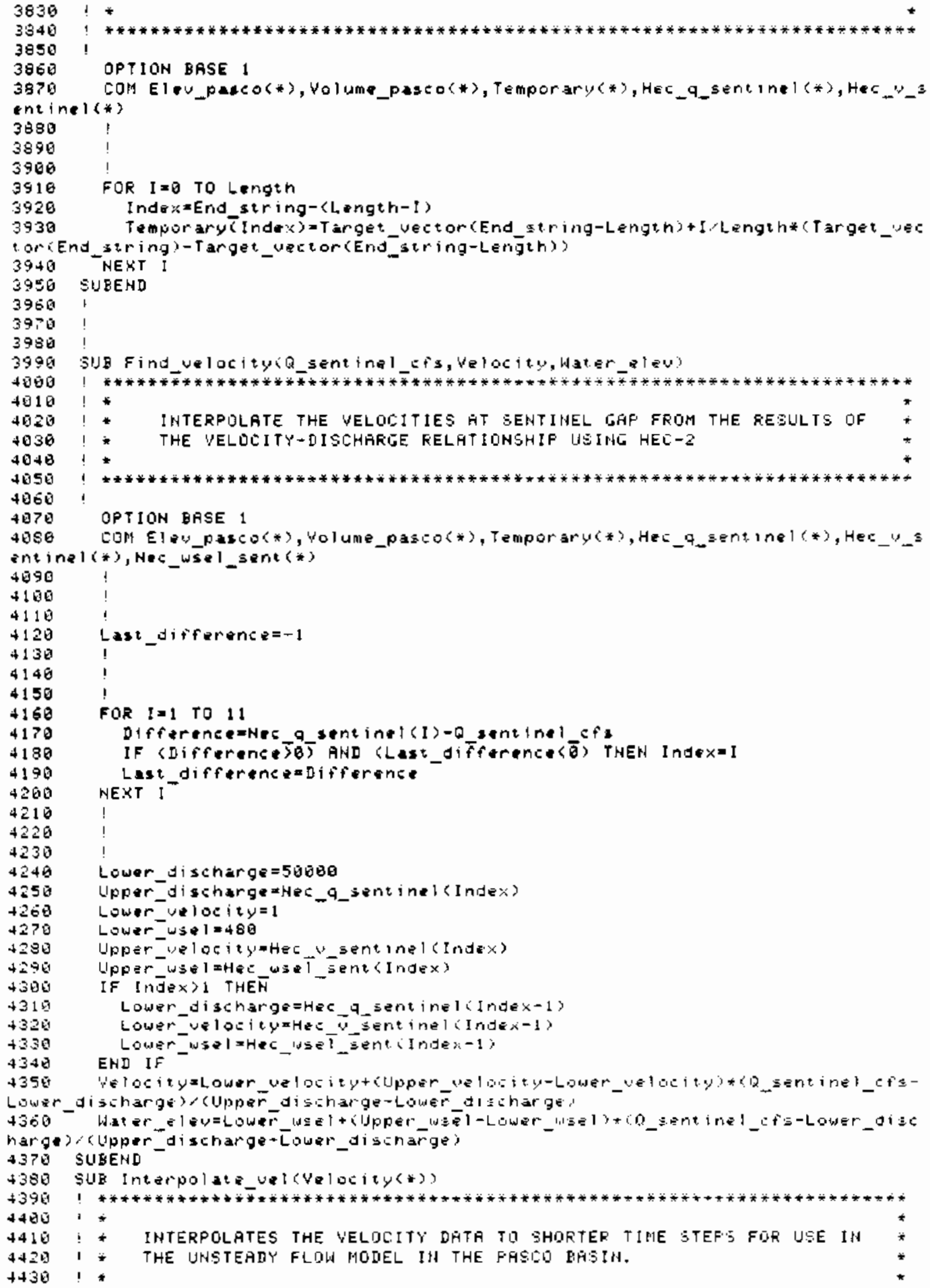




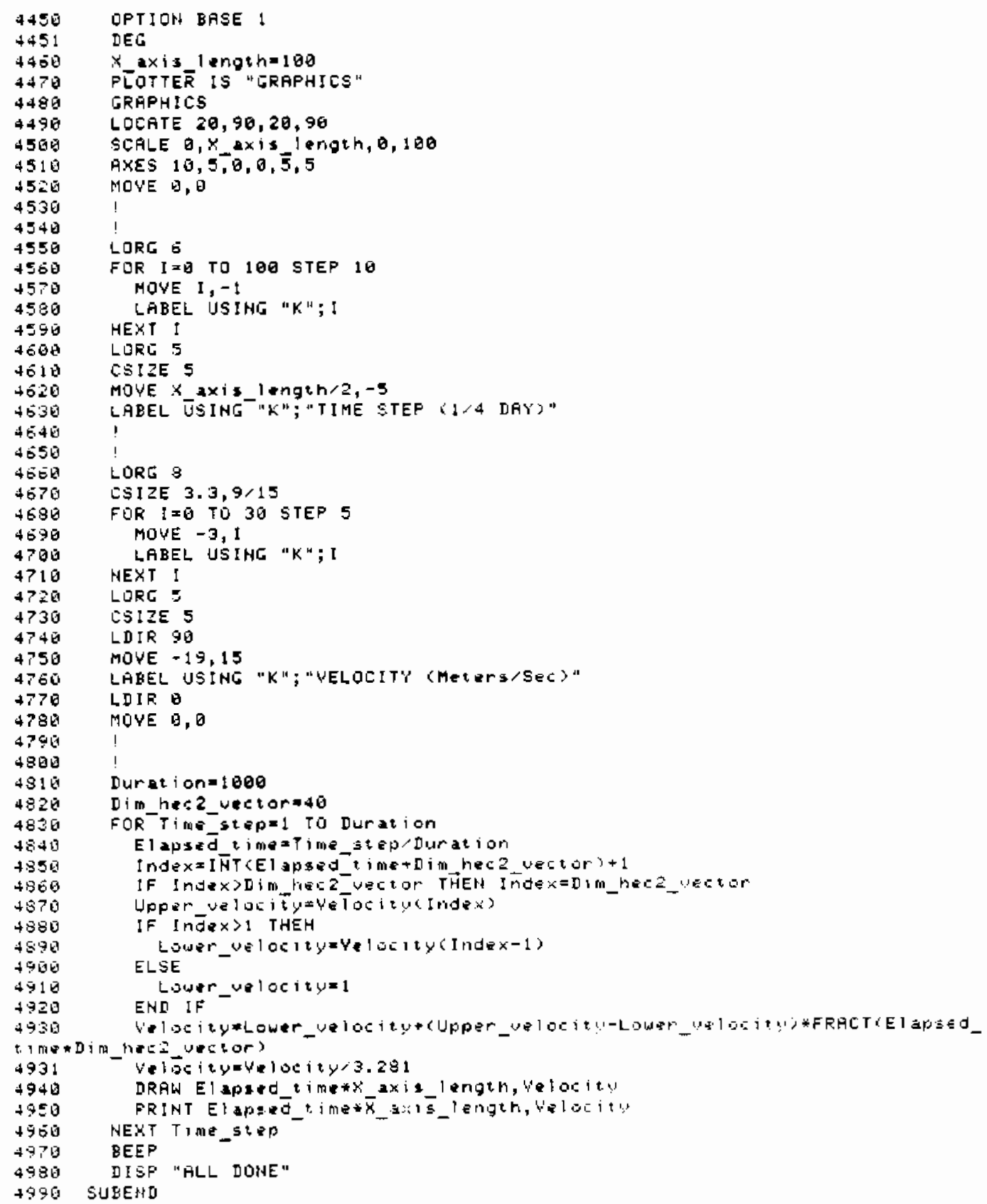


APPENDIX C

COMPUTER CODE FOR ADI METHOD 


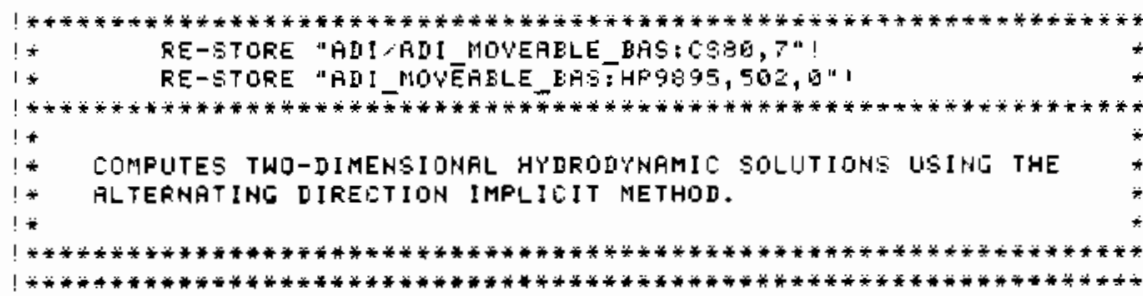




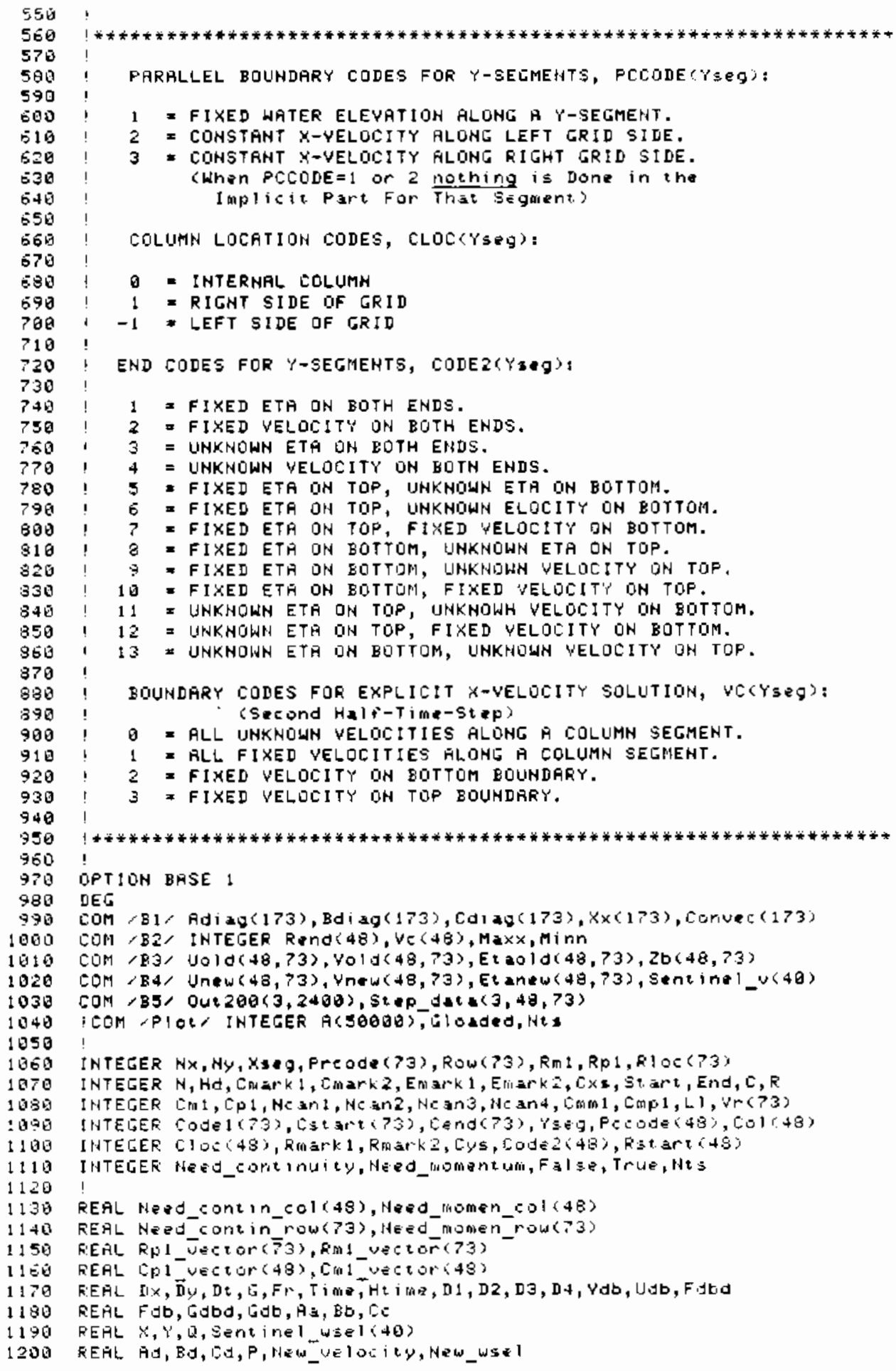




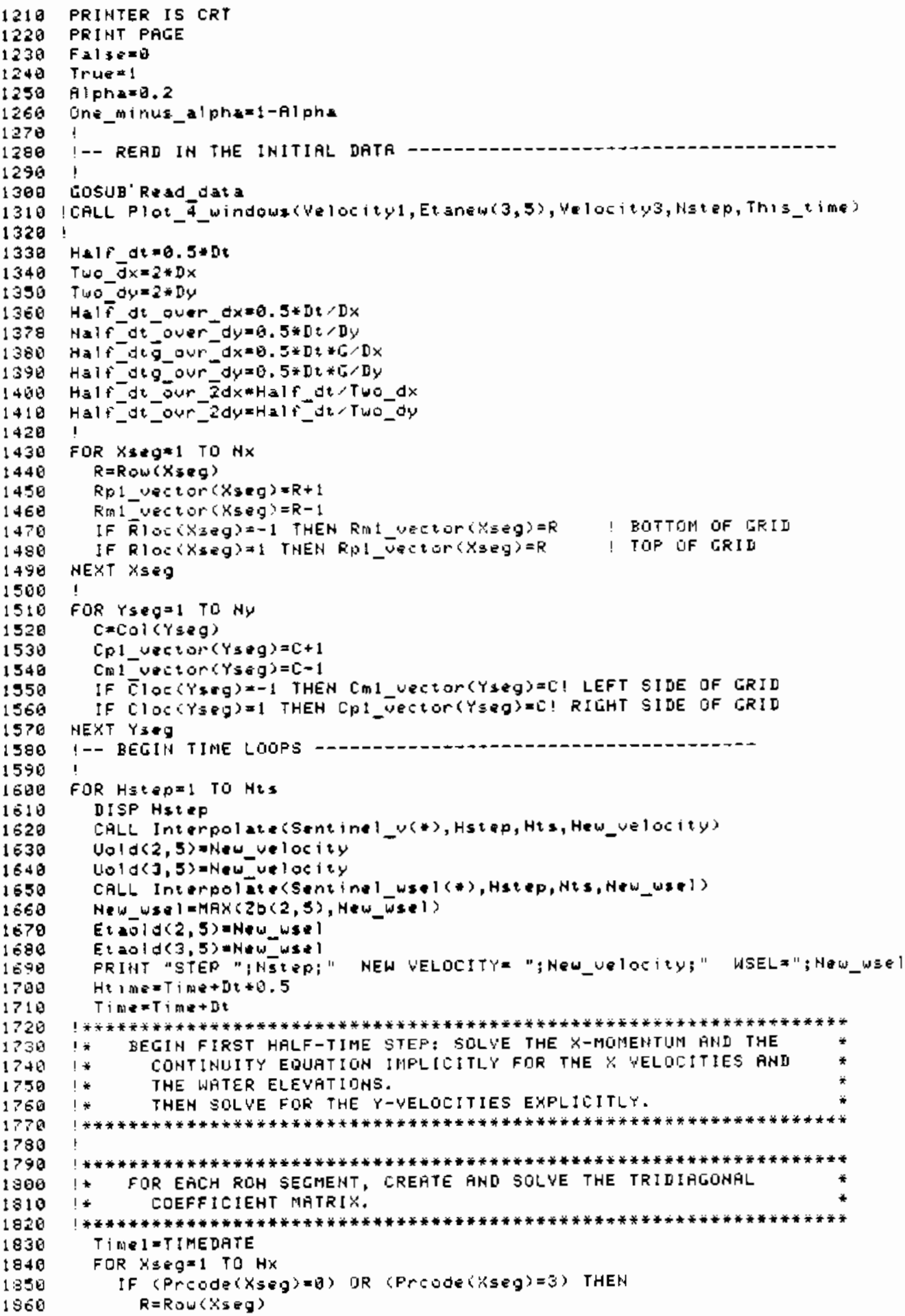




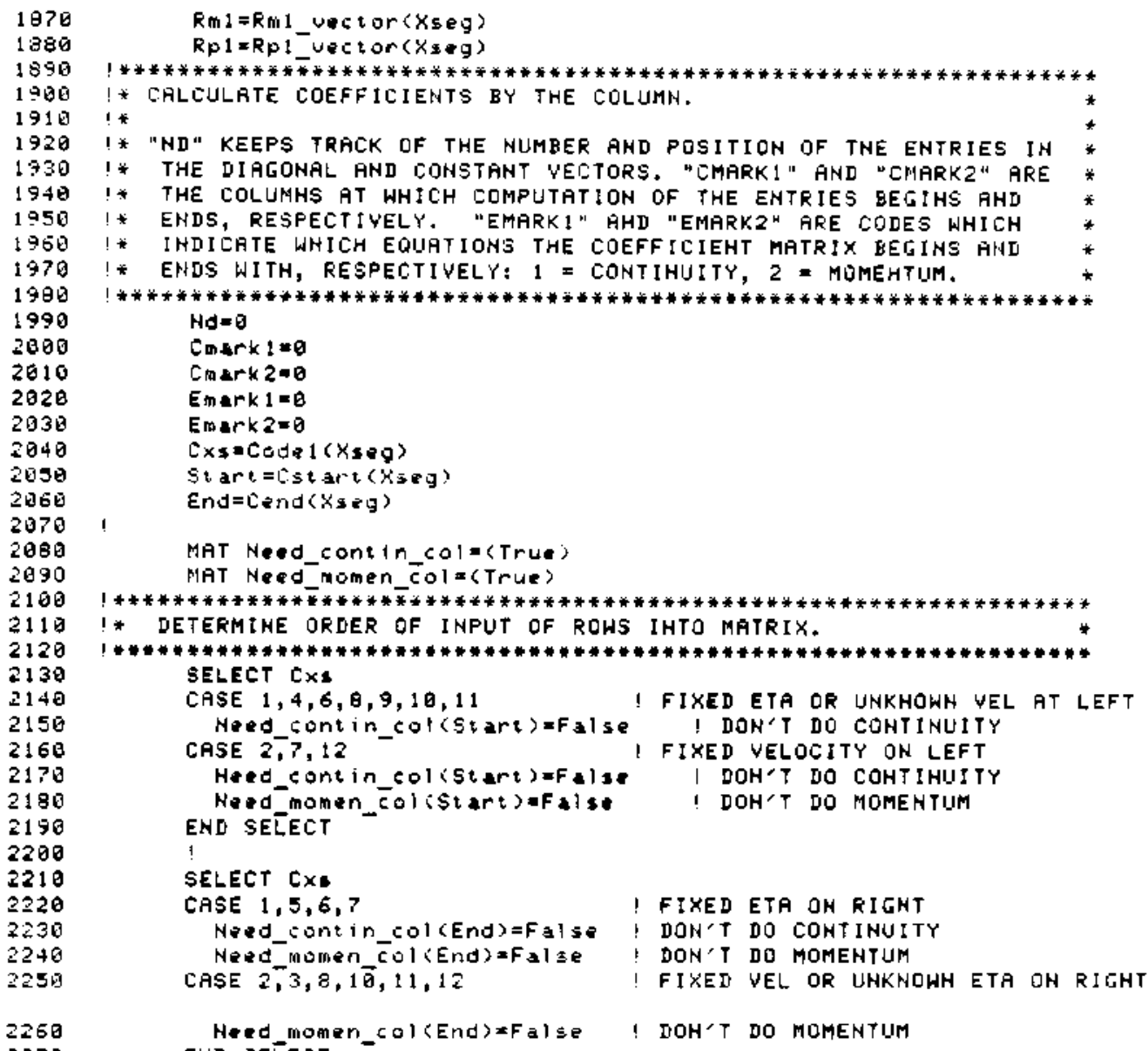




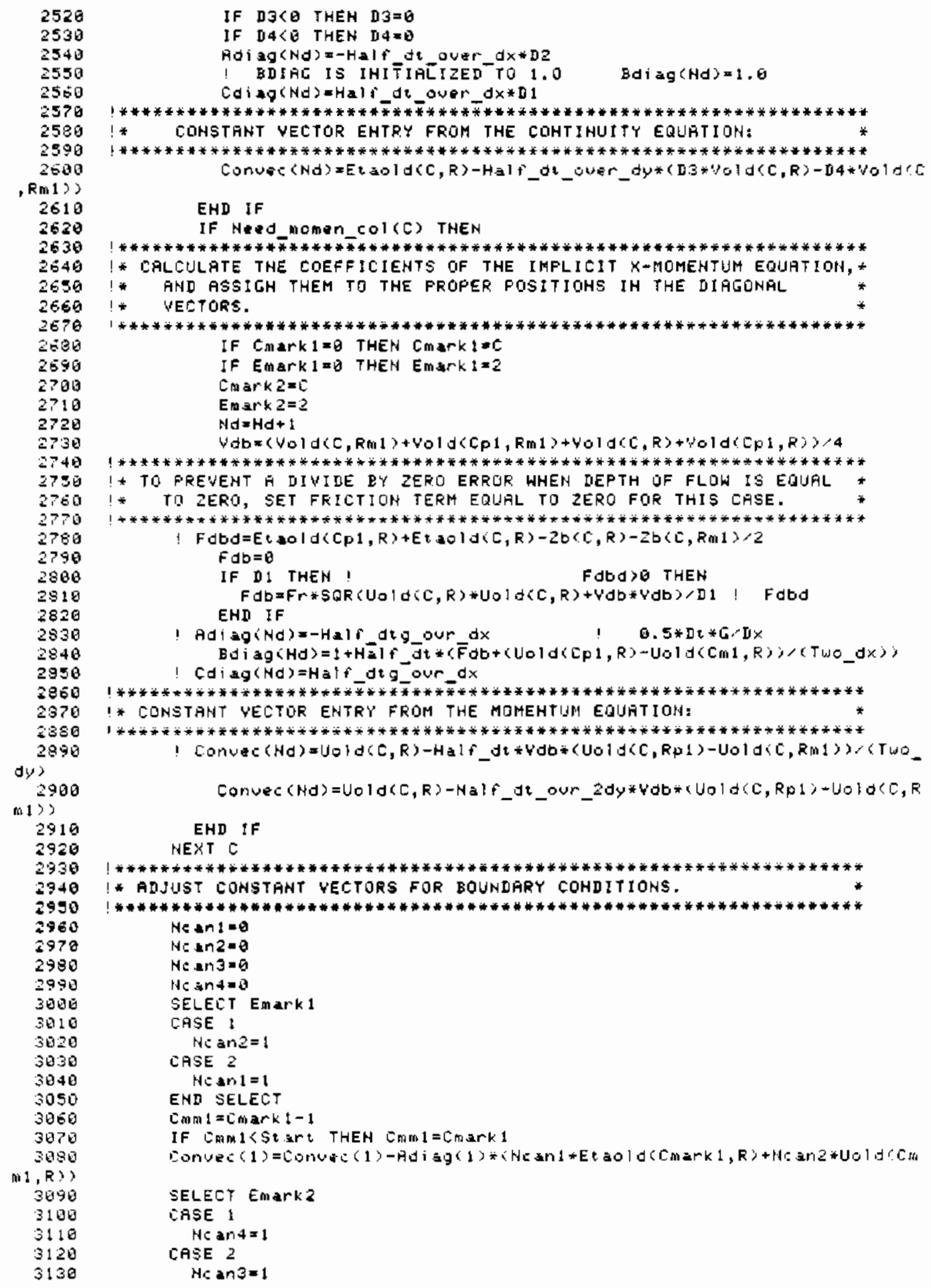




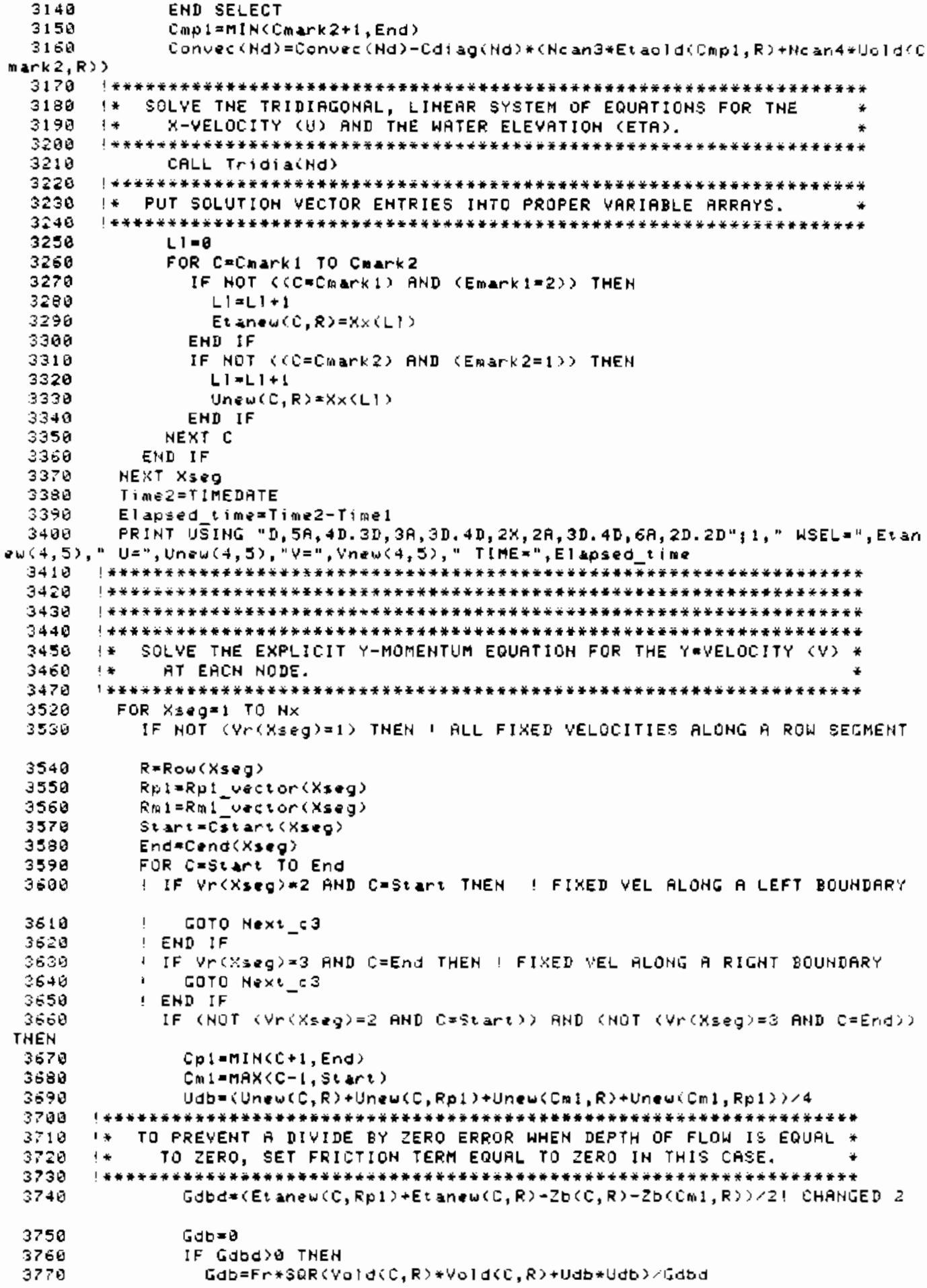




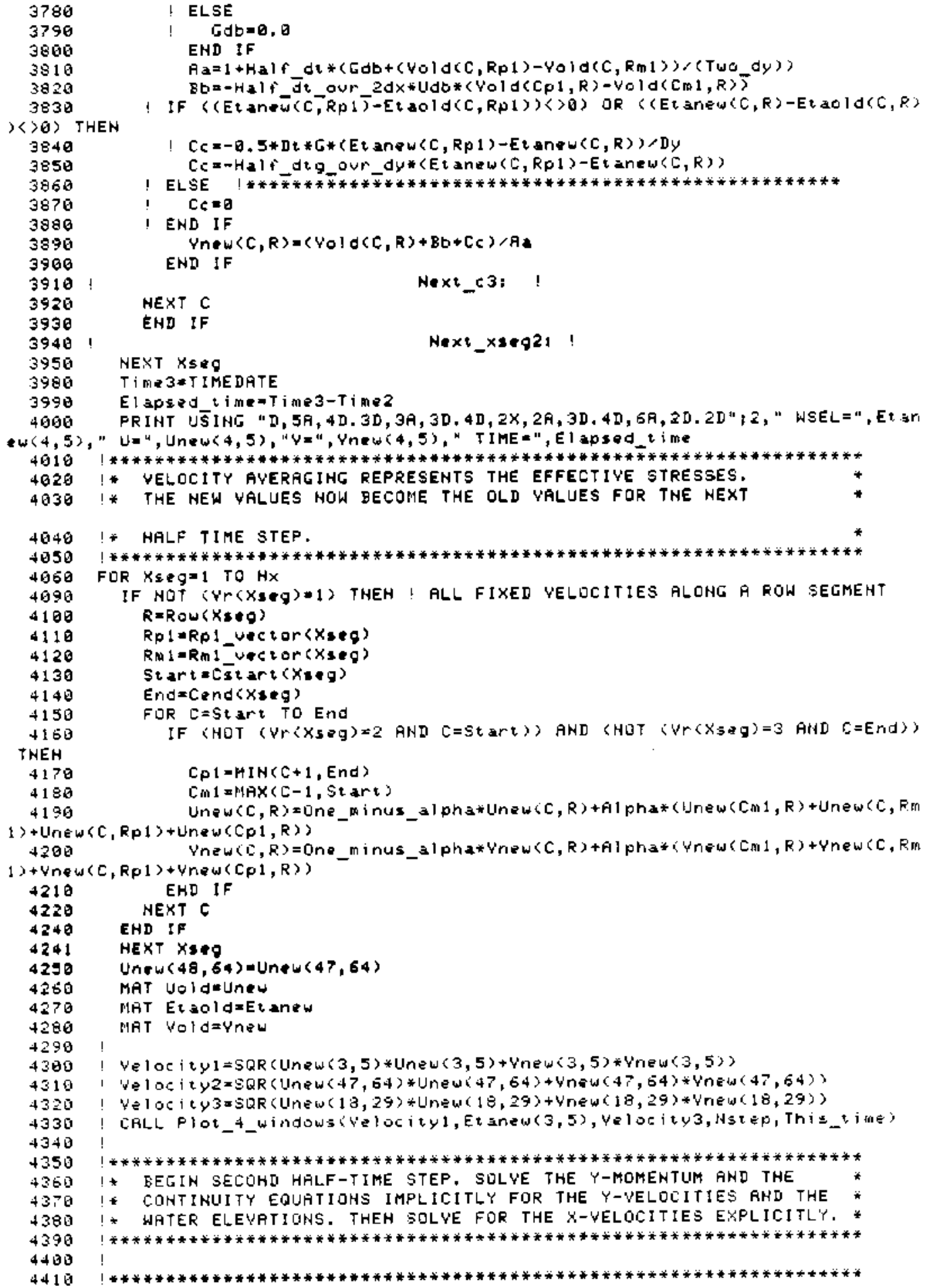




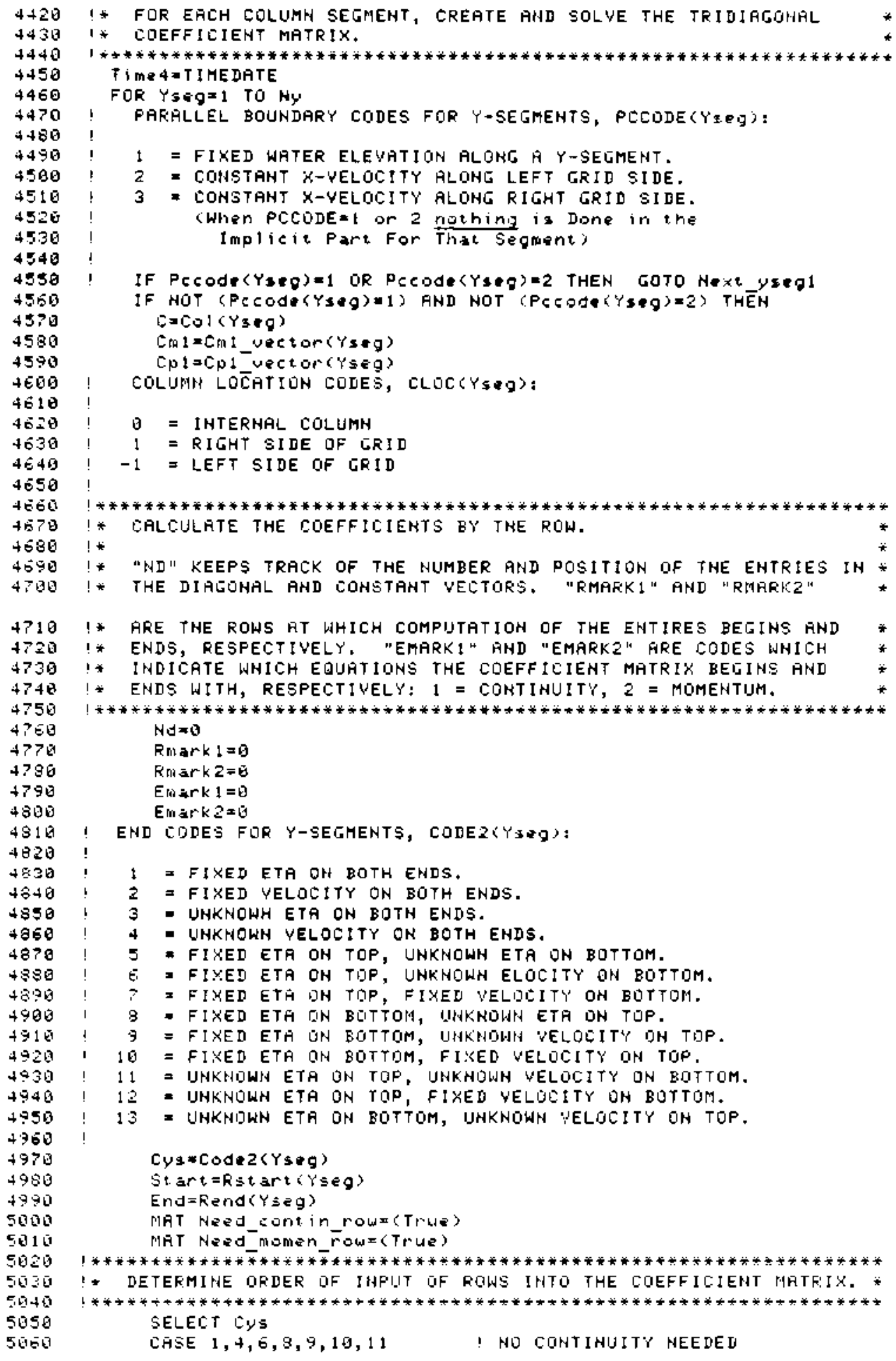




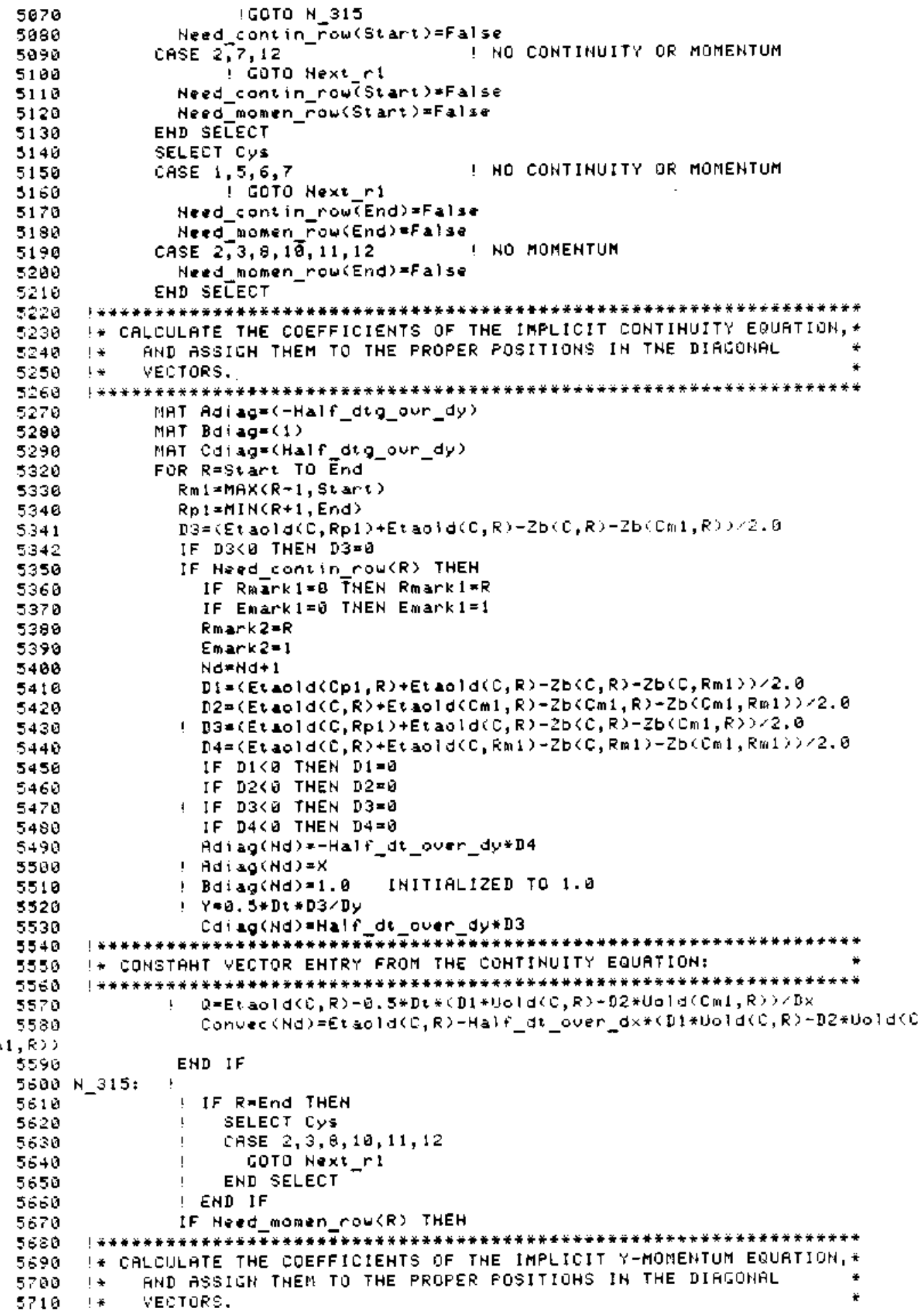




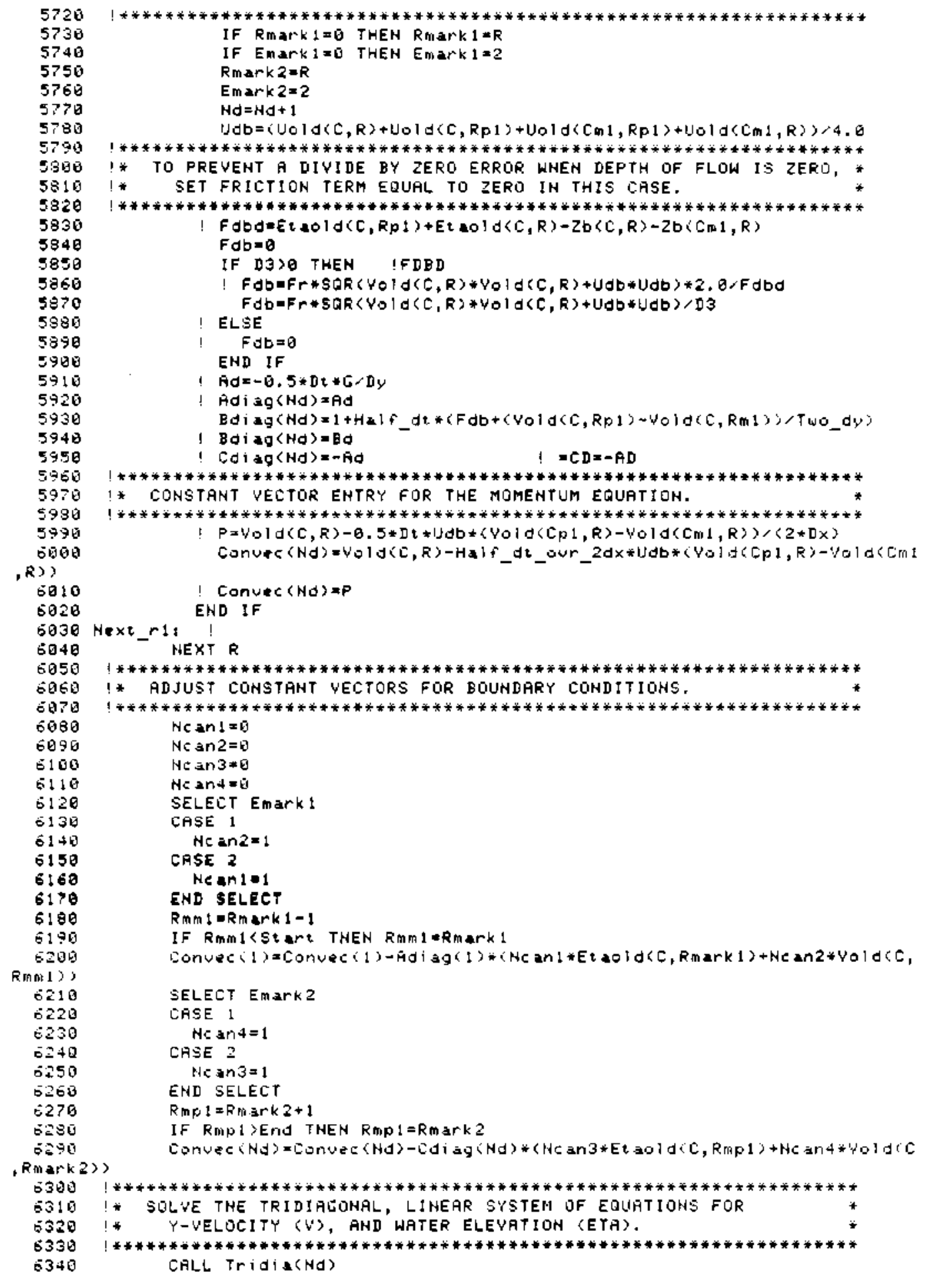




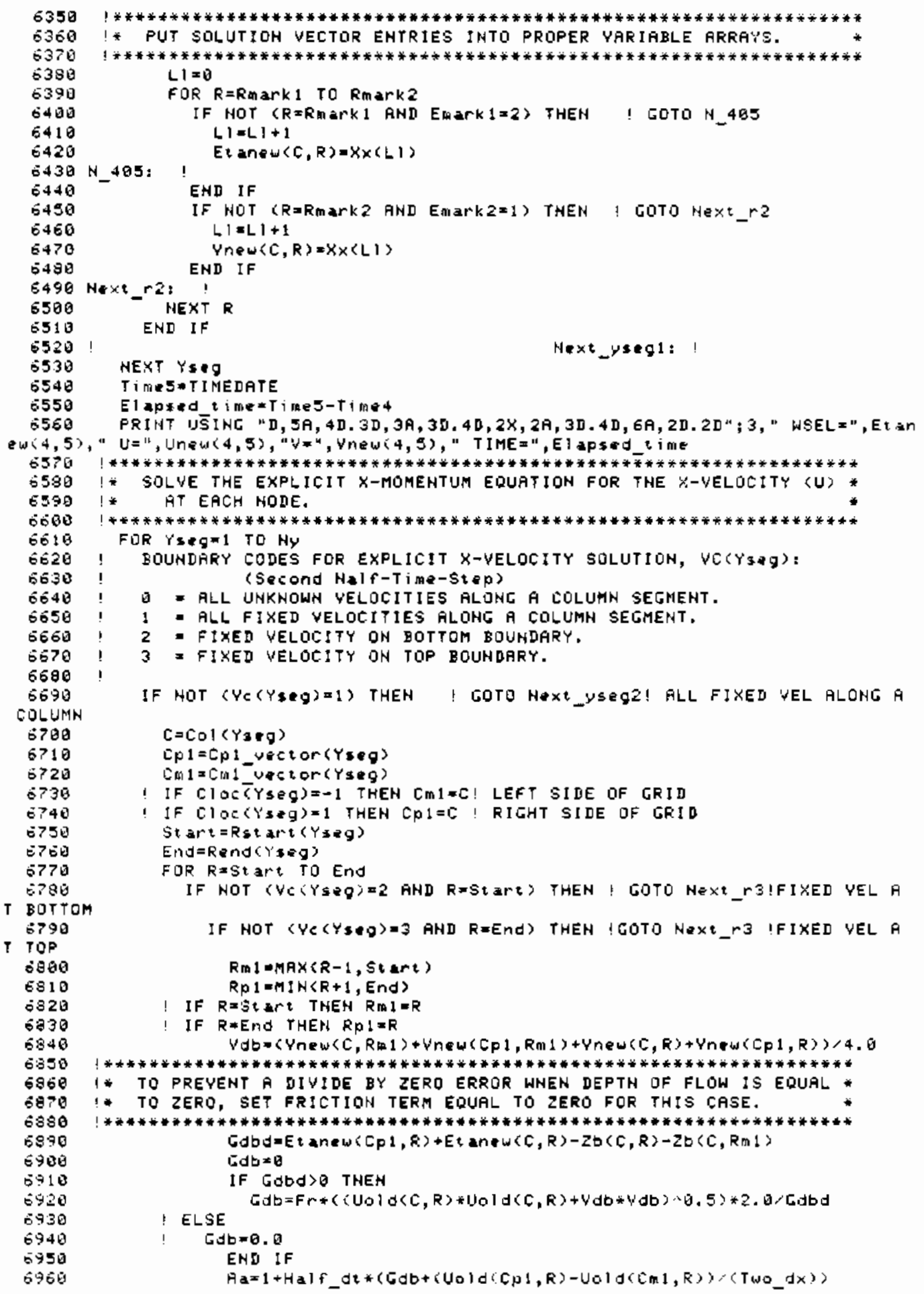




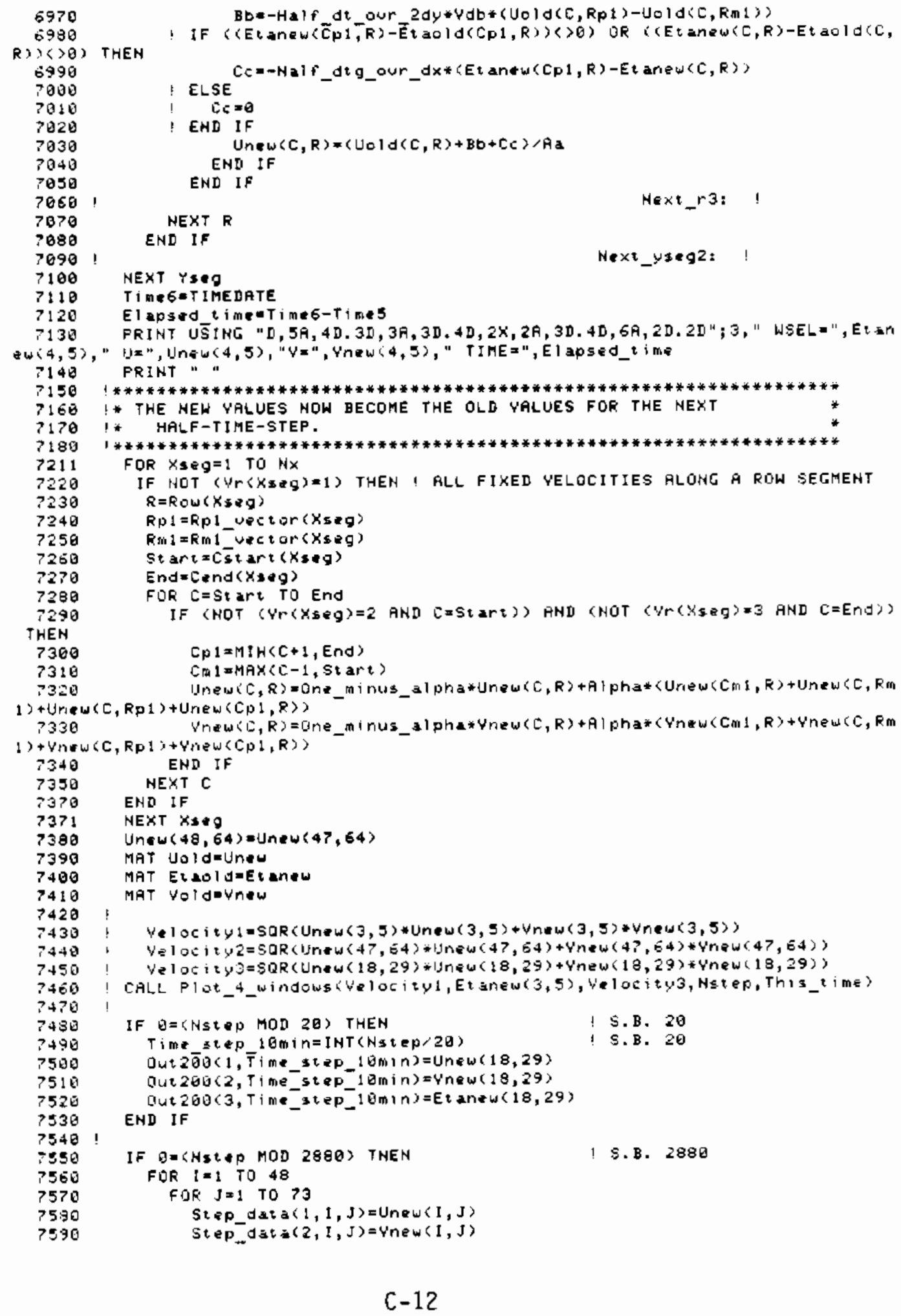




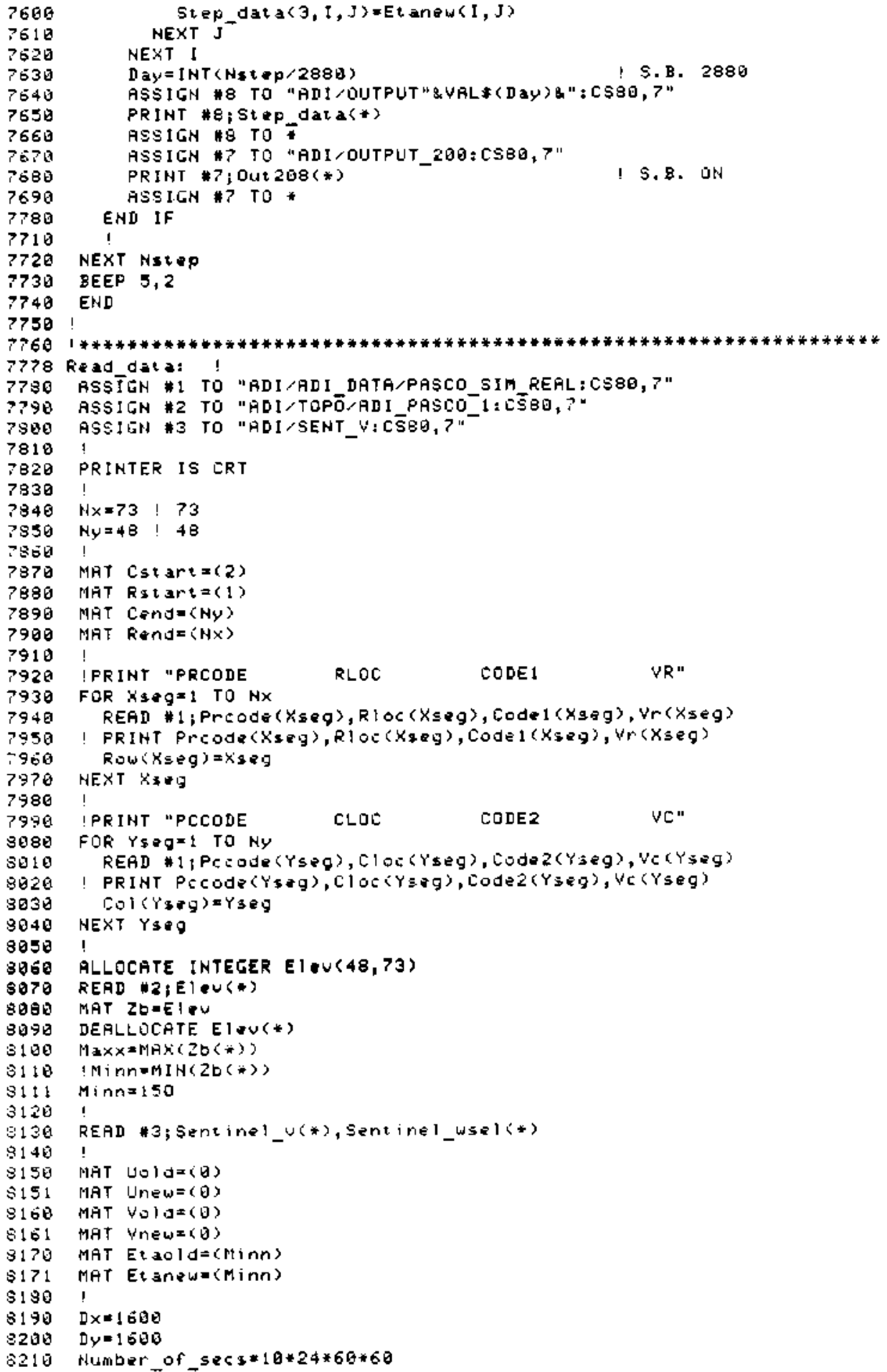




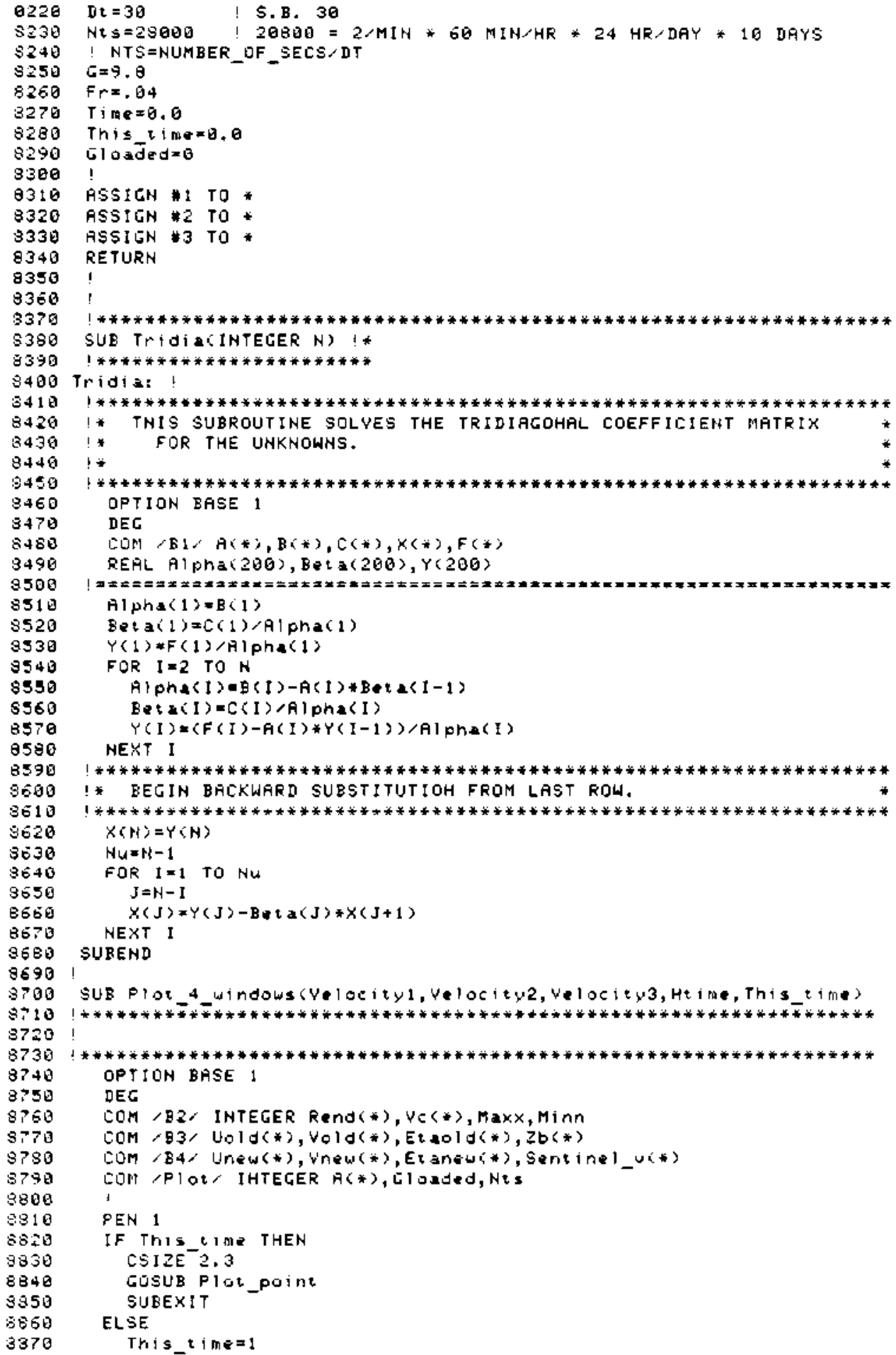




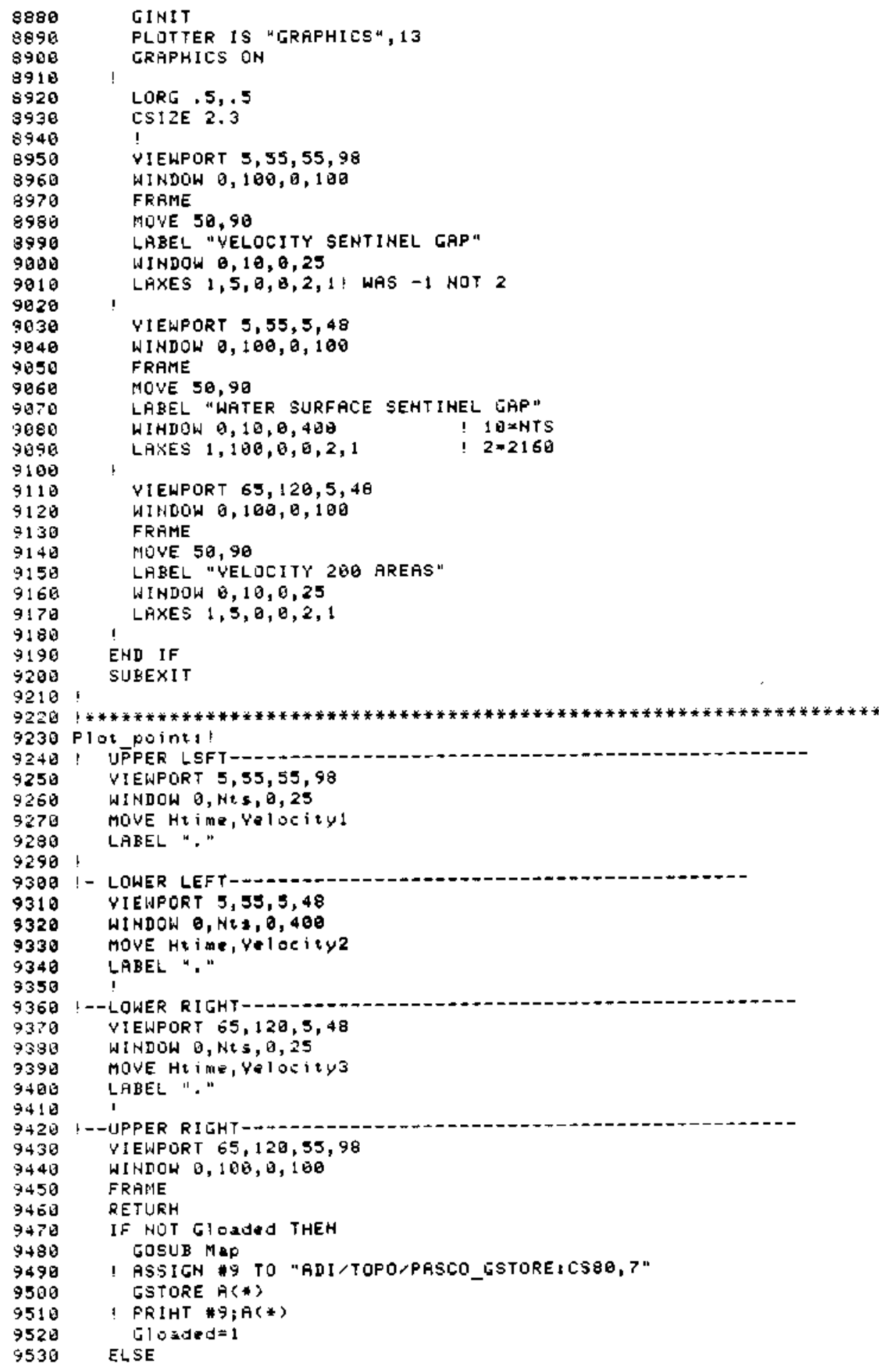




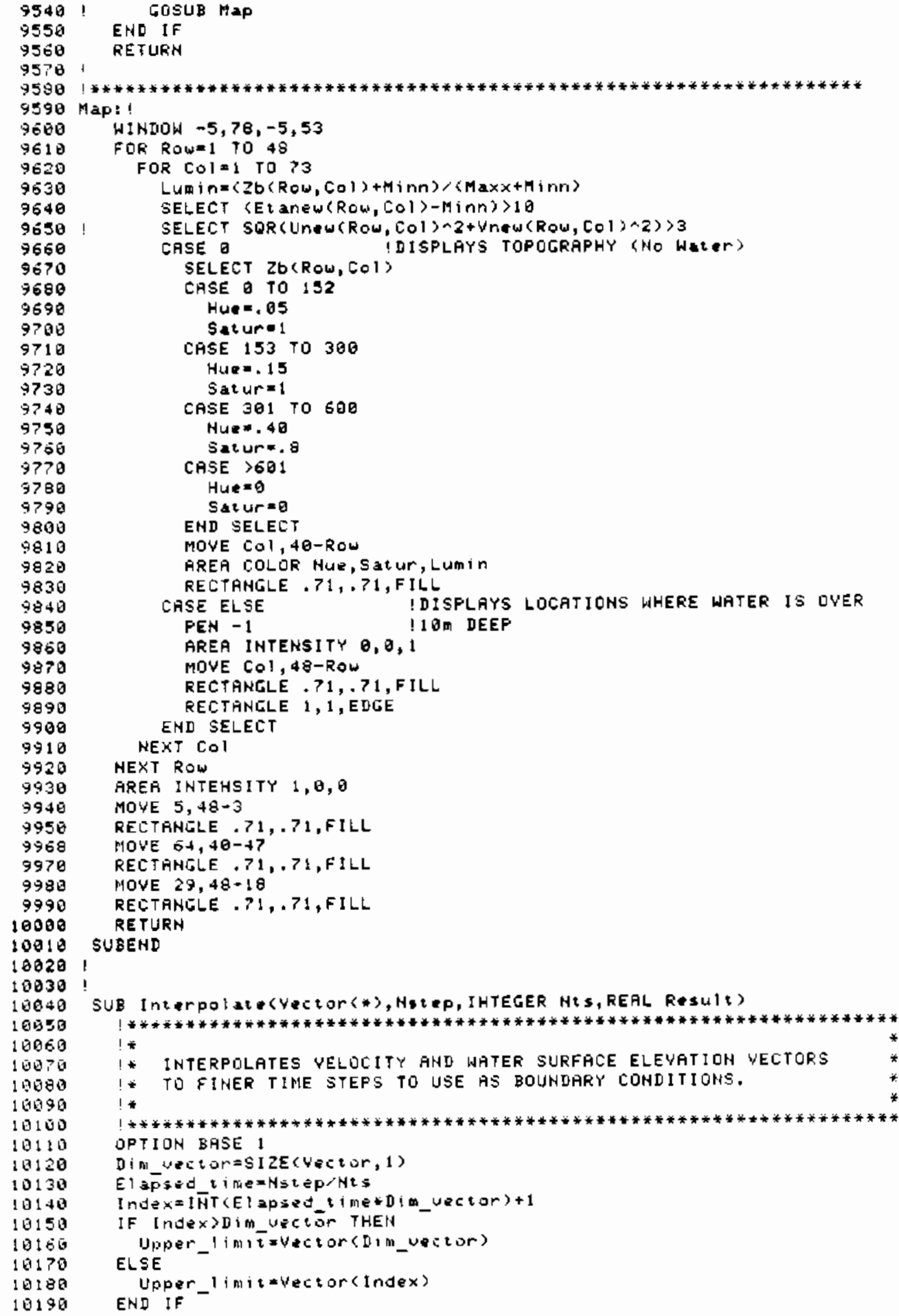




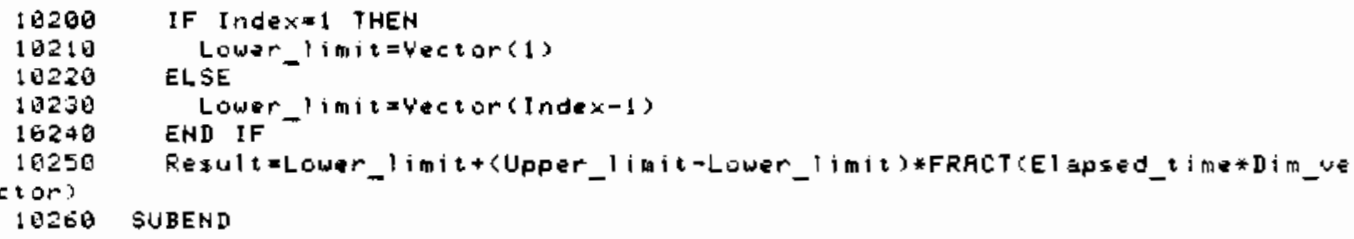


APPENDIX D

COMPUTER CODE FOR SEDIMENT TRANSPORT 


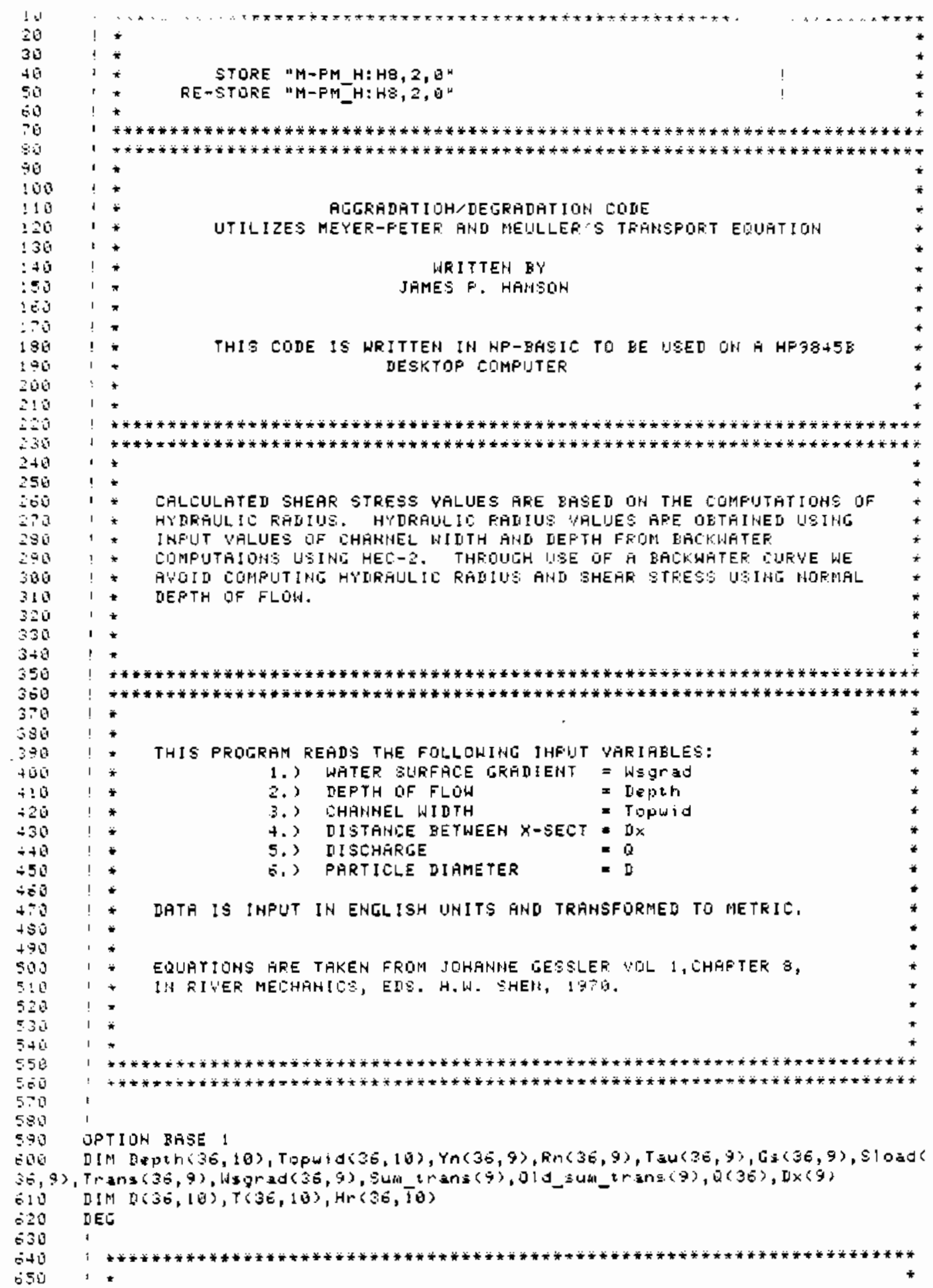




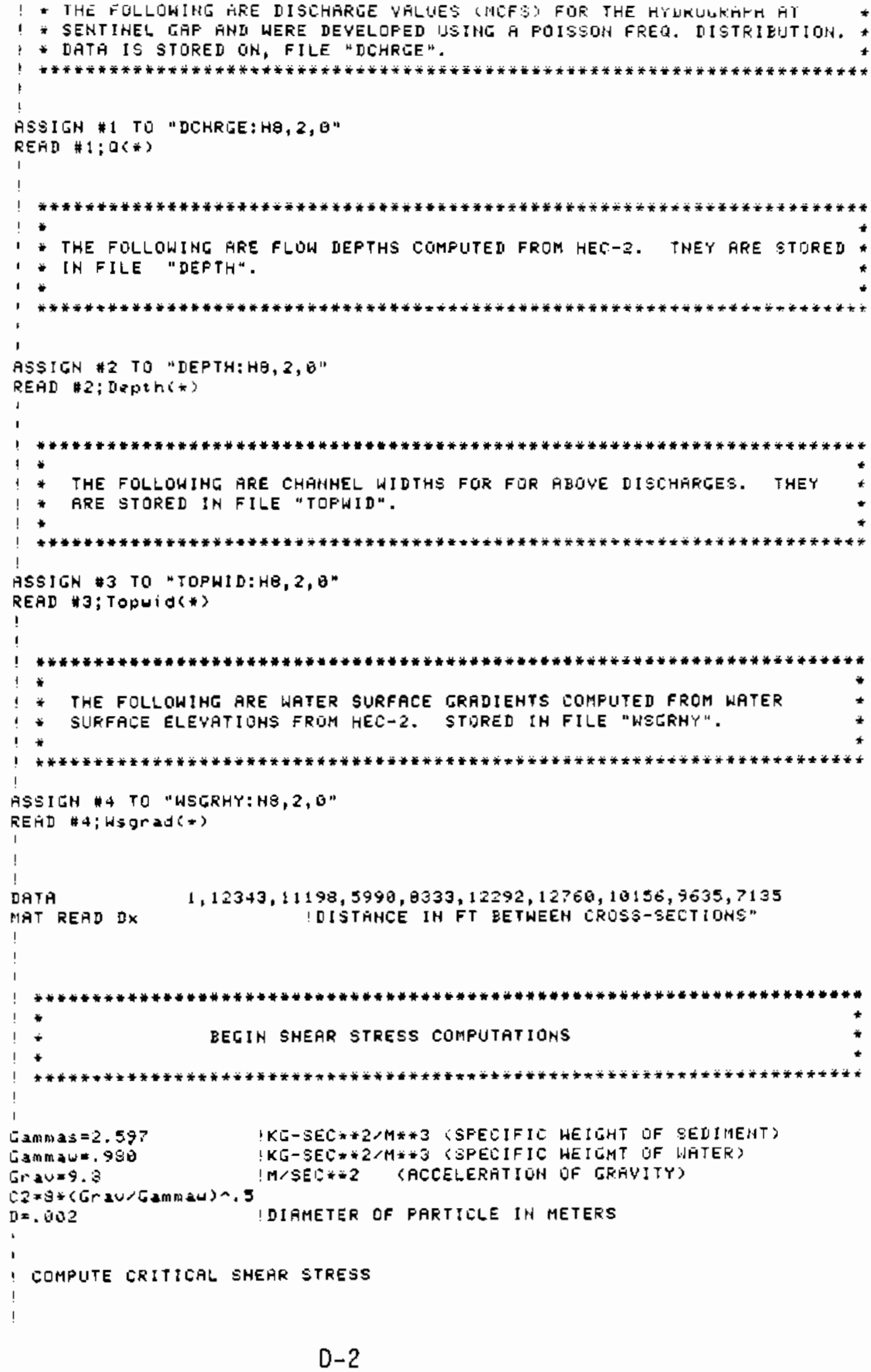




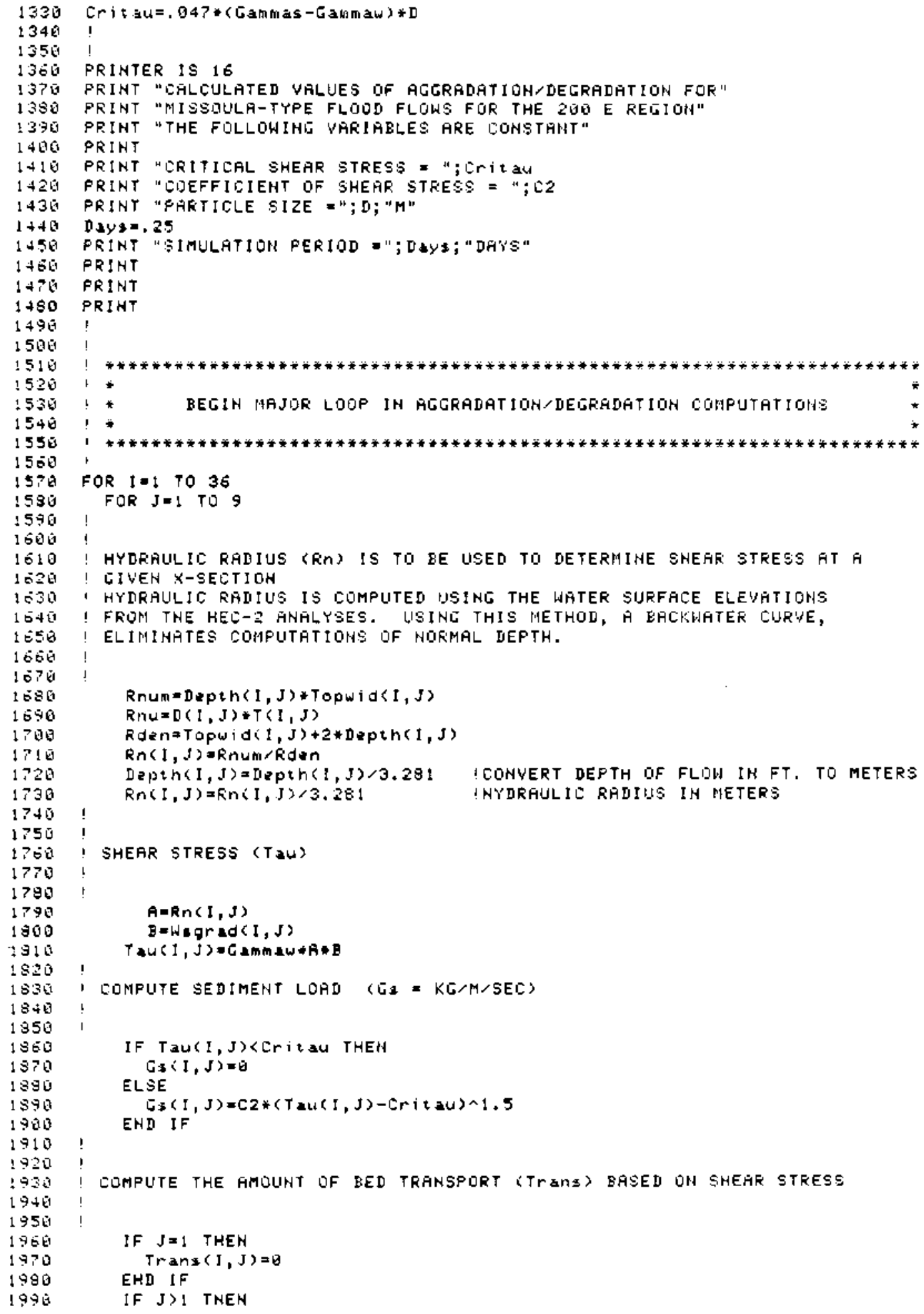




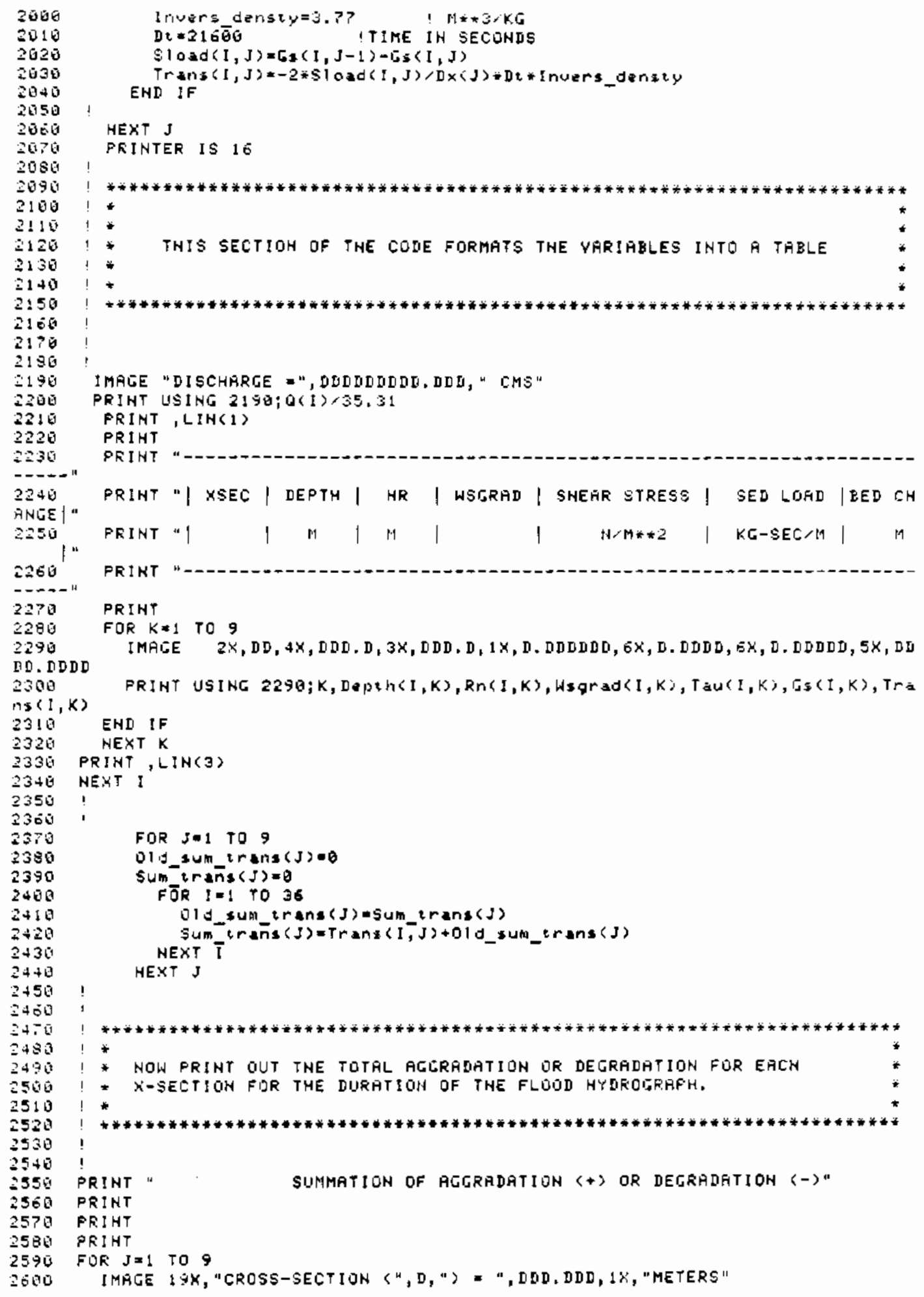


2610 PRIHT USIHG 2600; J, SLIm_trans(J)

2020 NEXT J

2630 !

$2640 \quad !$

2655 STOF

ㄷำ END 


\section{4}

. 


\section{APPENDIX E}

RESULTS USING MEYER-PETER AND MEULLER'S

EQUATION FOR SEDIMENT TRANSPORT 


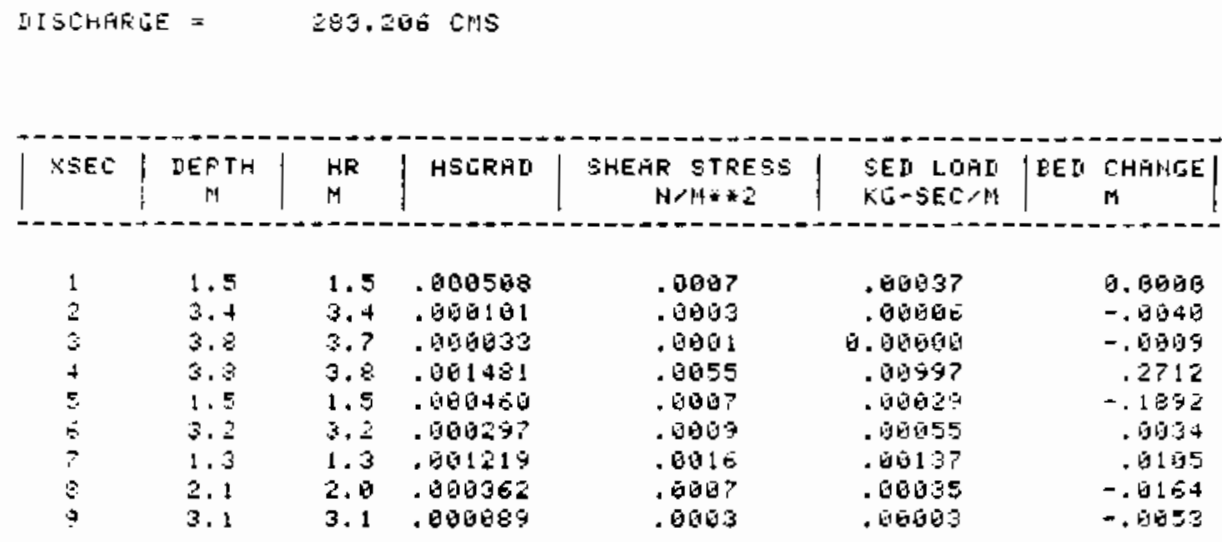

SIMAHTION OF MEGRAJRTIOH $(\rightarrow$ GR DEGRADATIOH $(-)$

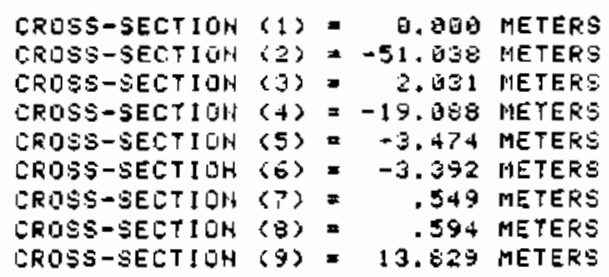




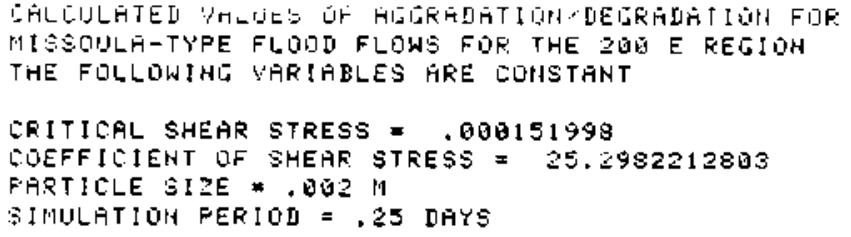

\begin{tabular}{|c|c|c|c|c|c|c|c|}
\hline XSEC & $\underset{M}{D E P T H}$ & HF & WSTRAD & $\begin{array}{c}\text { SHEAR STRESS } \\
M / M *+2\end{array}$ & $\begin{array}{l}\text { SED LDAJ } \\
K D-S E D / M\end{array}$ & EED & $\begin{array}{l}\mathrm{CH} H \mathrm{H} N \mathrm{E} \\
\mathrm{H}\end{array}$ \\
\hline 1 & 1.9 & 1.8 & .390556 & $.30 \pm 2$ & . ดดยร2 & & 0.8050 \\
\hline 2 & 4.3 & 4.2 & - $51+10121$ & .5065 & $.5601 ?$ & & $-.65: 36$ \\
\hline 3 & 4.7 & 4.7 & . $9000+2$ & .8052 & - Gugád & & -.0923 \\
\hline 4 & 4.8 & 4.8 & . Бே 1290 & $.60 \mathrm{~B}$ &.$\overline{0} 114 \overline{0}$ & & .3557 \\
\hline 5 & 2.0 & 1.9 & .5150552 & . 可 11 & . อัด & & -.2594 \\
\hline 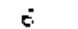 & 4,1 & 4.0 & .500281 & .0011 & .60074 & & . Б் \\
\hline$?$ & 2.1 & 2.1 &. Бै1 1993 & .4022 & .06241 & & .0213 \\
\hline 8 & 2.4 & 3.4 & $.000+90$ & . 6512 & . & & -.6253 \\
\hline 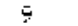 & 3.9 & 3.5 & 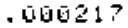 & . Бธอธอ & .60043 & & -. ดิดีढ \\
\hline
\end{tabular}

DISEHARGE $=\quad 3398.471$ EMS

\begin{tabular}{|c|c|c|c|c|c|c|c|}
\hline$X \leqslant E C$ & $\underset{M}{\text { DEPTH }}$ & $\begin{array}{l}H R \\
M\end{array}$ & WSGRAD & $\begin{array}{c}\text { SHEAR STRESS } \\
N / M * 2\end{array}$ & $\begin{array}{l}\text { SED LOAD } \\
K E-S E D-M\end{array}$ & BED & $\begin{array}{l}\text { CHAHGE } \\
M\end{array}$ \\
\hline $\begin{array}{l}1 \\
3 \\
3 \\
4 \\
5 \\
5 \\
7 \\
5 \\
9\end{array}$ & $\begin{array}{l}3.9 \\
7.7 \\
8.4 \\
8.5 \\
4.1 \\
5.4 \\
5.3 \\
4.2 \\
5.9\end{array}$ & $\begin{array}{l}3.7 \\
7.5 \\
8.3 \\
9.5 \\
+.0 \\
7.3 \\
5.2 \\
4.1 \\
5.8\end{array}$ & $\begin{array}{l}.001044 \\
.006203 \\
.004075 \\
.000632 \\
.000582 \\
.000243 \\
.000637 \\
.003920 \\
.000377\end{array}$ & $\begin{array}{l}.0038 \\
.0615 \\
.0505 \\
.0653 \\
.0534 \\
.0017 \\
.0633 \\
.0037 \\
.0025\end{array}$ & $\begin{array}{l}.00569 \\
.00126 \\
.00025 \\
.00922 \\
.00477 \\
.00159 \\
.00435 \\
.00543 \\
.05287\end{array}$ & & $\begin{array}{r}0.6501 \\
-.0572 \\
-.0142 \\
.5445 \\
-.0875 \\
-.0422 \\
.0357 \\
.0167 \\
-.0434\end{array}$ \\
\hline
\end{tabular}


DISDHFFEE = 16709.148 ENS

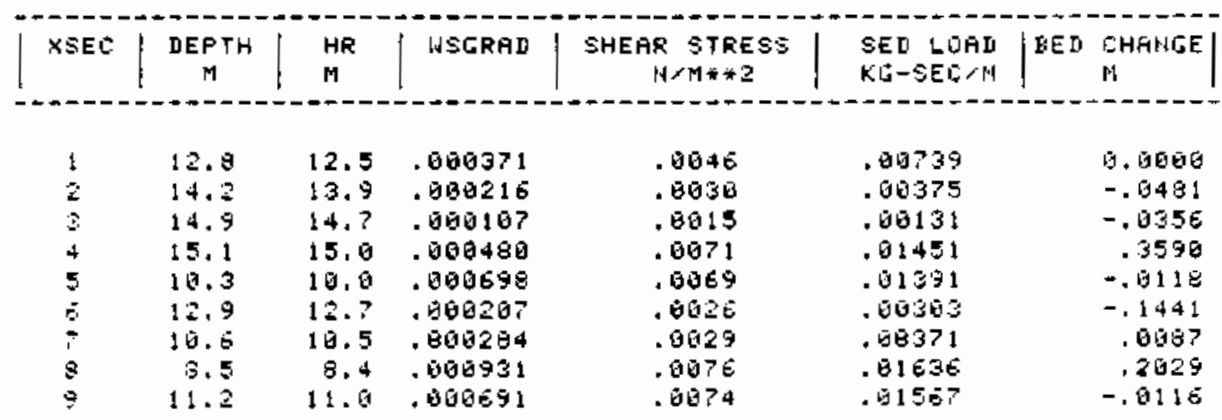

DISCHRREE =

62355.296 CMS

\begin{tabular}{|c|c|c|c|c|c|c|c|}
\hline XSEL & $\underset{M}{\text { DEPTH }}$ & $\begin{array}{l}\text { HR } \\
M\end{array}$ & WSCRAD & $\begin{array}{c}\text { SHEAR STRESS } \\
\text { MNI*2 }\end{array}$ & $\begin{array}{l}\text { SEL LQAD } \\
K G-S E C / M\end{array}$ & EED & $\begin{array}{l}\text { CHAHGE } \\
M\end{array}$ \\
\hline 1 & 14.3 & 14.0 & .001593 & .0215 & .88102 & & 0.0000 \\
\hline 2 & 20.3 & 19.9 & $.000+50$ & .6083 & .02033 & & -.8068 \\
\hline 3 & 21.9 & 21.5 & .989237 & .50058 & .00854 & & -.1714 \\
\hline 4 & 22.3 & 22.1 & .080057 & .0021 & $.0021 \mathrm{E}$ & & -.1729 \\
\hline 5 & 16.4 & 15.3 & .0100673 & .9108 & .02767 & & .4982 \\
\hline 6 & 19.0 & 13.5 & .000272 & .0050 & .00857 & & -.2531 \\
\hline$?$ & 17.6 & 15.8 & .560274 & .00945 & .95727 & & -.8166 \\
\hline$s$ & 14.8 & 14.6 & .000591 & .0142 & .04213 & & .5591 \\
\hline 5 & 17,7 & 17.3 & .001033 & .5175 & .05790 & & $.26 \in \sigma^{\circ}$ \\
\hline
\end{tabular}

DISEHARGE $=185915.980 \mathrm{CMS}$

\begin{tabular}{|c|c|c|c|c|c|c|}
\hline XSEC & $\begin{array}{c}\text { DEPTH } \\
M\end{array}$ & $\begin{array}{l}H R \\
M\end{array}$ & WSGRAD & $\begin{array}{c}\text { SHERR STRESS } \\
M / M * * 3\end{array}$ & $\begin{array}{l}\text { SED LURD } \\
\text { KE-SELAM }\end{array}$ & $\underset{M}{\text { EED IHFNGE }}$ \\
\hline $\begin{array}{l}1 \\
2 \\
3 \\
4 \\
5 \\
5 \\
7 \\
8 \\
9\end{array}$ & $\begin{array}{l}19.9 \\
29.9 \\
31.9 \\
32.5 \\
20.7 \\
27.5 \\
25.4 \\
23.6 \\
25.2\end{array}$ & $\begin{array}{l}19.4 \\
29.3 \\
31.4 \\
32.2 \\
26.5 \\
27.3 \\
25.2 \\
23.5 \\
24.7\end{array}$ & $\begin{array}{l}.002697 \\
.000575 \\
.006312 \\
.000118 \\
.000231 \\
.008245 \\
.060395 \\
.0100516 \\
.001595\end{array}$ & $\begin{array}{l}.0512 \\
.0165 \\
.0590 \\
.0037 \\
.0069 \\
.0155 \\
.0099 \\
.0119 \\
.0380\end{array}$ & $\begin{array}{l}.29155 \\
.05310 \\
.02331 \\
.00536 \\
.41132 \\
.01294 \\
.02418 \\
.03237 \\
.19678\end{array}$ & $\begin{array}{r}0.0066 \\
-3.1463 \\
-.4333 \\
-.4881 \\
.1165 \\
.0214 \\
.1435 \\
.1313 \\
2.8777\end{array}$ \\
\hline
\end{tabular}


DISCHAREE = TEPJUE. 514 LHS

\begin{tabular}{|c|c|c|c|c|c|c|}
\hline XSEC & DEPTH & $\begin{array}{l}\mathrm{HR} \\
\mathrm{M}\end{array}$ & WSGRAD & $\begin{array}{c}\text { SHEAR STRESS } \\
\mathrm{H} / H \neq \div\end{array}$ & $\begin{array}{l}\text { SED LÖHD } \\
\text { KG-SEC/M }\end{array}$ & BED CHAHEE \\
\hline $\begin{array}{l}1 \\
2 \\
3 \\
4 \\
5 \\
5 \\
1 \\
3 \\
5\end{array}$ & $\begin{array}{l}29.0 \\
40.7 \\
43.7 \\
44.6 \\
35.8 \\
39.3 \\
37.6 \\
35.0 \\
37.8\end{array}$ & $\begin{array}{l}28.4 \\
39.9 \\
43.1 \\
44.1 \\
38.5 \\
39.1 \\
36.8 \\
34.8 \\
37.2\end{array}$ & 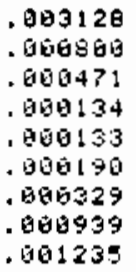 & $\begin{array}{l}.0871 \\
.0344 \\
.0199 \\
.0658 \\
.0150 \\
.0075 \\
.0119 \\
.0320 \\
.0450\end{array}$ & $\begin{array}{l}.04897 \\
.16014 \\
.07091 \\
.01077 \\
.09350 \\
.01520 \\
.03261 \\
.14399 \\
.24055\end{array}$ & $\begin{array}{r}1.6060 \\
-8.4383 \\
-1.3198 \\
-1.8109 \\
-.0431 \\
.15850 \\
.2146 \\
1.7958 \\
1.6322\end{array}$ \\
\hline
\end{tabular}

DISEHAREE = $1000849.618 \mathrm{cMS}$

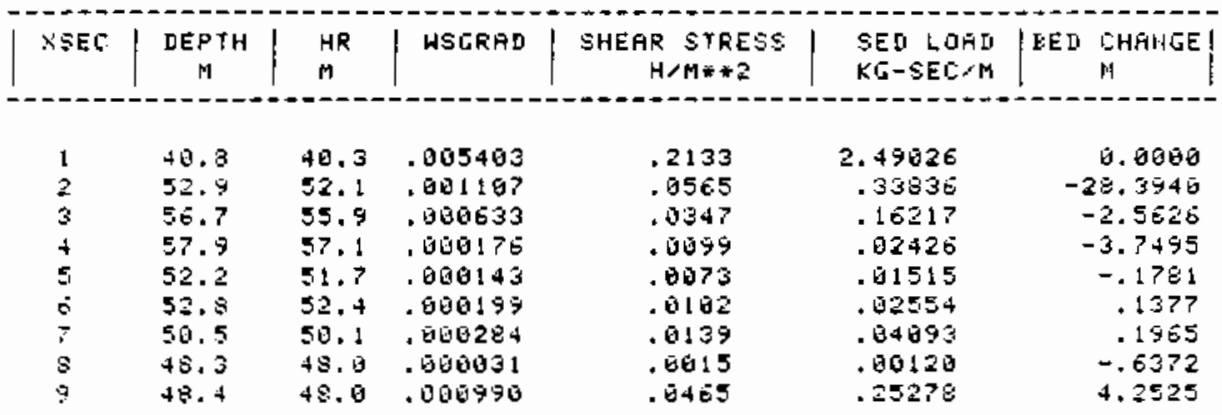

DISCHARGE = 1876239.020 CMS

\begin{tabular}{|c|c|c|c|c|c|c|}
\hline XSEC & DEPTH & $\begin{array}{l}H R \\
M\end{array}$ & WSGRAD & $\begin{array}{c}\text { SHEAR STRESS } \\
\mathrm{H} / \mathrm{M} * * 2\end{array}$ & 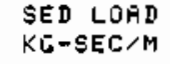 & $\begin{array}{c}\text { BED CHAHEE } \\
M\end{array}$ \\
\hline $\begin{array}{l}1 \\
2 \\
3 \\
4 \\
5 \\
5 \\
? \\
5 \\
5\end{array}$ & $\begin{array}{l}57.0 \\
65.3 \\
55.7 \\
76.1 \\
64.9 \\
05.5 \\
63.2 \\
50.9 \\
51.0\end{array}$ & $\begin{array}{l}56.4 \\
64.8 \\
69.0 \\
64.3 \\
64.0 \\
64.9 \\
62.7 \\
60.4 \\
60.5\end{array}$ & $\begin{array}{l}.002220 \\
.000994 \\
.000765 \\
.000282 \\
.000192 \\
.000153 \\
.000238 \\
.000060 \\
.060435\end{array}$ & $\begin{array}{l}.1227 \\
.0631 \\
.0509 \\
.0191 \\
.0121 \\
.0123 \\
.0146 \\
.0058 \\
.0200\end{array}$ & $\begin{array}{r}1.09507 \\
.39984 \\
.25958 \\
.06619 \\
.03284 \\
.03373 \\
.04414 \\
.06543 \\
.16519\end{array}$ & $\begin{array}{r}0.0000 \\
-9.0414 \\
-1.6036 \\
-6.8735 \\
-.6518 \\
.0118 \\
.1328 \\
-.6271 \\
1.5930\end{array}$ \\
\hline
\end{tabular}


IISCHAKLE $=\approx 1 な 159.445$ こMS

\begin{tabular}{|c|c|c|c|c|c|c|}
\hline xsE & $\begin{array}{c}\text { DEPTH } \\
M\end{array}$ & $\begin{array}{l}H R \\
M\end{array}$ & WSGRAD & $\begin{array}{c}\text { SHERR STRESS } \\
M / M+2\end{array}$ & $\begin{array}{l}\text { SED LOHD } \\
\text { KL-SEC/M }\end{array}$ & $\begin{array}{c}\text { BEI CHAHGE } \\
\text { M }\end{array}$ \\
\hline $\begin{array}{l}1 \\
2 \\
3 \\
4 \\
5 \\
5 \\
7 \\
3 \\
0\end{array}$ & $\begin{array}{l}77.4 \\
79.9 \\
61.2 \\
62.6 \\
77.4 \\
78.5 \\
76.2 \\
73.9 \\
73.9\end{array}$ & $\begin{array}{l}76.8 \\
79.3 \\
60.3 \\
81.7 \\
76.7 \\
77.3 \\
75.6 \\
73.1 \\
73.2\end{array}$ & $\begin{array}{l}.000658 \\
.060391 \\
.000755 \\
.006364 \\
.000273 \\
.000202 \\
.000198 \\
.000056 \\
.000371\end{array}$ & $\begin{array}{l}.8495 \\
.0364 \\
.0594 \\
.6291 \\
.0205 \\
.0154 \\
.0147 \\
.6040 \\
.0266\end{array}$ & $\begin{array}{l}.27755 \\
.13307 \\
.36465 \\
.12458 \\
.07365 \\
.194767 \\
.04419 \\
.04608 \\
.10885\end{array}$ & $\begin{array}{r}0.0000 \\
-1.9078 \\
3.3682 \\
-6.5274 \\
-.9558 \\
-.3438 \\
-.5444 \\
-.8112 \\
1.7372\end{array}$ \\
\hline
\end{tabular}

DISCHAREE $=4690739.167 \mathrm{CHS}$

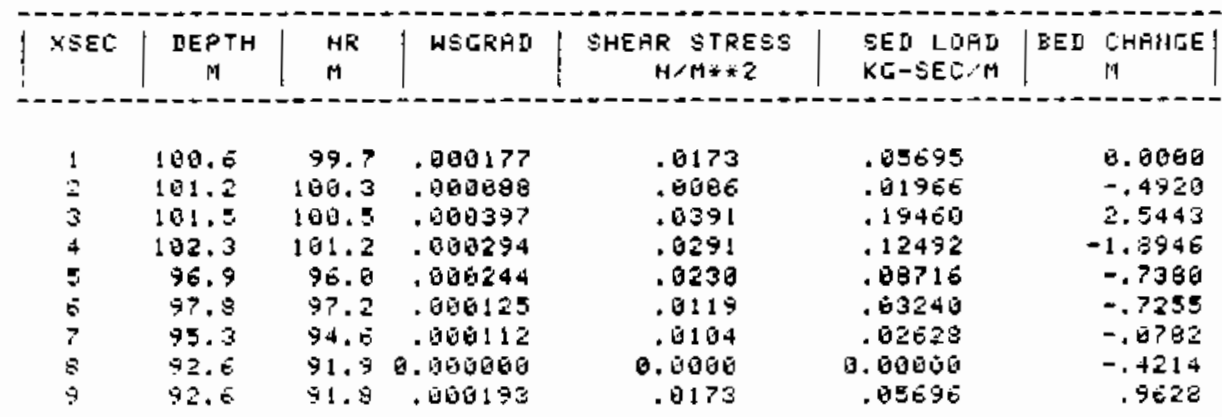

DISTHARLE = $5396+88,247 \mathrm{CMS}$

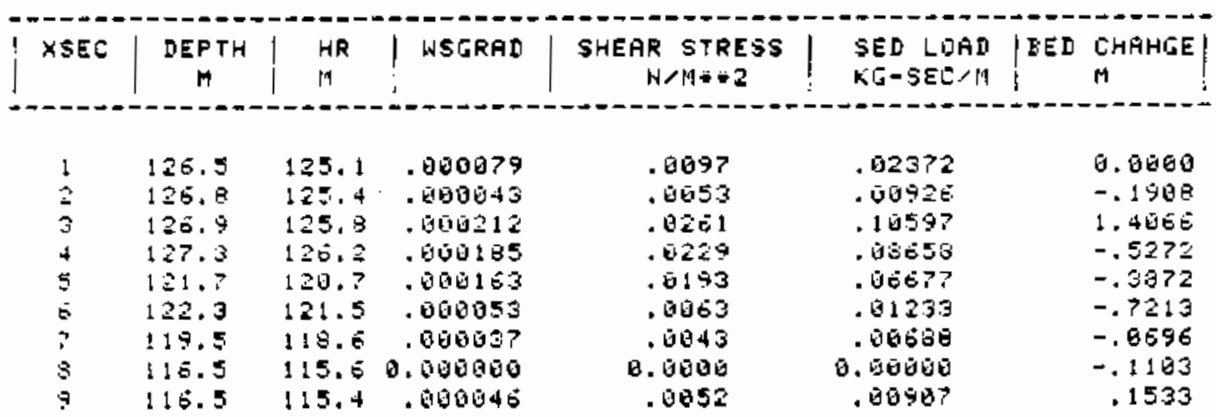




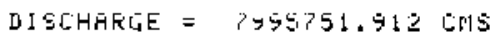

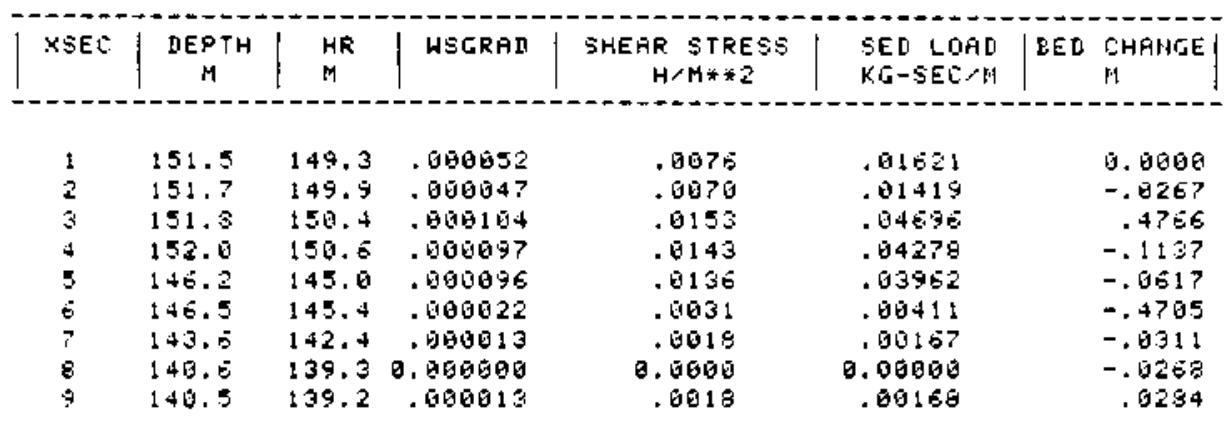

DISEHARCE $=9225998.301 \mathrm{CMS}$

\begin{tabular}{|c|c|c|c|c|c|c|c|}
\hline$X E E C$ & $\begin{array}{c}\text { DEPTH } \\
M\end{array}$ & $\begin{array}{l}\text { HR } \\
M\end{array}$ & | WSGRAD & $\begin{array}{c}\text { SMEAR STRESS } \\
M / M * * 2\end{array}$ & $\begin{array}{l}\text { SED LORD } \\
K G \rightarrow S E C, M\end{array}$ & BED & $\begin{array}{l}\text { CHRHGE } \\
\text { M }\end{array}$ \\
\hline $\begin{array}{l}1 \\
2 \\
3 \\
4 \\
5 \\
5 \\
7 \\
5 \\
5\end{array}$ & $\begin{array}{l}173.7 \\
173.9 \\
174.1 \\
174.2 \\
153.2 \\
168.5 \\
165.5 \\
162.4 \\
162.4\end{array}$ & $\begin{array}{l}171.3 \\
172.6 \\
172.3 \\
172.4 \\
166.8 \\
167.0 \\
164.4 \\
166.9 \\
160.8\end{array}$ & $\begin{array}{r}.080049 \\
.000042 \\
.000057 \\
.000006 \\
.000060 \\
.060011 \\
.600005 \\
0.000000 \\
0.000000\end{array}$ & $\begin{array}{r}.8093 \\
.0971 \\
.0896 \\
.0112 \\
.0198 \\
.0018 \\
.0008 \\
0.0060 \\
0.0000\end{array}$ & $\begin{array}{r}.01859 \\
.01457 \\
.02315 \\
.02719 \\
.92413 \\
.00169 \\
.00641 \\
0.00100 \\
0.60000\end{array}$ & & $\begin{array}{r}0.0000 \\
-.0536 \\
.1252 \\
.1535 \\
-.0585 \\
-.2974 \\
-.0153 \\
-.8065 \\
0.15050\end{array}$ \\
\hline
\end{tabular}

DISCHAREE = 9885018.408 CMS

\begin{tabular}{|c|c|c|c|c|c|c|c|}
\hline$X$ SEC & DEPTH & $\begin{array}{l}\text { HR } \\
M 1\end{array}$ & WSGRAD & $\begin{array}{c}\text { SHEAR STRESS } \\
\text { N/H } * 2\end{array}$ & $\begin{array}{l}\text { SED LOAD } \\
\text { KE-SEC }\end{array}$ & BED & $\begin{array}{l}\text { CMANEE } \\
\text { it }\end{array}$ \\
\hline 1 & 190.8 & 180.5 & .0196048 & .1988 & . $\bar{\Delta} \Omega \bar{U}+E$ & & ด. ตธ่อั \\
\hline 2 & 191.0 & 159,0 & . 196ธบัง & .0050 & .01024 & & -.1343 \\
\hline 3 & 191.1 & 189.1 & .600035 & $. \overline{\mathrm{G}} \mathrm{P}]$ & .01470 & & , เัตร \\
\hline+ & 171.1 & 139.3 & .506047 &.$\overline{0} 51$ & .02150 & & .1548 \\
\hline 5 & 135.2 & 133.5 & 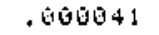 &.$\overline{0075}$ & .01561 & & -.1113 \\
\hline 6 & 135.3 & 133.7 & .90 kอ &. $\bar{G}$ & - घดอี 1 & &,- 2614 \\
\hline 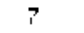 & 182.3 & 180.5 & 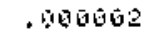 & .0603 & $.0 \cos 7$ & & -.0065 \\
\hline 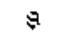 & 179.3 & 177.4 & ด. & 0.51360 & 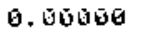 & & -.0011 \\
\hline 9 & 179.2 & 177.3 & 0. . & 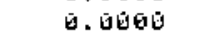 & 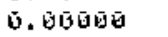 & & 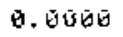 \\
\hline
\end{tabular}


IISCHARGE $=9885 \square 1 \mathrm{~B} .408 \mathrm{CMS}$

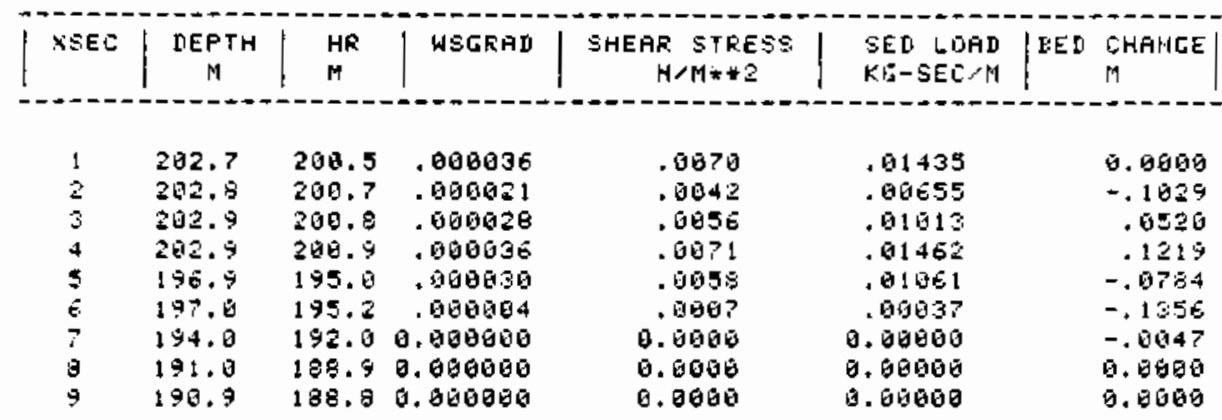

DISCHARLE = $9267963.155 \mathrm{cMS}$

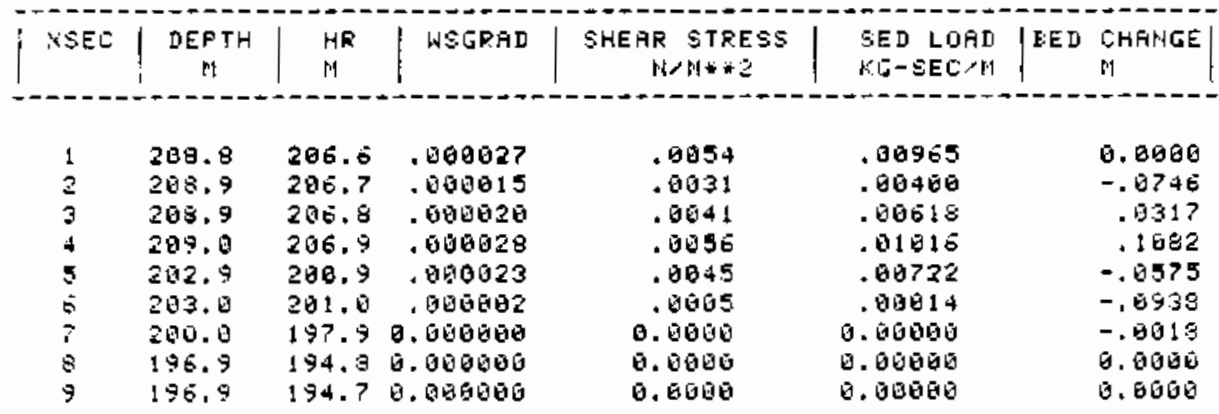

DISCHARGE = $9176720.476 \mathrm{CMS}$

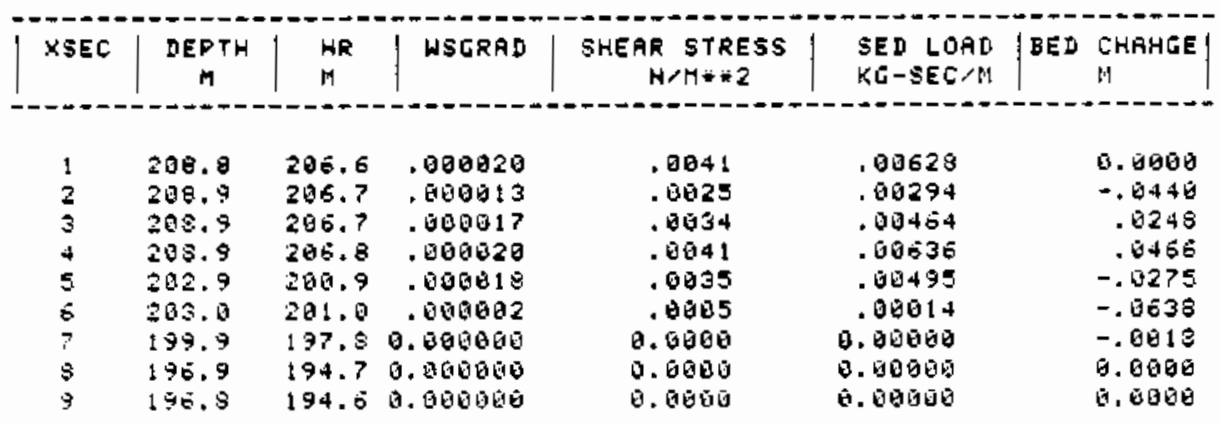


DISLHARGE = E813933.730 OMS

\begin{tabular}{|c|c|c|c|c|c|c|c|}
\hline XSEE & $\begin{array}{c}\text { DEFTH } \\
\text { M }\end{array}$ & $\begin{array}{l}H R \\
M\end{array}$ & WSGRAD & $\begin{array}{c}\text { SHEAR STRESS } \\
N / M * * 2\end{array}$ & $\begin{array}{l}\text { SED LOAD } \\
\text { KE-SEC } / A\end{array}$ & BED & $\begin{array}{l}\text { EHAHEE } \\
M\end{array}$ \\
\hline 1 & 203.0 & 200.8 & .895017 & .0033 & .65457 & & 0.6595 \\
\hline 2 & 203.1 & 281.0 & .000050 & .0819 & .80190 & & -.0352 \\
\hline$\hat{\imath}$ & 203.1 & 261.0 & . ดอDO13 & .01026 & .09312 & & .8177 \\
\hline 4 & 203.1 & 201.1 & .000017 & .0033 & .80449 & & .0372 \\
\hline 5 & 177,1 & 195.2 & .308015 & .0028 & .00345 & & -.5284 \\
\hline$\therefore$ & 197.1 & 195.2 & .606002 & .0803 & - Dgás & & -.5451 \\
\hline$?$ & 194.1 & 192,1 & 0.006000 & 0.0000 & B. 00000 & &.$- \Delta \sigma \omega \epsilon$ \\
\hline 8 & 191.0 & 109.0 & 0.050050 & 0.0505 & 0.80000 & & 0.0860 \\
\hline$\stackrel{\oplus}{9}$ & 191.8 & 138,9 & 0.000000 & 8.9600 & 0.00000 & & 0.5060 \\
\hline
\end{tabular}

DISCHAREE $=5379495.894 \mathrm{CMS}$

\begin{tabular}{|c|c|c|c|c|c|c|c|}
\hline XSEC & $\begin{array}{c}\text { DEPTH } \\
M\end{array}$ & $\begin{array}{l}H R \\
M\end{array}$ & WEITRDD & $\begin{array}{c}\text { SHEAR STRESS } \\
N / M * 2\end{array}$ & $\begin{array}{l}\text { SED LOAD } \\
\text { KE-SECIA1 }\end{array}$ & EED & $\begin{array}{l}\text { CHAHGE } \\
\text { M }\end{array}$ \\
\hline 1 & 192,3 & 190.1 & .000014 & .0826 & .00300 & & 0.5000 \\
\hline 2 & 192,4 & 190.4 & .000009 & .0017 & .00149 & & -.0195 \\
\hline 3 & 192.4 & 190.4 & .000010 & .0019 & .40130 & & .0645 \\
\hline 4 & 192.4 & 190.5 & .000014 & .0027 & .60323 & & .5385 \\
\hline 5 & 186.4 & 184.7 & .806311 & .0021 & .00211 & & -.8219 \\
\hline 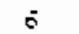 & 186.4 & 184.7 & .000002 & .0003 & .80004 & & -.0275 \\
\hline 7 & 183.4 & 181.6 & .000051 & .0102 & .00090 & & - . \\
\hline$s$ & 180.3 & 178,5 & $0.00 \mathrm{HE \theta}$ & ด. & 0. อดอย์ & & -.0050 \\
\hline 9 & 180.3 & 175.4 & 0.060000 & 5.8060 & $0 . \overline{10000}$ & & 0.0050 \\
\hline
\end{tabular}

DISEHARGE = $40345 \$ 1.119$ CMS

\begin{tabular}{|c|c|c|c|c|c|c|c|}
\hline XSEC & DEPTH & $\begin{array}{l}H R \\
M\end{array}$ & WSGRAD & $\begin{array}{c}\text { SHEAR STRESS } \\
W / M=-2\end{array}$ & $\begin{array}{l}\text { SED LOAD } \\
K G=S E L / A\end{array}$ & BED & $\underset{M}{\text { CHANGE }}$ \\
\hline 1 & $1>7.4$ & 174.9 & .0015009 & .0015 & .00129 & & 0.0865 \\
\hline 2 & 177.4 & 175.5 & 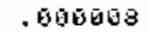 & .0014 & . घิ 109 & & - . ธิธี $2 \epsilon$ \\
\hline 3 & 177.4 & 175,7 & 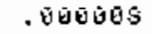 & .0614 & .00117 & & . ดิ 11 \\
\hline 4 & 177.5 & 175.7 & . orjoula & .0025 & . 05284 & & .0456 \\
\hline 5 & 121.4 & 159.9 & .508005 & .0015 & .00124 & & -.0313 \\
\hline 8 & 131.4 & 170.0 & . 00000a & .0003 & $.0000 \overline{3}$ & & -.0160 \\
\hline 7 & 169.4 & 166.8 & . 000601 & .0062 & .00000 & & -.0004 \\
\hline$s$ & 165.3 & 163.8 & 0.600000 & 0.0000 & 0.00056 & & -.0000 \\
\hline 9 & 165.3 & 163.7 & 0.806000 & 0.0000 & 0. 500000 & & 0.0006 \\
\hline
\end{tabular}


IISCHARGE $=286 \pm 903.144 \mathrm{CMS}$

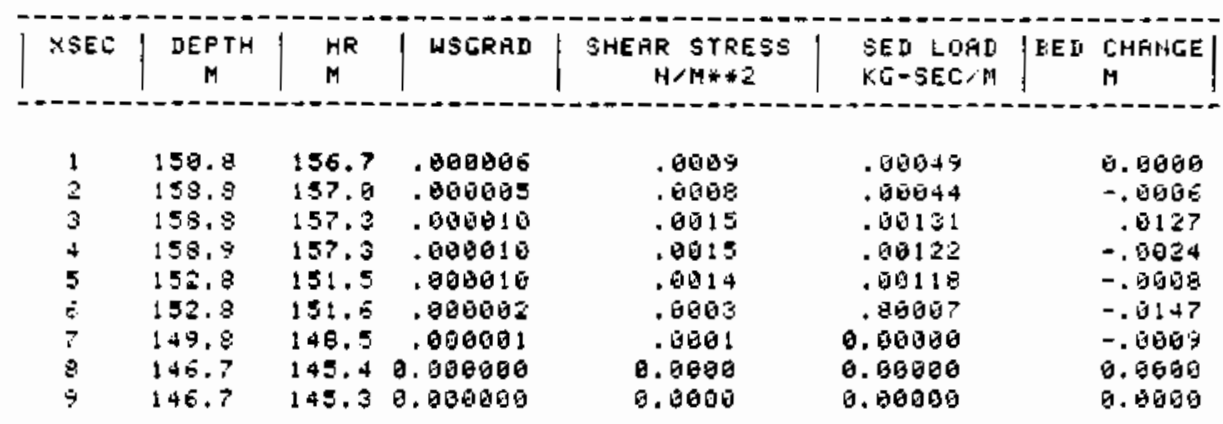

DISCMARLE = 1964882.470 CMS

\begin{tabular}{|c|c|c|c|c|c|c|c|}
\hline$x$ SEC & $\begin{array}{c}\text { DEPTH } \\
M\end{array}$ & $\begin{array}{l}\text { HR } \\
M\end{array}$ & WSGRAD & $\begin{array}{c}\text { SMERR STRESS } \\
H / M * * 2\end{array}$ & $\begin{array}{l}\text { SED LOFD } \\
K G-S E L / M\end{array}$ & BE & $\begin{array}{l}\text { CHAHGE } \\
\text { M }\end{array}$ \\
\hline $\begin{array}{l}1 \\
2 \\
3 \\
4 \\
5 \\
8 \\
7 \\
5 \\
9\end{array}$ & $\begin{array}{l}139.7 \\
138.7 \\
138.7 \\
138.7 \\
132.7 \\
122.7 \\
129.7 \\
120.6 \\
120.6\end{array}$ & $\begin{array}{l}137.0 \\
137.1 \\
137.4 \\
137.5 \\
131.6 \\
131.8 \\
128.7 \\
125.6 \\
126.5\end{array}$ & 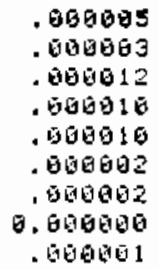 & $\begin{array}{l}.008 ? \\
.0001 \\
.0015 \\
.0013 \\
.0013 \\
.0003 \\
.0002 \\
0.0001 \\
.0001\end{array}$ & $\begin{array}{r}.00028 \\
.00008 \\
.06136 \\
.00098 \\
.06593 \\
.00055 \\
.00062 \\
0.06500 \\
0.00600\end{array}$ & & $\begin{array}{r}\text { d. } 0060 \\
-.002 ? \\
.0186 \\
-.0164 \\
-.0505 \\
-.0113 \\
-.0603 \\
-.5054 \\
0.0500\end{array}$ \\
\hline
\end{tabular}

DISCHRRGE = $1201506.655 \mathrm{CMS}$

\begin{tabular}{|c|c|c|c|c|c|c|c|}
\hline XSEC & $\begin{array}{c}\text { DEFTH } \\
M\end{array}$ & $\begin{array}{l}\text { HR } \\
M\end{array}$ & WSGRAD & $\begin{array}{c}\text { SHEAR STRESS } \\
N / M * * 2\end{array}$ & $\begin{array}{l}\text { SED LOAD } \\
K C-S E C / P 4\end{array}$ & BED & CHAHGE \\
\hline 1 & 118,6 & 117.3 & .000005 & .01900 & .351321 & & ธ. \\
\hline 2 & 118.0 & 117.4 & .000052 & .6002 & .00001 & & -.4826 \\
\hline 3 & 118.6 & 117.4 & 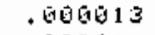 & .81515 & 50130 & & .5188 \\
\hline 4 & 115.5 & $\$ 17.6$ & .000011 & $.961=$ & . 1961991 & & -.8106 \\
\hline 5 & 112.5 & 111.5 & .050810 & .0011 & . & & -.0041 \\
\hline 6 & $51 \Omega . E$ & 111.9 & .0105004 & .0064 &.$\dot{0} \overline{0} 12$ & & -.0677 \\
\hline $\bar{i}$ & 109.5 & 168.5 & , 060003 & .0003 & . องeas & & -.9008 \\
\hline$s$ & 106.5 & 105.7 & 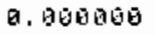 & 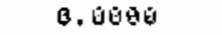 & 0.80000 & & -.6058 \\
\hline 9 & 105.5 & 145.0 & . & .6055 & .50613 & & .8622 \\
\hline
\end{tabular}


IISCHARIE $=3 \bar{U} 0906.259 \mathrm{CMS}$

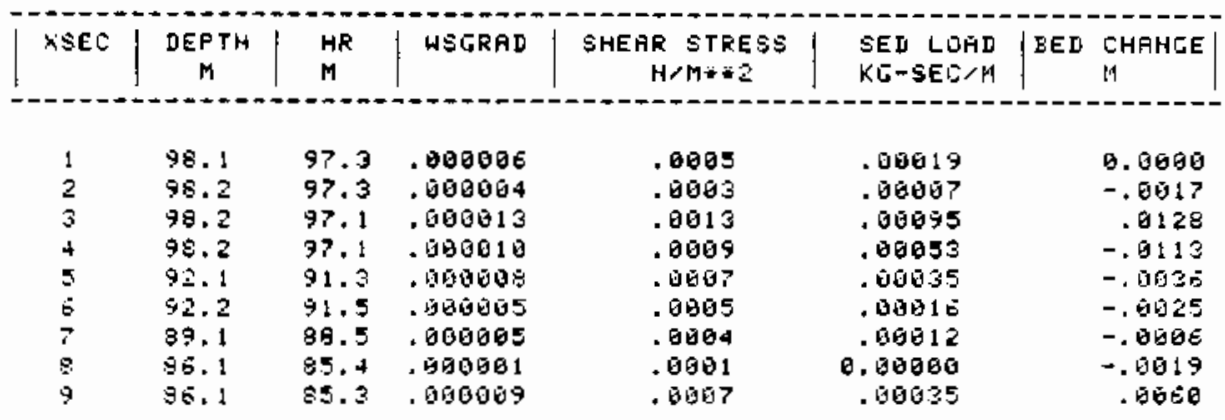

DISTHARGE $=480609.396 \mathrm{cmS}$

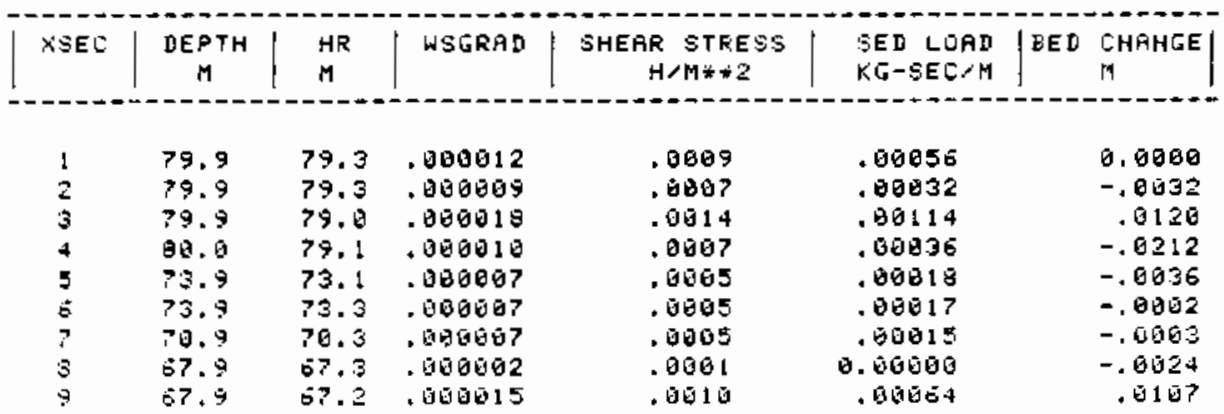

DISCHAREE $=277258.567$ CMS

\begin{tabular}{|c|c|c|c|c|c|c|c|}
\hline XSEC & DEPTH & $\begin{array}{l}H R \\
M\end{array}$ & WSGRAD & $\begin{array}{c}\text { SHEAR STRESS } \\
M / M * * 2\end{array}$ & $\begin{array}{l}\text { SED LOAD } \\
K E \text { SEC,M }\end{array}$ & 185 & CHANGE \\
\hline $\begin{array}{l}1 \\
2 \\
3 \\
4 \\
5 \\
5 \\
7 \\
8 \\
9\end{array}$ & $\begin{array}{l}62.8 \\
52.9 \\
53.0 \\
63.0 \\
57.0 \\
57.0 \\
54.0 \\
51.0 \\
51.0\end{array}$ & $\begin{array}{l}62.3 \\
62.3 \\
52.2 \\
62.2 \\
56.4 \\
56.5 \\
53.5 \\
50.5 \\
50.5\end{array}$ & $\begin{array}{l}.000029 \\
.000030 \\
.500027 \\
.000010 \\
.000607 \\
.006009 \\
.056014 \\
.000082 \\
.000048\end{array}$ & $\begin{array}{l}.0018 \\
.0019 \\
.0016 \\
.0086 \\
.0001 \\
.0005 \\
.0007 \\
.0001 \\
.0024\end{array}$ & $\begin{array}{r}.00156 \\
.00178 \\
.00144 \\
.00023 \\
.00010 \\
.00013 \\
.00035 \\
0.00040 \\
.00267\end{array}$ & & $\begin{array}{r}0.0008 \\
.0415 \\
-.0450 \\
-.0325 \\
-.0025 \\
.0010 \\
.0021 \\
-.0056 \\
.8451\end{array}$ \\
\hline
\end{tabular}


DISCHARGE $=154064.085$ LMS

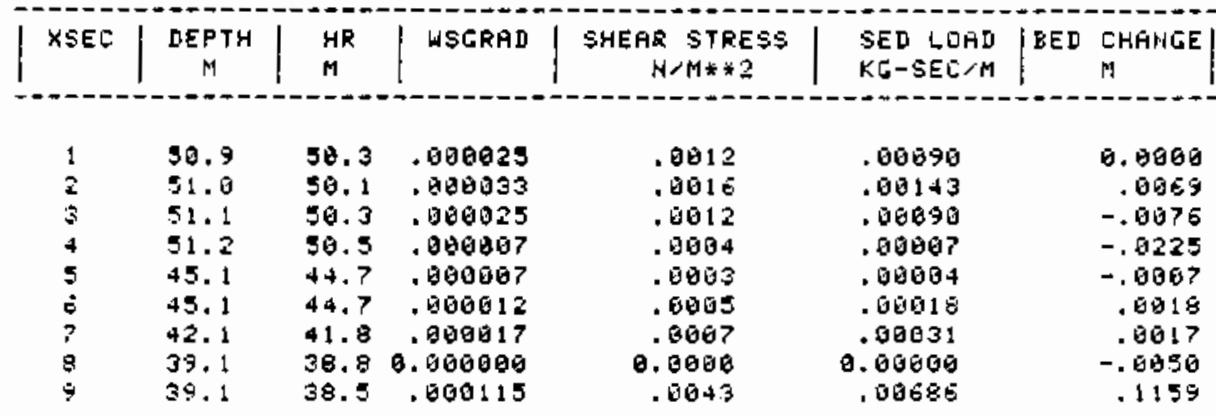

DISCHRREE $=\quad 82412.914$ CMS

\begin{tabular}{|c|c|c|c|c|c|c|c|}
\hline XSEC & $\underset{M}{\text { DEPTH }}$ & $\begin{array}{l}H R \\
M\end{array}$ & WSGRAD & $\begin{array}{c}\text { SHEAR STRESS } \\
H / M_{*} \neq 2\end{array}$ & $\begin{array}{l}\text { SED LDAD } \\
K G=S E C, M\end{array}$ & EED & $\underset{M}{\text { CHAHCE }}$ \\
\hline 1 & 40.2 & 39.7 & .000033 & .0013 & .00097 & & 0.0006 \\
\hline 2 & 40.4 & 39.5 & .000029 & .0011 & .00079 & & -.0925 \\
\hline 3 & 40.5 & 39.8 & .050020 & .0000 & .00040 & & $-.005 \epsilon$ \\
\hline 4 & +0.5 & +0.0 & .000006 & .0562 & .06502 & & -.6163 \\
\hline 5 & 34.4 & 34.2 & .000009 & .0003 & .00005 & & .0005 \\
\hline$\Xi$ & 34.4 & 34.1 & .000012 & .0064 & .00509 & & .0667 \\
\hline$i$ & 31.4 & 31.2 & .000028 & .0008 & .00045 & & .0047 \\
\hline$s$ & 28,5 & 28.3 & . Бே & .0003 & .08054 & & $\because \bar{\Delta} \in ?$ \\
\hline g & 28.5 & 28.0 & .0000178 & .0049 & .00928 & & .1393 \\
\hline
\end{tabular}

DISCHARGE = 42764.689 CKS

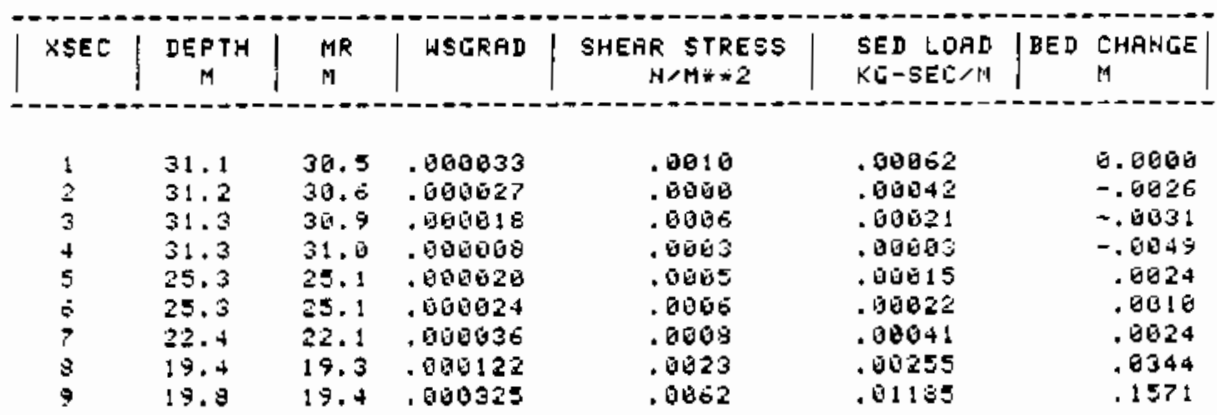




\begin{tabular}{|c|c|c|c|c|c|c|c|}
\hline XSEC & DEPTH & $\begin{array}{l}\text { HR } \\
M\end{array}$ & WSLRAD & $\begin{array}{c}\text { SHEAR STRESS } \\
W / P+22\end{array}$ & $\begin{array}{l}\text { SED LDAD } \\
\text { KG-SEC-M }\end{array}$ & $B E D$ & $\begin{array}{l}\text { CHAHGE } \\
M\end{array}$ \\
\hline $\begin{array}{l}1 \\
2 \\
3 \\
4 \\
1 \\
1 \\
5 \\
5 \\
8 \\
9\end{array}$ & $\begin{array}{l}23.2 \\
23.3 \\
23.4 \\
23.4 \\
17.4 \\
17.7 \\
14.9 \\
12.0 \\
13.1\end{array}$ & $\begin{array}{l}22.7 \\
22.9 \\
23.1 \\
23.2 \\
17.3 \\
17.5 \\
14.7 \\
11.8 \\
12.8\end{array}$ & $\begin{array}{l}.000038 \\
.006029 \\
.000025 \\
.000008 \\
.000077 \\
.000055 \\
.900060 \\
.000372 \\
.000550\end{array}$ & $\begin{array}{l}.0008 \\
.0087 \\
.0005 \\
.0002 \\
.0013 \\
.0009 \\
.0009 \\
.0043 \\
.0069\end{array}$ & $\begin{array}{l}.00046 \\
.00027 \\
.00013 \\
.00001 \\
.00057 \\
.00050 \\
.00057 \\
.00677 \\
.01400\end{array}$ & & $\begin{array}{r}0.0500 \\
-.0023 \\
-.0023 \\
-.0034 \\
.0193 \\
-.0557 \\
.0901 \\
.0934 \\
.1223\end{array}$ \\
\hline
\end{tabular}

DISCHAREE \& $19195 .+12$ CMS

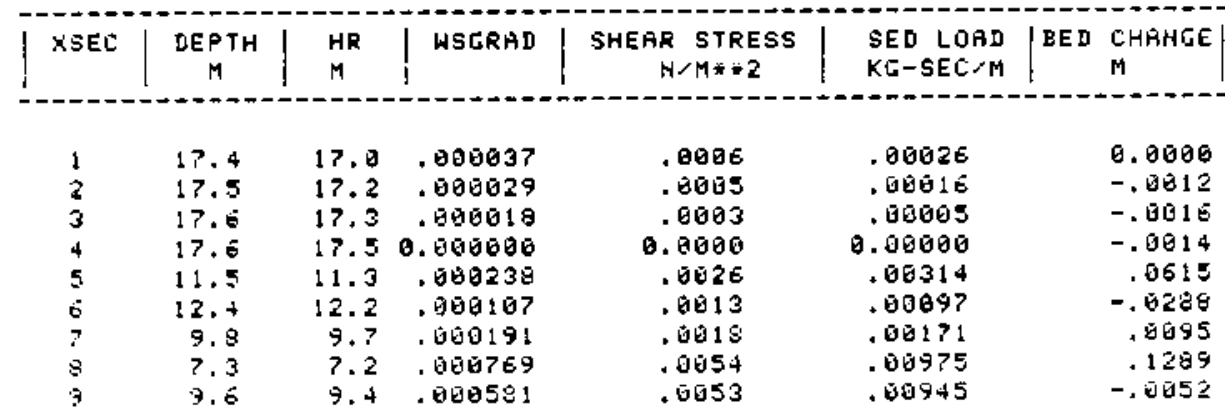

DISCHAREE = 4814.500 EMS

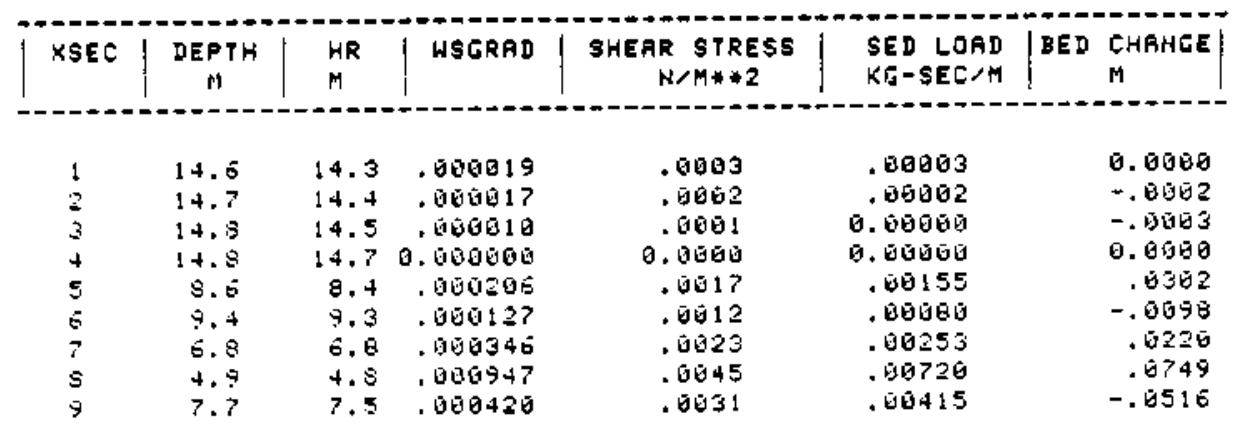




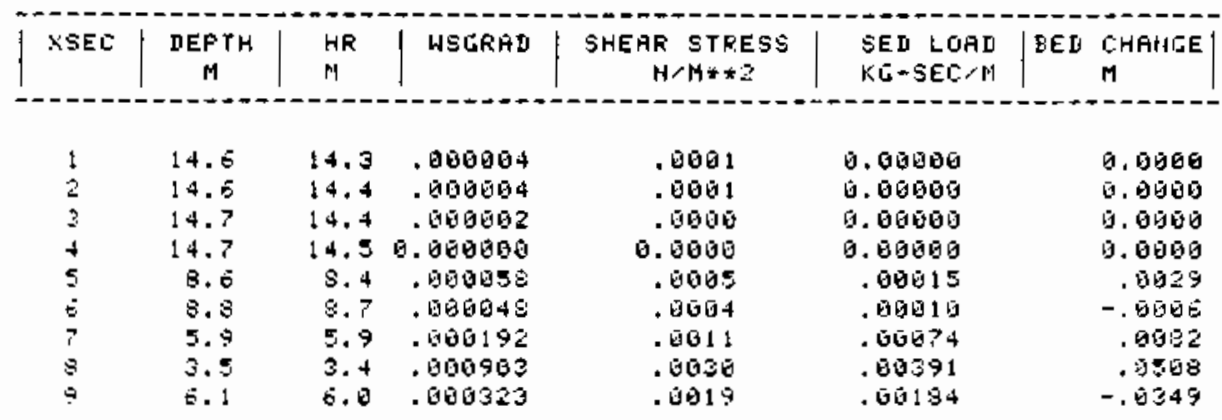

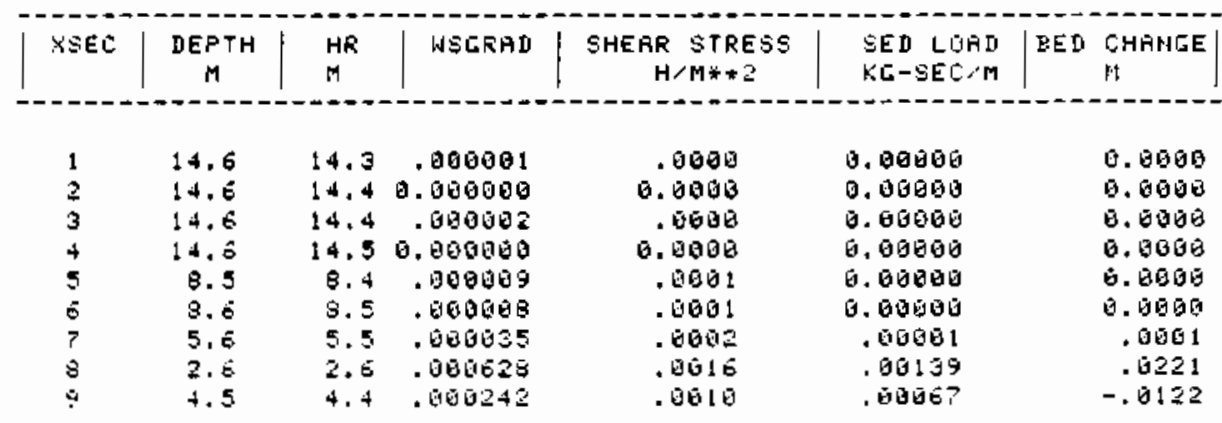

DISEHARLE $\Rightarrow \quad 283.206$ CMS

\begin{tabular}{|c|c|c|c|c|c|c|c|}
\hline$x S E C$ & DEPTH & $\begin{array}{l}\text { HR } \\
M\end{array}$ & WSGRAD & $\begin{array}{c}\text { SHEAR STRESS } \\
W / M=2\end{array}$ & $\begin{array}{l}\text { SED LQAD } \\
\text { KG- SEC } / M\end{array}$ & BED & CHANGE \\
\hline $\begin{array}{l}1 \\
2 \\
3 \\
4 \\
5 \\
5 \\
7 \\
5 \\
9\end{array}$ & $\begin{array}{l}1.4 \\
3.5 \\
3.8 \\
3.8 \\
1.5 \\
3.5 \\
1.3 \\
2.1 \\
3.1\end{array}$ & $\begin{array}{l}1.4 \\
3.4 \\
3.7 \\
3.8 \\
1.5 \\
3.2 \\
1.3 \\
2.0 \\
3.1\end{array}$ & $\begin{array}{l}.000544 \\
.000099 \\
.000033 \\
.011477 \\
.080409 \\
.000297 \\
.001219 \\
.0100362 \\
.006176\end{array}$ & $\begin{array}{l}.000 ? \\
.0003 \\
.0601 \\
.0555 \\
.0007 \\
.0009 \\
.6016 \\
.0007 \\
.0305\end{array}$ & $\begin{array}{r}.06035 \\
.60005 \\
0.04060 \\
.00977 \\
.01029 \\
.00055 \\
.00136 \\
.00035 \\
.00019\end{array}$ & & $\begin{array}{r}0.0060 \\
-.0639 \\
-.0609 \\
.2712 \\
-.1592 \\
.0634 \\
.0104 \\
-.0162 \\
-.0028\end{array}$ \\
\hline
\end{tabular}


s

. 


\section{DISTRIBUTION}

PNL-5684

UC-70

No. of

Copies

OFFSITE

30 DOE Technical Information Center

ONSITE

3 DOE Richland Operations office

R. A. Holten

E. A. Bracken

J. D. White

2 Rockwell Hanford Dperations

C. Defigh-Price

R. T. Wilde
No. of

Copies

60 Pacific Northwest Laboratory

J. B. Burnhan (28)

M. G. Foley (15)

G. W. Gee

M. J. Graham

D. K. Hilliard

G. V. Last

K. S. Murthy

I. C. Nelson

J. R. Raymond

J. G. Stephan

J. A. Srottl emyre

R. W. Wallace Publishing Coordination (2) Technical Information (5) 
$\downarrow$

1 